\title{
Repetitive task training for improving functional ability after stroke
} (Review)

French B, Thomas LH, Coupe J, McMahon NE, Connell L, Harrison J, Sutton CJ, Tishkovskaya S, Watkins CL

French B, Thomas LH, Coupe J, McMahon NE, Connell L, Harrison J, Sutton CJ, Tishkovskaya S, Watkins CL.

Repetitive task training for improving functional ability after stroke.

Cochrane Database of Systematic Reviews 2016, Issue 11. Art. No.: CD006073.

DOI: 10.1002/14651858.CD006073.pub3.

www.cochranelibrary.com 
TABLE OF CONTENTS

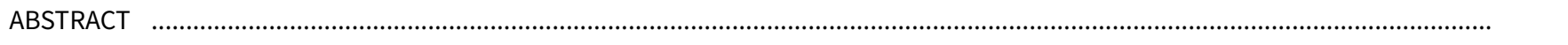

PLAIN LANGUAGE SUMMARY

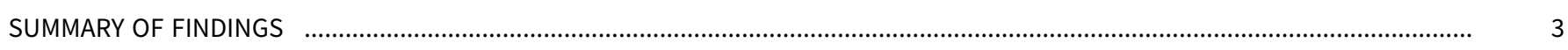

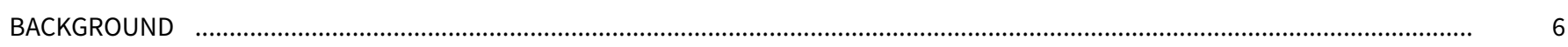

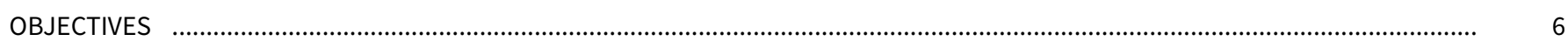

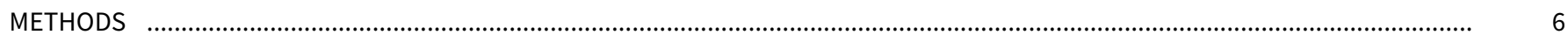

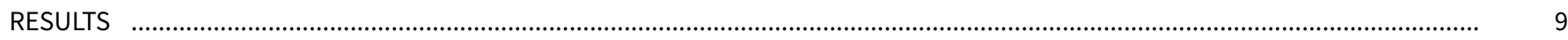

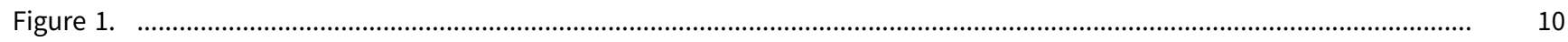

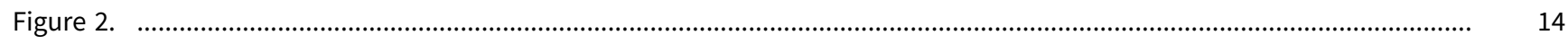

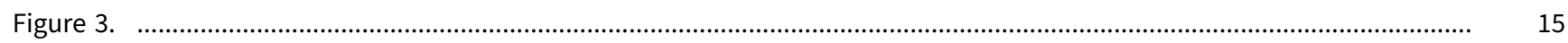

DISCUSSION

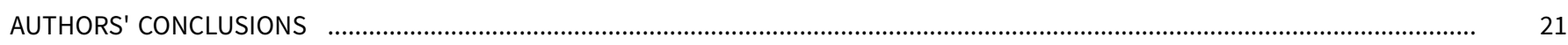

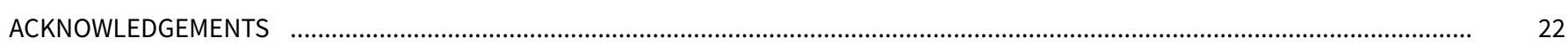

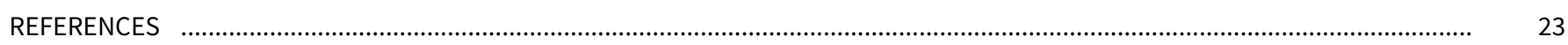

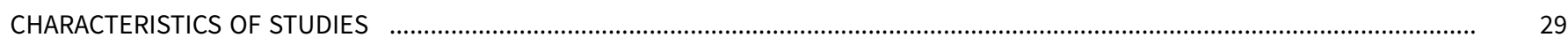

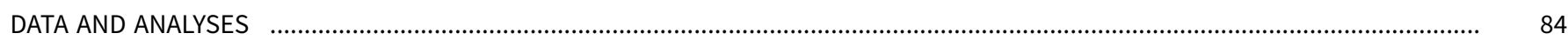

Analysis 1.1. Comparison 1 Upper limb function: post treatment, Outcome 1 Arm function. . ..................................................... 85

Analysis 1.2. Comparison 1 Upper limb function: post treatment, Outcome 2 Hand function. . ................................................... 85

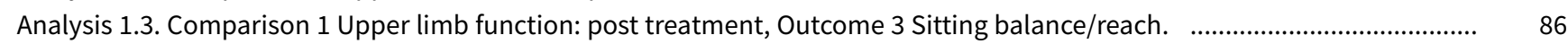

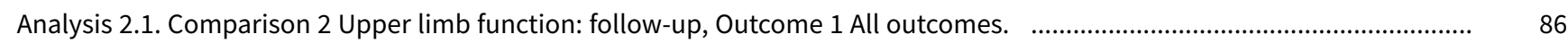

Analysis 3.1. Comparison 3 Upper limb function: subgroup analyses, Outcome 1 Dosage of task practice. ................................ 87

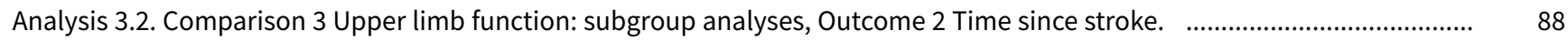

Analysis 3.3. Comparison 3 Upper limb function: subgroup analyses, Outcome 3 Type of intervention. .................................. 89

Analysis 4.1. Comparison 4 Lower limb function: post treatment, Outcome 1 Walking distance: change from baseline. ........... 90

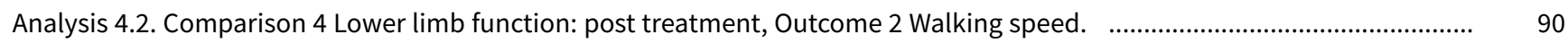

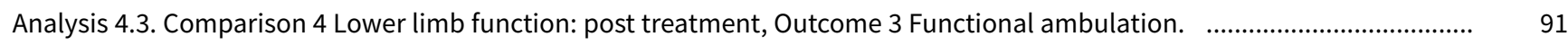

Analysis 4.4. Comparison 4 Lower limb function: post treatment, Outcome 4 Sit-to-stand: post treatment/change from 91 baseline.

Analysis 4.5. Comparison 4 Lower limb function: post treatment, Outcome 5 Lower limb functional measures. ........................ 92

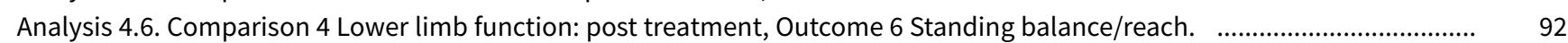

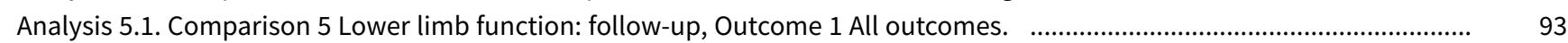

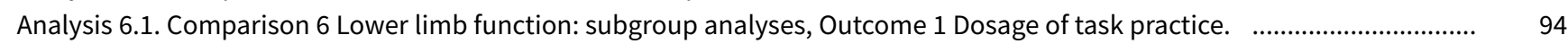

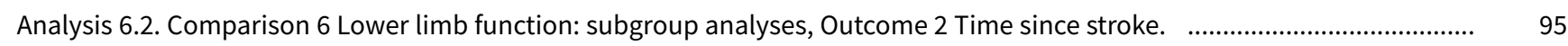

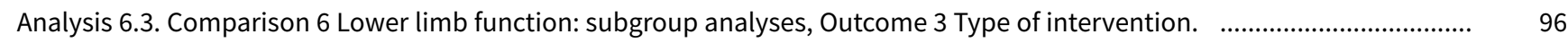

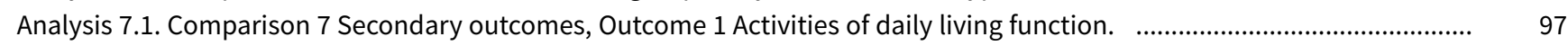

Analysis 7.2. Comparison 7 Secondary outcomes, Outcome 2 Global motor function scales. .................................................... 98

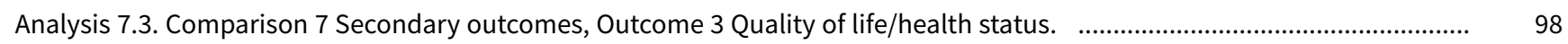

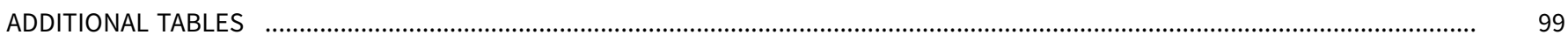

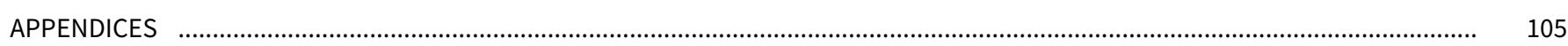

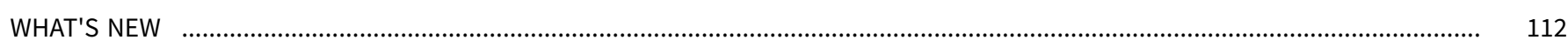

CONTRIBUTIONS OF AUTHORS

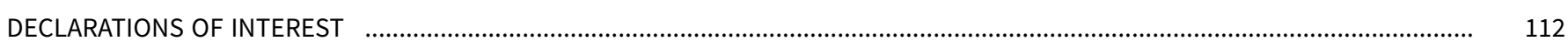

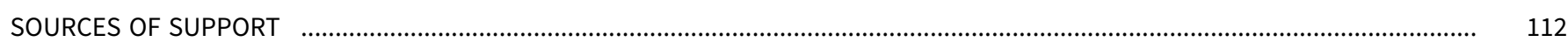

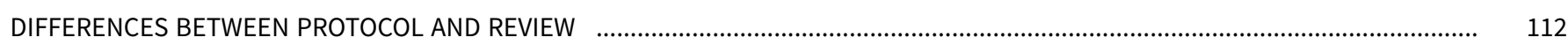

INDEX TERMS 
[Intervention Review]

\section{Repetitive task training for improving functional ability after stroke}

Beverley French ${ }^{1}$, Lois H Thomas², Jacqueline Coupe², Naoimh E McMahon², Louise Connell2, Joanna Harrison³, Christopher J Sutton², Svetlana Tishkovskaya4, Caroline L Watkins ${ }^{2}$

1Department of Nursing and Caring Sciences, University of Central Lancashire, Preston, UK. ${ }^{2}$ College of Health and Wellbeing, University of Central Lancashire, Preston, UK. ${ }^{3}$ Department of Nursing, University of Central Lancashire, Preston, UK. ${ }^{4}$ School of Health, University of Central Lancashire, Preston, UK

Contact: Lois H Thomas, College of Health and Wellbeing, University of Central Lancashire, Room 326, Brook Building, Preston, Lancashire, PR12HE, UK. Ihthomas@uclan.ac.uk.

Editorial group: Cochrane Stroke Group.

Publication status and date: New search for studies and content updated (conclusions changed), published in Issue 11, 2016.

Citation: French B, Thomas LH, Coupe J, McMahon NE, Connell L, Harrison J, Sutton CJ, Tishkovskaya S, Watkins CL. Repetitive task training for improving functional ability after stroke. Cochrane Database of Systematic Reviews 2016, Issue 11. Art. No.: CD006073. DOI: 10.1002/14651858.CD006073.pub3.

Copyright ( 2016 The Cochrane Collaboration. Published by John Wiley \& Sons, Ltd.

\section{A B S T R A C T}

\section{Background}

Repetitive task training (RTT) involves the active practice of task-specific motor activities and is a component of current therapy approaches in stroke rehabilitation.

\section{Objectives}

Primary objective: To determine if RTT improves upper limb function/reach and lower limb function/balance in adults after stroke.

Secondary objectives: 1) To determine the effect of RTT on secondary outcome measures including activities of daily living, global motor function, quality of life/health status and adverse events. 2) To determine the factors that could influence primary and secondary outcome measures, including the effect of 'dose' of task practice; type of task (whole therapy, mixed or single task); timing of the intervention and type of intervention.

\section{Search methods}

We searched the Cochrane Stroke Group Trials Register (4 March 2016); the Cochrane Central Register of Controlled Trials (CENTRAL) (the Cochrane Library 2016, Issue 5: 1 October 2006 to 24 June 2016); MEDLINE (1 October 2006 to 8 March 2016); Embase (1 October 2006 to 8 March 2016); CINAHL (2006 to 23 June 2016); AMED (2006 to 21 June 2016) and SPORTSDiscus (2006 to 21 June 2016).

\section{Selection criteria}

Randomised/quasi-randomised trials in adults after stroke, where the intervention was an active motor sequence performed repetitively within a single training session, aimed towards a clear functional goal.

\section{Data collection and analysis}

Two review authors independently screened abstracts, extracted data and appraised trials. We determined the quality of evidence within each study and outcome group using the Cochrane 'Risk of bias' tool and GRADE (Grades of Recommendation, Assessment, Development and Evaluation) criteria. We did not assess follow-up outcome data using GRADE. We contacted trial authors for additional information.

\section{Main results}

We included 33 trials with 36 intervention-control pairs and 1853 participants. The risk of bias present in many studies was unclear due to poor reporting; the evidence has therefore been rated 'moderate' or 'low' when using the GRADE system. 
There is low-quality evidence that RTT improves arm function (standardised mean difference (SMD) $0.25,95 \%$ confidence interval (CI) 0.01 to $0.49 ; 11$ studies, number of participants analysed $=749$ ), hand function (SMD $0.25,95 \% \mathrm{Cl} 0.00$ to 0.51 ; eight studies, number of participants analysed $=619$ ), and lower limb functional measures (SMD $0.29,95 \% \mathrm{Cl} 0.10$ to 0.48 ; five trials, number of participants analysed $=419$ ).

There is moderate-quality evidence that RTT improves walking distance (mean difference (MD) 34.80, $95 \% \mathrm{Cl} 18.19$ to 51.41 ; nine studies, number of participants analysed $=610$ ) and functional ambulation (SMD 0.35, 95\% Cl 0.04 to 0.66; eight studies, number of participants analysed $=525$ ). We found significant differences between groups for both upper-limb (SMD 0.92, 95\% Cl 0.58 to 1.26; three studies, number of participants analysed $=153$ ) and lower-limb (SMD $0.34,95 \% \mathrm{Cl} 0.16$ to 0.52 ; eight studies, number of participants analysed $=471$ ) outcomes up to six months post treatment but not after six months. Effects were not modified by intervention type, dosage of task practice or time since stroke for upper or lower limb. There was insufficient evidence to be certain about the risk of adverse events.

\section{Authors' conclusions}

There is low- to moderate-quality evidence that RTT improves upper and lower limb function; improvements were sustained up to six months post treatment. Further research should focus on the type and amount of training, including ways of measuring the number of repetitions actually performed by participants. The definition of RTT will need revisiting prior to further updates of this review in order to ensure it remains clinically meaningful and distinguishable from other interventions.

\section{PLAIN LANGUAGE SUMMARY}

\section{Repetitive task training for improving functional ability after stroke}

Review question: What are the effects of repeated practice of functional tasks on recovery after stroke when compared with usual care or placebo treatments?

Background: Stroke can cause problems with movement, often down one side of the body. While some recovery is common over time, about one third of people have continuing problems. Repeated practice of functional tasks (e.g. lifting a cup) is a treatment approach used to help with recovery of movement after stroke. This approach is based on the simple idea that in order to improve our ability to perform tasks we need to practice doing that particular task numerous times, like when we first learned to write. The types of practice that people do, and the time that they spend practicing, may affect how well this treatment works. To explore this further we also looked at different aspects of repetitive practice that may influence how well it works.

Study characteristics: We identified 33 studies with 1853 participants. Studies included a wide range of tasks to practice, including lifting a ball, walking, standing up from sitting and circuit training with a different task at each station. The evidence is current to June 2016.

Key results: In comparison with usual care (standard physiotherapy) or placebo groups, people who practiced functional tasks showed small improvements in arm function, hand function, walking distance and measures of walking ability. Improvements in arm and leg function were maintained up to six months later. There was not enough evidence to be certain about the risk of adverse events, for example falls. Further research is needed to determine the best type of task practice, and whether more sustained practice could show better results.

Quality of the evidence: We classified the quality of the evidence as low for arm function, hand function and lower limb functional measures, and as moderate for walking distance and functional ambulation. The quality of the evidence for each outcome was limited due poor reporting of study details (particularly in earlier studies), inconsistent results across studies and small numbers of study participants in some comparisons. 


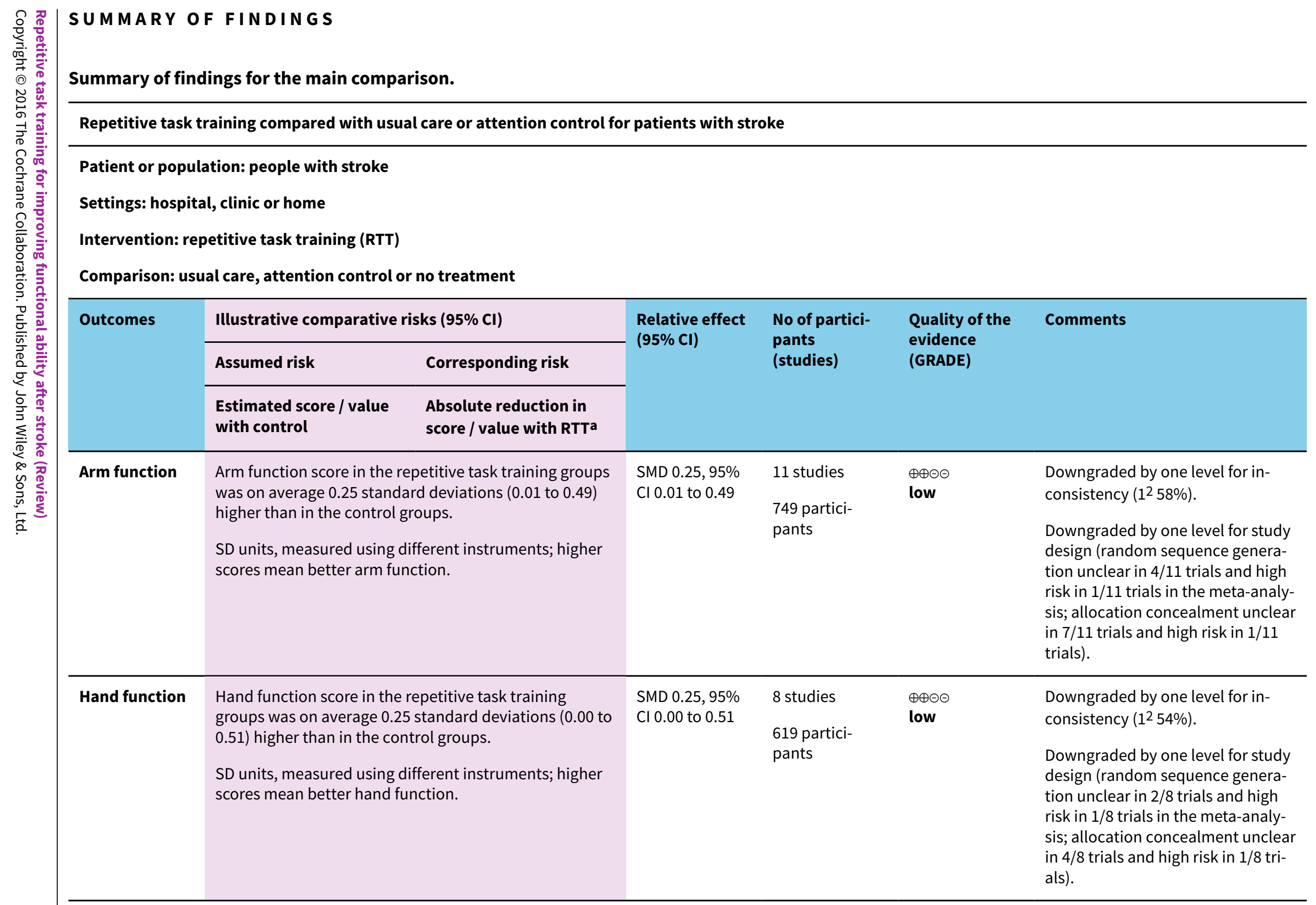




\begin{tabular}{|c|c|c|c|c|c|c|}
\hline lalking dis- & $\begin{array}{l}\text { The mean change in } \\
\text { walking distance (me- } \\
\text { tres walked in six min- } \\
\text { utes; a higher score means } \\
\text { greater walking distance) } \\
\text { in the control groups } \\
\text { ranged from -1.0 to } 118.5 \text {. }\end{array}$ & $\begin{array}{l}\text { The mean } \\
\text { change in } \\
\text { walking distance (me- } \\
\text { tres walked in six min- } \\
\text { utes; a higher score means } \\
\text { greater walking distance) } \\
\text { in the repetitive training } \\
\text { group ranged from } 19 \text { to } \\
221 .\end{array}$ & $\begin{array}{l}\text { MD } 34.80,95 \% \\
\text { Cl } 18.19 \text { to } \\
51.41\end{array}$ & $\begin{array}{l}9 \text { studies } \\
610 \text { partici- } \\
\text { pants }\end{array}$ & $\begin{array}{l}\oplus \oplus \oplus \ominus \\
\text { moderate }\end{array}$ & $\begin{array}{l}\text { Downgraded by one level for study } \\
\text { design (random sequence gener- } \\
\text { ation unclear in } 6 / 9 \text { trials in the } \\
\text { meta-analysis; allocation conceal- } \\
\text { ment unclear in } 6 / 9 \text { trials and high } \\
\text { risk in } 3 / 9 \text { trials). }\end{array}$ \\
\hline 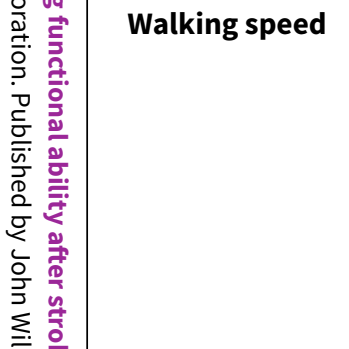 & $\begin{array}{l}\text { The mean walking speed } \\
\text { in the control groups } \\
\text { ranged from } \\
0.29 \text { to } 2.47 \text { metres per } \\
\text { second. A higher score } \\
\text { means faster walking } \\
\text { speed. }\end{array}$ & $\begin{array}{l}\text { The mean walking speed } \\
\text { in the intervention groups } \\
\text { ranged from } 0.39 \text { to } 2.03 \\
\text { metres per second. A high- } \\
\text { er score means faster } \\
\text { walking speed. }\end{array}$ & $\begin{array}{l}\text { SMD } 0.39,95 \% \\
\text { Cl }-0.02 \text { to } 0.79\end{array}$ & $\begin{array}{l}12 \text { studies } \\
685 \text { partici- } \\
\text { pants }\end{array}$ & $\begin{array}{l}\oplus \oplus \ominus \ominus \\
\text { low }\end{array}$ & $\begin{array}{l}\text { Downgraded by one level for in- } \\
\text { consistency (12 80\%). } \\
\text { Downgraded by one level for study } \\
\text { design (random sequence gener- } \\
\text { ation unclear in } 7 / 12 \text { trials in the } \\
\text { meta-analysis; allocation conceal- } \\
\text { ment unclear in } 9 / 12 \text { trials and high } \\
\text { risk in } 3 / 12 \text { trials). }\end{array}$ \\
\hline $\begin{array}{l}\text { Functional am- } \\
\text { bulation }\end{array}$ & \multicolumn{2}{|c|}{$\begin{array}{l}\text { Functional ambulation score in the repetitive task train- } \\
\text { ing groups was on average } 0.35 \text { standard deviations } \\
(0.04 \text { to } 0.66 \text { ) higher than in the control groups. } \\
\text { SD units, measured using different instruments; higher } \\
\text { scores mean better function. }\end{array}$} & $\begin{array}{l}\text { SMD } 0.35,95 \% \\
\text { CI } 0.04 \text { to } 0.66\end{array}$ & $\begin{array}{l}8 \text { studies } \\
525 \text { partici- } \\
\text { pants }\end{array}$ & $\begin{array}{l}\oplus \oplus \oplus \ominus \\
\text { moderate }\end{array}$ & $\begin{array}{l}\text { Downgraded by one level for study } \\
\text { design (random sequence gener- } \\
\text { ation unclear in } 4 / 8 \text { trials in the } \\
\text { meta-analysis; allocation conceal- } \\
\text { ment unclear in } 7 / 8 \text { trials and high } \\
\text { risk in } 1 / 8 \text { trials). }\end{array}$ \\
\hline $\begin{array}{l}\text { Lower limb } \\
\text { functional } \\
\text { measures }\end{array}$ & \multicolumn{2}{|c|}{$\begin{array}{l}\text { Lower limb functional measures in the repetitive task } \\
\text { training groups were on average } 0.29 \text { standard devia- } \\
\text { tions ( } 0.10 \text { to } 0.48 \text { ) higher than in the control groups. } \\
\text { SD units, measured using different instruments; higher } \\
\text { scores mean better function. }\end{array}$} & $\begin{array}{l}\text { SMD } 0.29,95 \% \\
\text { CI } 0.10 \text { to } 0.48\end{array}$ & $\begin{array}{l}5 \text { studies } \\
419 \text { partici- } \\
\text { pants }\end{array}$ & $\begin{array}{l}\oplus \oplus \ominus \ominus \\
\text { low }\end{array}$ & $\begin{array}{l}\text { Downgraded by one level for study } \\
\text { design (random sequence gener- } \\
\text { ation unclear in } 3 / 5 \text { trials in the } \\
\text { meta-analysis; allocation conceal- } \\
\text { ment unclear in } 3 / 5 \text { trials and high } \\
\text { risk in } 1 / 5 \text { trials). } \\
\text { Downgraded by one level for pub- } \\
\text { lication bias; } 4 \text { out of } 5 \text { are small } \\
\text { studies (less than } 50 \text { participants). }\end{array}$ \\
\hline $\begin{array}{l}\text { Global motor } \\
\text { function scales }\end{array}$ & \multicolumn{2}{|c|}{$\begin{array}{l}\text { Global motor function in the repetitive task training } \\
\text { groups was on average } 0.38 \text { standard deviations }(0.11 \text { to } \\
0.65) \text { higher than in the control groups. } \\
\text { SD units, measured using different instruments; higher } \\
\text { scores mean better function. }\end{array}$} & $\begin{array}{l}\text { SMD } 0.38,95 \% \\
\text { CI } 0.11 \text { to } 0.65\end{array}$ & $\begin{array}{l}5 \text { studies } \\
222 \text { partici- } \\
\text { pants }\end{array}$ & $\begin{array}{l}\oplus \oplus \oplus \ominus \\
\text { moderate }\end{array}$ & $\begin{array}{l}\text { Downgraded by one level for study } \\
\text { design (random sequence gener- } \\
\text { ation unclear in } 4 / 5 \text { trials in the } \\
\text { meta-analysis; allocation conceal- } \\
\text { ment unclear in } 4 / 5 \text { trials and high } \\
\text { risk in } 1 / 5 \text { trials). }\end{array}$ \\
\hline
\end{tabular}


Adverse events Barreca 2004: $3 / 25$ (12\%) falls in the intervention group versus 4/23 (17.4\%) in the control group, OR 0.65, $95 \% \mathrm{Cl}$ 0.13 to 3.27 .

Holmgren 2010: 11 participants in total fell during study (32\%), five in the intervention group and six in the attention control group.

van de Port 2012: 29 falls reported in the circuit training group and 26 in the usual physiotherapy group $(P=0.93)$. Two serious adverse events were reported in the circuit training group: one participant fell and consulted a GP and one patient experienced arrhythmias during one session.

Winstein 2016: 168 serious adverse events involving 109 participants. The most common were hospitalisation ( $n=143,25 \%$ of randomised participants) and recurrent stroke $(n=42,9 \%$ of randomised participants). Adverse events were not presented by trial arm.

Salbach 2004: intervention-related reasons for withdrawal that could be interpreted as adverse events included one participant out of 47 in a mobility training group who experienced the onset of groin pain. Four participants also fell during the mobility intervention but did not suffer injury and continued to participate in the group. Two falls also occurred during evaluation.

Two trials narratively reported no adverse effects (de Sèze 2001; McClellan 2004).

a As a rule of thumb, 0.2 SD represents a small difference, 0.5 a moderate, and 0.8 a large difference.

CI: confidence interval; MD: mean difference; SMD: standardised mean difference; OR: odds ratio; SD: standard deviation

GRADE Working Group grades of evidence

High quality: Further research is very unlikely to change our confidence in the estimate of effect.

Moderate quality: Further research is likely to have an important impact on our confidence in the estimate of effect and may change the estimate.

Low quality: Further research is very likely to have an important impact on our confidence in the estimate of effect and is likely to change the estimate.

Very low quality: We are very uncertain about the estimate. 


\section{B A C K G R O U N D}

\section{Description of the condition}

Although the age-related incidence of stroke may be falling, the absolute number of people who have a stroke every year and the overall global burden of stroke in terms of disability-adjusted lifeyears are increasing (Feigin 2014). Stroke is still the major cause of long-term neurological disability in adults (Wolfe 2000). Prevalence rates of disability and impairment vary according to sampling of cohorts, but in the acute stage of stroke approximately half of all stroke survivors are left with severe functional problems (Lawrence 2001). Estimates of recovery of independent ambulation in studies recruiting cohorts early after stroke range from $41 \%$ to $85 \%$ (Dallas 2008; Feigin 1996; Kwah 2013; Verbeek 2011; Wade 1987; Wandel 2000); those of recovery of independent upper limb function range from 32\% to 34\% (Au-Yeung 2009; Heller 1987; Nijland 2010). Only $5 \%$ to $20 \%$ of people with initial upper limb impairment after stroke fully regain arm function, with $30 \%$ to $66 \%$ regaining no functional use at six months (Heller 1987; Nakayama 1994; Sunderland 1989; Wade 1983). At three weeks and six months after stroke, $40 \%$ and $15 \%$ of people are unable to walk independently indoors (Wade 1987), with only $18 \%$ regaining unrestricted walking ability (Lord 2004).

\section{Description of the intervention}

Systematic reviews of treatment interventions for the paretic upper limb suggest that participants benefit from exercise programmes in which functional tasks are directly trained (Van Peppen 2004). A meta-analysis has shown that more intensive therapy may at least improve the rate of activities of daily living (ADL) recovery (Kwakkel 2004), particularly if a direct functional approach is adopted (Kwakkel 1999; Van der Lee 2001). More recently, a review of the evidence for physical therapy post stroke concluded there is strong evidence for high intensity practice (additional therapy time of 17 hours over 10 weeks) with a high number of repetitions within a single-treatment session and a functional goal (Verbeek 2014). Repetitive task practice combines elements of both intensity of practice and functional relevance.

\section{How the intervention might work}

Many aspects of rehabilitation involve repetition of movement. Repeated motor practice has been hypothesised to reduce muscle weakness and spasticity (Nuyens 2002), and to form the physiological basis of motor learning (Butefisch 1995), while sensorimotor coupling contributes to the adaptation and recovery of neuronal pathways (Dobkin 2004). Active cognitive involvement, functional relevance and knowledge of performance are hypothesised to enhance learning (Carr 1987; Schmidt 2014). However, most interventions evaluated in randomised controlled trials (RCTs) do not explicitly target specific pathophysiological processes (Langhorne 2009).

\section{Why it is important to do this review}

Repetitive task training (RTT) has the potential to be a resourceefficient component of stroke rehabilitation, including delivery in a group setting, or self-initiated practice in the home environment. Repetition of movement is the basic mechanism of action associated with many interventions showing promise in improving motor function (Langhorne 2009) (e.g. constraintinduced movement therapy (Corbetta 2015), treadmill training
(Mehrholz 2014), and training with electromechanical devices, for example robots (Mehrholz 2015b)). This review is important as it considers whether RTT alone leads to functional gains in the absence of other mechanisms of action.

\section{O B J E C T I VES}

Primary objective: To determine if repetitive task training (RTT) improves upper limb function/reach and lower limb function/ balance in adults after stroke.

Secondary objectives: 1) To determine the effect of RTT on secondary outcome measures including activities of daily living (ADL), global motor function, quality of life/health status, and adverse events. 2) To determine the factors that could influence primary and secondary outcome measures, including the effect of 'dose' of task practice; type of task (whole therapy, mixed or single task); timing of the intervention; and type of intervention.

\section{METHODS}

\section{Criteria for considering studies for this review}

\section{Types of studies}

We included RCTs and quasi-randomised trials (defined as methods of allocating people to a trial that are not random, but are intended to produce similar groups when used to allocate participants, such as those allocating by date or alternation (Higgins 2011)). One arm of the trial had to include RTT, compared against usual practice (including 'no treatment'), or an attention control group. We excluded studies where RTT was a component of both the experimental and control treatments. Examples of attention control treatments are comparable time spent receiving therapy on a different limb, or participating in an activity with no potential motor benefits. We accepted usual practice comparison groups when the intervention received by the control group was considered a normal or usual component of stroke rehabilitation practices, including neurophysiological or orthopaedic approaches. We assumed that, early after stroke, usual practice would mean that people would receive some therapy.

\section{Types of participants}

Adults (18 years and older) who have suffered a stroke. Stroke is defined by the World Health Organization (WHO) as "a syndrome of rapidly developing symptoms and signs of focal, and at times global, loss of cerebral function lasting more than 24 hours or leading to death, with no apparent cause other than that of vascular origin" (WHO 1989). We included trials starting any time after an acute stroke and in any setting. We excluded studies of participants with mixed aetiology (for example, participants with acquired brain injury) unless data were available relating to the participants with stroke only.

\section{Types of interventions}

One arm of the trial had to include an intervention where an active motor sequence was performed repetitively within a single training session, and where the practice was aimed towards a clear functional goal. Functional goals could involve complex whole tasks (e.g. picking up a cup), or pre-task movements for a whole limb or limb segment such as grasp, grip, or movement in a trajectory to facilitate an ADL-type activity (e.g. sit-to-stand). To be included, trials of repetitive activity were required to involve 
complex multi-joint movement with functional measurement of outcome, rather than the exercise of a single joint or muscle group orientated to motor performance outcomes.

We included any intensity and duration of task training schedule but only included trials if the time duration or number of repetitions within a session of practice and the number of sessions delivered could be identified. We included trials that clearly used motor relearning as a whole therapy approach if we could identify the amount of task-specific training received.

We included trials combining RTT with person-delivered, mechanical or robotic movement assistance if the purpose of the assistance was to facilitate a task-related repetition. We excluded studies if assisted movement was predominant, or could not easily be related to a functional goal.

We excluded trials if they combined RTT with another intervention where the influence of task repetition could not be isolated, for example electrical stimulation, virtual environments, forced use, bilateral movement, or mental rehearsal. We also excluded trials if the intervention used mechanical means simply to increase strength or endurance.

We contacted trial authors for clarification of the nature of the intervention if it was unclear whether the trial met our definition.

\section{Types of outcome measures}

\section{Primary outcomes}

The primary outcomes we chose were global and limb-specific functional measures. Due to the large range of measures used across trials, selection of outcome measures was done by the review authors to facilitate quantitative pooling. If more than one measure was available in an outcome category, we prioritised measures of functional motor ability used in the primary trials as follows in the different categories.

\section{- Upper limb function/reach}

- Arm function: Motor Assessment Scale - upper limb component, Action Research Arm Test, Frenchay Arm Test, Wolf Motor Function Test, Functional Test of the Hemiparetic Upper Extremity, Box and Block Test, Southern Motor Group Assessment

- Hand function: Motor Assessment Scale - hand, Jebsen Test of Hand Function*, Peg Test*, Stroke Impact Scale - hand domain

- Sitting balance/reach: Reaching Performance Scale, Functional Reach

- Lower limb function/standing balance

- Lower limb function: walking distance, walking speed, functional ambulation, Timed Up and Go Test/sit-to-stand*; measures of lower limb function, such as the Rivermead Motor Assessment, Sødring Motor Evaluation Scale, Walking Ability Questionnaire, Stroke Impact Scale - mobility domain.

- Standing balance/reach: Berg Balance Scale, Standing Equilibrium Index, Functional Reach, Activities Based Confidence Scale, Timed Balance Test

\section{Secondary outcomes}

- Activities of daily living (ADL)

- Barthel Index, Functional Independence Measure, Modified Rankin Scale, Global Dependency Scale, Canadian Occupational Performance Measure

- Global motor function (including arm, leg and trunk and gross motor function [e.g. the ability to move from lying to sitting on the side of the bed])

- Motor Assessment Scale, Rivermead Motor Assessment Scale, Sødring Motor Evaluation Scale

- Measures of quality of life, health status, user satisfaction, carer burden, motivation or perceived improvement

- For example, Nottingham Health Profile*, SF36, Dartmouth Cooperative Chart*

- Adverse events

- For example, pain, injury, falls

*Items marked with an asterisk are measures where a low score equals a positive outcome. The data were expressed as negative values for these studies. In all other measures, a high score indicates a good outcome, and data were expressed as positive values.

\section{Timing of outcome assessment}

Primary outcome timing was at the end of the treatment period. If the end of the treatment period was not clearly defined, we chose outcome measures at three months post treatment as primary, because we considered this to be the average period of rehabilitation input. Outcome data are presented for follow-up less than six months post treatment, and between six months to one year post treatment. At both follow-up points, we entered data for the primary outcome if a primary outcome was specified and data were available; otherwise, we included data for available outcomes with similar outcomes chosen across studies where data were provided for more than one outcome.

\section{Search methods for identification of studies}

See the 'Specialized register' section in the Cochrane Stroke Group module. We searched for trials in all languages and arranged translation of relevant papers where necessary.

\section{Electronic searches}

We searched the Cochrane Stroke Group Trials Register; this was searched by the Managing Editor on 4 March 2016. In addition, we searched the following electronic databases: the Cochrane Central Register of Controlled Trials (CENTRAL: the Cochrane Library 2016, Issue 5: 1 October 2006 to 24 June 2016; Appendix 1); MEDLINE (1 October 2006 to 8 March 2016; Appendix 2); Embase (1 October 2006 to 8 March 2016; Appendix 3); CINAHL (2006 to 23 June 2016; Appendix 4); AMED (2006 to 21 June 2016; Appendix 5); and SPORTSDiscus (2006 to 21 June 2016; Appendix 6). We developed the MEDLINE search strategy with the help of the Cochrane Stroke Group Information Specialist and adapted it for the other databases.

\section{Searching other resources}

We searched reference lists of relevant studies and contacted authors to identify missing data. In an effort to identify further published, unpublished and ongoing trials we searched the following resources using broad descriptors for stroke, rehabilitation, and physical therapy: 
- ClinicalTrials.gov 15 June 2016 (http://clinicaltrials.gov/);

- World Health Organization (WHO) International Clinical Trials Registry Platform Search Portal 15 June 2016 (http:// apps.who.int/trialsearch/).

\section{Data collection and analysis}

\section{Selection of studies}

Two review authors (from JC, LC, BF, JH, NM, LT) independently screened references identified from the searches of the electronic databases and excluded irrelevant studies. We obtained the fulltext papers of the remaining studies and the same two review authors assessed these for inclusion according to the inclusion criteria. We resolved disagreements through discussion and by referral to a third review author as necessary. We provided reasons for excluding potentially relevant studies.

\section{Data extraction and management}

Two review authors (from JC, LC, NM, LT) independently conducted data extraction using a pre-designed data extraction form for each selected study. Data extracted included citation details, method of randomisation, study population, intervention methods and delivery, reasons for losses to follow-up, post therapy and follow-up outcome measures, and methodological quality. In addition, we extracted information relating to treatment monitoring, acceptability, and adherence where available. We resolved disagreements by discussion, and by referral to a third author (LT) as necessary. We contacted study authors by email to request any missing information necessary for the review.

\section{Assessment of risk of bias in included studies}

Two review authors (LT and NM) used Cochrane's 'Risk of bias' tool to independently assess the methodological quality of the included studies (Higgins 2011). The tool covers the domains of sequence generation, allocation concealment, blinding of outcome assessors, incomplete outcome data and selective reporting. We classified items as 'low risk', 'high risk' or 'unclear risk' of bias. We resolved disagreements with help from a third review author (JC).

\section{Measures of treatment effect}

For continuous outcomes using similar measurement scales, we used the mean difference (MD) with 95\% confidence intervals (Cls). If similar outcomes were measured using different outcome scales, we combined results using standardised mean difference (SMD) and 95\% Cls. For continuous outcomes, we extracted means and standard deviations of post-therapy scores. We also extracted means and standard deviations of change from baseline scores where available across trials. We used the $\mathrm{Chi}^{2}$ test to explore differences between subgroups.

One outcome contained both dichotomous and continuous measurement units, which we analysed using the generic inverse variance method. Four different outcome measures were used in seven trials. Three of these were continuous measures: Timed Up \& Go Test (Blennerhassett 2004b; Dean 2000; Salbach 2004a); Motor Assessment Scale sit-to-stand (Langhammer 2000; Van Vliet 2005); sit-to-stand (time in seconds) (Howe 2005), the exception being 'Number of people able to stand independently and safely on two consecutive occasions' (Barreca 2004). For the six trials with continuous outcomes, we calculated the SMD and corresponding standard error in Review Manager 5 (RevMan 2014) from the SMD estimate and $\mathrm{Cl}$ and re-entered for the GIV-based meta-analysis of sit-to stand. For Barreca 2004, we converted the log OR and its standard error (SE) to an approximate SMD scale.

\section{Unit of analysis issues}

\section{Studies with multiple treatment groups}

Two trials compared upper versus lower limb training, so are included as four intervention-control pairs (Blennerhassett 2004; Salbach 2004). Blennerhassett 2004a refers to a upper limb training group versus lower limb attention control, and Blennerhassett 2004b refers to an lower limb training group versus upper limb training attention control. Salbach 2004a refers to a lower limb training group versus upper limb training attention control, and Salbach 2004b refers to the upper limb training group versus lower limb training attention control. In the subgroup and sensitivity analyses, these intervention-control pairs are not included as separate trials, as we considered that the impacts of the interventions on upper and lower limb function in the same person might not be completely independent. Results for the primary outcome of the lower limb training groups were selected as representative, as studies were showing that treatment effects were greater in the lower limb than in the upper limb. One trial compared upper and lower limb training groups against the same control group (Kwakkel 1999). To avoid the control group being included twice, and to use a limb-specific rather than a global or ADL measure, we selected the lower limb training versus splint control comparison for the sensitivity analyses.

\section{Dealing with missing data}

If data were not in a form suitable for quantitative pooling, we contacted trial authors for additional information. We attempted to obtain post therapy scores from trial authors who had reported median and inter-quartile ranges. We presented trials reporting change scores with standard deviations in separate analyses.

\section{Assessment of heterogeneity}

We assessed the degree of heterogeneity among the trials using the $I^{2}$ statistic for each outcome. If less than or equal to $50 \%$, we used a fixed-effect meta-analysis. If the $\mathrm{I}^{2}$ statistic was greater than $50 \%$, we explored the individual trial characteristics to identify potential sources of heterogeneity. We then performed meta-analysis using both fixed-effect and random-effects modelling to assess sensitivity to the choice of modelling approach.

We addressed clinical and methodological diversity by incorporating subgroup or sensitivity analyses for type of participant (time from stroke), intervention (type and amount of intervention), and study design (comparison group, equivalence of treatment).

To test for subgroup effects we used the $\mathrm{Chi}^{2}$ test with a $5 \%$ significance level.

\section{Assessment of reporting biases}

We searched clinical trial registers to assist in reducing publication bias. We also investigated selective outcome reporting through the comparison of the methods section of papers with the results reported. 


\section{Data synthesis}

Where there were acceptable levels of heterogeneity, we pooled results. We used both random-effects and fixed-effect metaanalysis with $95 \% \mathrm{Cl}$ using Review Manager 5 (RevMan 2014). We pooled outcomes measured with different instruments using the SMD.

We documented the quality of evidence for each outcome based on criteria considered within the GRADE (Grading of Recommendations Assessment, Development and Evaluation) approach (Guyatt 2008); this includes the following.

- Risk of bias due to flawed design or conduct of studies (sequence generation, allocation concealment, blinding of outcome assessors and incomplete outcome data). We reassessed all studies from the original review using the updated 'Risk of bias' tool (Higgins 2011).

- Imprecision (e.g. when confidence intervals for treatment effect are wide).

- Inconsistency (e.g. when point estimates vary widely, the $\mathrm{I}^{2}$ is large).

- Indirectness (e.g. variations in participants, interventions, comparisons and outcomes).

- Publication bias (may be explored with the use of funnel plots and classed as not suspected, suspected, strongly suspected or very strongly suspected).

Three review authors (JC, NM and LT) assessed and documented risk of bias related to study design, imprecision, inconsistency, indirectness and publication bias for each outcome within comparisons presented.

We employed GRADE to interpret findings and to create a 'Summary of findings' table (Guyatt 2008) for the following outcomes: arm function, hand function, walking distance, walking speed, functional ambulation, lower limb functional measures and global motor function. The table provides outcome-specific information concerning the overall quality of evidence from studies included in the comparison, the magnitude of effect of the intervention and the sum of available data on the outcomes considered. We downgraded the evidence from 'high quality' by one level for serious (or by two for very serious) study limitations (risk of bias, indirectness of evidence, serious inconsistency, imprecision of effect estimates or potential publication bias). We did not assess follow-up outcomes using GRADE.

\section{Subgroup analysis and investigation of heterogeneity}

We undertook planned subgroup analyses for all primary outcomes separately for upper limb and lower limb function, due to the potential differential impact (Table 1). Planned subgroup analyses were as follows:

- dosage of task practice: dosage of task practice was calculated by multiplying the number of weeks, by the number of sessions per week, by the session duration in hours. Trials were divided into those providing up to and including 20 hours training, and those providing more than 20 hours training in total;

- time since stroke: mean time since stroke at recruitment was used to classify trials as within zero to six months post stroke or more than six months post stroke. As a number of trials recruited very early post stroke, a post-hoc analysis grouping was included for trials recruiting within 14 days of stroke;

- type of intervention: trials were classified as either 1) whole therapy approaches, where rehabilitation in total was directed by a motor relearning or movement science approach, 2) mixed functional task training, where therapy included a mixed combination of functional tasks, and 3) single task training, where one task was practiced repeatedly.

We intended to consider if effect sizes were related to whether training was based on pre-functional versus functional activities, or pre-intervention level of disability. In the event, we excluded most pre-functional trials because they contained a large proportion of passive or active-assisted movement, and levels of disability proved too difficult to classify because of mixed groups of participants and unsuitable measures and data for this purpose. Therefore, we have not presented these planned subgroup analyses.

We prioritised outcomes for subgroup analyses by the study authors' primary outcome choice, or the review authors' judgement as to the most suitable measure for the intervention, for example a balance measure for trials training balance functions. If more than one measure was available, we prioritised lower limb outcomes in the following order: 1) walking speed, 2) walking distance, 3) functional ambulation, and 4) lower limb functional measures. We prioritised upper limb outcomes as 1) arm function, and 2) hand function. We omitted one trial from the subgroup and sensitivity analyses because it used a dichotomous outcome (Barreca 2004).

\section{Sensitivity analysis}

We carried out planned sensitivity analyses for allocation concealment (adequate or inadequate/unclear). In addition, we included post hoc sensitivity analyses to consider the impact of different comparison groups (attention control, usual care), equivalence of therapy time (equivalent time, additional time), and intervention delivery (individual versus group). We did not undertake planned sensitivity analyses for intervention setting (hospital versus home) because of an insufficient numbers of trials.

\section{RE S U L T S}

\section{Description of studies}

\section{Results of the search}

We identified 66,028 records from the database searches. After deduplication we screened 55,011 records and excluded 54,100 as not relevant. In total 911 records progressed to filtering in full text (Figure 1). Out of the 911 full papers retrieved, we excluded a further 878 . We subsequently excluded studies where there was uncertainty whether or not they met the inclusion criteria - details are presented in the Characteristics of excluded studies table, In total, we identified 19 new studies and added them to the 14 studies previously included in the 2007 review. A total of 33 studies are now included in the review. We categorised 11 studies as on-going (Characteristics of ongoing studies) and 14 studies as awaiting assessment (Characteristics of studies awaiting classification). 
Figure 1. Study flow diagram (2007 review and update 2016 figures)

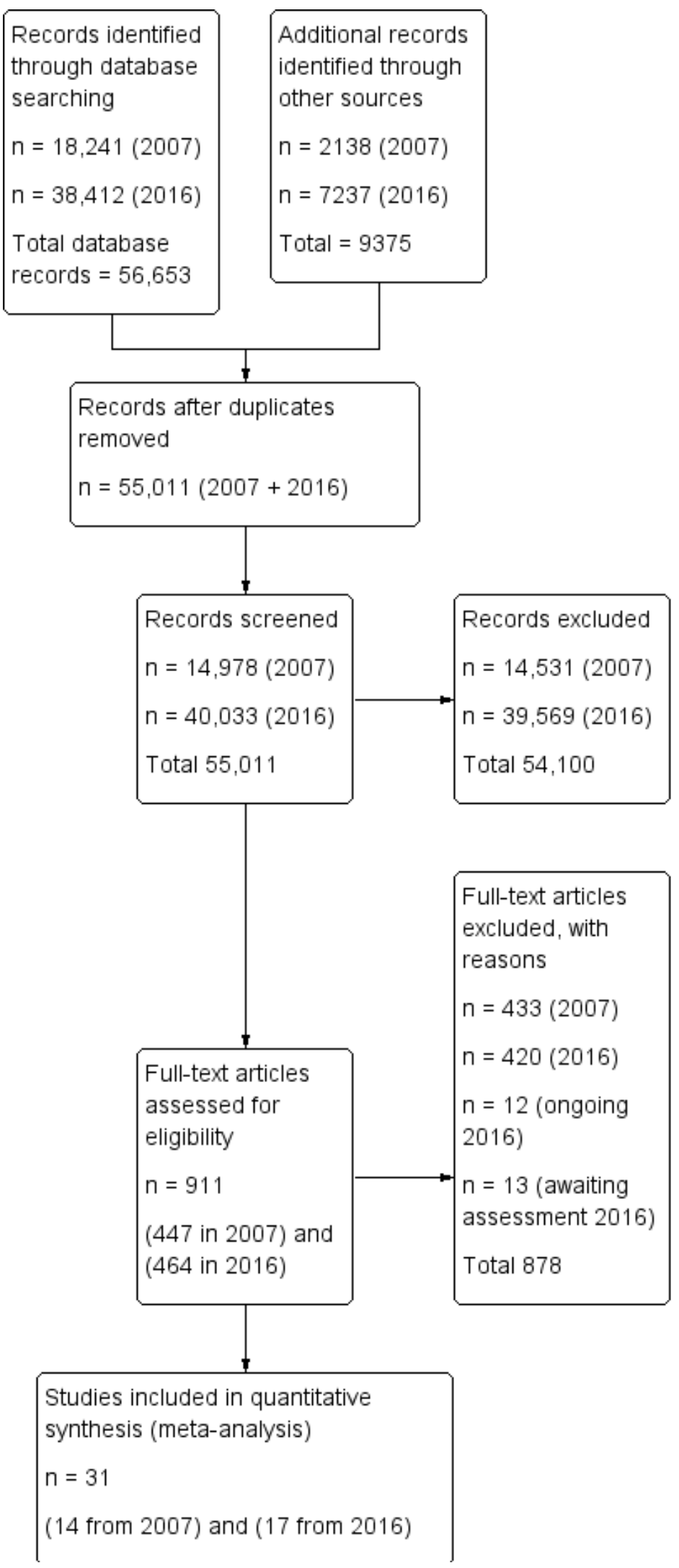


Figure 1. (Continued)

$$
\text { (14 from 2007) and (17 from 2016) }
$$

\section{Included studies}

We identified 33 trials, comprising 36 intervention-control pairs, which met the inclusion criteria. One paper (Kwakkel 1999) refers to a trial with two intervention-control pairs which have been referenced separately in the review: Kwakkel 1999a refers to a lower limb training group versus splint control, Kwakkel 1999b refers to an upper limb training group versus splint control. Blennerhassett 2004 includes two intervention-control pairs: Blennerhassett 2004a refers to an upper limb training group versus lower limb attention control, and Blennerhassett 2004b refers to a lower limb training group versus upper limb training attention control. Salbach 2004 has two intervention-control pairs: Salbach 2004a refers to a lower limb training group versus upper limb training attention control, and Salbach 2004b refers to the upper limb training group versus lower limb training attention control. In five trials (Baer 2007; Olawale 2011; Peurala 2009; Winstein 2004; Winstein 2016) there were three arms. We only included the data for the interventioncontrol pair of repetitive task training (RTT) versus control in the review.

\section{Design}

Of the 33 included trials, 32 were RCTs (Arya 2012; Baer 2007; Barreca 2004; Blennerhassett 2004; Dean 1997; Dean 2000; Dean 2007; de Sèze 2001; Frimpong 2014; Gordon 2013; Holmgren 2010; Howe 2005; Kim 2012; Kim 2014; Kim 2016; Kwakkel 1999; Langhammer 2000; Lennon 2009; McClellan 2004; Mudge 2009; Olawale 2011; Park 2011; Peurala 2009; Ross 2009; Salbach 2004; Song 2015; Tung 2010; van de Port 2012; Van Vliet 2005; Winstein 2004; Winstein 2016; Yen 2005), and one is a quasi-randomised trial (Turton 1990). Four of the trials were pilot randomised controlled trials (Dean 2000; de Sèze 2001; Howe 2005; Winstein 2004). Four of the trials were multicentre (Arya 2012; Kwakkel 1999; van de Port 2012; Winstein 2016). Nine of the trials were stratified before randomisation using: baseline level of walking deficit (Lennon 2009; Peurala 2009; Salbach 2004), cognition and falls risk (Holmgren 2010), gender and side of stroke (Langhammer 2000); rehabilitation centre (van de Port 2012), stroke severity (Baer 2007; Winstein 2004), and motor severity and time from stroke onset (Winstein 2016).

\section{Sample size}

Eleven trials had 25 participants or less (Dean 1997; Dean 2000; Dean 2007; de Sèze 2001; Frimpong 2014; Kim 2012; Kim 2014; Kim 2016; Park 2011; Song 2015; Turton 1990). Ten trials had between 26 and 49 participants (Barreca 2004; Blennerhassett 2004; Holmgren 2010; Howe 2005; McClellan 2004; Peurala 2009; Ross 2009; Tung 2010; Winstein 2004; Yen 2005). Twelve trials had 50 participants or more (Arya 2012; Baer 2007; Gordon 2013; Kwakkel 1999; Langhammer 2000; Lennon 2009; Mudge 2009; Olawale 2011; Salbach 2004; van de Port 2012; Van Vliet 2005; Winstein 2016).

\section{Country}

Of the 33 trials, three were carried out in Canada (Barreca 2004; Dean 2000; Salbach 2004), five in Australia (Blennerhassett 2004; Dean 1997; Dean 2007; McClellan 2004; Ross 2009), four in the UK
(Baer 2007; Howe 2005; Turton 1990; Van Vliet 2005), two in Taiwan (Tung 2010; Yen 2005), five in Korea (Kim 2012; Kim 2014; Kim 2016; Park 2011; Song 2015), two in the Netherlands (Kwakkel 1999; van de Port 2012), two in the USA (Winstein 2004; Winstein 2016), one in Norway (Langhammer 2000), two in Africa (Frimpong 2014; Olawale 2011), one in India (Arya 2012), one in Jamaica (Gordon 2013), one in Sweden (Holmgren 2010), one in Finland (Peurala 2009), one in Ireland (Lennon 2009), one in New Zealand (Mudge 2009), and one in France (de Sèze 2001).

\section{Participants}

The 33 trials included 2014 participants, of which 1853 were included in the 36 intervention-control pairs relevant to this review. All of the trials included both genders, with 10 trials having more than 60\% male participants (Arya 2012; Barreca 2004; Dean 1997; Dean 2007; Frimpong 2014; Holmgren 2010; Kim 2016; Salbach 2004; Tung 2010; van de Port 2012). In 10 trials, the participants had a mean age of less than 60 (Arya 2012; Blennerhassett 2004; Frimpong 2014; Kim 2012; Kim 2014; Olawale 2011; Park 2011; Tung 2010; Turton 1990; van de Port 2012), and in seven trials the mean age was over 70 (Baer 2007; Holmgren 2010; Howe 2005; Langhammer 2000; Lennon 2009; Salbach 2004; Van Vliet 2005). Fourteen trials included only participants after a first stroke (Arya 2012; Dean 2000; Dean 2007; de Sèze 2001; Frimpong 2014; Kim 2014; Kim 2016; Kwakkel 1999; Langhammer 2000; Park 2011; Peurala 2009; Tung 2010; Winstein 2004; Yen 2005). Six trials included participants with either first or recurrent stroke (Blennerhassett 2004; Holmgren 2010; Howe 2005; Lennon 2009; Mudge 2009; Salbach 2004). In the remaining trials, it was unclear whether inclusion was limited to first stroke only.

\section{Mean time since stroke}

Mean time since stroke was one month or less in 10 trials (Barreca 2004; Dean 2007; Howe 2005; Kim 2016; Kwakkel 1999; Langhammer 2000; Lennon 2009; Peurala 2009; Van Vliet 2005; Winstein 2004), between one and three months in five trials (Arya 2012; Blennerhassett 2004; de Sèze 2001; Frimpong 2014; Winstein 2016), between three and six months in four trials (Holmgren 2010; McClellan 2004; Turton 1990; van de Port 2012), and between six and 12 months in five trials (Gordon 2013; Kim 2014; Olawale 2011; Salbach 2004; Yen 2005). Participants were in the chronic phase of stroke in nine trials (Baer 2007; Dean 1997; Dean 2000; Kim 2012; Mudge 2009; Park 2011; Ross 2009; Song 2015; Tung 2010).

\section{Interventions}

Upper limb RTT interventions were tested in six trials (Arya 2012; Ross 2009; Turton 1990; Winstein 2004; Winstein 2016; Yen 2005). Lower limb repetitive task-oriented training interventions were tested in 17 trials (Barreca 2004; Dean 2000; Frimpong 2014; Gordon 2013; Holmgren 2010; Kim 2012; Kim 2014; Kim 2016; Lennon 2009; McClellan 2004; Mudge 2009; Olawale 2011; Park 2011; Peurala 2009; Song 2015; Tung 2010; van de Port 2012). Of these trials, two of the interventions focused specifically on sit-to-stand practice (Barreca 2004; Tung 2010) and six of the interventions focused on walking practice (Gordon 2013; Kim 2014; Lennon 2009; Olawale 2011; Park 2011; Peurala 2009). Three trials 
investigated RTT interventions for both the upper and lower limb (Blennerhassett 2004; Kwakkel 1999; Salbach 2004). Four trials investigated RTT interventions that focused specifically on: sitting balance (Dean 1997; Dean 2007), trunk control (de Sèze 2001), and balance (Howe 2005), and two trials investigated whole therapy approaches (Langhammer 2000; Van Vliet 2005).

\section{Setting}

The intervention was delivered solely in an inpatient setting in 11 trials (Barreca 2004; Blennerhassett 2004; Dean 2007; Frimpong 2014; de Sèze 2001; Howe 2005; Kim 2014; Kwakkel 1999; Lennon 2009; Peurala 2009; Winstein 2016). In three trials the intervention was delivered during both inpatient and outpatient rehabilitation (Ross 2009; Van Vliet 2005; Winstein 2004), with one trial continuing to deliver the intervention in community settings and the patients' own homes (Langhammer 2000). Nine trials delivered the intervention as outpatient rehabilitation (Arya 2012; Dean 2000; Mudge 2009; Olawale 2011; Park 2011; Salbach 2004; Tung 2010; van de Port 2012; Yen 2005). Two trials delivered the intervention in community settings (Gordon 2013; Holmgren 2010), and four trials delivered the intervention solely in the patients' home environments (Baer 2007; Dean 1997; McClellan 2004; Turton 1990). In three trials it was not clear in which setting the intervention was delivered (Kim 2012; Kim 2016; Song 2015).

\section{Amount of task practice}

The number of hours of task practice varied considerably across the interventions. Six trials were estimated to have provided less than 10 hours training in total (Dean 1997; Dean 2007; Howe 2005; Lennon 2009; Tung 2010; Van Vliet 2005). A further 16 trials provided between 10 and 21 hours training (Arya 2012; Barreca 2004; Blennerhassett 2004; Dean 2000; Frimpong 2014; Gordon 2013; Kim 2012; Kim 2014; Langhammer 2000; Mudge 2009; Olawale 2011; Park 2011; Peurala 2009; Salbach 2004; Song 2015; Winstein 2004). Four trials provided between 30 and 40 hours training (Kim 2016; Ross 2009; van de Port 2012; Winstein 2016), and four trials prescribed more than 40 hours therapy (Kwakkel 1999; McClellan 2004; Turton 1990; Yen 2005). In one trial, the number of hours was not reported (Baer 2007). As only four of the included trials reported the duration of the RTT component of the task training sessions (Arya 2012; Mudge 2009; Peurala 2009; Ross 2009), we have used figures for the total duration of the task training sessions as these were more frequently reported in the included studies.

\section{Duration of training}

The length of time that training was spread over varied from two to four weeks in 19 trials (Arya 2012; Baer 2007; Blennerhassett 2004; Dean 1997; Dean 2000; Dean 2007; de Sèze 2001; Howe 2005; Kim 2012; Kim 2014; Kim 2016; Lennon 2009; Mudge 2009; Park 2011; Peurala 2009; Song 2015; Tung 2010; Winstein 2004; Yen 2005). The intervention was between four and 12 weeks in eight trials (Barreca 2004; Frimpong 2014; Holmgren 2010; McClellan 2004; Ross 2009; Salbach 2004; Turton 1990; Winstein 2016) and between 12 and 20 weeks in four trials (Gordon 2013; Kwakkel 1999; Olawale 2011; van de Port 2012). For two trials, the duration of training was over the inpatient rehabilitation period, with therapy for some participants in an outpatient setting if required (Langhammer 2000; Van Vliet 2005).

\section{Intervention delivery}

The RTT interventions were delivered by trained therapists in all but four of the included trials. In three trials trained staff input was restricted to prescription and review of self-administered homework exercise programmes (Baer 2007; McClellan 2004; Turton 1990). Trained therapy assistants provided balance training in one trial (Howe 2005), and registered practical nurses delivered sit-to-stand training in one trial (Barreca 2004). A group or circuit training approach was used in eight studies (Barreca 2004; Blennerhassett 2004; Dean 2000; Frimpong 2014; Kim 2016; Mudge 2009; Song 2015; van de Port 2012 ). In one trial it was unclear who delivered the intervention (Kim 2014).

\section{Comparison interventions}

Eleven trials compared the intervention against an attention control: two trials used a recreation or cognitive therapy control group (Barreca 2004; Dean 1997), two used educational sessions (Holmgren 2010; Mudge 2009), one used a splint control (Kwakkel 1999), one used light massage (Gordon 2013), one used a sham sitting protocol (Dean 2007) and four used a comparison training programme for the upper or lower limb (Blennerhassett 2004; Dean 2000; McClellan 2004; Salbach 2004). Eighteen trials compared the intervention against usual care. Equivalent hours of therapy were provided in eight trials (Arya 2012; de Sèze 2001; Langhammer 2000; Lennon 2009; Olawale 2011; van de Port 2012; Van Vliet 2005; Winstein 2016).The RTT group received additional practice in 14 trials (Baer 2007; Frimpong 2014; Holmgren 2010; Howe 2005; Kim 2012; Kim 2014; Kim 2016; Park 2011; Peurala 2009; Ross 2009; Song 2015; Tung 2010; Turton 1990; Winstein 2004). It is unclear whether the duration of therapy for the intervention-control pair was equivalent for Yen 2005.

\section{Outcomes}

The 33 included trials used a wide range of different outcome measures, measurement statistics, and time intervals for follow-up. Measures selected by the review team for each outcome category are detailed below, and in Table 2 for ease of reference per outcome category. In some studies, more than one measure was available for a category, and in this case, we prioritised measures as detailed in the Methods section.

\section{Primary outcomes}

\section{Upper limb functional outcome measures}

- Arm function: Action Research Arm Test (Arya 2012; Kwakkel 1999b; Ross 2009), Wolf Motor Function Test (Winstein 2016; Yen 2005), Motor Assessment Scale - arm (Blennerhassett 2004a; Langhammer 2000; Van Vliet 2005), Box and Block Test (Salbach 2004b), Functional Test of the Hemiparetic Upper Extremity (Winstein 2004), Southern Motor Group Assessment - upper limb activity (Turton 1990), Frenchay Arm Test (Baer 2007).

- Hand function: 9 Hole Peg Test (Salbach 2004b), 10 Hole Peg Test (Turton 1990), Motor Assessment Scale - hand (Blennerhassett 2004a; Langhammer 2000; Van Vliet 2005), Wolf Motor Funtion Test (functional ability) (Ross 2009), Stroke Impact Scale - hand domain (Winstein 2016).

- Sitting balance and reach: Reaching distance (Dean 1997; Dean 2007), Sitting Equilibrium Index (de Sèze 2001), Motor Assessment Scale - balanced sitting (Langhammer 2000; Van Vliet 2005), lateral reach - time to return to quiet sitting (Howe 2005). 


\section{Lower limb functional outcome measures}

- Walking distance: 6 Minute Walk Test (Blennerhassett 2004b; Dean 2000; Gordon 2013; Kim 2014; Kim 2016Mudge 2009; Park 2011; Salbach 2004a; van de Port 2012).

- Walking speed: 10 Metre Walk speed (Dean 1997; Dean 2000; Dean 2007; Frimpong 2014; Kim 2012; Kim 2014; Kwakkel 1999a; Olawale 2011; Park 2011), 5 Metre Walk Speed (Lennon 2009; Salbach 2004a; van de Port 2012), 6 Metre Walk Speed (Van Vliet 2005).

- Functional ambulation: Functional Ambulation Classification (de Sèze 2001; Frimpong 2014; Kwakkel 1999a), Motor Assessment Scale - walking (Langhammer 2000; McClellan 2004; Van Vliet 2005); Walking Ability Questionnaire (Park 2011), Stroke Impact Scale - mobility domain (van de Port 2012).

- Sit-to-stand: Timed Up and Go (Baer 2007; Blennerhassett 2004b; Dean 2000; Kim 2012; Salbach 2004a), Motor Assessment Scale - sit-to-stand (Langhammer 2000; Van Vliet 2005), sit-tostand time in seconds (Howe 2005), and number of people able to stand safely and independently on two occasions (Barreca 2004).

- Lower limb function: Sødring Motor Evaluation Scale - trunk, balance and gait subscale (Langhammer 2000), Step Test (Baer 2007; Blennerhassett 2004b; Dean 2000), Motor Assessment Scale - leg and trunk (Van Vliet 2005).

- Standing balance and reach: Upright Equilibrium Index (de Sèze 2001), Functional Reach (McClellan 2004), Berg Balance Scale (Holmgren 2010; Kim 2012; Kim 2016; Salbach 2004a; Tung 2010), Activities Based Confidence Scale (Park 2011), Timed Balance Test (van de Port 2012).

\section{Secondary outcomes}

\section{ADL measures}

The Barthel Index (Baer 2007; Gordon 2013; Holmgren 2010; Kim 2016; Kwakkel 1999; Langhammer 2000; Salbach 2004; Van Vliet 2005), the Canadian Occupational Performance Measure (Ross 2009), Functional Independence Measure (de Sèze 2001), Frenchay Activity Index (Baer 2007). Three trials used the Barthel Index scoring out of 20 (Baer 2007; de Sèze 2001; Van Vliet 2005), while the other trials used the scoring out of 100.

\section{Global motor function}

Motor Assessment Scale (Baer 2007; Langhammer 2000), Balance Master System (Tung 2010), Rivermead Gross Function subscale (Van Vliet 2005), Rivermead Mobility Index (Peurala 2009), Stroke Impact Scale - social participation subscale (van de Port 2012).

\section{Quality of life/health status measures}

Dartmouth Primary Care Cooperative Chart (COOP) (Barreca 2004), Nottingham Health Profile (NHP) (Kwakkel 1999; Langhammer 2000), the Short Form-36 (health component) (Gordon 2013), Stroke Impact Scale (Baer 2007).

\section{Adverse events}

Number of falls (Barreca 2004; Holmgren 2010; van de Port 2012) and other serious and non-serious adverse events (e.g. arrhythmias) (van de Port 2012; Winstein 2016) were measured.

\section{Outcomes used at follow-up}

\section{Upper limb outcome measures}

We used the following outcomes for Comparisons 2.1.1 and 2.1.2:

Action Research Arm Test (Arya 2012),Time to complete Jebson Taylor Hand Test (Blennerhassett 2004), Sitting Equilibrium Index (de Sèze 2001), Lateral Reach Test - time to return to quiet sitting (Howe 2005), Maximum reach distance (Dean 2007), Motor Assessment Scale - upper arm (Langhammer 2000;Van Vliet 2005), Functional test of the hemiparetic upper extremity (Winstein 2004), Wolf Motor Function Test (Winstein 2016).

\section{Lower limb outcome measures}

We used the following outcomes for Comparisons 5.1.1 and 5.1.2:

Upright Equilibrium Index (de Sèze 2001), Walking speed with assistive device (Dean 2000), 10 Metre Walk Test (Dean 2007), Berg Balance Scale (Holmgren 2010 - Comparison 5.1.1), Barthel Index (Holmgren 2010 - Comparison 5.1.2), Sit-to-stand-to-sit (Howe 2005), Walking speed (Lennon 2009), Functional Reach Test (McClellan 2004), 6 Minute Walk Test (Blennerhassett 2004; Mudge 2009), Comfortable Walk Test (van de Port 2012) and Motor Assessment Scale - walking (Langhammer 2000; Van Vliet 2005).

\section{Excluded studies}

There is a large number of excluded studies described in Characteristics of excluded studies. Because of the difficulties in determining whether trial interventions included task-specific functional repetition, we have attempted to be as transparent as possible about the basis on which we excluded trials. The reasons for exclusion were:

- not repetition, or unable to determine amount of practice: five studies;

- comparison group also includes repetitive task practice: nine studies;

- alternative mechanism of action: 10 studies.

We were unable to obtain subgroup data relating to stroke patients in one study (Sherrington 2008).

\section{Ongoing studies}

There are 11 ongoing studies, where the information available is sufficient to say that the interventions are RTT. Five trials involved training for standing, balance or sit-to-stand (Hariohm 2013; Korner-Bitensky 2013; Kumaran 2010; Stuart 2009; Tanne 2008) . Six trials involved upper limb task-specific training (NCT02765152; Bosomworth 2013; NCT02235974; CTRI/2015/06/005877; Schultz 2012; Turton 2011) (Characteristics of ongoing studies).

\section{Studies awaiting classification}

Fourteen studies are awaiting classification (Baglary 2013; Bhaskar 2009; Brkic 2016; NCT02429180; Eng 2009; Ferrari 2015; Gandhi 2015; Indurkar 2013; Knox 2014; Kumar 2012; Pandian 2014; ChiCTR-ICR-15005992; Zhu 2013; Xu 2012) (Characteristics of studies awaiting classification).

\section{Risk of bias in included studies}

See Figure 2 and Figure 3. 
Figure 2. 'Risk of bias' summary: review authors' judgements about each risk of bias item for each included study.

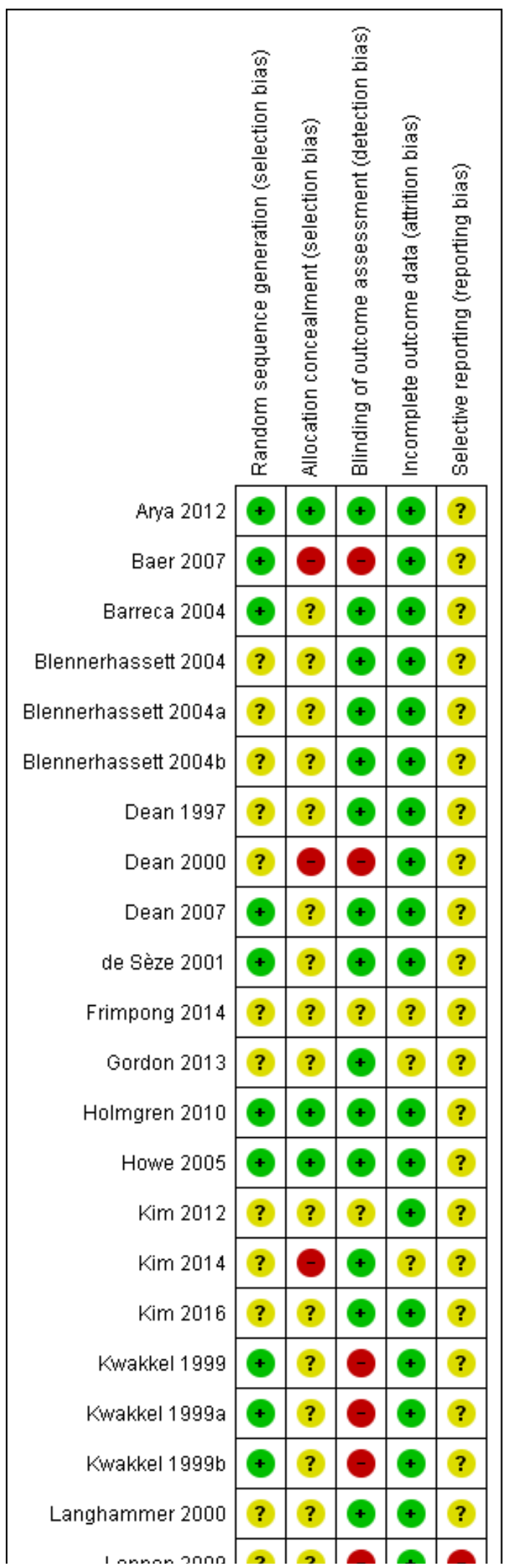


Figure 2. (Continued)

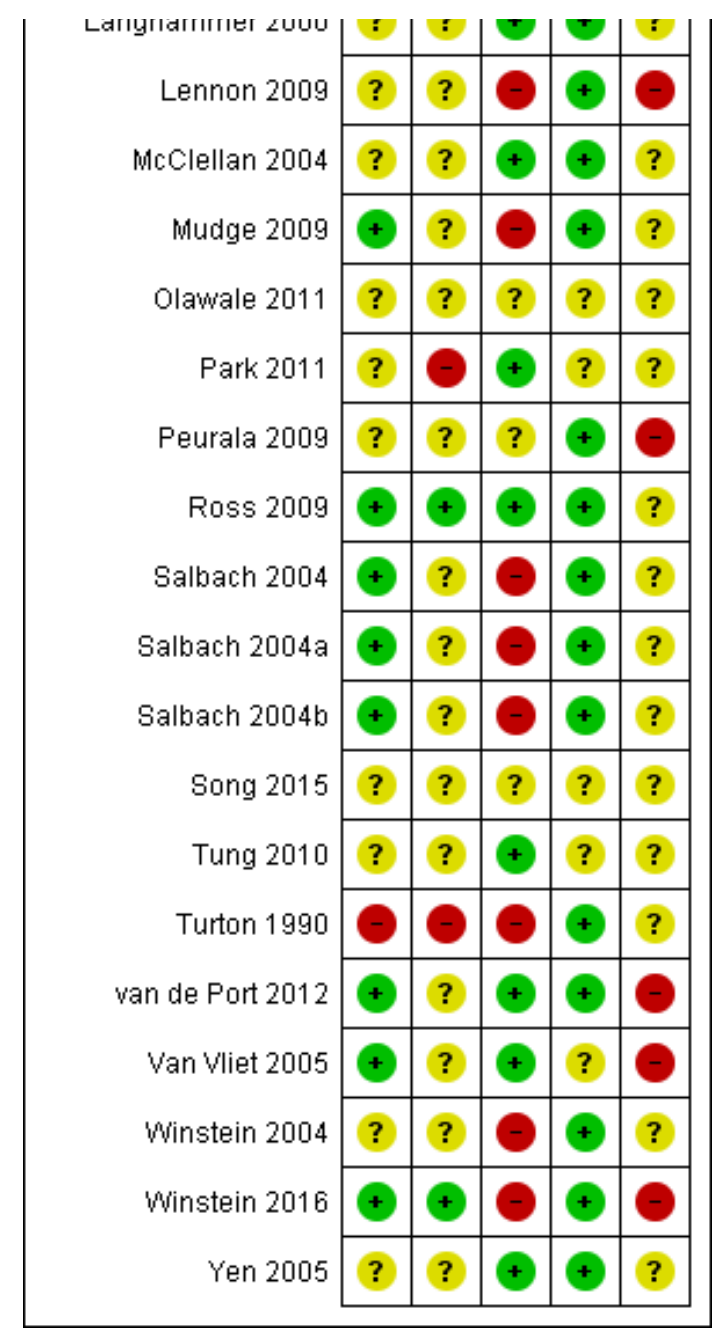

Figure 3. 'Risk of bias' graph: review authors' judgements about each risk of bias item presented as percentages across all included studies.

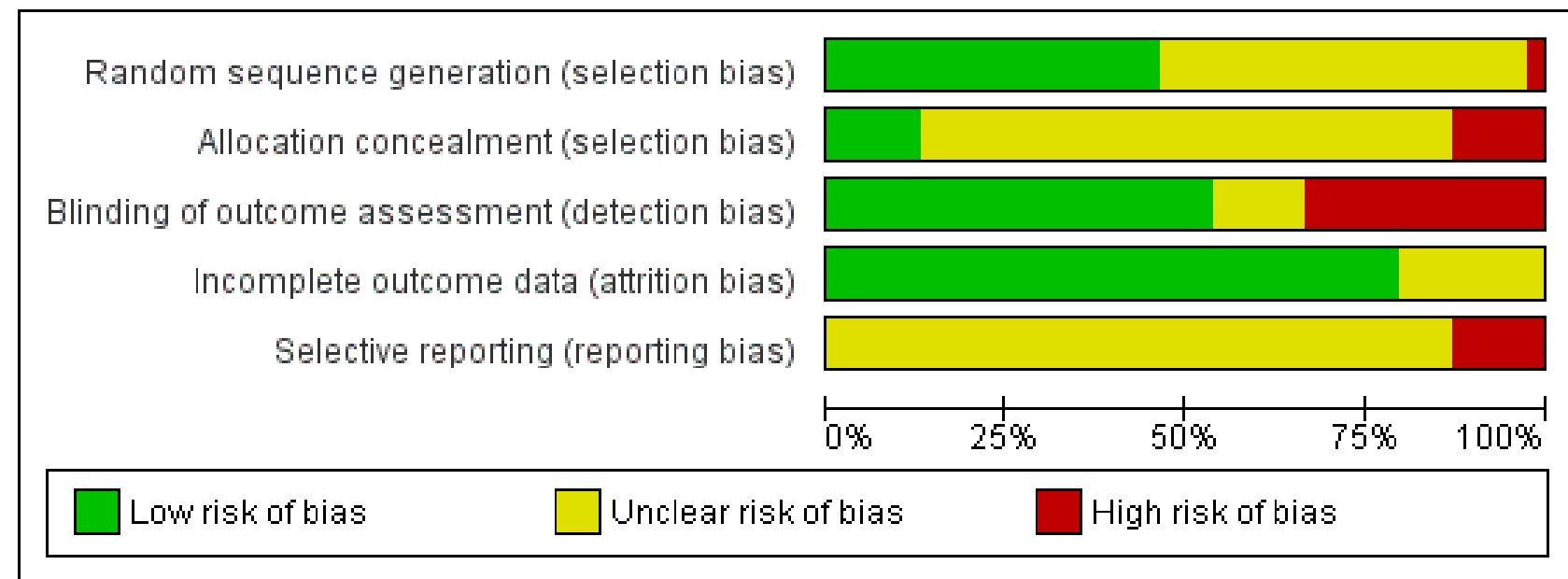




\section{Allocation}

Random sequence generation was adequate in 14 trials (Arya 2012; Baer 2007; Barreca 2004; Dean 2007; de Sèze 2001; Holmgren 2010; Howe 2005; Kwakkel 1999; Mudge 2009; Ross 2009; Salbach 2004; van de Port 2012; Van Vliet 2005; Winstein 2016). Allocation concealment was adequate in five trials (Arya 2012; Holmgren 2010; Howe 2005; Ross 2009; Winstein 2016).

\section{Blinding}

20 trials reported blinding of the outcome assessor (Arya 2012; Barreca 2004; Blennerhassett 2004; Dean 1997; Dean 2007; de Sèze 2001; Gordon 2013; Holmgren 2010; Howe 2005; Kim 2014;Kim 2016; Langhammer 2000; McClellan 2004; Park 2011; Ross 2009; Tung 2010; van de Port 2012; Van Vliet 2005; Winstein 2016; Yen 2005), however unblinding occurred in two trials (Baer 2007; Winstein 2016).

\section{Incomplete outcome data}

We deemed 25 trials to be at low risk of bias in relation to incomplete outcome data (Arya 2012; Baer 2007; Barreca 2004; Blennerhassett 2004; Dean 1997; Dean 2000; Dean 2007; de Sèze 2001; Holmgren 2010; Howe 2005; Kim 2012; Kim 2016; Kwakkel 1999; Langhammer 2000; Lennon 2009; McClellan 2004; Mudge 2009; Peurala 2009; Ross 2009; Salbach 2004; Turton 1990; van de Port 2012; Winstein 2004; Winstein 2016; Yen 2005).

\section{Selective reporting}

There were no study protocols available for any of the included trials to allow us to make a judgement of low risk of bias in relation to selective reporting with the exception of one recent trial (Winstein 2016) . All primary measures were not reported in five studies (Lennon 2009; Peurala 2009; van de Port 2012; Van Vliet 2005; Winstein 2016).

\section{Other potential sources of bias}

To detect systematic differences in care provided to participants in comparison groups other than the intervention under investigation, we assessed trials to determine whether groups were treated equally. In 15 studies participants in the intervention group received additional hours of therapy (Baer 2007; Frimpong 2014; Holmgren 2010; Howe 2005; Kim 2012; Kim 2014; Kim 2016; Park 2011; Peurala 2009; Ross 2009; Song 2015; Tung 2010; Turton 1990; van de Port 2012; Winstein 2004).

There is some evidence of baseline imbalance in 10 trials (de Sèze 2001; Dean 2000; Dean 2007; Kim 2012; Langhammer 2000; Lennon 2009; Tung 2010; Turton 1990; van de Port 2012; Van Vliet 2005); in van de Port 2012 analyses were adjusted for covariates at baseline.

\section{Effects of interventions}

See: Summary of findings for the main comparison

\section{Primary outcomes}

Results are presented for 1) upper limb, and 2) lower limb outcomes. All results are post therapy, except for Langhammer 2000, which is three months post stroke, and Van Vliet 2005, which is three months post baseline. We were not able to obtain data suitable for pooling from Baer 2007 and Song 2015.

\section{Upper limb function: post treatment}

Results are presented for 1) arm function, 2) hand function, and 3) sitting balance and reach.

\section{Comparison 1.1: Arm function}

Eleven trials recruiting 844 participants measured arm function (Arya 2012; Blennerhassett 2004a; Kwakkel 1999b; Langhammer 2000; Ross 2009; Salbach 2004b; Turton 1990; Van Vliet 2005; Winstein 2004; Winstein 2016; Yen 2005). Data were available for $88.7 \%(\mathrm{~N}=749)$ of participants. The impact of functional training on upper limb function post therapy overall indicated a statistically significant effect favouring the treatment group: standardised mean difference (SMD) 0.25, 95\% confidence interval (CI) 0.01 to 0.49 (Analysis 1.1, GRADE: low quality).

\section{Comparison 1.2: Hand function}

Eight trials recruiting 701 participants measured hand function (Arya 2012; Blennerhassett 2004a; Langhammer 2000; Ross 2009; Salbach 2004b; Turton 1990; Van Vliet 2005; Winstein 2016). Data were available for $88.3 \%(N=619)$ of participants. The impact of functional training on hand function was statistically significant favouring the treatment group: SMD $0.25,95 \% \mathrm{Cl} 0.00$ to 0.51 (Analysis 1.2, GRADE: low quality).

\section{Comparison 1.3: Sitting balance/reach}

Six trials, recruiting 268 participants, measured sitting balance or functional reach (de Sèze 2001; Dean 1997; Dean 2007; Howe 2005; Langhammer 2000; Van Vliet 2005). Data were available for $82.8 \%(\mathrm{~N}=222$ ) of participants. There was some heterogeneity of treatment effects $\left(1^{2}=48 \%\right)$, although not sufficient to merit the use of a random-effects approach. The impact of functional training on sitting balance and reach was statistically significant: SMD 0.28 , 95\% Cl 0.01 to 0.55 (Analysis 1.3, GRADE: low quality).

\section{Upper limb function: follow-up}

\section{Comparison 2.1: All outcomes}

\section{Less than six months post treatment}

Three trials recruiting 158 participants measured some aspect of upper limb function for retention effects of repetitive task training (RTT) interventions under six months post treatment (Arya 2012; de Sèze 2001; Howe 2005). Data were available for $96.8 \%(N=153)$ of participants. There was a large effect size, which was statistically significant: SMD $0.92,95 \% \mathrm{Cl} 0.58$ to 1.26 (Analysis 2.1).

\section{Between six and 12 months post treatment}

Six trials recruiting 505 participants measured arm function for retention effects of RTT interventions between six and 12 months post treatment (Blennerhassett 2004a; Dean 2007; Langhammer 2000; Van Vliet 2005; Winstein 2004; Winstein 2016 ). Data were available for $81.6 \%$ ( $\mathrm{N}=412$ ) of participants. Results showed no effect of treatment: SMD $0.10,95 \% \mathrm{Cl}-0.09$ to 0.30 (Analysis 2.1).

\section{Upper limb function: subgroup analyses}

\section{Comparison 3.1: Dosage of task practice}

Trials were classified according to whether they provided zero to 20 hours of therapy (nine trials), or more than 20 hours of therapy (six trials). The difference between groups did not reach statistical significance (Chi2 $=0.39, \mathrm{df}=1, \mathrm{P}=0.53$ ) (Analysis 3.1). 


\section{Comparison 3.2: Time since stroke}

Trials were classified according to whether they recruited within 15 days post stroke (four trials), 16 days to six months post stroke (seven trials), or more than six months post stroke (four trials). The difference between the groups did not reach statistical significance $\left(\mathrm{Chi}^{2}=1.16, \mathrm{df}=2, \mathrm{P}=0.56\right)$ (Analysis 3.2).

\section{Comparison 3.3: Type of intervention}

Trials were classified according to whether they were whole therapy approaches (three trials), mixed task training (eight trials), or single task training (four trials). The difference between the groups did not reach statistical significance $\left(\mathrm{Chi}^{2}=4.01, \mathrm{df}=2, \mathrm{P}=0.13\right.$ ) (Analysis 3.3).

\section{Lower limb function: post treatment}

Results are presented for 1) walking distance, 2) walking speed, 3) functional ambulation, 4) sit-to-stand, 5) lower limb function, and 6) standing balance/reach. All results are post therapy, except for Langhammer 2000, which is three months post stroke, and Van Vliet 2005, which is three months post baseline.

\section{Comparison 4.1: Walking distance: change from baseline}

Nine trials recruiting 638 participants measured walking distance (Blennerhassett 2004b; Dean 2000; Gordon 2013; Kim 2014; Kim 2016; Mudge 2009; Park 2011; Salbach 2004a; van de Port 2012). Data were available for $95.6 \%(\mathrm{~N}=610)$ of participants. Change from baseline scores are presented. Using a random-effects model because of significant heterogeneity in treatment effects, results were statistically significant: mean difference (MD) $34.80,95 \% \mathrm{Cl}$ 18.19 to 51.41 (Analysis 4.1, GRADE: moderate quality). In effect, participants in the experimental groups could walk on average 35 metres further in six minutes than those in the control groups.

\section{Comparison 4.2: Walking speed}

Twelve trials recruiting 748 participants measured walking speed, with data available for $91.6 \%(\mathrm{~N}=685)$ of participants (Dean 1997; Dean 2000; Dean 2007; Frimpong 2014; Kim 2014; Kwakkel 1999a; Lennon 2009; Olawale 2011; Park 2011; Salbach 2004a; van de Port 2012; Van Vliet 2005). Results were not statistically significant: SMD $0.39,95 \% \mathrm{Cl}-0.02$ to 0.79 (Analysis 4.2, GRADE: low quality).

\section{Comparison 4.3: Functional ambulation}

Eight trials recruiting 592 participants measured functional ambulation, with data available for $88.7 \%(\mathrm{~N}=525)$ of participants (de Sèze 2001; Frimpong 2014; Kwakkel 1999a; Langhammer 2000; McClellan 2004; Park 2011; van de Port 2012; Van Vliet 2005). Results indicated a statistically significant effect: SMD $0.35,95 \% \mathrm{Cl} 0.04$ to 0.66 (Analysis 4.3, GRADE: moderate quality).

\section{Comparison 4.4: Sit-to-stand: post treatment/change from baseline}

Seven trials recruiting a total of 397 participants included a measure of sit-to-stand, with data available for $87 \%(\mathrm{~N}=346)$ (Barreca 2004; Blennerhassett 2004b; Dean 2000; Howe 2005; Langhammer 2000; Salbach 2004a; Van Vliet 2005). Results were significant overall: SMD $0.35,95 \% \mathrm{Cl} 0.13$ to 0.56 (Analysis 4.4).

\section{Comparison 4.5: Lower limb functional measures}

Five trials recruiting 473 participants included a measure of lower limb function, with data available for $88.6 \%(\mathrm{~N}=419)$ of participants (Blennerhassett 2004b; Dean 2000; Langhammer 2000; van de Port
2012; Van Vliet 2005). Results overall showed a small but statistically significant effect size: SMD $0.29,95 \% \mathrm{Cl} 0.10$ to 0.48 (Analysis 4.5, GRADE: low quality).

\section{Comparison 4.6: Standing balance/reach}

Nine trials recruiting 520 participants measured standing balance or functional reach, with data available for $96.9 \%(N=504)$ (de Sèze 2001; Holmgren 2010; Kim 2012; Kim 2016; McClellan 2004; Park 2011; Salbach 2004a; Tung 2010; van de Port 2012). Results showed a small but statistically significant effect size: SMD $0.24,95 \% \mathrm{Cl} 0.07$ to 0.42 (Analysis 4.6).

\section{Lower limb function: follow-up}

\section{Comparison 5.1: all outcomes}

\section{Less than six months post treatment}

Eight trials recruiting 496 participants measured some aspect of lower limb function for retention effects of RTT interventions under six months post treatment (de Sèze 2001; Dean 2000; Holmgren 2010; Howe 2005; Lennon 2009; McClellan 2004; Mudge 2009; van de Port 2012). Data were available for $95.0 \%(N=471)$ of participants. Effects across trials were homogeneous $(12=6 \%)$. Results showed a moderate effect size which was statistically significant: SMD 0.34 , $95 \% \mathrm{Cl} 0.16$ to 0.52 (Analysis 5.1).

\section{Between six to 12 months post treatment}

Six trials recruiting 318 participants measured some aspect of lower limb function for retention effects of RTT interventions between six to 12 months post treatment (Blennerhassett 2004b; Dean 2007; Holmgren 2010; Langhammer 2000; Lennon 2009; Van Vliet 2005). Data were available for $84.3 \%(\mathrm{~N}=268)$ of participants. Results showed no treatment effect: SMD $0.06,95 \% \mathrm{Cl}-0.18$ to 0.31 (Analysis 5.1).

\section{Lower limb function: subgroup analyses}

\section{Comparison 6.1: Dosage of task practice}

Eight trials providing more than 20 hours of task practice showed a moderate, statistically significant effect size: SMD $0.33,95 \% \mathrm{Cl} 0.16$ to 0.50 . There was a small, statistically significant effect from 16 trials providing 20 hours training or less: SMD $0.39,95 \% \mathrm{Cl} 0.07$ to 0.71 . However, the difference in effects between these subgroups was not statistically significant $\left(\mathrm{Chi}^{2}=0.08, \mathrm{df}=1, \mathrm{P}=0.77\right.$ ) (Analysis 6.1).

\section{Comparison 6.2: Time since stroke}

The analysis suggests that size of the effect on lower limb function is the same whether recruitment to training is within 15 days post stroke (five trials): SMD $0.16,95 \% \mathrm{Cl}-0.15$ to 0.46 , from 15 days to six months of stroke (nine trials): SMD $0.52,95 \% \mathrm{Cl}-0.03$ to 1.07 , or more than six months post stroke ( 10 trials): SMD $0.41,95 \% \mathrm{Cl} 0.21$ to 0.60 . There was no statistically significant difference between subgroups $\left(\mathrm{Chi}^{2}=2.29, \mathrm{df}=2, \mathrm{P}=0.32\right)$ (Analysis 6.2).

\section{Comparison 6.3: Type of intervention}

Results for single task (five trials): SMD $0.07,95 \% \mathrm{Cl}-0.42$ to 0.55 , and whole therapy approaches (two trials): SMD $0.10,95 \% \mathrm{Cl}-0.24$ to 0.43 were not statistically significant. Mixed training ( 17 trials) had a moderate and statistically significant effect: SMD 0.42, 95\% $\mathrm{Cl} 0.17$ to 0.67 . There was no statistically significant difference between subgroups (Chi2 $=3.16, \mathrm{df}=2, \mathrm{P}=0.21$ ) (Analysis 6.3). 


\section{Secondary outcomes}

Results are presented for 1) ADL function, 2) global motor function, 3) quality of life/health status, and 4) adverse events.

\section{Comparison 7.1: Activities of daily living (ADL) function}

Eleven intervention-control pairs, recruiting a total of 616 participants, used a measure of ADL with data available for $85.5 \%$ ( $N=527$ ) (de Sèze 2001; Gordon 2013; Holmgren 2010; Kim 2016; Kwakkel 1999a; Kwakkel 1999b; Langhammer 2000; Ross 2009; Salbach 2004a; Salbach 2004b; Van Vliet 2005). Kwakkel 1999 comprises the combined results for the upper and lower limb training groups compared against a splint control group, based on the assumption that effect sizes are similar for the two interventioncontrol pairs. The data presented for Salbach 2004 are the results for the lower limb training group compared against the upper limb training attention control group (Salbach 2004a). Overall results indicated a small effect size that was statistically significant: SMD $0.28,95 \% \mathrm{Cl} 0.10$ to 0.45 (Analysis 7.1 ).

\section{Comparison 7.2: Global motor function}

Five trials, recruiting a total of 269 participants measured global motor function (Kim 2014; Langhammer 2000; Peurala 2009; Tung 2010; Van Vliet 2005). Results were available for $82.5 \%(\mathrm{~N}=222)$ of participants and indicated a small to moderate effect size; this was statistically significant: SMD $0.38,95 \% \mathrm{Cl} 0.11$ to 0.65 (Analysis 7.2, GRADE: moderate quality). There were too few trials to undertake planned subgroup analyses for global functional outcomes.

\section{Comparison 7.3: Quality of life/health status}

Four intervention-control pairs recruiting 305 participants used a measure of quality of life or health status, with data available for 86.6\% ( $N=264$ ) (Barreca 2004; Gordon 2013; Kwakkel 1999; Langhammer 2000). All results are post therapy except Kwakkel 1999, which was measured at 26 weeks. There was a small effect size, which was statistically significant: SMD $0.28,95 \% \mathrm{Cl} 0.04$ to 0.53 (Analysis 7.3).

\section{Adverse events}

One trial of sit-to-stand training presented data for the number of falls: intervention group $3 / 25$ (12\%) versus control group 4/23 (17.4\%), OR 0.65, 95\% Cl 0.13 to 3.27 (Barreca 2004). In one trial of an intensive lower limb exercise programme, 11 participants in total fell during the study (32\%), five in the intervention group and six in the attention control group (Holmgren 2010). Fall frequency was reported as 1.35 falls per person per year. Three participants in each group (18\%) fell more than once; the most falls for any single subject was six. In the FIT-Stroke trial, 29 falls were reported in the circuit training group and 26 in the usual physiotherapy group $(\mathrm{P}=$ 0.93) (van de Port 2012). Two serious adverse events were reported in the circuit training group: one participant fell and consulted a GP and one patient experienced arrhythmias during one session.

In one trial of an upper limb intervention there were 168 serious adverse events involving 109 participants (Winstein 2016). The most common were hospitalisation ( $\mathrm{N}=143,25 \%$ of randomised participants) and recurrent stroke ( $\mathrm{N}=42,9 \%$ of randomised participants). Adverse events were not presented by trial arm.

Two trials narratively reported no adverse effects (de Sèze 2001; McClellan 2004). In Salbach 2004, intervention-related reasons for withdrawal that could be interpreted as adverse events included one participant out of 47 in a mobility training group who experienced the onset of groin pain. Four participants also fell during the mobility intervention but did not suffer injury and continued to participate in the group. Two falls also occurred during evaluation. No other trials reported intervention-related reasons for withdrawal, however one study reported a withdrawal due to "disinterest" in the intervention group and one withdrawal who did not like the group sessions in the comparison group (Mudge 2009).

\section{Sensitivity analyses}

We carried out planned sensitivity analysis to investigate the following.

\section{Studies with adequate allocation concealment (i.e. removing studies with high or unclear risk of bias for allocation concealment)}

The significance of post treatment results was affected for Comparison 1.1 Arm function (removing eight studies: Blennerhassett 2004a; Kwakkel 1999b; Langhammer 2000; Salbach 2004b; Turton 1990; Van Vliet 2005; Winstein 2004; Yen 2005) (SMD $0.38,95 \% \mathrm{Cl}-0.40$ to 1.15 ), and Comparison 1.2 Hand function (removing five studies: Blennerhassett 2004a; Langhammer 2000; Salbach 2004b; Turton 1990; Van Vliet 2005) (SMD 0.38, 95\% Cl -0.22 to 0.98 ).

Sensitivity analysis was not possible for the following primary outcomes as one or no studies had adequate allocation concealment: sitting balance/reach, walking distance, walking speed, functional ambulation, sit-to-stand, lower limb functional measures and standing balance/reach.

\section{Studies with an attention control comparison (i.e. removing studies with a usual care comparison)}

The significance of post-treatment results was affected for Comparison 1.1 Arm function (removing eight studies: Arya 2012; Langhammer 2000; Ross 2009; Turton 1990; Van Vliet 2005; Winstein 2004; Winstein 2016; Yen 2005) (SMD 0.17, 95\% Cl -0.16 to 0.49), Comparison 1.2 Hand function (removing six studies: Arya 2012; Langhammer 2000; Ross 2009; Turton 1990; Van Vliet 2005; Winstein 2016) (SMD 0.19, 95\% Cl -0.17 to 0.55), Comparison 4.3 Functional ambulation (removing six studies> de Sèze 2001; Frimpong 2014; Langhammer 2000; Park 2011; van de Port 2012; Van Vliet 2005) (SMD $0.19,95 \% \mathrm{Cl}-0.72$ to 1.10 ), Comparison 4.5 Lower limb functional measures (removing three studies: Langhammer 2000; van de Port 2012; Van Vliet 2005) (SMD 0.60, 95\% Cl -0.05 to 1.25), and Comparison 4.6 Standing balance/reach (removing six studies: de Sèze 2001; Kim 2012; Kim 2016; Park 2011; Tung 2010; van de Port 2012) (SMD $0.21,95 \% \mathrm{Cl}-0.12$ to 0.54 ).

Results were not affected for Comparison 1.3 Sitting balance/reach, Comparison 4.1 Walking distance, Comparison 4.2 Walking speed and Comparison 4.4 Sit-to-stand.

\section{Studies with no additional therapy time (i.e. removing studies with additional therapy time)}

The significance of post-treatment results was affected for Comparison 1.3 Sitting balance/reach (removing one study, Howe 2005) (SMD 0.28, 95\% Cl -0.01 to 0.57), Comparison 4.3 Functional ambulation (removing three studies, Frimpong 2014; Park 2011; van de Port 2012) (SMD 0.25, 95\% Cl -0.03 to 0.54), Comparison 
4.5 Lower limb functional measures (removing one study, van de Port 2012) (SMD $0.20,95 \% \mathrm{Cl}-0.10$ to 0.50 ) and Comparison 4.6 Standing balance/reach (removing six studies, Holmgren 2010; Kim 2012; Kim 2016; Park 2011; Tung 2010; van de Port 2012) (SMD 0.29, $95 \% \mathrm{Cl}-0.06$ to 0.63$)$.

Results were not affected for Comparison 1.1 Arm function, Comparison 1.2 Hand function, Comparison 4.1 Walking distance, Comparison 4.2 Walking speed and Comparison 4.4 Sit-to-stand

\section{Studies where the intervention was delivered at an individual level (i.e. removing studies delivered at a group level)}

The significance of post-treatment results was affected for Comparison 4.3 Functional ambulation (removing two studies: Frimpong 2014; van de Port 2012) (SMD $0.24,95 \% \mathrm{Cl}-0.01$ to 0.48 ) and Comparison 4.5 Lower limb functional measures (removing three studies: Blennerhassett 2004b; Dean 2000; van de Port 2012) (SMD $0.09,95 \% \mathrm{Cl}-0.24$ to 0.43 ).

Results were not affected for Comparison 4.1 Walking distance, Comparison 4.2 Walking speed and Comparison 4.6 Sit-to-stand.

\section{DISCUSSION}

\section{Summary of main results}

\section{Upper limb function/sitting balance}

There was evidence for the effectiveness of repetitive task training (RTT) on arm function (SMD 0.25, 95\% Cl 0.01 to 0.49 ; GRADE: low quality), hand function (SMD $0.25,95 \% \mathrm{Cl} 0.00$ to 0.51 ; GRADE: low quality), and sitting balance/functional reach (SMD $0.28,95 \% \mathrm{CI}$ 0.01 to 0.55 ; GRADE: low quality). There is evidence the effect was maintained up to six months post therapy (SMD $0.92,95 \% \mathrm{Cl} 0.58$ to 1.26), but not between six months and one year post therapy (SMD $0.10,95 \% \mathrm{Cl}-0.09$ to 0.30 ). Treatment effects were not modified by dosage of task practice, type of intervention, or time since stroke.

Results for arm and hand function are no longer significant when studies with unclear or poor allocation concealment are removed from the analysis; removing studies with a usual care comparison also changes the direction of significance. Results for sitting balance/reach are no longer significant when one study with additional therapy time is removed.

One study appears to be an outlier, with a much larger treatment effect on arm function than other studies in the comparison (Arya 2012). This may be explained by the inclusion of participants with less severe stroke (National Institute of Health Stroke Scale score < 14) and participants able to participate in "intensive exercise". The study also reported received intensity of intervention (around 55 minutes per session for the intervention group); this information was rarely reported and it is therefore uncertain whether the specified level of intervention was achieved in the majority of studies.

\section{Lower limb function/standing balance}

There was evidence for a statistically significant small to moderate impact of RTT training on walking distance (MD 34.80, 95\% Cl 18.19 to 51.41 ; GRADE: moderate quality), sit-to-stand (SMD $0.35,95 \% \mathrm{Cl}$ 0.13 to 0.56 ) and functional ambulation (SMD $0.35,95 \% \mathrm{Cl} 0.04$ to 0.66; GRADE: moderate quality). There was also evidence of effect on lower limb functional measures (SMD $0.29,95 \% \mathrm{Cl} 0.10$ to 0.48 ;
GRADE: low quality), and standing balance/reach (SMD 0.24, 95\% Cl 0.07 to 0.42 ). Results at follow-up were statistically significant at up to six months post therapy (SMD $0.34,95 \% \mathrm{Cl} 0.16$ to 0.52 ), but not up to one year post therapy (SMD $0.06,95 \% \mathrm{Cl}-0.18$ to 0.31 ). There is no evidence to suggest task training is more effective if delivered within 15 days, between 16 days and six months, or more than six months after stroke. Effects of larger versus smaller amounts of training also did not reach statistical significance $(P=0.77)$; type of training (whole therapy, mixed training or single task training) also did not reach statistical significance $(P=0.21)$, however the sample size for single task training (112) and whole therapy (138) was comparatively small.

Results for functional ambulation, lower limb functional measures, and standing balance/reach were no longer significant when studies with a usual care comparison were removed. Removing studies with additional therapy time changed results to nonsignificant for functional ambulation, lower limb functional measures, and standing balance/reach. Results for functional ambulation and lower limb functional measures also became nonsignificant when studies delivering the intervention in a group setting were removed.

One recent study appears to be an outlier, with a larger effect on walking speed and functional ambulation than other studies in these comparisons (Frimpong 2014). Possible explanations could be the small sample size (20 participants in total) and poor study quality: insufficient details were provided for all risk of bias elements. Removing this study from the analysis does not change the direction of statistical significance in either comparison.

\section{Secondary outcomes}

For the five trials using global motor function measures, there was a small effect on global motor function (SMD $0.38,95 \% \mathrm{Cl} 0.11$ to 0.65 ) (Kim 2014; Langhammer 2000; Peurala 2009; Tung 2010; Van Vliet 2005). There was a small, statistically significant effect on activities of daily living (ADL) (SMD 0.28, 95\% $\mathrm{Cl} 0.10$ to 0.45 ) and perceptions of quality of life/health status (SMD $0.28,95 \% \mathrm{Cl} 0.04$ to 0.53 ). There was insufficient evidence to be certain of the risk of adverse events.

\section{Overall completeness and applicability of evidence}

The included trials were clinically diverse in focus and there are gaps in the evidence base, particularly for people who are more than six months post stroke. Only four trials evaluated the impact of RTT on upper limb function in people more than six months post stroke: three trials for 20 hours or less (Dean 1997; Mudge 2009; Salbach 2004b), and two for more than 20 hours (Ross 2009; Yen 2005). Only five trials evaluated the impact of more than 20 hours of RTT on upper limb function in people zero to six months post stroke (Arya 2012; Kwakkel 1999b; Turton 1990; Winstein 2016). More trials have focused on the impact of RTT on lower limb function, but there are also gaps in the evidence, with only six trials evaluating more than 20 hours lower limb training in people zero to six months post stroke (Holmgren 2010; Kim 2016; Kwakkel 1999a; McClellan 2004; Peurala 2009; van de Port 2012 ).

Although we were unable to classify participants into more disabled or less disabled participant subgroups, the Characteristics of included studies table illustrates the wide range of disability levels of the participants within the included trials. However, many of the trials had inclusion criteria specifying either minimum, or minimum and maximum levels of ability, motivation to participate, 
and ability to understand instruction. The evidence provided by the review therefore appears to be widely applicable, perhaps with the exception of very severely disabled people with little postural control or voluntary movement, those with very mild deficits, and those with severe communication difficulties. Seven of the 33 included studies (Howe 2005; Holmgren 2010; Kwakkel 1999; Lennon 2009; Ross 2009; van de Port 2012; Van Vliet 2005) reported stroke subtype using the Oxfordshire Community Stroke Project classification tool (Bamford 1991).

The acceptability and safety of RTT to all types of participants is unclear. While there were few adverse effects reported overall, the lack of formal reporting means this finding is inconclusive. Of the information provided about reasons for dropouts in the trials, the most frequent cause was physical illness, and only a very small proportion of those participating dropped out for physical reasons that might have been related to the intervention. There was also a small number of participants who were lost to follow-up for reasons related to compliance or treatment preference.

Information about recruitment was not often provided but, of those that did provide information, a large trial recruiting inpatients early after stroke had a relatively low number of refusals to participate (for example, Kwakkel 1999 had four out of 101 participants who did not give consent), while a trial recruiting in the community after rehabilitation had high numbers of refusal of the intervention (Salbach 2004a had 73\% refusal). It may be that some forms of intervention are less acceptable, or that interventions only appeal to a subset of stroke survivors, particularly if travel is involved.

We were unable to reach any conclusions about the impact of numbers of repetitions as a measure of the intensity of practice, as this information was rarely provided. The amount of task practice is therefore a measure of the intervention sessions' duration rather than the amount of time spent doing repetitive task practice or the number of repetitions.

We were also unable to comment on the resource implications of different sites of treatment, therapist-delivered versus selfdelivered interventions, or group versus individual delivery, as there were too few trials for comparison. However, the presence of three trials involving self-delivery in the home environment (Holmgren 2010 (last week of the intervention only); McClellan 2004; Turton 1990), and six trials involving group delivery of taskspecific training (Barreca 2004; Blennerhassett 2004; Dean 2000; Kim 2012; Mudge 2009; van de Port 2012), suggest that these modes of delivery are feasible. The two studies that collected information showed generally high levels of satisfaction with the programme (Barreca 2004; Dean 2000). Attendance levels at community programmes were also very good, suggesting that these training programmes were well received by those who chose to participate.

Our review aimed to assess whether RTT alone leads to functional gains in the absence of other mechanisms of action. However, it could be argued that RTT as an intervention necessarily includes some additional mechanisms, For example, many of the trials referred to motor learning principles as the basis for the intervention. This approach involves a much more complex set of principles than just task-specific repetition, including targeting to individual needs, task variation, and particular forms of feedback. Inclusion of these trials in the review suggests reducing motor learning or movement science therapies to their lowest common denominator, but even those trials that did not claim a basis in such approaches often also included aspects of active learning, task shaping, feedback, or individualisation of treatment.

Our definition of RTT, and subsequent decisions about study inclusion, have consequences for the applicability of the evidence. We excluded trials when the repetition described appeared to be primarily for strength or endurance training, for example cycling or gait training, and when the type of training appeared divorced from the functional aim, for example backward walking training, slot machines, or computer games. By the exclusion of trials of what could be defined as 'pre-functional' types of movement, we will effectively have excluded a group of people who cannot yet participate in functional movement. The same consequence applies to the exclusion of trials with a large element of passive and active-assisted movement.

Since the publication of the original review RTT has become an established intervention tested in rehabilitation trials. The quality of reporting of RTT interventions has also greatly improved. As a consequence, it is likely that new studies included in this update will more closely resemble the inclusion criteria and definition of RTT than those included in the original review.

\section{Quality of the evidence}

Poor reporting, particularly in the earlier studies, meant the overall risk of bias was unclear for many studies: only eight out of the 33 trials had adequate allocation concealment, however 22 studies had blinded outcome assessment. Many of the trials were small, with 21 trials having less than 50 participants. The inclusion of pilot and feasibility trials (five studies) suggests many were not powered to detect a difference between intervention groups. Eleven studies not described as pilot or feasibility trials reported a power calculation; in a further 13 studies this was not reported.

\section{Potential biases in the review process}

When designing the review, we made an early decision to consider the effect of RTT on upper and lower limb function outcomes separately, as we thought that there might be a differential impact. The results of the review support this decision, although there are two disadvantages. Firstly, we are unable to give an overall effect estimate for RTT, although considering the different interventions and objectives of upper and lower limb training this may not have been a clinically meaningful figure. Secondly, subgroup analyses are smaller, and therefore less well powered than they would have been if all trials had been combined. As the number of studies reported in the subgroup analyses are small, the results should be treated with caution.

Our major focus in this review was impact on task-specific function. In practice, we excluded a large number of studies on the basis that we did not judge the outcomes to be functional, or the intervention to be task-specific. We have also included studies where our interpretation of the intervention was that repetition of functional movement was a major mechanism of action (for example, de Sèze 2001). Whether balance training is truly 'functional' is also a matter of interpretation.

Although interventions were often well described, it was sometimes difficult to estimate the relative intensity of treatment, especially within mixed interventions. Information on the number of repetitions was rarely available. This potentially means that 
the review is investigating the impact of functional task specificity rather more than the element of repetition. Our decision was to include trials if we could clearly identify the amount of practice.

The included trials used a wide range of outcome measures, methodologies and time intervals for follow-up making summary statistics difficult. We made strenuous efforts to obtain data suitable for pooling for each outcome, but sometimes these were not available, and the method of pooling less than optimum, such as the use of standardised mean difference for walking speed. It would have been better to use outcome changes compared with baseline, especially for analyses with smaller numbers of participants, but these were also not available across trials. We also generally used fixed-effect analyses, which some might criticise due to the presence of some clinical heterogeneity in the treatments and trials combined.

The subgroup analysis of trial design (that is, attention control versus usual care control) did reach statistical significance ( $P$ $=0.88$ ). However, maintaining the upper and lower limb trials separately meant that further subdivision into type of comparison group was not feasible.

\section{Agreements and disagreements with other studies or reviews}

In contrast to the original review, which found no evidence of significant benefit from RTT of the upper limb, this update suggests significant benefit both on arm and hand function, with benefits sustained at short-term follow-up (up to six months post intervention). However, studies were heterogeneous (12 58\% and $54 \%$ for arm and hand function, respectively). Repetitive task training of the lower limb found significant benefit on all primary and secondary outcome measures with the exception of walking speed. This is in line with recent reviews on physical therapy (Verbeek 2014) and interventions directed at motor recovery after stroke (Langhorne 2009).

Treatment effects of longer versus shorter amounts of training did not reach statistical significance for the upper limb, suggesting results are not moderated by the amount of practice. Upper limb findings do not support a recent review and meta-analysis of physical therapy post stroke (Verbeek 2014), suggesting highintensity practice (specifically an additional 17 hours therapy time over 10 weeks) is necessary for functional benefit. Findings also do not support the identified dose-response relationship between amount of therapy and improved outcome for upper limb training found in Kwakkel 2004.

For the lower limb, the effect of more than 20 hours of task training was greater than that of zero to 20 hours training, but the difference between subgroups was not significant. $(P=0.77)$, contrary to the findings of Van der Lee 2001, where more than 20 hours was found to be preferable to up to 20 hours of training. A recent review of physical therapy approaches similarly concluded that in relation to the dose of intervention, subgroup analysis revealed a dose of 30 to 60 minutes per day delivered five to seven days per week was effective in terms of independence in ADL (Pollock 2014b). Results from subgroup analysis suggest further research into the dose-response relationship in lower limb interventions should be a priority.
There were small positive effects on global motor function, ADL and functional ambulation. Even though the amount of change is small, the clinical benefit of the change in activities of daily living is likely to be meaningful in relation to quality of life (Van Exel 2004).

In those studies that did show a benefit and provided later assessments, improvements at the end of training were evident in both upper and lower limb function up to six months post treatment but not beyond. It is unclear from this review whether this is related to characteristics of the participants, the intensity of training or the degree of improvement required before detectable change was noted.

Evidence from this review does not support the suggestion that earlier provision of treatment results in greater functional improvement. Improvement in function was possible even in the later stages of recovery (Page 2004).

In a review of physiotherapy treatments after stroke (Pollock 2014b), it is suggested that research should be conducted to determine the efficacy of clearly described individual techniques and task-specific treatments. Clear definition of individual techniques still remains a challenge but this review suggests that focusing on specific treatments is possible; there are now taxonomies for grouping such interventions (e.g. Pollock 2014a). Readers may not agree with some of our classification of studies, but the review authors compared all interventions in detail to make these difficult decisions.

The mechanisms of action responsible for any lower limb functional gain are still unclear. Many of the interventions were mixed, and while all contained repetition and functional practice, they could also include elements of endurance or strength training. However, the review of treadmill training found people after stroke who receive treadmill training with or without body weight support are not more likely to improve their ability to walk independently compared with people after stroke not receiving treadmill training, but there may be improvement in walking speed and walking endurance (Mehrholz 2014). Results of a recent review of robotaided therapy on arm function found moderate quality evidence that robotics may be effective in improving upper limb impairment and ADL outcomes (Mehrholz 2015b). However, robotics may not be more beneficial than conventional therapy at the same dose. Given that repetition is a major mechanism of action in both treadmill and robotics, this would suggest that reflecting real-world task complexity in training is a significant factor. However, other potential mechanisms of action are also implicit in some of the trial interventions, such as self-efficacy, task-novelty, and motivation to participate in the interventions delivered in a group setting.

\section{AUTHORS' CONCLUSIONS}

\section{Implications for practice}

The results of this review provide low- or moderate-quality evidence to validate the general principle that repetitive, taskspecific training for lower limbs can result in functional gain when compared against other forms of usual care or attention control. There is low-quality evidence of improvement in arm and hand function following repetitive task training (RTT) of the upper limb. Effects for both upper and lower limb appear to be sustained up to six months post treatment. Some caution is needed in interpreting the lack of evidence of adverse effects, as few trials specifically 
monitored these as outcomes. If task-specific training is used in clinical practice, adverse effects should be monitored.

\section{Implications for research}

Further primary research should be directed towards exploration of the amount of lower limb task training actually performed, as opposed to the length of the therapy session, and include number of repetitions, and how to maintain functional gain after six months post treatment. It is unclear whether task training accelerates recovery or simply improves performance for a finite time interval. This review provided some evidence of a treatment effect for upper limb function, although, with the exception of two studies (Arya 2012; Winstein 2016), sample sizes were small. The conclusion of this review about evidence for efficacy of task training for arm function is therefore tentative. More intensive therapy (over 20 hours) does not appear to be more effective for either the upper or lower limb.

There were insufficient trials included in the review to evaluate the efficacy and cost-effectiveness of different intervention delivery methods for RTT, such as group training, or practice in the home environment. Further randomised controlled trials should evaluate practical ways of delivering RTT interventions. In particular, the acceptability of circuit type training interventions in community settings needs to be evaluated. Further research should also address practical ways of maintaining post-therapy functional gain beyond six months. Future trials should be powered to detect costeffectiveness as well as clinical effect, and should include a quality of life measure as one of the outcomes.
We were unable to investigate the impact on people of different levels of pre-intervention disability, because of the wide range of baseline measures used. Analyses of this type would be facilitated by the inclusion in trials of baseline data using a common measure, such as the Barthel Index, which can be related to population norms dependent on time since stroke.

This review did not compare repetitive functional task training against other interventions not currently viewed as a component of usual care. Future updates of this review are likely to compare RTT against other interventions (for example, resistance training, constraint-induced movement therapy or robotics), or in combination with other interventions (e.g. strength training) rather than RTT against "usual care". The definition of RTT will need revisiting prior to further updates of this review in order to ensure it remains clinically meaningful and distinguishable from other interventions (for example, treadmill training, Mehrholz 2014).

\section{ACKNOWLEDGEMENTS}

We acknowledge the support of Hazel Fraser from the Cochrane Stroke Group for her help in the review process. We also thank all of the trial authors who kindly replied to our requests for information. We thank the authors of the original review: Anne Forster, Peter Langhorne, Christopher Price, and Andrew Walker. Finally, we would like to thank the following for their helpful comments on the first draft of the review: Alex Pollock, Joshua Cheyne, Valentina Assi, Jan Mehrholz, Ailie Turton, Brian Stafford, and Matiram Pun. 


\section{R E F E R E N C E S}

\section{References to studies included in this review}

Arya 2012 \{published data only\}

Arya KN, Verma R, Garg RK, Sharma VP, Agarwal M, Aggarwal GG. Meaningful task-specific training (MTST) for stroke rehabilitation: a randomized controlled trial. Topics in Stroke Rehabilitation 2012;19(3):193-211.

\section{Baer 2007 \{unpublished data only\}}

Baer G. An investigation into a home-based mobility rehabilitation programme for late-stage stroke. A pilot randomised trial. Physiotherapy 2007;93(Supp 1):S546.

\section{Barreca 2004 \{published and unpublished data\}}

Barreca S, Sigouin CS, Lambert C, Ansley B. Effects of extra training on the ability of stroke survivors to perform an independent sit-to stand: a randomized controlled trial. Journal of Geriatric Physical Therapy 2004;27(2):59-64. [MEDLINE: 200422110]

\section{Blennerhassett 2004 \{published and unpublished data\}}

Blennerhassett J, Dite W. Additional task-related practice improves mobility and upper limb function early after stroke: a randomised controlled trial. Australian Journal of Physiotherapy 2004;50(4):219-24. [MEDLINE: 15574110]

\section{Blennerhassett 2004a \{published and unpublished data\}}

Blennerhassett J, Dite W. Additional task-related practice improves mobility and upper limb function early after stroke: a randomised controlled trial. Australian Journal of Physiotherapy 2004;50(4):219-24. [MEDLINE: 15574110]

\section{Blennerhassett 2004b \{published and unpublished data\}}

Blennerhassett J, Dite W. Additional task-related practice improves mobility and upper limb function early after stroke: a randomised controlled trial. Australian Journal of Physiotherapy 2004;50(4):219-24. [MEDLINE: 15574110]

\section{Dean 1997 \{published and unpublished data\}}

Dean CM, Shepherd RB. Task-related training improves performance of seated reaching tasks after stroke. Stroke 1997;28:722-8. [MEDLINE: 9099186]

\section{Dean 2000 \{published and unpublished data\}}

Dean CM, Richards CL, Malouin F. Task-related circuit training improves performance of locomotor tasks in chronic stroke: a randomized, controlled pilot trial. Archives of Physical Medicine and Rehabilitation 2000;81:409-17. [MEDLINE: 10768528]

\section{Dean 2007 \{published data only\}}

Dean CM, Channon EF, Hall JM. Sitting training early after stroke improves sitting ability and quality and carries over to standing up but not to walking: a randomised controlled trial. Australian Journal of Physiotherapy 2007;53:97-102.

\section{de Sèze 2001 \{published data only\}}

de Sèze $M$, Wiart L, Bon-Saint-Côme A, Debelleix X, de Sèze $M$, Joseph $P$, et al. Rehabilitation of postural disturbances of hemiplegic patients by using trunk control retraining during exploratory exercises. Archives of Physical and Medical Rehabilitation 2001;82:793-800. [MEDLINE: 11387585]

\section{Frimpong 2014 \{published data only\}}

Frimpong E, Olawale OA, Antwi DA, Antwi-Boasiako C, Dzudzor B. Task-oriented circuit training improves ambulatory functions in acute stroke: a randomized controlled trial. Journal of Medicine and Medical Sciences 2014;5(8):169-75.

Gordon 2013 \{published data only\}

Gordon CD, Wilks R, McCaw-Binns A. Effect of aerobic exercise (walking) training on functional status and healthrelated quality of life in chronic stroke survivors. Stroke 2013;44:1179-81.

\section{Holmgren 2010 \{published data only\}}

* Holmgren E, Gosman-Hedstrom G, Lindstrom B, Wester P. What is the benefit of a high-intensive exercise program on health-related quality of life and depression after stroke? A randomized controlled trial. Advances in Physiotherapy 2010;12:125-33.

Holmgren E, Lindstrom B, Gosman-Hedstrom G, Nyberg L, Wester P. What is the benefit of a high intensive exercise program? A randomized controlled trial. Advances in Physiotherapy 2010;12:115-24.

Howe 2005 \{published data only\}

Howe TE, Taylor I, Finn P, Jones H. Lateral weight transference exercises following acute stroke: a preliminary study of clinical effectiveness. Clinical Rehabilitation 2005;19:45-53. [MEDLINE: 15704508]

\section{Kim 2012 \{published data only\}}

Kim, BH, Lee SM, Bae YH, Yu JH, Kim TH. The effect of a task-oriented training on trunk control ability, balance and gait of stroke patients. Journal of Physical Therapy Science 2012;24:519-22.

\section{Kim 2014 \{published data only\}}

Kim M, Cho K, Lee W. Community walking training program improves walking function and social participation in chronic stroke patients. Tohoku Journal of Experimental Medicine 2014;234:281-6.

\section{Kim 2016 \{published data only\}}

Kim SM, Han EY, Kim BR, Hyun CW. Clinical application of circuit training for subacute stroke patients: a preliminary study. Journal of Physical Therapy Science 2016;28:169-74.

Kwakkel 1999 \{published and unpublished data\}

Kwakkel G, Wagenaar RC, Twisk JWR, Langhorst GJ, Koetsier JC. Intensity of leg and arm training after primary middle-cerebralartery stroke: a randomised trial. Lancet 1999;354:191-6. [MEDLINE: 10421300]

Kwakkel 1999a \{published and unpublished data\} Kwakkel G, Wagenaar RC, Twisk JWR, Langhorst GJ, Koetsier JC. Intensity of leg and arm training after primary middle-cerebral- 
artery stroke: a randomised trial. Lancet 1999;354:191-6. [MEDLINE: 10421300]

\section{Kwakkel 1999b \{published and unpublished data\}}

Kwakkel G, Wagenaar RC, Twisk JWR, Langhorst GJ, Koetsier JC. Intensity of leg and arm training after primary middle-cerebralartery stroke: a randomised trial. Lancet 1999 1999;354:191-6. [MEDLINE: 10421300]

\section{Langhammer 2000 \{published and unpublished data\}}

* Langhammer B, Stanghelle JK. Bobath or Motor Relearning Programme? A comparison of two different approaches of physiotherapy in stroke rehabilitation: a randomized controlled study. Clinical Rehabilitation 2000;14:361-9. [MEDLINE: 10945420]

Langhammer B, Stanghelle JK. Bobath or Motor Relearning Programme? A follow-up one and four years post stroke. Clinical Rehabilitation 2003;17:731-4. [MEDLINE: 14606738]

\section{Lennon 2009 \{unpublished data only\}}

Lennon S. Gait-specific training within Bobath therapy in acute stroke: a randomised controlled trial. Unpublished Research Report 2009.

\section{McClellan 2004 \{published data only\}}

McClellan R, Ada L. A six week, resource-efficient mobility program after discharge from rehabilitation improves standing in people affected by stroke: placebo-controlled, randomised trial. Australian Journal of Physiotherapy 2004;50:163-7. [MEDLINE: 15482247]

\section{Mudge 2009 \{published data only\}}

Mudge S, Barber A, Stott S. Circuit-based rehabilitation improves gait endurance but not usual walking activity in chronic stroke: a randomized controlled trial. Archives of Physical Medicine and Rehabilitation 2009;90:1989-96.

\section{Olawale 2011 \{published data only\}}

Olawale OA, Jaja SI, Anigbogu CN, Appiah-Kubi KO, JonesOkai D. Exercise training improves walking function in an African group of stroke survivors: a randomized controlled trial. Clinical Rehabilitation 2011;25:442-50.

\section{Park 2011 \{published data only\}}

Park HJ, Oh DW, Kim SY, Choi JD. Effectiveness of communitybased ambulation training for walking function of post-stroke hemiparesis: a randomized controlled pilot trial. Clinical Rehabilitation 2011;25:451-9.

\section{Peurala 2009 \{published data only\}}

Peurala SH, Airaksinen O, Huuskonen P, Jäkälä P, Juhakoski M, Sandell K, et al. Effects of intensive therapy using gait trainer or floor walking exercises early after stroke. Journal of Rehabilitation Medicine 2009;41:166-73.

\section{Ross 2009 \{published data only\}}

Ross LF, Harvey LA, Lannin NA. Do people with acquired brain impairment benefit from additional therapy specifically directed at the hand? A randomized controlled trial. Clinical Rehabilitation 2009;23:492-503.

\section{Salbach 2004 \{published and unpublished data\}}

Higgins J, Salbach NM, Wood-Dauphinee S, Richards CL, Côté R, Mayo NE. The effect of a task oriented intervention on arm function in people with stroke: a randomized controlled trial. Clinical Rehabilitation 2006;20:296-310.

Salbach NM, Mayo NE, Robichaud-Ekstrand S, Hanley JA, Richards CL, Wood-Dauphinee S. The effect of a task-oriented walking intervention on improving balance self-efficacy poststroke: a randomized, controlled trial. Journal of the American Geriatric Society 2005;53:576-82.

* Salbach NM, Mayo NE, Wood-Dauphinee S, Hanley JA, Richards CL, Côte R. A task-orientated intervention enhances walking distance and speed in the first year post stroke: a randomized controlled trial. Clinical Rehabilitation 2004;18:509-19.

\section{Salbach 2004a $\{$ published and unpublished data\}}

Salbach NM, Mayo NE, Robichaud-Ekstrand S, Hanley JA, Richards CL, Wood-Dauphinee S. The effect of a task-oriented walking intervention on improving balance self-efficacy poststroke: a randomized, controlled trial. Journal of the American Geriatric Society 2005;53:576-82. [MEDLINE: 15817001]

* Salbach NM, Mayo NE, Wood-Dauphinee S, Hanley JA, Richards CL, Côte R. A task-orientated intervention enhances walking distance and speed in the first year post stroke: a randomized controlled trial. Clinical Rehabilitation 2004;18:509-19. [MEDLINE: 15293485]

\section{Salbach 2004b \{published and unpublished data\}}

Higgins J, Salbach NM, Wood-Dauphinee S, Richards CL, Côté R, Mayo NE. The effect of a task oriented intervention on arm function in people with stroke: a randomized controlled trial. Clinical Rehabilitation 2006;20:296-310. [MEDLINE: 16719028]

\section{Song 2015 \{published data only\}}

Song HS, Kim JY, Park SD. Effect of the class and individual applications of task-oriented circuit training on gait ability in patients with chronic stroke. Journal of Physical Therapy Science 2015;27:187-9.

\section{Tung 2010 \{published data only\}}

Tung FL, Yang YR, Lee CC, Wang RY. Balance outcomes after additional sit-to-stand training in subjects with stroke: a randomized controlled trial. Clinical Rehabilitation 2010;24:533-42.

\section{Turton 1990 \{published data only\}}

Turton A, Fraser C. The use of home therapy programmes for improving recovery of the upper limb following stroke. British Journal of Occupational Therapy 1990;53(11):457-62. [MEDLINE: 1993165745]

\section{van de Port 2012 \{published data only\}}

van de Port IGL, Wevers LEG, Lindeman E, Kwakkel G. Effects of circuit training as alternative to usual physiotherapy after stroke: randomised controlled trial. BMJ 2012;344:e2672. 
Van Vliet 2005 \{published and unpublished data\}

Van Vliet P, Lincoln NB, Robinson E. Comparison of the content of two physiotherapy approaches for stroke. Clinical Rehabilitation 2001;15:398-414.

* Van Vliet PM, Lincoln NB, Foxall A. Comparison of Bobath based and movement science based treatment for stroke: a randomised controlled trial. Journal of Neurology, Neurosurgery and Psychiatry 2005;76:503-8. [MEDLINE: 15774435]

Winstein 2004 \{published and unpublished data\}

Winstein CJ, Rose DK, Tan SM, Lewthwaite R, Chui HC, Azen SP. A randomized controlled comparison of upperextremity rehabilitation strategies in acute stroke: a pilot study of immediate and long-term outcomes. Archives of Physical Medicine and Rehabilitation 2004;85:620-8. [MEDLINE: 15083439]

\section{Winstein 2016 \{published and unpublished data\}}

Winstein CJ, Wolf SL, Dromerick A, Blanton S, Nelsen MA, Lane $\mathrm{CJ}$, et al. Interdisciplinary comprehensive arm rehabilitation evaluation (ICARE): a randomized controlled trial. Proceedings of the International Stroke Conference 2013. 6-8 February 2013; Honolulu, Hawaii, USA. (Abst CT p17) 2013.

* Winstein CJ, Wolf SL, Dromerick AW, Lane CJ, Nelson MA, Lewthwaite R, for the Interdisciplinary Comprehensive Arm Rehabilitation Evaluation (ICARE) Investigative Team. Effect of a task-oriented rehabilitation program on upper extremity recovery following motor stroke. The ICARE randomized clinical trial. Journal of the American Medical Association 2016;315(6):571-81.

Winstein CJ, Wolf SL, Dromerick AW, Lane CJ, Nelson MA, Lewthwaite R, the ICARE Investigative Team. Interdisciplinary Comprehensive Arm Rehabilitation Evaluation (ICARE): a randomized controlled trial protocol. BMC Neurology 2013;13:5.

Yen 2005 \{published data only\}

Yen JG, Wang RY, Chen HH, Hong CT. Effectiveness of modified constraint-induced movement therapy on upper limb function in stroke subjects. Acta Neurologica Taiwanica 2005;14(1):16-20. [MEDLINE: 15835284]

\section{References to studies excluded from this review}

Allison 2005 \{published data only\}

Allison R, Dennett R. Pilot randomized controlled trial to assess the impact of additional supported standing practice on functional ability post stroke. Clinical Rehabilitation 2007;21:614-9.

\section{Almhdawi 2014 \{published data only\}}

Almhdawi KA, Mathiowetz V, White M. Multidisciplinary clinical rehabilitation effects of occupational therapy taskoriented approach in upper extremity poststroke rehabilitation. International Journal of Stroke 2014;9 Suppl:217.

\section{Askim 2010 \{published data only\}}

Askim T, Morkved S, Engen A, Roos K, Aas T, Indredavik B. Effects of a community-based intensive motor training program combined with early supported discharge after treatment in a comprehensive stroke unit. A randomized, controlled trial. Stroke 2010;41:1697-703.

Banta 2013 \{published data only\}

Banta MW, Wilks M, Pidcoe PE, Sima A, Devers A. Novel, hightech walking recovery program improves motor recovery. Stroke 2013;44:Abst WMP86.

\section{Conroy 2011 \{published data only\}}

Conroy SS, Whitall J, Dipietro L, Jones-Lush LM, Zhan M, Finley MA. Effect of gravity on robot-assisted motor training after chronic stroke: a randomized trial. Archives of Physical Medicine and Rehabilitation 2011;92:1754-61.

English 2016 \{published data only\}

English C, Healy GN, Olds T, Parfitt G, Borkoles E, Coates A, et al. Reducing sitting time after stroke: a phase II safety and feasibility randomized controlled trial. Archives of Physical Medicine and Rehabilitation 2016;97:273-80.

Harijan 2013 \{unpublished data only\}

Harijan K. Effect of Square Stepping Exercise on Gait Performance in Post Stroke [Masters Dissertation]. Rajiv Gandhi University of Health Sciences, 2013.

Hillier 2010 \{published data only\}

Hillier S, English C, Crotty M, Segal L, Bernhardt J, Esterman A. Circuit class or seven-day therapy for increasing intensity of rehabilitation after stroke: protocol of the CIRCIT trial. International Journal of Stroke 2011;6:560-5.

Hubbard 2015 \{published data only\}

Hubbard IJ, Carey LM, Budd WT, Levi CR, McElduff P, Hudson S, et al. A randomized controlled trial of the effect of early upper-limb training on stroke recovery and brain activation. Neurorehabilitation and Neural Repair 2015;29:703-13.

Li 2008 \{published data only\}

Li Z, Zhao J, Taub E. Recovery effect of constraint-induced movement therapy on upper extremity activity of stroke patients with hemiparesis. Journal of Jilin University (Medicine Edition) 2008 ;34:511-14.

\section{Logan 2014 \{published data only\}}

Logan PA, Armstrong S, Avery TJ, Barer D, Barton GR, Darby J, et al. Rehabilitation aimed at improving outdoor mobility for people after stroke: a multicentre randomised controlled study (the Getting out of the House Study). Health Technology Assessment 2014;18:vii-113.

\section{Lord 2008 \{published data only\}}

Lord S, McPherson KM, McNaughton HK, Rochester L, Weatherall M. How feasible is the attainment of community ambulation after stroke? A pilot randomized controlled trial to evaluate community-based physiotherapy in subacute stroke. Clinical Rehabilitation 2008;22:215-25.

\section{Malagoni 2016 \{published data only\}}

Malagoni AM, Cavazza S, Ferraresi G, Grassi G, Felisatti M, Lamberti N, et al. Effects of a "test in-train out" walking program 
versus supervised standard rehabilitation in chronic stroke patients: a feasibility and pilot randomized study. European Journal of Physical and Rehabilitation Medicine 2016 [Epub ahead of print].

\section{McCombe Waller 2014 \{published data only\}}

McCombe Waller S, Whitall J, Glickman L. Feasibility of bilateral arm training in the subacute setting (Abst Poster 17). Neurorehabilitation and Neural Repair 2014;28(4):NP7.

Onigbinde 2009 \{published data only\}

Onigbinde AT, Awotidebe T, Awosika H. Effect of 6 weeks wobble board exercises on static and dynamic balance of stroke survivors. Technology and Health Care 2009;17:387-92.

\section{Pang 2013 \{published data only\}}

Pang MYC. Whole body vibration in chronic stroke. https:// clinicaltrials.gov/ct2/show/NCT01822704 (accessed 30 November 2005.

\section{Rao 2013 \{published data only\}}

Rao T. A community applied research of traditional Chinese medicine rehabilitation scheme on balance dysfunction after stroke. http://www.chictr.org.cn/showprojen.aspx?proj=5919 (accessed 14 December 2015).

\section{Saeys 2012 \{published data only\}}

Saeys W, Vereeck L, Truijen S, Lafosse C, Wuyts FP, Van De Heyning P. Randomized controlled trial of truncal exercises early after stroke to improve balance and mobility. Neurorehabilitation and Neural Repair 2012;26(3):231-8.

\section{Sherrington 2008 \{published data only\}}

Sherrington C, Pamphlett PI, Jacka JA, Olivetti LM, Nugent JA, Hall JM, et al. Group exercise can improve participants' mobility in an outpatient rehabilitation setting: a randomized controlled trial. Clinical Rehabilitation 2008;22:493-502.

\section{Shimodozono 2013 \{published data only\}}

Shimodozono M, Noma T, Nomoto Y, Hisamatsu N, Kamada K, Miyata R, et al. Benefits of a repetitive facilitative exercise program for the upper paretic extremity after subacute stroke: a randomized controlled trial. Neurorehabilitation and Neural Repair 2013;27:296-305

\section{Tang 2009 \{published data only\}}

Tang W, Yang B. Influence of sensory function training on motor function of cerebral apoplexy patients complicated with hemiplegia. Chinese Nursing Research 2009;23:1905-6.

\section{Taub 2013 \{published data only\}}

Taub E, Uswatte G, Mark VW, Morris DM, Barman J, Bowman MH, et al. Method for enhancing real-world use of a more affected arm in chronic stroke. Transfer package of constraint-induced movement therapy. Stroke 2013;44:1383-8.

\section{Verheyden 2009 \{published data only\}}

Verheyden G, Vereeck L, Truijen S, Troch M, LaFosse C, Saeys W, et al. Additional exercises improve trunk performance after stroke: a pilot randomized controlled trial. Neurorehabilitation and Neural Repair 2009;23:281-6.

\section{Vloothuis 2013 \{published data only\}}

Vloothuis JDM. CAREgiver participation to improve intensity of training after stroke, a pilot study of a new intervention. http://www.trialregister.nl/trialreg/admin/rctview.asp?TC=3739 (accessed 2 December 2014).

\section{Wang 2011 \{published data only\}}

Wang Q, Zhao J, Zhu Q, Li J, Meng P. Comparison of conventional therapy, intensive therapy and modified constraint-induced movement therapy to improve upper extremity function after stroke. Journal of Rehabilitation Medicine 2011;43:619-25.

\section{References to studies awaiting assessment}

Baglary 2013 \{published data only\}

Baglary S. Effects of backward walking training in stroke patients (MSc dissertation). Bangalore, India: Rajiv Gandhi University, 2013.

\section{Bhaskar 2009 \{published data only\}}

Bhaskar VG. Efficacy of modified hand function activities in rehabilitation of stroke patients. Indian Journal of Physiotherapy and Occupational Therapy 2009;3:16-9.

\section{Brkic 2016 \{published and unpublished data\}}

Brkic L, Shaw L, Van Wijck F, Price C, Watkins C, Forster A, et al. Repetitive arm functional tasks after stroke (RAFTAS) study. Proceedings of the 8th UK Stroke Forum Conference. 3-5 December 2013; Harrogate, UK. 2013:58-59 (Abst OG9).

* Brkic L, Shaw L, van Wijck F, Francis R, Price C, Forster A, et al. Repetitive arm functional tasks after stroke (RAFTAS): a pilot randomised controlled trial. Pilot and Feasibility Studies 2016;2:50

\section{ChiCTR-ICR-15005992 \{published data only\}}

Early and Intensive Rehabilitation after Stroke. http:// apps.who.int/trialsearch/Trial2.aspx?TrialID=ChiCTRICR-15005992 (accessed 22 June 2016).

\section{Eng 2009 \{unpublished data only\}}

Eng J. The effect of an inpatient home-work exercise program on leg function after stroke. clinicaltrials.gov/ct2/show/ NCT00908479 (accessed 02 December 2014).

\section{Ferrari 2015 \{published data only\}}

Ferrari FF, Gandolfi MLG, Picelli AP, La Marchina EL, Tosoni RT, Geroin GC, et al. Effects of a specific rehabilitation treatment on post-stroke pusher syndrome recovery - a randomized controlled trial. Cerebrovascular Diseases 2015;39 Suppl 2:112.

\section{Gandhi 2015 \{published data only\}}

Gandhi D, Pandian J, Lindley R, Alim M, Maulik P, Murthy GVS, et al. Family-led rehabilitation after stroke in India: the ATTEND trial. International Journal of Stroke 2015;10:174.

Indurkar 2013 \{published data only\}

Indurkar I, lyer S. To study the effect of task orientated intervention on walking distance, speed and balance efficiency 
in post stroke patients. Indian Journal of Physiotherapy and Occupational Therapy 2013;7:67-72.

\section{Knox 2014 \{published data only\}}

Knox M, Stewart A, Richards C. Does a little go a long way? Efficicient rehabilitation of persons with stroke in the public healthcare sector in RSA. Proceedings of the Stroke and Hypertension Congress; 2014 Aug 22-24; Durban, South Africa. 2014.

\section{Kumar 2012 \{published data only\}}

Kumar C, Goyal R. The effect of task orientated training on hand functions in stroke patients - a randomized control trial. Indian Journal of Physiotherapy and Occupational Therapy 2012;6:87-91.

\section{NCT02429180 \{published data only\}}

NCT02429180. Rehabilitation Training after Stroke (ReTrain). https://clinicaltrials.gov/ct2/show/NCT02429180 (accessed 22 June 2016)

\section{Pandian 2014 \{published data only\}}

Pandian JD, Felix C, Alim M, Gandhi DBC. On-going clinical trials the attend trial-family-led rehabilitation after stroke in India: a modified version of early supported discharge with a caregiver delivered home based poststroke rehabilitation. International Journal of Stroke 2014;9:252-3.

\section{Xu 2012 \{published data only\}}

Xu W, Su Y, Liu X, Li K, Wang H, Su Y, et al. Influence of early walking training to stroke hemiplegic patients' lower limb motor function. Heart 2012;98:E158.

\section{Zhu 2013 \{published data only\}}

Zhu L, Song WQ, Zhang R, Liu, L. Effect of rehabilitation training for optimizing motor skills on upper limb function recovery after stroke. Chinese Journal of Cerebrovascular Diseases 2013;10:22-5.

\section{References to ongoing studies}

\section{Bosomworth 2013 \{unpublished data only\}}

Bosomworth H. RATULS: Robot Assisted Training for the Upper Limb after Stroke UKCRN ID 15309. http://public.ukcrn.org.uk/ Search/StudyDetail.aspx?StudyID=15309 (accessed 03 December 2014).

\section{CTRI/2015/06/005877 \{published data only\}}

Short term effect of circuit class training for improvement of upper limit in stroke patients: a Randomized Clinical Trial. http://apps.who.int/trialsearch/Trial2.aspx? TrialID=CTRI/2015/06/005877 (accessed 22 June 2016).

\section{Hariohm 2013 \{unpublished data only\}}

Hariohm K, Prakash V, Vasanthan R, Daran JKD, Samuel RJ. An RCT protocol on efficacy of deep knee flexion exercises on improving activities involving deep knee flexion and quality of life in persons with stroke. Cerebrovascular Diseases 2013;36 Suppl 1:15.

\section{Korner-Bitensky 2013 \{unpublished data only\}}

Korner-Bitensky N, Clemson L. Randomized pilot trial of usual care versus LIFE (lifestyle intervention using functional exercise to reduce falls) in those with mild stroke. International Stroke Conference Poster Abstracts: Stroke. 2013; Vol. 44: Abstract TP319.

Kumaran 2010 \{unpublished data only\}

Kumaran S. Effectiveness and feasibility of a task and context based exercise program in stroke patients: a randomized controlled trial.. http://www.ctri.nic.in/Clinicaltrials/ pmaindet2.php?trialid=1486 CTRI/2010/091/000278 (accessed 15 November 2013)

\section{NCT02235974 \{published data only\}}

Critical Periods After Stroke Study (CPASS). https:// clinicaltrials.gov/ct2/show/NCT02235974 (accessed 30 June 2016).

NCT02765152 \{published data only\}

Effects of training rhythmic and discrete aiming movements on the upper limb control and functionality after stroke: randomized controlled trial. https://clinicaltrials.gov/ct2/show/ NCT02765152 (accessed 22 June 2016).

\section{Schultz 2012 \{unpublished data only\}}

Schultz B. Use of repetitive facilitative exercise program in established stroke. ClinicalTrials.gov NCT01574599 (accessed 09 January 2014).

\section{Stuart 2009 \{unpublished data only\}}

Adaptive Physical Activity for chronic stroke (APA-Stroke). Ongoing study 2009.

\section{Tanne 2008 \{published data only\}}

Tanne D. Virtual reality training program for ambulatory patients with chronic gait deficits after stroke. https:// clinicaltrials.gov/ct2/show/NCT00600379 (accessed 20 November 2013)

Turton 2011 \{unpublished data only\}

Turton A. Home based reach to grasp training after stroke. http://public.ukcrn.org.uk/Search/StudyDetail.aspx? StudyID=9226 (accessed 26 November 2013).

\section{Additional references}

\section{Au-Yeung 2009}

Au-Yeung SS, Hui-Chan CW. Predicting recovery of dextrous hand function in acute stroke. Disability and Rehabilitation 2009;31:394-401.

\section{Bamford 1991}

Bamford J, Sandercock P, Dennis M, Burn J, Warlow C. Classification and natural history of clinically identifiable subtypes of cerebral infarction. Lancet 1991;337(8756):1521-6.

\section{Butefisch 1995}

Butefisch C, Hummelsheim H, Denzler P, Mauritz KH. Repetitive training of isolated movements improves the outcome of motor 
rehabilitation of the centrally paretic hand. Journal of the Neurological Sciences 1995;130(1):59-68. [MEDLINE: 212]

\section{Carr 1987}

Carr J, Shepherd R. A Motor Relearning Programme For Stroke. Oxford: Butterworth Heinemann, 1987. [MEDLINE: 251]

\section{Corbetta 2015}

Corbetta D, Sirtori V, Castellini G, Moja L, Gatti R. Constraintinduced movement therapy for upper extremities in people with stroke. Cochrane Database of Systematic Reviews 2015, Issue 10. [DOI: 10.1002/14651858.CD004433.pub3]

\section{Dallas 2008}

Dallas MI, Rone-Adams S, Echternach JL, Brass LM, Bravata DM. Dependence in prestroke mobility predicts adverse outcomes among patients with acute ischemic stroke. Stroke 2008;39:2298-303.

\section{Dobkin 2004}

Dobkin BH. Strategies for stroke rehabilitation. Lancet Neurology 2004;3(9):528-36. [MEDLINE: 122]

\section{Feigin 1996}

Feigin L, Sharon B, Czaczkes B, Rosin AJ. Sitting equilibrium 2 weeks after a stroke can predict the walking ability after 6 months. Gerontology 1996;42:348-53.

\section{Feigin 2014}

Feigin VL, Forouzanfar MH, Krishnamurthi R, Mensah GA, Connor M, Bennett DA, the Global Burden of Diseases, Injuries, and Risk Factors Study 2010 (GBD 2010) and the GBD Stroke Experts Group. Global and regional burden of stroke during 1990-2010: findings from the Global Burden of Disease Study 2010. Lancet 2014;383(9913):245-54.

\section{Guyatt 2008}

Guyatt GH, Oxman AD, Vist G, Kunz R, Falck-Ytter Y, for the GRADE Working Group. Rating quality of evidence and strength of recommendations GRADE: an emerging consensus on rating quality of evidence and strength of recommendations. $B M J$ 2008;336:924-6.

\section{Heller 1987}

Heller A, Wade DT, Wood VA, Sunderland A, Hewer RL, Ward E. Arm function after stroke: measurement and recovery over the first three months. Journal of Neurology, Neurosurgery and Psychiatry 1987;50(6):714-9. [MEDLINE: 258]

\section{Higgins 2011}

Higgins JPT, Altman DG, Gøtzsche PC, Jüni P, Moher D, Oxman AD, et al. The Cochrane Collaboration's tool for assessing risk of bias in randomised trials. BMJ 2011;343:d5928.

\section{Kwah 2013}

Kwah LK, Harvey LA, Diong J, Herbert RD. Models containing age and NIHSS predict recovery of ambulation and upper limb function six months after stroke: an observational study. Journal of Physiotherapy 2013;59(3):189-97.

\section{Kwakkel 2004}

Kwakkel G, van Peppen R, Wagenaar RC, Dauphinee SW, Richards C, Ashburn A, et al. Effects of augmented exercise therapy time after stroke - a meta-analysis. Stroke 2004;35(11):2529-36. [MEDLINE: 117]

\section{Langhorne 2009}

Langhorne P, Coupar F, Pollock A. Motor recovery after stroke: a systematic review. Lancet Neurology 2009;8:741-54.

\section{Lawrence 2001}

Lawrence ES, Coshall C, Dundas R, Stewart J, Rudd AG, Howard R, et al. Estimates of the prevalence of acute stroke impairments and disability in a multi-ethnic population. Stroke 2001;32(6):1279-84. [MEDLINE: 254]

\section{Lord 2004}

Lord S, McPherson K, McNaughton H, Rochester L, Weatherall M. Community ambulation after stroke: how important and obtainable is it and what measures appear predictive? Archives of Physical Medicine and Rehabilitation 2004;85:234-9. [MEDLINE: 181

\section{Mehrholz 2014}

Mehrholz J, Pohl M, Elsner B. Treadmill training and body weight support for walking after stroke. Cochrane Database of Systematic Reviews 2014, Issue 1. [DOI: 10.1002/14651858.CD002840.pub3]

\section{Mehrholz 2015b}

Mehrholz J, Pohl M, Platz T, Kugler J, Elsner B. Electromechanical and robot-assisted arm training for improving activities of daily living, arm function, and arm muscle strength after stroke. Cochrane Database of Systematic Reviews 2015, Issue 11. [DOI: 10.1002/14651858.CD006876.pub4]

\section{Nakayama 1994}

Nakayama H, Jorgensen HS, Raaschou HO, Olsen TS. Recovery of upper extremity function in stroke patients: the Copenhagen study. Archives of Physical Medicine and Rehabilitation 1994;75:852-7. [MEDLINE: 24]

\section{Nijland 2010}

Nijland RHM, van Wegen EEH, Harmeling-van der Wel BC, Kwakkel G, the EPOS Investigators. Presence of finger extension and shoulder abduction within 72 hours after stroke predicts functional recovery. Early Prediction of functional Outcome after Stroke: the EPOS Cohort Study. Stroke 2010;41:745-50.

\section{Nuyens 2002}

Nuyens GE, De Weerdt WJ, Spaepen AJ Jr, Kiekens C, Feys HM. Reduction of spastic hypertonia during repeated passive knee movements in stroke patients. Archives of Physical Medicine and Rehabilitation 2002;83(7):930-5.

\section{Page 2004}

Page SJ, Gater DR, Bach-Y-Rita P. Reconsidering the motor recovery plateau in stroke rehabilitation. Archives of Physical Medicine \& Rehabilitation 2004;85(8):1377-81. [MEDLINE: 15295770] 


\section{Pollock 2014a}

Pollock A, Farmer SE, Brady MC, Langhorne P, Mead GE, Mehrholz J, et al. Interventions for improving upper limb function after stroke. Cochrane Database of Systematic Reviews 2014, Issue 11. [DOI: 10.1002/14651858.CD010820.pub2]

\section{Pollock 2014b}

Pollock A, Baer G, Campbell P, Choo PL, Forster A, Morris J, et al. Physical rehabilitation approaches for the recovery of function and mobility following stroke. Cochrane Database of Systematic Reviews 2014, Issue 4. [DOI: 10.1002/14651858.CD001920.pub3]

\section{RevMan 2014 [Computer program]}

The Nordic Cochrane Centre, The Cochrane Collaboration. Review Manager (RevMan). Version 5.3. Copenhagen: The Nordic Cochrane Centre, The Cochrane Collaboration, 2014.

\section{Schmidt 2014}

Schmidt RA, Lee TD. Motor Learning and Performance. 5th Edition. Champaign, IL: Human Kinetics, 2014.

\section{Sunderland 1989}

Sunderland A, Tinson D, Bradley L, Hewer RL. Arm function after stroke. An evaluation of grip strength as a measure of recovery and a prognostic indicator. Journal of Neurology, Neurosurgery and Psychiatry 1989;52(11):1267-72. [MEDLINE: 256]

\section{Van der Lee 2001}

Van der Lee JH, Snels IA, Beckerman H, Lankhorst GJ, Wagenaar RC, Bouter LM. Exercise therapy for arm function in stroke patients: a systematic review of randomized controlled trials. Clinical Rehabilitation 2001;15(1):20-31. [MEDLINE: 162]

\section{Van Exel 2004}

Van Exel NJA, Reimer SO, Koopmanschap MA. Assessment of post-stroke quality of life in cost-effectiveness studies: the usefulness of the Barthel Index and the EuroQol-5D. Quality of Life Research 2004;13(2):427-33.

\section{Van Peppen 2004}

Van Peppen RPS, Kwakkel G, Wood-Dauphinee S, Hendriks HJM, van der Wees PJ, Dekker J. The impact of physical therapy on functional outcomes after stroke: what's the evidence?. Clinical Rehabilitation 2004;18(8):833-62. [MEDLINE: 35]

\section{Verbeek 2011}

Verbeek JM, Van Wegen EE, Harmeling-Van der Wel BC, Kwakkel G. Is accurate prediction of gait in nonambulatory stroke patients possible within 72 hours poststroke?: The EPOS Study. Neurorehabilitation and Neural Repair 2011;25:268-74.

\section{Verbeek 2014}

Verbeek JM, van Wegen E, van Peppen R, van der Wees PJ, Hendriks E, Rietberg M, et al. What is the evidence for physical therapy poststroke? A systematic review and meta-analysis. PLoS One 2014;9(2):e87987.

\section{Wade 1983}

Wade DT, Langton-Hewer R, Wood VA, Skilbeck CE, Ismail HM. The hemiplegic arm after stroke: measurement and recovery. Journal of Neurology, Neurosurgery \& Psychiatry 1983;46(6):521-4. [MEDLINE: 257]

\section{Wade 1987}

Wade DT, Langton-Hewer R. Functional abilities after stroke: measurement, natural history and prognosis. Journal of Neurology Neurosurgery and Psychiatry 1987;50:177-82. [MEDLINE: 298]

\section{Wandel 2000}

Wandel A, Jorgensen HS, Nakayama H, Raaschou HO, Olsen TS. Prediction of walking function in stroke patients with initial lower extremity paralysis: the Copenhagen Stroke Study. Archives of Physical Medicine and Rehabilitation 2000;81:736-8.

\section{WHO 1989}

World Health Organization Task Force. Recommendations on stroke prevention, diagnosis, and therapy: report of the WHO Task Force on stroke and other cerebrovascular disorders. Stroke 1989;20:1407-31. [MEDLINE: 299]

\section{Wolfe 2000}

Wolfe CD. The impact of stroke. British Medical Bulletin 2000;56(2):275-86.

\section{References to other published versions of this review \\ French 2006}

French B, Forster A, Langhorne P, Leathley MJ, McAdam J, Price $\mathrm{CIM}$, et al. Repetitive task training for improving functional ability after stroke. Cochrane Database of Systematic Reviews 2006, Issue 3. [DOI: 10.1002/14651858.CD006073]

\section{French 2007}

French B, Thomas LH, Leathley MJ, Sutton CJ, McAdam J, Forster A, et al. Repetitive task training for improving functional ability after stroke. Cochrane Database of Systematic Reviews 2007, Issue 4. [DOI: 10.1002/14651858.CD006073.pub2]

* Indicates the major publication for the study

\section{CHARACTERISTICS OF STUDIES}

Characteristics of included studies [ordered by study ID]

Arya 2012

\begin{tabular}{ll}
\hline Methods & An assessor-blinded, multicentre randomised controlled design \\
\hline Participants & India
\end{tabular}


Arya 2012 (Continued)

Participants were recruited from an inpatient neurology ward and occupational therapy unit of a rehabilitation institute. Date of recruitment not reported

\section{3 participants: 51 RTT, 52 control}

Inclusion criteria: first episode of unilateral stroke with hemiparesis, 4 to 24 weeks post stroke, functional ambulation classification level I and above, ability to understand instructions (Hindi Mental State Examination $>24$ ), National Institute of Health Stroke Scale score $<14$, able to cope with intensive training program, Brunnstrom stage of arm recovery of 2 to 5

Exclusion criteria: perceptual deficits such as neglect and apraxia, dementia, depression, impaired vision, impaired conscious level, concomitant medical illness, cardiovascular instability (resting systolic blood pressure $>200 \mathrm{mmHg}$ and resting diastolic blood pressure $>100 \mathrm{mmHg}$ ), shoulder subluxation, aphasia, sensory loss

Mean age: RTT 51.67 years (SD 7.96), control 50.21 years (SD 7.60)

$60.2 \%$ male

Stroke details: first stroke, ischaemic $66.9 \%$, haemorrhagic $33.0 \%$

Timing post stroke: RTT 11.92 weeks (SD 6.49), control 12.37 weeks (SD 6.64)

Pre-intervention functional ability level:

Functional ambulation classification level I and above

RTT intervention: Meaningful Task Specific Training (MTST) is a training program for upper extremity rehabilitation of post stroke clients based on principles of motor learning, experience dependent neuroplasticity, and shaping techniques

MTST mainly comprises the specific number of meaningful tasks, which are common to all the patients

The tasks have to be practiced repetitively either with unilateral (the most affected extremity) or bilateral upper limb/s, depending on the task requirement

It also has a component of individualised meaningful tasks, which have to be selected from a task bank for repetitive practice

Sessions were delivered as one-to-one outpatient rehabilitation in day care units 1 hour per day (unclear number of times per week) for 4 weeks

Comparison group: the control group was given an intervention of the same duration based on the Brunnstrom movement therapy and Bobath neurodevelopmental technique

Outcome measures were recorded at baseline, 4 weeks (post treatment) and 8 weeks
Upper limb functional outcome measures: Fugl-Meyer assessment, Action Research Arm Test, Graded
Wolf Motor Function Test, Motor Activity Log
Wolf Motor Function Test, Motor Activity Log

Notes significant differences at baseline
1 experimental dropout due to personal reasons
No adverse events reported

\section{Risk of bias}

\begin{tabular}{lll}
\hline Bias & Authors' judgement & Support for judgement \\
\hline $\begin{array}{l}\text { Random sequence genera- } \\
\text { tion (selection bias) }\end{array}$ & Low risk & A random-number generator program was used \\
\hline
\end{tabular}


Arya 2012 (Continued)

$\begin{array}{ll}\begin{array}{l}\text { Allocation concealment } \\ \text { (selection bias) }\end{array} \quad \text { Low risk } & \begin{array}{l}\text { Intervention assignments were enclosed in sealed envelopes, which were } \\ \text { opaque and sequentially numbered }\end{array}\end{array}$

\begin{tabular}{lll}
\hline $\begin{array}{l}\text { Blinding of outcome as- } \\
\text { sessment (detection bias) } \\
\text { All outcomes }\end{array}$ & Low risk & $\begin{array}{l}\text { Blinded assessors were trained to administer the measures properly, and they } \\
\text { did not participate in providing the interventions }\end{array}$ \\
\hline $\begin{array}{l}\text { Incomplete outcome data } \\
\text { (attrition bias) }\end{array}$ & Low risk & Missing data balanced across intervention groups \\
$\begin{array}{l}\text { All outcomes } \\
\text { An intention-to-treat analysis was used with the last observation carried for- } \\
\text { ward for the missing data }\end{array}$
\end{tabular}

\begin{tabular}{ll}
\hline $\begin{array}{l}\text { Selective reporting (re- } \\
\text { porting bias) }\end{array}$ & Unclear risk $\quad$ No study protocol \\
\hline
\end{tabular}

\section{Baer 2007}

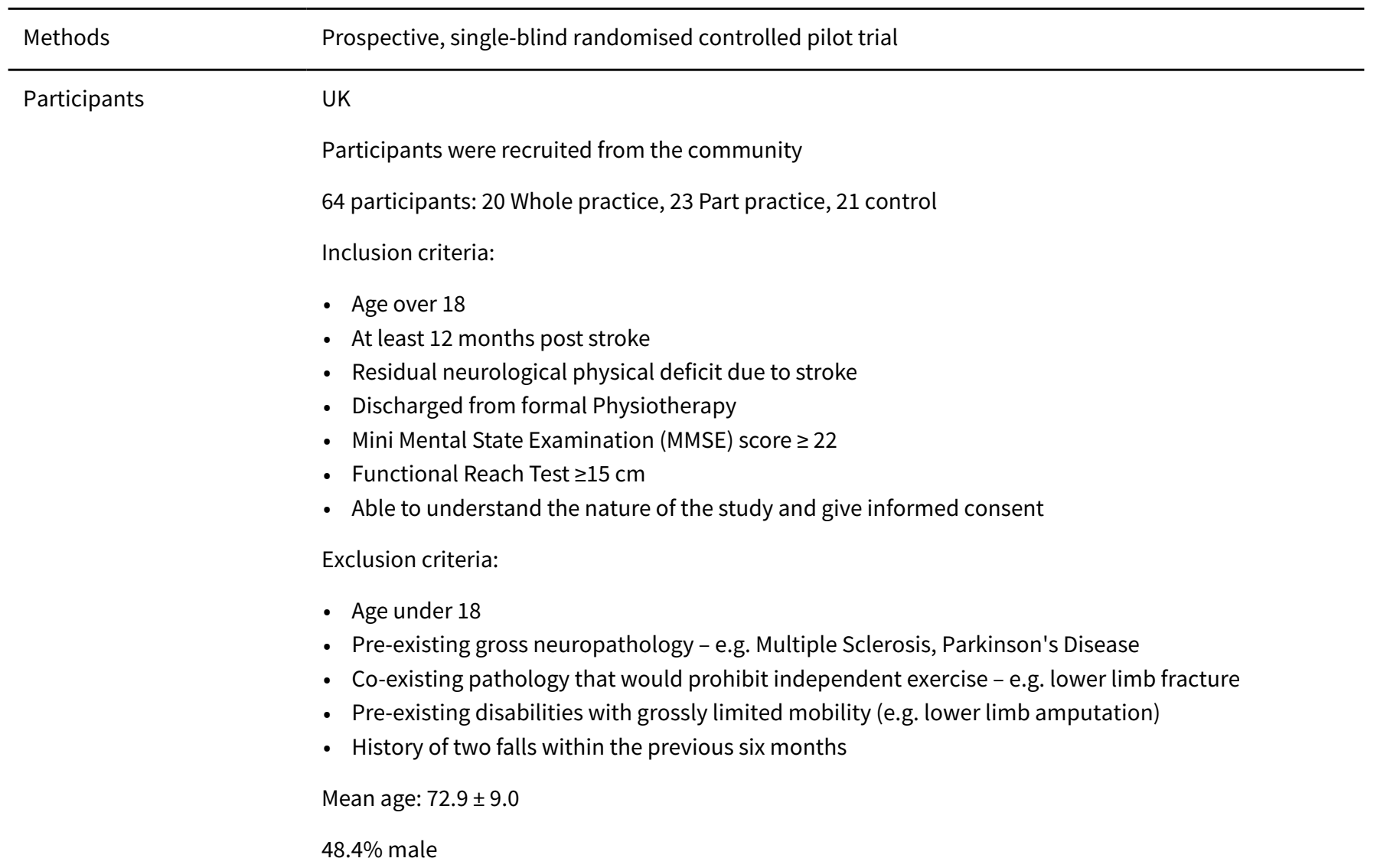

\section{Stroke details: 38 right CVA, 26 left CVA}

Timing post stroke: $30.3 \pm 28.8$ months

Pre-intervention functional activity level: RTT WP MAS mean 26.5 (SD 8.5), RTT PP 28.1 (7.9), control 26.5 (8.9); (MAS score $\geq 32$ designated as "mild", $\leq 31$ designated "moderate to severe")

Interventions

RTT intervention: the exercises consisted of practising standing up from a chair, sitting down, stepping onto a step, stepping off a step, pronation and supination holding a bottle and reaching and grasping. All participants allocated to an exercise "arm" of the trial practised the same functional exercises but in different ways: entirety (whole practice) or component parts (part practice). The clinical research assis- 
Baer 2007 (Continued)

tant encouraged participants to increase the number of repetitions of exercises practiced if assessed to be appropriate

The target number of repetitions of each exercise was documented in the exercise diary and participants were requested to document the actual number undertaken

Comparison group: participants did not receive any physical intervention or exercise instruction but received the same number of visits by the research assistant to counteract the possible therapist interaction effect

Outcomes

Outcome measures were recorded at baseline ( 2 measurements 2 weeks apart), 4 weeks (post treatment) and 72 hours and 3 months post treatment

Upper limb functional outcome measure: Frenchay Arm Test

Lower limb functional outcome measures: Timed Up and Go 2m, Step Test, Step-up count of 15 seconds

Other outcome measures: Barthel Index, MAS, Frenchay Activity Index, Stroke Impact Scale (activity)

\section{Notes}

\section{Risk of bias}

\begin{tabular}{lll}
\hline Bias & Authors' judgement & Support for judgement \\
\hline $\begin{array}{l}\text { Random sequence genera- } \\
\text { tion (selection bias) }\end{array}$ & Low risk & $\begin{array}{l}\text { Randomised blocks within } 4 \text { strata of participants were used, based on side } \\
\text { and severity of stroke, due to the small numbers of participants }\end{array}$ \\
\hline $\begin{array}{l}\text { Allocation concealment } \\
\text { (selection bias) }\end{array}$ & High risk & Method of concealment not described \\
\hline $\begin{array}{l}\text { Blinding of outcome as- } \\
\text { sessment (detection bias) } \\
\text { All outcomes }\end{array}$ & High risk & $\begin{array}{l}\text { Outcome data collected by the principal investigator who was blind to group } \\
\text { allocation. The outcome assessor became aware of group allocation for 3 par- } \\
\text { ticipants }\end{array}$ \\
\hline $\begin{array}{l}\text { Incomplete outcome data } \\
\text { (attrition bias) } \\
\text { All outcomes }\end{array}$ & Low risk & $\begin{array}{l}\text { At the short-term follow-up point, data were missing for } 5 \text { control, } 3 \text { RTT PP } \\
\text { and one RTT WP participant. Reasons are given by intervention group; for 2/5 } \\
\text { of participants in the control group reasons were not illness related. }\end{array}$ \\
\hline $\begin{array}{l}\text { Selective reporting (re- } \\
\text { porting bias) }\end{array}$ & Unclear risk & No study protocol \\
\hline
\end{tabular}

\section{Barreca 2004}

\begin{tabular}{ll}
\hline Methods & Single centre RCT \\
\hline Participants & Canada \\
& 48 participants: 25 RTT, 23 control \\
& Participants were recruited from stroke rehabilitation units between 2000 and 2001 \\
& $\begin{array}{l}\text { Inclusion criteria: between the ages of } 18 \text { to } 90 \text { years, medically stable, had a postural control of Stage } 3 \\
\text { or greater as measured by the Chedoke-McMaster Stroke Assessment (CMSA), and failed the third item } \\
\text { of the CMSA Stage 4 Postural Control } \\
\text { Exclusion criteria: none stated }\end{array}$
\end{tabular}


Barreca 2004 (Continued)

Median age: RTT 67 years (IQR 56 - 72), control 70 years (IQR 64 - 78)

$65 \%$ male

Stroke details: not stated whether first or recurrent stroke, $73 \%$ ischaemic, $42 \%$ right hemiparesis

Timing post stroke: RTT median 30 days (IQR 21 to 48), control median 31 days (IQR 18 to 50)

Pre-intervention functional ability level: lack of postural control

Interventions

RTT intervention: sit-to-stand training. Group class practice in attaining standing from sitting from a variety of different heights and surfaces

Training was additional to usual care, which included daily strengthening exercise, repetitive training, functional training, electrical stimulation and other exercise

Sessions were 45 minutes, 3 times per week until competence or discharge (approximately 6 weeks) $=$ 13.5 hours + practice on ward

Each session aimed to involve 3 practice sets of 5 sit-to-stand manoeuvres per class

Average total repetitions during training $=450$ to 500

Classes had 6 to 7 participants, supervised by 2 registered practical nurses, with extra practice delivered by nurses trained on the sit-to-stand protocol in a ward setting using videotapes, written instruction and practice

Comparison group: usual care and recreation therapy

Outcomes Outcome measures were recorded at baseline and at competence or discharge (approximately 6 weeks)

Balance/sit-to-stand outcome measures: ability to stand independently and safely on 2 consecutive occasions

Adverse events outcome measures: number of falls

QoL/health status outcome measures: satisfaction with ability to stand, Dartmouth Primary Care Cooperative Chart

Notes No significant differences in baseline characteristics

\section{Risk of bias}

\begin{tabular}{lll}
\hline Bias & Authors' judgement & Support for judgement \\
\hline $\begin{array}{l}\text { Random sequence genera- } \\
\text { tion (selection bias) }\end{array}$ & Low risk & Assigned by coin flip \\
\hline $\begin{array}{l}\text { Allocation concealment } \\
\text { (selection bias) }\end{array}$ & Unclear risk & Inadequately reported \\
\hline
\end{tabular}

\begin{tabular}{|c|c|c|}
\hline $\begin{array}{l}\text { Blinding of outcome as- } \\
\text { sessment (detection bias) }\end{array}$ & Low risk & $\begin{array}{l}\text { A research physiotherapist, blind to the study, tested the participants' STS } \\
\text { movement once per week }\end{array}$ \\
\hline
\end{tabular}
All outcomes

No loss to follow-up at end of treatment phase

Incomplete outcome data Low risk No loss to follow-up at end of treatment phase
(attrition bias)
All outcomes

Selective reporting (re- Unclear risk $\quad$ No study protocol
porting bias)




\begin{tabular}{|c|c|}
\hline Methods & Single-centre RCT \\
\hline \multirow[t]{10}{*}{ Participants } & Australia \\
\hline & 30 participants: 15 mobility group, 15 upper limb group \\
\hline & $\begin{array}{l}\text { Participants were recruited from inpatient admissions, with a primary diagnosis of stroke, to a rehabili- } \\
\text { tation centre between } 2001 \text { and } 2003\end{array}$ \\
\hline & Inclusion criteria: able to walk 10 metres and provide informed consent \\
\hline & Exclusion criteria: deteriorating medical condition, independent community ambulation \\
\hline & Mean age: mobility group 53.9 years (SD 19.8), upper limb group 56.3 years (SD 10.5) \\
\hline & $56.6 \%$ male \\
\hline & Stroke details: first or recurrent stroke, $73 \%$ ischaemic, $47 \%$ right hemiparesis \\
\hline & Timing post stroke: mobility group 36 days (SD 25.1), upper limb group 50 days (SD 49.2) \\
\hline & $\begin{array}{l}\text { Pre-intervention functional ability level: Six Minute Walk Test: mobility group } 183 \text { metres (SD 85), upper } \\
\text { limb group } 181 \text { metres (SD 85) }\end{array}$ \\
\hline \multirow[t]{9}{*}{ Interventions } & RTT interventions: \\
\hline & $\begin{array}{l}\text { - Mobility group: circuit training including sit-to-stand, step-ups, obstacle course, plus stretch- } \\
\text { ing/strengthening exercise, and some endurance training (stationary bikes/treadmill) }\end{array}$ \\
\hline & $\begin{array}{l}\text { - Upper limb group: reach and grasp, hand-eye co-ordination activities, stretching and strengthening } \\
\text { exercises }\end{array}$ \\
\hline & Sessions were during inpatient rehabilitation and additional to usual care of 5 hours per week \\
\hline & Sessions were 60 minutes, 5 times per week for 4 weeks $=20$ hours \\
\hline & Each circuit included $10 \times 5$-minute workstations \\
\hline & Sessions were delivered by a physical therapist in groups of up to 4 participants \\
\hline & Comparison group: Blennerhassett 2004a lower limb attention control \\
\hline & Blennerhassett 2004b upper limb attention control \\
\hline
\end{tabular}

Outcomes Outcome measures were recorded at baseline, 4 weeks (post treatment) and 6 months after training

Upper limb functional outcome measures: MAS, Jebsen Taylor Test of Hand Function

Lower limb functional outcome measures: Six Minute Walk Test, Step Test

Balance/sit-to-stand outcome measures: Timed Up and Go Test

$\begin{array}{ll}\text { Notes } & \text { No significant differences reported at baseline } \\ 3 \% \text { lost to follow-up at end of treatment phase } \\ \text { No likely intervention-related withdrawals } \\ \text { Average attendance was approximately } 80 \% \text {, with no significant difference between the groups }\end{array}$

\section{Risk of bias}

Bias Authors' judgement Support for judgement


Blennerhassett 2004 (Continued)

\begin{tabular}{lll}
$\begin{array}{l}\text { Random sequence genera- } \\
\text { tion (selection bias) }\end{array}$ & Unclear risk & Inadequately reported \\
\hline $\begin{array}{l}\text { Allocation concealment } \\
\text { (selection bias) }\end{array}$ & Unclear risk & $\begin{array}{l}\text { Randomisation performed by a person independent from the study, drawing a } \\
\text { pre-sealed opaque envelope that specified group allocation, unclear if sequen- } \\
\text { tially numbered }\end{array}$ \\
\hline
\end{tabular}

\begin{tabular}{lll}
\hline $\begin{array}{l}\text { Blinding of outcome as- } \\
\text { sessment (detection bias) } \\
\text { All outcomes }\end{array}$ & Low risk & Outcome assessors blinded to group allocation \\
\hline $\begin{array}{l}\text { Incomplete outcome data } \\
\text { (attrition bias) } \\
\text { All outcomes }\end{array}$ & Low risk & $\begin{array}{l}\text { One withdrawal in the upper limb group due to hip fracture from fall post dis- } \\
\text { charge }\end{array}$ \\
\hline $\begin{array}{l}\text { Selective reporting (re- } \\
\text { porting bias) }\end{array}$ & Unclear risk & No study protocol \\
\hline
\end{tabular}

Blennerhassett 2004a

\begin{tabular}{ll}
\hline Methods See Blennerhassett 2004 \\
\hline Participants
\end{tabular}

\section{Participants}

Interventions

\section{Outcomes}

\section{Notes}

\section{Risk of bias}

\begin{tabular}{|c|c|c|}
\hline Bias & Authors' judgement & Support for judgement \\
\hline $\begin{array}{l}\text { Random sequence genera- } \\
\text { tion (selection bias) }\end{array}$ & Unclear risk & See Blennerhassett 2004 \\
\hline $\begin{array}{l}\text { Allocation concealment } \\
\text { (selection bias) }\end{array}$ & Unclear risk & See Blennerhassett 2004 \\
\hline $\begin{array}{l}\text { Blinding of outcome as- } \\
\text { sessment (detection bias) } \\
\text { All outcomes }\end{array}$ & Low risk & See Blennerhassett 2004 \\
\hline $\begin{array}{l}\text { Incomplete outcome data } \\
\text { (attrition bias) } \\
\text { All outcomes }\end{array}$ & Low risk & See Blennerhassett 2004 \\
\hline $\begin{array}{l}\text { Selective reporting (re- } \\
\text { porting bias) }\end{array}$ & Unclear risk & See Blennerhassett 2004 \\
\hline
\end{tabular}


Blennerhassett 2004b

\begin{tabular}{ll}
\hline Methods & See Blennerhassett 2004 \\
\hline Participants & \\
\hline
\end{tabular}

Interventions

\section{Outcomes}

Notes

\section{Risk of bias}

Bias Authors' judgement Support for judgement

Random sequence genera- Unclear risk See Blennerhassett 2004

tion (selection bias)

\begin{tabular}{lll}
\hline $\begin{array}{l}\text { Allocation concealment } \\
\text { (selection bias) }\end{array}$ & Unclear risk & See Blennerhassett 2004
\end{tabular}

\begin{tabular}{lll}
\hline Blinding of outcome as- & Low risk & See Blennerhassett 2004 \\
sessment (detection bias) &
\end{tabular}

All outcomes

Incomplete outcome data Low risk See Blennerhassett 2004
(attrition bias)
All outcomes

Selective reporting (re- Unclear risk $\quad$ See Blennerhassett 2004
porting bias)

\section{de Sèze 2001}

\begin{tabular}{ll}
\hline Methods & Single-centre pilot RCT \\
\hline Participants & France \\
& 20 participants: 10 RTT, 10 control group \\
& Participants recruited from a neurorehabilitation unit in 1998 \\
& Inclusion criteria: hemiplegia caused by a single stroke occurring at least 1 month previously, static im- \\
& balance of the trunk resulting from the stroke \\
& Exclusion criteria: multiple cerebral lesions, disorders of the locomotor system, a severe visual or au- \\
& ditory deficit, a severe deficit of executive functions, or deterioration in the general state of health that \\
& might alter postural performances \\
& Mean age: RTT 63.5 years (SD 17), control 67.7 years (SD 15) \\
& $55 \%$ male
\end{tabular}

Stroke details: first stroke, 35\% ischaemic, 25\% right hemiparesis

Time since stroke: RTT 36.8 days (SD 25), control 27.7 days (SD 15)

Pre-intervention functional ability level: lack of postural balance 
de Sèze 2001 (Continued)

Interventions
RTT intervention: postural training using the Bon Saint Côme device - a custom-moulded orthosis that holds a pointing device, used by the participant to point to targets on a vertical panel which are activated to emit light and sound signals

Sessions were in addition to 1 hour of usual care and were 60 minutes (unclear whether 5 or 7 days per week), for 4 weeks $=20$ to 28 hours

Sessions were delivered individually by a physical therapist

Comparison group: 2 hours of usual care (Bobath inspired approach and functional therapy plus a session of occupational therapy 5 days per week)

Outcomes were recorded at baseline, 4 weeks (post treatment), and 2 months
Balance/sit-to-stand outcome measures: Sitting Equilibrium Index, Upright Equilibrium Index
Lower limb functional outcome measures: Functional Ambulation Classification
Impairment outcome measures: Trunk Control Test, Motricity Index, Ashworth Scale
ADL outcome measures: Functional Independence Measure

Notes

Postural deficit and unilateral neglect tended to be more severe in the device group at baseline, although not significant

No intervention-related reasons for withdrawal

Attendance: all participants completed training

\section{Risk of bias}

\begin{tabular}{|c|c|c|}
\hline Bias & Authors' judgement & Support for judgement \\
\hline $\begin{array}{l}\text { Random sequence genera- } \\
\text { tion (selection bias) }\end{array}$ & Low risk & $\begin{array}{l}\text { The participants were distributed consecutively into } 2 \text { groups of } 10 \text { each by us- } \\
\text { ing a randomisation table }\end{array}$ \\
\hline $\begin{array}{l}\text { Allocation concealment } \\
\text { (selection bias) }\end{array}$ & Unclear risk & No details reported \\
\hline $\begin{array}{l}\text { Blinding of outcome as- } \\
\text { sessment (detection bias) } \\
\text { All outcomes }\end{array}$ & Low risk & $\begin{array}{l}\text { The clinician who evaluated the patients did not know to which group they be- } \\
\text { longed }\end{array}$ \\
\hline $\begin{array}{l}\text { Incomplete outcome data } \\
\text { (attrition bias) } \\
\text { All outcomes }\end{array}$ & Low risk & No withdrawals or dropouts \\
\hline $\begin{array}{l}\text { Selective reporting (re- } \\
\text { porting bias) }\end{array}$ & Unclear risk & No study protocol \\
\hline
\end{tabular}

Dean 1997

\begin{tabular}{ll}
\hline Methods & RCT \\
\hline Participants & Australia \\
& 20 participants: 10 RTT, 10 control group \\
& Participants were recruited from stroke clubs around Sydney. Date of recruitment not reported \\
\hline
\end{tabular}


Dean 1997 (Continued)

Inclusion criteria: diagnosis of stroke resulting in hemiplegia at least 12 months previous, discharged from all rehabilitation services, ability to understand instructions and give informed consent, no or-

thopaedic problem that would interfere with seated reaching, ability to sit unsupported for 20 minutes

Exclusion criteria: none stated

Mean age: RTT 68.2 years (SD 8.2), control 66.9 years (SD 8.2)

$70 \%$ male

Stroke details: not stated whether first or recurrent stroke; $40 \%$ right-sided stroke

Time since stroke: RTT 6.7 years (SD 5.8), control 5.9 years (SD 2.9)

Pre-intervention functional ability level: walking speed: RTT $0.41 \mathrm{~m} / \mathrm{s}$ (SD 0.25 ), control $0.52 \mathrm{~m} / \mathrm{s}$ (SD 0.28)

Interventions

RTT intervention: training designed to improve sitting balance and involving emphasis on appropriate loading of the affected leg while practicing reaching tasks using the unaffected hand to grasp objects located beyond arm's length

Intervention was after discharge from all rehabilitation programmes

Sessions were 30 minutes, 5 days per week for 2 weeks $=5$ hours

Sessions were delivered by a physical therapist in the participant's own home.

Comparison group: upper extremity attention control - performance of cognitive manipulative tasks while seated at a table

\begin{tabular}{ll}
\hline Outcomes & Outcomes were recorded at baseline and at 2 weeks (post treatment) \\
& Lower limb functional outcome measures: 10 Metre Walk Speed \\
& Balance/sit-to-stand outcome measures: reaching distance, reaching speed \\
\hline Notes & $\begin{array}{l}\text { No significant differences reported at baseline } \\
5 \% \text { loss to follow-up at end of treatment phase } \\
\text { No intervention-related reasons for withdrawal }\end{array}$ \\
\hline
\end{tabular}

\section{Risk of bias}

\begin{tabular}{lll}
\hline Bias & Authors' judgement & Support for judgement \\
\hline $\begin{array}{l}\text { Random sequence genera- } \\
\text { tion (selection bias) }\end{array}$ & Unclear risk & Not reported \\
\hline $\begin{array}{l}\text { Allocation concealment } \\
\text { (selection bias) }\end{array}$ & Unclear risk & $\begin{array}{l}\text { Participants allocated by drawing a card from a box of } 10 \text { experimental and } 10 \\
\text { control cards }\end{array}$ \\
\hline $\begin{array}{l}\text { Blinding of outcome as- } \\
\text { sessment (detection bias) } \\
\text { All outcomes }\end{array}$ & Low risk & $\begin{array}{l}\text { Walking speed and cognitive-manipulative tasks were evaluated by an asses- } \\
\text { sor blinded to the participant's group allocation }\end{array}$ \\
& $\begin{array}{l}\text { Biomechanical data collection and analysis for the seated reaching tasks and } \\
\text { sit-to-stand were computerised, which minimised experimenter bias because } \\
\text { group allocation was not evident to the operator }\end{array}$
\end{tabular}

Incomplete outcome data Low risk 1 withdrawal in control group due to medical complications

(attrition bias)

All outcomes 
Dean 1997 (Continued)

Selective reporting (re- $\quad$ Unclear risk $\quad$ No study protocol
porting bias)

Dean 2000

\begin{tabular}{ll}
\hline Methods & Pilot RCT \\
\hline Participants & Canada \\
12 participants: 6 RTT, 6 control group \\
Participants were recruited from a rehabilitation research group database. Date of recruitment not re- \\
ported \\
Inclusion criteria: first stroke, at least 3 months post stroke, discharged from all rehabilitation services, \\
able to attend a rehabilitation centre 3 times per week for 4 weeks, able to walk 10 metres \\
Exclusion criteria: any medical condition that would prevent participation \\
Mean age: RTT 66.2 years (SD 7.7), control 62.3 years (SD 6.6) \\
58\% male \\
Stroke details: first stroke, 58\% right hemiparesis \\
Timing post stroke: RTT 2.3 years (SD 0.7), control 1.3 years (SD 0.9) \\
Pre-intervention functional ability level: Walking velocity: RTT 76 cm/s (SD 44), control 76 cm/s (SD 39)
\end{tabular}

Interventions

RTT intervention: lower limb circuit training of 10 workstations including sitting reach, sit-to-stand, stepping, heel lifts, standing balance, leg strengthening, treadmill walking, obstacle walking, slope and stair walking, plus participation in walking races and relays

Intervention was after discharge from all rehabilitation programmes

Sessions were 60 minutes, 3 times per week for 4 weeks $=12$ hours

Sessions were delivered to a group of 6 participants by 2 physical therapists, in an rehabilitation centre setting

Comparison group: circuit programme designed to improve function of the affected upper limb

Outcomes

Outcomes were recorded at baseline, 4 weeks (post treatment), and 2 months after completion of training

Lower limb functional outcome measures: Six Minute Walk Test, 10 Metre Walk Speed (with and without assistive device), Step Test

Balance/sit-to-stand outcome measures: Timed Up and Go Test

Notes

No significant difference in walking velocity at baseline for total group, but after withdrawals, measures of walking speed and distance favoured the control group

$25 \%$ loss to follow-up at end of treatment phase

Two participants withdrew before training (one due to transport costs)

Nine participants attended at least 9 out of 12 sessions

\section{Risk of bias}


Dean 2000 (Continued)

\begin{tabular}{|c|c|c|}
\hline Bias & Authors' judgement & Support for judgement \\
\hline $\begin{array}{l}\text { Random sequence genera- } \\
\text { tion (selection bias) }\end{array}$ & Unclear risk & Inadequately reported \\
\hline $\begin{array}{l}\text { Allocation concealment } \\
\text { (selection bias) }\end{array}$ & High risk & Drawing cards from a box \\
\hline $\begin{array}{l}\text { Blinding of outcome as- } \\
\text { sessment (detection bias) } \\
\text { All outcomes }\end{array}$ & High risk & $\begin{array}{l}\text { Independent rater blinded to participant allocation for the clinical assess- } \\
\text { ments but may have been unmasked as a result of the observer inadvertently } \\
\text { viewing } 1 \text { training session }\end{array}$ \\
\hline $\begin{array}{l}\text { Incomplete outcome data } \\
\text { (attrition bias) } \\
\text { All outcomes }\end{array}$ & Low risk & Missing outcome data balanced in numbers across groups \\
\hline $\begin{array}{l}\text { Selective reporting (re- } \\
\text { porting bias) }\end{array}$ & Unclear risk & No study protocol \\
\hline
\end{tabular}

Dean 2007

Methods Randomised placebo-controlled trial

Participants

Australia

12 participants: 6 RTT, 6 control group

Participants were recruited from a hospital rehabilitation facility between January and June 2000.

Inclusion criteria: a diagnosis of first stroke resulting in hemiplegia within the previous three months; no orthopaedic problems which would interfere with the ability to perform seated reaching tasks; no visual problems which would interfere with reaching to pick up objects or reading; a score of at least 3 on Item 3 (sitting balance) of the MAS for Stroke; the ability to reach with intact arm a distance equivalent to $140 \%$ of arm's length; no major cognitive or perceptual problems identified using the short portable mental status questionnaire; no left neglect identified using the Letter Cancellation Test; the ability to give informed consent; and the ability to understand instructions.

Exclusion criteria: none stated

Mean age: RTT 60 years (SD 7), control 74 years (SD 12)

$\%$ male not reported. Ratio of males to females: RTT 5:1, control 4:2

Stroke details: side of hemiplegia RTT 3:3, control 1:5

Timing post stroke: RTT 21 days (SD 8), control 37 days (SD 23)

Pre-intervention functional activity level: not reported

Interventions

RTT intervention: sitting training protocol designed to improve sitting by reaching beyond arm's length using the unaffected hand whilst focusing on: smooth co-ordinated motion of the trunk and arm to get the hand to the object; appropriate loading of the affected foot; and preventing the use of maladaptive strategies such as widening the base of support. While reaching beyond arm's length, reach distance, direction, thigh support, seat height, and task were varied systematically. Training was progressed over the 2-week period by increasing the reach distance and the number of repetitions

Sessions were delivered to individuals by the first or second author or undergraduate physiotherapy students 
Dean 2007 (Continued)

Comparison group: sham training protocol; participants completed a series of 11 cognitive-manipulative tasks Participants were seated at a table, well supported in a chair with back and armrests, with their forearms resting on the table. The workspace was confined so that reach distance was less than $50 \%$ of arm's length which minimised perturbations to balance. Training was progressed over the 2week period by increasing the number of repetitions and cognitive difficulty of the cognitive-manipulative tasks

Both training programmes were 10 sessions of 30 minutes spread over a two week period $=5$ hours

\begin{tabular}{ll} 
Outcomes & Outcomes were recorded at baseline, 2 weeks (post treatment) and 28 weeks \\
& Upper limb functional outcome measures: Functional Reach Test (primary outcome); standardised \\
& "reach to grasp and drink a glass of water" task; average reach movement time \\
& Lower limb functional outcome measures: 10 metre Walk Test \\
\hline Notes & $\begin{array}{l}\text { Potential baseline imbalance in time from stroke to admission to trial: RTT mean 21 days (SD 8), control } \\
\text { mean } 37 \text { days (SD 23) }\end{array}$
\end{tabular}

\section{Risk of bias}

\begin{tabular}{lll}
\hline Bias & Authors' judgement & Support for judgement \\
\hline $\begin{array}{l}\text { Random sequence genera- } \\
\text { tion (selection bias) }\end{array}$ & Low risk & $\begin{array}{l}\text { Sequence generated by a person independent of the study using random num- } \\
\text { ber tables, blocked to ensure equal numbers of experimental and control par- } \\
\text { ticipants }\end{array}$ \\
\hline
\end{tabular}

\begin{tabular}{|c|c|c|}
\hline $\begin{array}{l}\text { Allocation concealment } \\
\text { (selection bias) }\end{array}$ & Unclear risk & $\begin{array}{l}\text { Randomisation was concealed from the recruiter and assessor by using sealed } \\
\text { opaque envelopes containing the allocation; not clear if envelopes sequential- } \\
\text { ly numbered }\end{array}$ \\
\hline
\end{tabular}

Blinding of outcome as- Low risk
sessment (detection bias)

All outcomes

"The third author remained blinded to group allocation and collected the out-
comes measures post training and six months later. The collection of some
outcome measures required two persons, one of whom was not blinded. To re-
duce bias, the blinded assessor (third author) gave all instructions and mea-
sured outcomes which were not collected by the computer."
Missing outcome data balanced across groups
1 participant in the RTT group and 2 participants in the control group lost to
follow-up at 6 months

\begin{tabular}{ll}
$\begin{array}{l}\text { Incomplete outcome data } \\
\text { (attrition bias) }\end{array}$ & Missing outcome data balanced across groups \\
All outcomes & $\begin{array}{l}1 \text { participant in the RTT group and } 2 \text { participants in the control group lost to } \\
\text { follow-up at } 6 \text { months }\end{array}$ \\
\hline
\end{tabular}

Selective reporting (re- Unclear risk No protocol available

porting bias)

\section{Frimpong 2014}

\begin{tabular}{ll}
\hline Methods & RCT \\
\hline Participants & Ghana \\
& 20 participants: 10 RTT, 10 control \\
& Participants were recruited from stroke survivors referred for physiotherapy. Date of recruitment not \\
reported & $\begin{array}{l}\text { Inclusion criteria: first-episode single stroke, stroke duration of < } 3 \text { months, ability to walk } 10 \text { metres in- } \\
\text { dependently with or without walking aid and Functional Ambulatory Category (FAC) score of } 3 \text { or more }\end{array}$
\end{tabular}


Exclusion criteria: participants with aphasia, cardiac arrhythmias or any other conditions making exercises contraindicated

Mean age: RTT $57.6 \pm 0.3$ years, control $55.8 \pm 6.7$

$64 \%$ male

Stroke details: ischaemic stroke $66.6 \%$ (6), haemorrhagic stroke $33.3 \%$ (3)

Time since stroke: RTT 2.2 months (SD 0.8), control 2.4 months (SD 0.9)

Pre-intervention functional ability: 6 Minute Walk Test: RTT 249.5 metres (SD 10.7), control 253.0 (SD 12.5)

Interventions

RTT intervention: circuit training for 105 minutes, 3 times per week for 8 weeks including treadmill walking, push-ups, squatting, straight leg raise, stairs walking and cycling exercises

Comparison group: conventional therapy of passive and active exercises. Participants also performed upper limb strengthening exercises, walking re-education, as well as standing and balance retraining carried out between parallel bars

\begin{tabular}{ll}
\hline Outcomes & Outcomes were recorded at baseline, week 4 and week 8 (post intervention) \\
& Lower limb functional outcome measures: 6 Minute Walk Test, 10 Metre Walk Test, Functional Ambula- \\
& tory Category
\end{tabular}

Notes No apparent baseline imbalance

\section{Risk of bias}

\begin{tabular}{lll}
\hline Bias & Authors' judgement & Support for judgement \\
\hline $\begin{array}{l}\text { Random sequence genera- } \\
\text { tion (selection bias) }\end{array}$ & Unclear risk & "Subjects were randomized into two groups" \\
\hline $\begin{array}{l}\text { Allocation concealment } \\
\text { (selection bias) }\end{array}$ & Unclear risk & Method of concealment not reported \\
\hline $\begin{array}{l}\text { Blinding of outcome as- } \\
\text { sessment (detection bias) } \\
\text { All outcomes }\end{array}$ & Unclear risk & No mention of blinding \\
\hline $\begin{array}{l}\text { Incomplete outcome data } \\
\text { (attrition bias) } \\
\text { All outcomes }\end{array}$ & Unclear risk & Number of participants not reported in data tables \\
\hline $\begin{array}{l}\text { Selective reporting (re- } \\
\text { porting bias) }\end{array}$ & Unclear risk & No protocol available \\
\hline
\end{tabular}

Gordon 2013

\begin{tabular}{ll}
\hline Methods & RCT \\
\hline Participants & Jamaica \\
& 128 participants: 64 RTT, 64 control \\
& Participants were recruited from 3 hospitals. Date of recruitment not reported
\end{tabular}


Gordon 2013 (Continued)

Inclusion criteria: 40 years of age or older, community dwelling, 6 to 24 months after stroke, able to walk with or without assistive devices, not currently in a rehabilitation or regular exercise programme, not having any disorder that would compromise exercise training, such as unstable cardiovascular diseases, no cognitive deficits

Exclusion criteria: none stated

Mean age: RTT 63.4 years (SD 9.4), control 64.9 years (SD 11.1)

$45.3 \%$ male

Stroke details: ischaemic $71.1 \%$ (91), haemorrhagic $11.7 \%$ (15)

Time since stroke: RTT 12.8 months (SD 3.6), control 11.8 months (SD 3.6)

Pre-intervention functional ability level: use of walking aid at recruitment: RTT $26.6 \%(n=17)$, control $32.8 \%(n=21)$

RTT intervention: participants were supervised by trained instructors to walk briskly along a prescribed
course for 15 minutes, 3 times per week, for 12 weeks initially, progressing by 5 minutes per week up to
30 minutes in their home or community = 9 to 18 hours
Comparison group: light massage to the affected limbs for 25 minutes, 3 times per week for 12 weeks at
home

Outcomes were recorded at baseline, 6 weeks and 12 weeks (post treatment)
Lower limb functional outcome measures: 6 Minute Walk Test
Impairment outcome measures: Motricity Index
QoL/health status outcome measures: Physical and Mental Component Summary scores of the Medical
Outcomes Survey 36-Item Short-Form Health Survey (SF-36)
ADL outcome measures: Barthel Index, instrumental ADL dimension of the Older Americans Resources
and Services Questionnaire

Notes No significant differences between groups at baseline

2 intervention-related withdrawals (programme too difficult $(n=1)$ and participant not happy with group assignment $(\mathrm{n}=1))$

No major adverse events during or immediately after the sessions

\section{Risk of bias}

Bias Authors' judgement Support for judgement

Random sequence genera- Unclear risk Block randomisation used but not clear how the sequence was generated tion (selection bias)

\begin{tabular}{lll}
\hline $\begin{array}{l}\text { Allocation concealment } \\
\text { (selection bias) }\end{array}$ & Unclear risk & Not reported \\
\hline $\begin{array}{l}\text { Blinding of outcome as- } \\
\text { sessment (detection bias) } \\
\text { All outcomes }\end{array}$ & Low risk & Assessment by a physical therapist blinded to group assignment \\
\hline $\begin{array}{l}\text { Incomplete outcome data } \\
\text { (attrition bias) }\end{array}$ & Unclear risk & $\begin{array}{l}\text { Similar number of dropouts from intervention and control groups (7 and } 5 \text { re- } \\
\text { spectively) }\end{array}$ \\
& & $\begin{array}{l}\text { Time of dropout not reported } \\
\end{array}$
\end{tabular}


Gordon 2013 (Continued)

Reasons per group not reported

Selective reporting (re- $\quad$ Unclear risk $\quad$ No study protocol
porting bias)

Holmgren 2010

\begin{tabular}{ll}
\hline Methods & Single-blind RCT \\
\hline Participants
\end{tabular}

34 participants: 15 RTT, 19 control

Participants were recruited from Umeå Stroke Unit. There were 3-monthly recruitment periods between February 2005 and June 2007

Inclusion criteria: first-ever or recurrent ischaemic or haemorrhagic stroke 3 to 6 months before enrolment and randomisation, age $\geq 55$, the ability to walk 10 metres with or without a walking device, the ability to understand and comply with instructions in Swedish, risk of fall at the time of enrolment according to subjective clinical observations in the assessment situation performed by the experienced physiotherapists in the study

Exclusion criteria: the ability to walk outdoors independently, i.e. without personal assistance or walking device, severe aphasia or severe vision or hearing impairment, a medical condition that a physician determined was inconsistent with study participation, e.g. cancer or severe congestive heart failure with expected short remaining life expectancy, recurrent stroke within 3 months before study start, living more than $100 \mathrm{~km}$ away from the training facilities

Mean age: RTT 77.7 years (SD 7.6), control 79.2 years (SD 7.5)

$62 \%$ male

Stroke details: first or recurrent stroke, $97 \%$ ischaemic, $3 \%$ haemorrhagic

Time since stroke: RTT 139.7 days (SD 37.3), control 126.8 days (SD 28.2)

Pre-intervention functional activity level: Barthel Index: RTT 44.3 (Cl 40.0 to 48.7), control 44.2 ( $\mathrm{Cl} 39.3$ to 49.2 )

Interventions

RTT intervention: the intervention was based on the HIFE (High Intensity Functional Exercise) program, to improve the participants lower-limb strength, balance and gait ability

The program includes lower-limb strength (e.g. chair stand) and balance exercises (e.g. weight shifting outside support surface), standing (e.g. knee bend) and walking (e.g. obstacle crossing course)

A home visit was conducted by a physiotherapist and an occupational therapist to determine each participant's ability to perform ADLs and lifestyle activities and to experience the participants daily difficulties in their own environment

Sessions were 45 minutes, 6 times per week (twice daily) for 5 weeks $=22.5$ hours

Comparison group: participants met once per week for a 1 hour of educational session during the 5week period

The session was led by an occupational therapist, group discussions were about communication difficulties, fatigue, depressive symptoms, mood swings, personality changes and dysphagia, all more or less hidden dysfunctions after stroke and how to cope with these difficulties

There was no special focus on the risks of falling in these discussions 
Holmgren 2010 (Continued)

Balance/sit-to-stand outcome measures: Berg Balance Scale, Falls Efficacy Scale, number of falls

ADL outcome measures: Barthel Index, Frenchay Activities Index

\begin{tabular}{ll}
\hline Notes & No significant differences between groups at baseline \\
11 participants in total fell during study $(32 \%), \operatorname{RTT}(n=5)$, control $(n=6)$ \\
\hline
\end{tabular}

\section{Risk of bias}

\begin{tabular}{lll}
\hline Bias & Authors' judgement & Support for judgement \\
\hline $\begin{array}{l}\text { Random sequence genera- } \\
\text { tion (selection bias) }\end{array}$ & Low risk & Minimisation software program \\
\hline $\begin{array}{l}\text { Allocation concealment } \\
\text { (selection bias) }\end{array}$ & Low risk & $\begin{array}{l}\text { The randomisation procedure was conducted by the 2 principal investigators } \\
\text { who were involved neither in the assessments, nor in the RTT or control group }\end{array}$ \\
& $\begin{array}{l}\text { Both investigators were blinded to allocation at the time of randomisation, } \\
\text { which was made possible by using code numbers for each participant }\end{array}$ \\
\hline $\begin{array}{l}\text { Blinding of outcome as- } \\
\text { sessment (detection bias) } \\
\text { All outcomes }\end{array}$ & Low risk & $\begin{array}{l}\text { All assessments were done by blinded staff, who were instructed that if they } \\
\text { had any reason to believe that they had revealed a participant's group they } \\
\text { should make an adverse event report. The staff in the intervention did not take } \\
\text { part in any of the assessments }\end{array}$ \\
\hline $\begin{array}{l}\text { Incomplete outcome data } \\
\text { (attrition bias) } \\
\text { All outcomes }\end{array}$ & Low risk & Small number of dropouts, reasons provided \\
\hline $\begin{array}{l}\text { Selective reporting (re- } \\
\text { porting bias) }\end{array}$ & Unclear risk & No study protocol \\
\hline
\end{tabular}

Howe 2005

\begin{tabular}{ll}
\hline Methods & Pilot RCT \\
\hline
\end{tabular}

Participants UK

35 participants: 18 RTT, 17 control

Participants recruited from admissions to an acute stroke unit between 2001 and 2002

Inclusion criteria: aged 18 and over, acute vascular stroke presenting with hemiplegia, medically stable, able to co-operate, previously independent in mobility + ADL

Exclusion criteria: any history of other neurological pathology, conditions or medication affecting balance, dementia, impaired consciousness levels, concomitant medical illness or musculoskeletal condition, serious perceptual problems

Mean age: RTT 71.5 years (SD 10.9), control 70.7 years (SD 7.6)

$51 \%$ male

Stroke details: first or recurrent stroke, $47 \%$ right hemiparesis

Time since stroke: RTT 26.5 days (SD 15.7), control 23.1 days (SD 17.5)

Pre-intervention functional ability level: RMI on admission: RTT 24.7 (SD 8.1), control 24.4 (SD 8.9) 
Howe 2005 (Continued)

Interventions
RTT intervention: usual care plus exercises aimed at improving lateral weight transference in sitting and standing; this included repetition of self-initiated goal-oriented activities in various postures

16 tasks in total, with 10 repetitions of each exercise

Sessions were delivered by trained physiotherapy assistants and were 30 minutes, 3 times per week for 4 weeks $=6$ hours

Comparison group: usual care, no details given

Outcomes were recorded at baseline, 4 weeks (post treatment) and 8 weeks
Balance/sit-to-stand outcome measures: sit-to-stand, stand-to-sit (time in seconds), lateral reach test
(time to return to quiet sitting)

\begin{tabular}{ll}
\hline Notes & No significant differences reported at baseline \\
$6 \%$ lost to follow-up at end of treatment phase \\
No intervention-related reasons for withdrawal \\
Attendance: participants completed 10.6 sessions on average
\end{tabular}

\section{Risk of bias}

\begin{tabular}{lll}
\hline Bias & Authors' judgement & Support for judgement \\
\hline $\begin{array}{l}\text { Random sequence genera- } \\
\text { tion (selection bias) }\end{array}$ & Low risk & Randomised permuted blocks \\
\hline $\begin{array}{l}\text { Allocation concealment } \\
\text { (selection bias) }\end{array}$ & Low risk & $\begin{array}{l}\text { The project manager held details of assignment and revealed these to the re- } \\
\text { cruiting physiotherapist via telephone only when the participant was due to be } \\
\text { allocated to a group }\end{array}$ \\
\hline $\begin{array}{l}\text { Blinding of outcome as- } \\
\text { sessment (detection bias) } \\
\text { All outcomes }\end{array}$ & Low risk & $\begin{array}{l}\text { The code was not broken until all participants had completed the study and all } \\
\text { analysis was complete }\end{array}$ \\
\hline $\begin{array}{l}\text { Incomplete outcome data } \\
\text { (attrition bias) }\end{array}$ & Low risk & $\begin{array}{l}\text { Outcome assessors blind to treatment group } \\
\text { All outcomes }\end{array}$ \\
\hline $\begin{array}{l}\text { Selective reporting (re- } \\
\text { porting bias) }\end{array}$ & Unclear risk & $\begin{array}{l}\text { Small number of dropouts balanced across groups with similar reasons for } \\
\text { dropout }\end{array}$ \\
\hline
\end{tabular}

Kim 2012

\begin{tabular}{ll}
\hline Methods & RCT \\
\hline Participants & Korea \\
& 20 participants: 10 RTT, 10 control \\
& Inpatient recruitment, date of recruitment not reported \\
& Inclusion criteria: ability to walk 10 metres independently using an aid or orthotic with or without su- \\
pervision or aid and a minimum score of 20 in the Korean Mini-Mental State Examination
\end{tabular}


Kim 2012 (Continued)

Exclusion criteria: joint contraction, pain or fracture of the musculoskeletal system, hemianopsia

Mean age: RTT 52.50 years (SD 11.72), control 53.40 years (SD 12.11)

$\%$ male: not reported

Stroke details: not reported

Time since stroke: RTT 7.70 years (SD 6.11), control 13.10 years (SD 10.62)

Pre-intervention functional activity level: Timed Up and Go Test: RTT 29.84 seconds (SD 13.32), control 39.10 seconds (SD 14.97)

Interventions

RTT intervention: the training consists of 10 walking-related tasks designed to strengthen the lower extremities, and enhance the walking balance, speed and distance in a progressive manner

The 10 tasks were: step-ups; balance beam; kicking a ball; stand up and walk; obstacle course; treadmill; walk and carry; speed walk; walk backwards; and stairs. Before commencing training, the participants warmed up for 5 minutes to improve their range of motion and flexibility. Each item was practiced for 5 minutes, and 1 minute of rest time was allowed between each item

Sessions were in addition to conservative physical therapy and were 1 hour, 3 times per week for 4 weeks $=12$ hours

Comparison group: conservative physical therapy for 1 hour per day, 5 days per week for 4 weeks

Conservative physical therapy consisted of joint mobilisation, muscle strengthening, and balance training

\begin{tabular}{ll}
\hline Outcomes & Outcomes were recorded at baseline and 4 weeks (post treatment) \\
& Lower limb functional outcome measures: 10 Metre Walk Speed, \\
& Balance/sit-to-stand outcome measures: Trunk Impairment Scale, Berg Balance Scale, Timed Up \& Go \\
Test
\end{tabular}

\section{Risk of bias}

\begin{tabular}{lll}
\hline Bias & Authors' judgement & Support for judgement \\
\hline $\begin{array}{l}\text { Random sequence genera- } \\
\text { tion (selection bias) }\end{array}$ & Unclear risk & Patients 'randomly allocated' but no further information provided \\
\hline $\begin{array}{l}\text { Allocation concealment } \\
\text { (selection bias) }\end{array}$ & Unclear risk & Not reported \\
\hline $\begin{array}{l}\text { Blinding of outcome as- } \\
\text { sessment (detection bias) } \\
\text { All outcomes }\end{array}$ & Unclear risk & Not reported \\
\hline $\begin{array}{l}\text { Incomplete outcome data } \\
\text { (attrition bias) } \\
\text { All outcomes }\end{array}$ & Low risk & No dropouts \\
\hline $\begin{array}{l}\text { Selective reporting (re- } \\
\text { porting bias) }\end{array}$ & Unclear risk & No study protocol \\
\hline
\end{tabular}


Kim 2014

\begin{tabular}{ll}
\hline Methods & RCT \\
\hline Participants & Republic of Korea \\
& 26 participants: $13 \mathrm{RTT} ; 13$ control \\
& Participants were recruited from inpatients in a rehabilitation hospital. Date of recruitment not report- \\
& ed \\
& Inclusion criteria: hemiparesis from a single stroke occurring at least six months before; sufficient cog- \\
& nition to follow simple instructions and understand the purpose of the study (Korean version of the Mi- \\
& ni-Mental State Examination score of $\geq 24$ points); gait speed $<0.8$ m/s; ability to walk 10 metres inde- \\
pendently without an assistive device; absence of a musculoskeletal condition that could potentially & affect the ability to walk safely; and absence of hemispatial neglect \\
& Exclusion criteria: participation in other studies or rehabilitation programs; or severe heart disease or \\
& uncontrolled hypertension and pain \\
& Mean age: 50.45 years \\
& $50 \%$ male \\
& Stroke details: $59 \%$ right hemiparesis (no baseline data reported for 4 participants who dropped out) \\
& Time since stroke: 231.64 days \\
& Pre-intervention functional ability: 10 metre Walk Test (m/s) RTT mean $0.51 \pm 0.16$, control mean $0.48 \pm$ \\
& 0.18
\end{tabular}

Interventions

RTT intervention: a Community Walking Training Programme comprising various community environments, including walking near the hospital setting, walking outside of the hospital setting on uneven ground, walking outside of the hospital setting on uneven ground with obstacles, and visiting a shopping centre

Comparison group: All participants took part in the same standard rehabilitation programme consisting of conventional physical and occupational therapy. Conventional physical therapy, including increased trunk stability, lower-extremity muscle strength, and gait, was performed for 30 minutes per day, 5 times a week, for 4 weeks. Occupational therapy, consisting of an upper-extremity training program for ADL, was performed for 30 minutes per day, 5 times a week, for 4 weeks

\begin{tabular}{|c|c|c|}
\hline \multirow[t]{3}{*}{ Outcomes } & \multicolumn{2}{|c|}{ Outcomes were recorded at baseline and 4 weeks (post treatment) } \\
\hline & \multicolumn{2}{|c|}{$\begin{array}{l}\text { Lower limb functional outcome measures: } 10 \text { Metre Walk Test, } 6 \text { Minute Walk Test and Community Walk } \\
\text { Assessment }\end{array}$} \\
\hline & \multicolumn{2}{|c|}{ QoL: Stroke Impact Scale social participation domain } \\
\hline Notes & \multicolumn{2}{|c|}{ No apparent baseline imbalance } \\
\hline \multicolumn{3}{|l|}{ Risk of bias } \\
\hline Bias & Authors' judgement & Support for judgement \\
\hline $\begin{array}{l}\text { Random sequence genera- } \\
\text { tion (selection bias) }\end{array}$ & Unclear risk & "patients were randomly assigned" \\
\hline $\begin{array}{l}\text { Allocation concealment } \\
\text { (selection bias) }\end{array}$ & High risk & $\begin{array}{l}\text { "sealed envelopes were prepared in advance and marked on the inside with an } \\
\text { O or X." }\end{array}$ \\
\hline
\end{tabular}


Kim 2014 (Continued)

Blinding of outcome as- Low risk Blinded outcome assessment. sessment (detection bias)

All outcomes

\begin{tabular}{lll}
$\begin{array}{l}\text { Incomplete outcome data } \\
\text { (attrition bias) } \\
\text { All outcomes }\end{array}$ & Unclear risk & $\begin{array}{l}\text { "Two subjects each in the CWTP and control groups dropped out due to health } \\
\text { conditions, personal reasons, or discharge." Reasons not given by intervention } \\
\text { group }\end{array}$ \\
\hline $\begin{array}{l}\text { Selective reporting (re- } \\
\text { porting bias) }\end{array}$ & Unclear risk & No study protocol \\
\hline
\end{tabular}

Kim 2016

\begin{tabular}{ll}
\hline Methods & Randomised controlled single-blind study \\
\hline
\end{tabular}

Participants Korea

20 participants: 10 RTT; 10 control

Inpatient recruitment between August 2012 and October 2013

Inclusion criteria: a clinical diagnosis of a first stroke confirmed by neuroimaging (CT or MRI); a hemiparesis; a time interval between stroke and recruitment of 3 months or less; the ability to comprehend the instructions for the testing procedures; and mild to moderate walking deficit, as indicated by Functional Ambulation Category (FAC) between 3 and 4

Exclusion criteria: severe cognitive impairment (K-MMSE $\leq 10)$ or aphasia; previous stroke history; not independent 'sit-to-stand' activity (Berg Balance Scale score < 18); acute systemic illness or infection; a significant orthopaedic condition or pain that limited participation in exercise; and visual impairment or vestibular system deficit that caused balance impairment

Mean age: $65.6 \pm 9.2$ years

$65 \%$ male

Stroke details: first stroke; ischaemic $80 \%$ (16), haemorrhage $20 \%$ (4)

Time since stroke: RTT 30.1 days (SD 21.8), control 29.9 days (SD 20.3)

Pre-intervention functional activity level: 6 Minute Walk Test RTT 167.5 metres (SD 121.8), control 157.5 metres (SD 64.0)

Interventions

RTT intervention: participants participated in 90-minute circuit-training classes, 5 times per week for 4 weeks. Circuit training consisted of a 5-minute warm-up period, five classes of 15 minutes duration interspersed with a 1 minute rest and a 5-minute cool-down period. There were 5 categories of complex exercises including trunk exercise and active sitting practice, sit-to-stand practice, standing and walking practice, aerobic exercise training and strengthening training

Comparison group: participants in the control group received conventional individual physiotherapy for 30 minutes twice a day (total 60 minutes), 5 days a week for 4 weeks

Outcomes Outcomes were recorded at baseline and 4 weeks (post treatment)

Lower limb functional outcome measures: Fugl-Meyer lower limb score, Berg Balance Scale, 6 Minute Walk Test

ADL: Korean version of the Modified Barthel Index

Notes No apparent baseline imbalance


Kim 2016 (Continued)

Risk of bias

\begin{tabular}{|c|c|c|}
\hline Bias & Authors' judgement & Support for judgement \\
\hline $\begin{array}{l}\text { Random sequence genera- } \\
\text { tion (selection bias) }\end{array}$ & Unclear risk & "Participants were randomly allocated" \\
\hline $\begin{array}{l}\text { Allocation concealment } \\
\text { (selection bias) }\end{array}$ & Unclear risk & $\begin{array}{l}\text { A sealed envelope technique was used; unclear if envelopes were opaque and } \\
\text { sequentially numbered }\end{array}$ \\
\hline $\begin{array}{l}\text { Blinding of outcome as- } \\
\text { sessment (detection bias) } \\
\text { All outcomes }\end{array}$ & Low risk & Blinded outcome assessment \\
\hline $\begin{array}{l}\text { Incomplete outcome data } \\
\text { (attrition bias) } \\
\text { All outcomes }\end{array}$ & Low risk & All participants completed the study \\
\hline $\begin{array}{l}\text { Selective reporting (re- } \\
\text { porting bias) }\end{array}$ & Unclear risk & No protocol available \\
\hline
\end{tabular}

\section{Kwakkel 1999}

Methods Multicentre RCT

Participants The Netherlands

101 participants: 31 leg training group, 33 arm training group, 37 control

Participants recruited from 7 hospitals in the Netherlands between1994 and1997

Inclusion criteria: primary first-ever stroke in the territory of the middle cerebral artery, confirmed by $\mathrm{CT}$ or MRI, aged 30 to 80 years, impaired motor function of the arm and leg, inability to walk at first assessment

Exclusion criteria: complicating medical history or severe deficits in communication, memory or understanding

Mean age: leg training group 64.5 years (SD 9.7), arm training group 69 years (SD 9.8), control group 64.1 years (SD 15)

$43 \%$ male

Stroke details: first-ever stroke, $41 \%$ right hemiparesis

Timing post stroke: leg training group 7.0 days (SD 2.5), arm training group 7.2 days (SD 2.8), control group 7.5 days (SD 2.9)

Pre-intervention functional ability level: Barthel Index of 9 or lower

Interventions Leg training group: sitting, standing and weight-bearing exercise, with an emphasis on achieving stability and improving gait velocity

Treadmill training was used if available

If treatment at disability level was not possible, strengthening exercises were used

Arm training group: functional exercise to facilitate forced arm and hand activity such as leaning, punching a ball, grasping, reaching, dressing, hair-combing and moving objects 
Intervention was in addition to basic rehabilitation, which consisted of 15 minutes arm rehabilitation, 15 minutes leg rehabilitation and 1.5 hours per week of ADL training by an occupational therapist

Sessions were delivered individually by a physiotherapist and were 30 minutes, 5 days per week for 20 weeks $=50$ hours

Comparison group: immobilisation of the paretic arm and leg by means of an inflatable pressure splint

Kwakkel 1999a: arm training versus splint control

Kwakkel 1999b: leg training versus splint control

Outcomes Outcomes were recorded at baseline, and weekly between weeks 1 to 10, and every 2 weeks between week 11 to 26

Final measurements were at 26 weeks

Results are presented for baseline, weeks 6, 12, 20 and 26

Lower limb functional outcome measures: Functional Ambulation Classification, walking speed (comfortable and maximum)

Upper limb functional outcome measures: Action Research Arm test

ADL outcome measures: Barthel Index

QoL/health status outcome measures: Nottingham Health Profile

Notes

No significant differences reported at baseline

$12 \%$ lost to follow-up at end of treatment phase

No likely intervention-related reasons for withdrawal, although 2 participants refused the splint control treatment

Compliance with delivery of intended amounts of training was monitored, and achieved

\section{Risk of bias}

\begin{tabular}{lll}
\hline Bias & Authors' judgement & Support for judgement \\
\hline $\begin{array}{l}\text { Random sequence genera- } \\
\text { tion (selection bias) }\end{array}$ & Low risk & $\begin{array}{l}\text { Restricted randomisation (permuted blocks of nine) was applied, using ran- } \\
\text { dom number tables for each of 3 participating hospitals }\end{array}$ \\
\hline $\begin{array}{l}\text { Allocation concealment } \\
\text { (selection bias) }\end{array}$ & Unclear risk & Allocation was concealed by use of sealed envelopes \\
\hline $\begin{array}{l}\text { Blinding of outcome as- } \\
\text { sessment (detection bias) } \\
\text { All outcomes }\end{array}$ & High risk & $\begin{array}{l}\text { Assessors were blind to group allocation, Treatment assignment was uninten- } \\
\text { tionally disclosed for 10 participants (1 leg training, 4 arm training, } 5 \text { control } \\
\text { group) }\end{array}$ \\
\hline $\begin{array}{l}\text { Incomplete outcome data } \\
\text { (attrition bias) } \\
\text { All outcomes }\end{array}$ & Low risk & $\begin{array}{l}\text { Number of dropouts balanced across groups, reasons do not appear to be re- } \\
\text { lated to the intervention }\end{array}$ \\
\hline $\begin{array}{l}\text { Selective reporting (re- } \\
\text { porting bias) }\end{array}$ & Unclear risk & No study protocol \\
\hline
\end{tabular}


Kwakkel 1999a

Methods See Kwakkel 1999

\section{Participants}

Interventions

\section{Outcomes}

Notes

\section{Risk of bias}

\begin{tabular}{|c|c|c|}
\hline Bias & Authors' judgement & Support for judgement \\
\hline $\begin{array}{l}\text { Random sequence genera- } \\
\text { tion (selection bias) }\end{array}$ & Low risk & See Kwakkel 1999 \\
\hline $\begin{array}{l}\text { Allocation concealment } \\
\text { (selection bias) }\end{array}$ & Unclear risk & See Kwakkel 1999 \\
\hline $\begin{array}{l}\text { Blinding of outcome as- } \\
\text { sessment (detection bias) } \\
\text { All outcomes }\end{array}$ & High risk & See Kwakkel 1999 \\
\hline $\begin{array}{l}\text { Incomplete outcome data } \\
\text { (attrition bias) } \\
\text { All outcomes }\end{array}$ & Low risk & See Kwakkel 1999 \\
\hline $\begin{array}{l}\text { Selective reporting (re- } \\
\text { porting bias) }\end{array}$ & Unclear risk & See Kwakkel 1999 \\
\hline
\end{tabular}

\section{Kwakkel 1999b}

Methods See Kwakkel 1999

\section{Participants}

Interventions

\section{Outcomes}

\section{Notes}

\section{Risk of bias}

\begin{tabular}{lll}
\hline Bias & Authors' judgement & Support for judgement \\
\hline $\begin{array}{l}\text { Random sequence genera- } \\
\text { tion (selection bias) }\end{array}$ & Low risk & See Kwakkel 1999 \\
\hline $\begin{array}{l}\text { Allocation concealment } \\
\text { (selection bias) }\end{array}$ & Unclear risk & See Kwakkel 1999 \\
\hline $\begin{array}{l}\text { Blinding of outcome as- } \\
\text { sessment (detection bias) }\end{array}$ & High risk & See Kwakkel 1999 \\
\hline
\end{tabular}


Kwakkel 1999b (Continued)

All outcomes

Incomplete outcome data Low risk $\quad$ See Kwakkel 1999
(attrition bias)

All outcomes

\begin{tabular}{lll}
\hline $\begin{array}{l}\text { Selective reporting (re- } \\
\text { porting bias) }\end{array}$ & Unclear risk & See Kwakkel 1999 \\
\end{tabular}

\section{Langhammer 2000}

Methods Stratified, single-centre RCT

\section{Participants}

\section{Norway}

61 participants: 33 RTT, 28 control

Participants were recruited from a hospital in Norway between 1996 and1997

Inclusion criteria: first-ever stroke with hemiparesis verified clinically and by CT

Exclusion criteria: more than 1 stroke incident, subarachnoid bleeding, tumours of the brain, other severe medical conditions in combination with stroke, 5 or more points on each of the scores on the MAS

Mean age: 78 years (SD 9), range 49 to 75 years

$59 \%$ male

Stroke details: first stroke, $56 \%$ right hemiparesis

Time since stroke: baseline measures taken within 3 days of admission

Pre-intervention functional ability level: Barthel Index: RTT 56 (SD 28), control 46 (SD 36)

\section{Interventions}

RTT intervention: Motor Relearning Programme as per Carr 1987

Functional task training in ordinary settings, with ordinary tasks, using the principles of maximal repetition, task and setting variation

RTT intervention was instead of usual care

Sessions were delivered by hospital and outpatient physiotherapists and were 40 minutes minimum per session, 5 days per week for as long as hospitalised, and continuing into the community, although receipt of physiotherapy in community settings was variable

After discharge, some participants received therapy in their own homes, at rehabilitation centres, or private outpatient departments, dependent on need

Comparison group: Bobath Programme

\section{Outcomes}

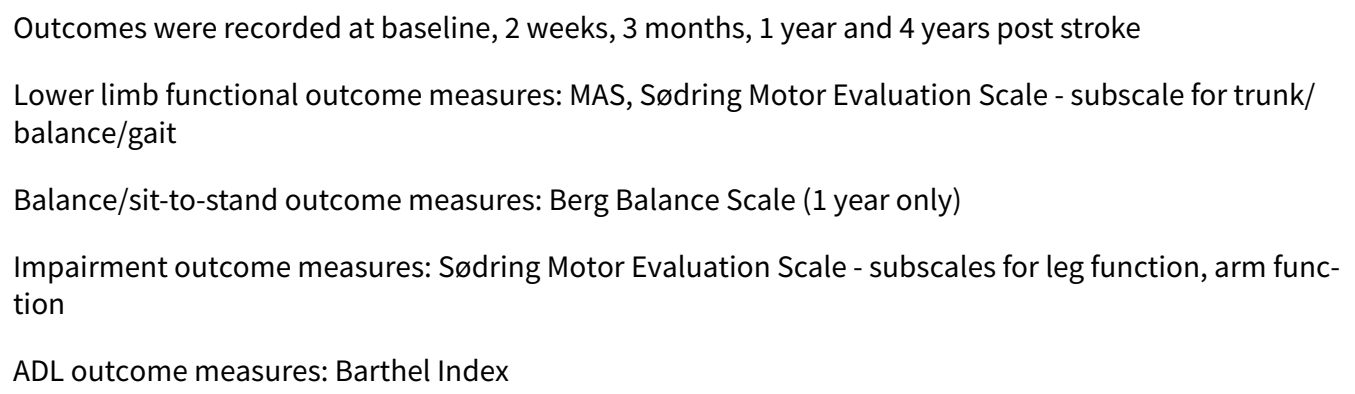

ADL outcome measures: Barthel Index 
Langhammer 2000 (Continued)

QoL/health status outcome measures: Nottingham Health Profile

Notes Baseline differences: control group slightly more dependent at entry, but no significant difference in MAS, Sødring Motor Evaluation Scale or Barthel Index

\section{Risk of bias}

\begin{tabular}{|c|c|c|}
\hline Bias & Authors' judgement & Support for judgement \\
\hline $\begin{array}{l}\text { Random sequence genera- } \\
\text { tion (selection bias) }\end{array}$ & Unclear risk & Inadequately reported \\
\hline $\begin{array}{l}\text { Allocation concealment } \\
\text { (selection bias) }\end{array}$ & Unclear risk & Not reported \\
\hline $\begin{array}{l}\text { Blinding of outcome as- } \\
\text { sessment (detection bias) } \\
\text { All outcomes }\end{array}$ & Low risk & $\begin{array}{l}\text { The study was double-blind, and the code was sealed until the last test was } \\
\text { performed at } 3 \text { months follow-up }\end{array}$ \\
\hline $\begin{array}{l}\text { Incomplete outcome data } \\
\text { (attrition bias) } \\
\text { All outcomes }\end{array}$ & Low risk & Number of dropouts balanced across groups and reasons provided \\
\hline $\begin{array}{l}\text { Selective reporting (re- } \\
\text { porting bias) }\end{array}$ & Unclear risk & No study protocol \\
\hline
\end{tabular}

Lennon 2009

\begin{tabular}{|c|c|}
\hline Methods & $\mathrm{RCT}$ \\
\hline \multirow[t]{10}{*}{ Participants } & Ireland \\
\hline & 61 participants, $31 \mathrm{RTT}, 30$ control \\
\hline & Participants were recruited from an inpatient stroke unit between October 2004 and July 2007 \\
\hline & Inclusion criteria: stroke admissions within 21 days post stroke \\
\hline & Exclusion criteria: none stated \\
\hline & Mean age: RTT 71.55 (SD 13.31), control 72.13 (SD 9.93) \\
\hline & $58.4 \%$ male \\
\hline & Stroke details: first or recurrent stroke, 55.7\% right hemisphere \\
\hline & Timing post stroke: RTT 10.81 days (SD 5.22), control 10.73 (SD 5.09) \\
\hline & $\begin{array}{l}\text { Pre-intervention functional ability level: Barthel Index: RTT } 10.10 \text { (SD 3.75), control 9.93 (SD 3.66); MAS: } \\
\text { RTT 18.32 (SD 11.59), control 19.97 (SD 10.98) }\end{array}$ \\
\hline \multirow[t]{2}{*}{ Interventions } & $\begin{array}{l}\text { RTT intervention: } 20 \text { minutes of conventional therapy based on Bobath principles and } 20 \text { minutes of } \\
\text { gait-specific training administered by a research therapist } 5 \text { times per week for } 4 \text { weeks }=6.6 \text { hours of } \\
\text { RTT }\end{array}$ \\
\hline & $\begin{array}{l}\text { Comparison group: } 40 \text { minutes of conventional therapy based on Bobath principles administered by } \\
\text { the stroke unit therapists }\end{array}$ \\
\hline Outcomes & Outcomes were recorded at baseline, 4 weeks (post treatment) and at 3 and 6 months \\
\hline
\end{tabular}


ADL outcome measures: Barthel Index

QoL/health status outcome measures: London Handicap Score

\begin{tabular}{|c|c|}
\hline \multirow[t]{3}{*}{ Notes } & $\begin{array}{l}\text { Baseline characteristics were similar in terms of age, gender, side of hemiplegia, time since stroke on- } \\
\text { set, stroke severity and walking speed }\end{array}$ \\
\hline & $\begin{array}{l}\text { There was insufficient contrast in treatment between the groups (i.e. therapists in the Bobath group } \\
\text { practiced early ambulation more frequently than therapists in the RTT group) }\end{array}$ \\
\hline & $\begin{array}{l}\text { Within the RTT group, there were three times the number of Total Anterior Circulation Infarct strokes } \\
\text { (a poor prognostic indicator for recovery of independent mobility), more participants with a previous } \\
\text { stroke and more participants requiring the assistance of } 2 \text { people to walk }\end{array}$ \\
\hline
\end{tabular}

\section{Risk of bias}

\begin{tabular}{lll}
\hline Bias & Authors' judgement & Support for judgement \\
\hline $\begin{array}{l}\text { Random sequence genera- } \\
\text { tion (selection bias) }\end{array}$ & Unclear risk & Inadequately reported \\
\hline $\begin{array}{l}\text { Allocation concealment } \\
\text { (selection bias) }\end{array}$ & Unclear risk & Stratified by age and walking ability, in blocks of 4 using sealed envelopes \\
\hline $\begin{array}{l}\text { Blinding of outcome as- } \\
\text { sessment (detection bias) } \\
\text { All outcomes }\end{array}$ & High risk & $\begin{array}{l}\text { 3 physiotherapists assisted with both intervention and outcome assessment } \\
\text { following resignation of 1 research associate }\end{array}$ \\
\hline $\begin{array}{l}\text { Incomplete outcome data } \\
\text { (attrition bias) } \\
\text { All outcomes }\end{array}$ & Low risk & No dropouts \\
\hline $\begin{array}{l}\text { Selective reporting (re- } \\
\text { porting bias) }\end{array}$ & High risk & Findings for the London Handicap Score (measured at 6 months) not reported \\
\hline
\end{tabular}

McClellan 2004

Methods RCT

Participants

Australia

26 participants: 15 RTT, 11 control

Participants were recruited on discharge from physiotherapy services in 6 hospitals in 1 region. Date of recruitment not reported

Inclusion criteria: stroke within the past 18 months, 45 years and older, living in the community, score > 0 and $<6$ on MAS, score $<6$ on Item 7 or 8 of the MAS

Exclusion criteria: unable to consent, uncontrolled cardiac symptoms or other medical conditions that limited exercise, or with a pacemaker

Mean age: RTT 69 years (SD 13), control 72 years (SD 9)

$50 \%$ male

Stroke details: unclear whether first or recurrent stroke, $50 \%$ right hemiparesis 
McClellan 2004 (Continued)

Timing post stroke: RTT median 6.5 months (IQR 5.5), control median 4.5 months (IQR 3)

Pre-intervention functional ability level: all participants could walk, but with difficulty

Interventions

RTT intervention: home-based exercise programme aimed at improving mobility in standing balance and walking, based on a list of 23 activities arranged hierarchically on their challenge to balance

The home programme used video self-modelling prepared on the baseline visit to the clinic to prescribe the exercise programme, telephone monitoring to encourage compliance, and 2 clinic visits for programme review

Sessions were prescribed 60 minutes per day over 6 weeks $=42$ hours

Participants were required to keep a record of practice

Comparison group: home-based exercise programme of same duration based on improving upper limb function, starting from basic movement through to functional activity, using the same self-instructional video, self- and telephone-monitoring and clinic visits as the experimental group

$\begin{array}{ll}\text { Outcomes } & \text { Outcomes were recorded at baseline, } 6 \text { weeks (post treatment) and } 14 \text { weeks } \\ \text { Lower limb functional outcome measures: MAS - walking } \\ \text { Balance/sit-to-stand outcome measures: Functional Reach Test } \\ \text { Notes } & \text { No baseline comparisons reported } \\ 19 \% \text { lost to follow-up by end of treatment phase } \\ \text { No likely intervention-related reasons for withdrawal } \\ \text { Participants reported } 75 \% \text { compliance with prescribed exercises }\end{array}$

\section{Risk of bias}

\section{Bias}

Random sequence genera- Unclear risk tion (selection bias)

Allocation concealment Unclear risk (selection bias)

\section{Authors' judgement Support for judgement}

Blinding of outcome as- $\quad$ Low risk $\quad$ Outcome measures were collected by a measurer blinded to group allocation
sessment (detection bias)
All outcomes

\begin{tabular}{lll}
\hline $\begin{array}{l}\text { Incomplete outcome data } \\
\text { (attrition bias) } \\
\text { All outcomes }\end{array}$ & Low risk & Number of dropouts balanced across groups and reasons provided \\
\hline $\begin{array}{l}\text { Selective reporting (re- } \\
\text { porting bias) }\end{array}$ & Unclear risk & No study protocol \\
\hline
\end{tabular}

\begin{tabular}{ll} 
Mudge 2009 & \\
\hline Methods & Single-blind RCT \\
\hline Participants & New Zealand
\end{tabular}


Mudge 2009 (Continued)

\section{8 participants: 31 RTT, 27 control}

Participants were recruited through the Stroke Foundation of New Zealand, stroke clubs and the local hospital stroke service between June 2007 and February 2008

Inclusion criteria: 1 or more strokes more than 6 months earlier, had been discharged from rehabilitation, and were able to walk independently (with an aid if necessary). Some residual gait difficulty was required, as defined by a score of less than 2 on at least 1 of the walking items of the physical functioning scale of the 36-Item Short Form Health Survey

Exclusion criteria: progressive neurologic disease, other significant health problems that adversely affected walking ability, more than 2 falls in the previous 6 months, unstable cardiac conditions, uncontrolled hypertension, or congestive heart failure

Mean age: RTT 69.8 (SD 13.12), control 69.61 (SD 12.81)

$55 \%$ male

Stroke details: first or recurrent stroke, 59\% right hemisphere

Timing post stroke: RTT 49.2 months (SD 40.9), control 69.1 months (SD 54.7)

Pre-intervention functional ability level: median score on the physical functioning index of the 36-item Short Form Health Survey: RTT 19, control 17

Interventions

RTT intervention: the circuit exercise groups contained up to 9 participants and were led by 1 of the investigators, assisted by 2 physiotherapy students. There were 15 stations in the circuit, which were graded to each participant's ability and progressed as tolerated. Each station contained either a taskoriented gait or standing balance activity, or strengthening of a lower extremity muscle in a way designed to improve gait (e.g. sit-to-stand, self-sway, standing balance, step-ups, balance beam, standing hamstring curl, tandem walk, Swiss ball squats, tandem stance, calf raise, backward walk, lunges, side leg lifts, marching in place, obstacle course). The total exercise time was 30 minutes, although sessions lasted between 50 to 60 minutes, including stretching, sessions were 3 times per week for 4 weeks $=6$ hours of RTT

Comparison group: participants in the control group attended eight 90-minute sessions over 4 weeks in groups of up to 8 . The control group was run by an occupational therapist and consisted of 4 social and 4 educational sessions. The duration of the control group sessions was designed to match the duration of the intervention sessions in order to control for possible effects of dosage

Outcomes Outcomes were recorded at baseline, 4 weeks (post treatment) and 3 months

Lower limb functional outcome measure: mean number of steps per day measured by the StepWatch Activity Monitor, 10 Metre Walk Speed, 6 Minute Walk Test, RMI, Physical Activity and Disability Scale

ADL outcome measures: Activities-Based Confidence Scale

Notes No apparent baseline imbalance

\section{Risk of bias}

\begin{tabular}{lll}
\hline Bias & Authors' judgement & Support for judgement \\
\hline $\begin{array}{l}\text { Random sequence genera- } \\
\text { tion (selection bias) }\end{array}$ & Low risk & $\begin{array}{l}\text { Computer-generated random numbers by an individual not associated with } \\
\text { the study }\end{array}$ \\
\hline $\begin{array}{l}\text { Allocation concealment } \\
\text { (selection bias) }\end{array}$ & Unclear risk & Inadequately reported \\
\hline $\begin{array}{l}\text { Blinding of outcome as- } \\
\text { sessment (detection bias) }\end{array}$ & High risk & $\begin{array}{l}\text { Unmasking of independent assessor occurred for 3 participants who stated or } \\
\text { implied their group allocation }\end{array}$
\end{tabular}


Mudge 2009 (Continued)

All outcomes

Incomplete outcome data Low risk Number of dropouts balanced across groups and reasons provided
(attrition bias)

(attrition bias)

All outcomes

Selective reporting (re- Unclear risk $\quad$ No study protocol
porting bias)

porting bias)

Olawale 2011

\begin{tabular}{ll}
\hline Methods & Prospective randomised controlled study \\
\hline Participants & Africa
\end{tabular}

40 participants: 20 RTT, 20 control

Participants were recruited from people referred for outpatient management at the physiotherapy department of a tertiary hospital. Date of recruitment not reported

Inclusion criteria: all participants were people whose stroke occurred not less than 3 months, and not more than 24 months, before entering the study. Participants were included if they were able to walk 10 metres independently with or without a walking aid

Exclusion criteria: none specifically reported but ability to walk $<10$ metres excluded

Mean age: RTT 56.8 years (SD 8.3), control 57.2 years (SD 5.9)

$55 \%$ male

Stroke details: $52.5 \%$ right hemisphere

Timing post stroke: RTT 10.7 months (SD 6.8), control 10.3 (SD 5.9)

Pre-intervention functional ability level: able to walk $\geq 10$ metres

RTT intervention: on each day of treatment/training, participants observed a pre-exercise rest period of 10 minutes during which heart rate and blood pressure measurements were made. The RTT group went through a 1-hour session of conventional physiotherapy including 25 minutes of overground walking exercise training. The overground walking exercise training involved walking over ground at a natural safe speed (i.e. walking at own pace in order to cover as much ground as possible within the training period) on a $15 \times 10$ metre walk course marked out on the flat floor of a remedial gymnasium. In each case, exercise would be terminated any time the participant reported symptoms of exertional intolerance, i.e. outside the target zone on Borg's rate of perceived exertion (RPE) scale. Participants took part in $3 \times 25$ minute sessions per week for a 12 -week period $=15$ hours

Comparison group: the conventional physiotherapy rehabilitation consisted of 1 hour of active and passive range of motion (ROM) exercises, strength training and balance training, as applicable

Outcomes Outcomes were recorded at baseline, 4 weeks, 8 weeks and 12 weeks (post treatment)

Lower limb functional outcome measures: 10 Metre Walk Speed, 6 Minute Walk Test

Equivalence of groups at baseline was not reported
5 participants were lost to follow-up

\section{Risk of bias}


Olawale 2011 (Continued)

\begin{tabular}{lll} 
Bias & Authors' judgement & Support for judgement \\
\hline $\begin{array}{l}\text { Random sequence genera- } \\
\text { tion (selection bias) }\end{array}$ & Unclear risk & Inadequately reported \\
\hline $\begin{array}{l}\text { Allocation concealment } \\
\text { (selection bias) }\end{array}$ & Unclear risk & Not reported \\
\hline $\begin{array}{l}\text { Blinding of outcome as- } \\
\text { sessment (detection bias) } \\
\text { All outcomes }\end{array}$ & Unclear risk & Not reported \\
\hline $\begin{array}{l}\text { Incomplete outcome data } \\
\text { (attrition bias) } \\
\text { All outcomes }\end{array}$ & Unclear risk & Withdrawals not explained \\
\hline $\begin{array}{l}\text { Selective reporting (re- } \\
\text { porting bias) }\end{array}$ & Unclear risk & No study protocol \\
\hline
\end{tabular}

Park 2011

\begin{tabular}{ll}
\hline Methods & Randomised, single-blind, controlled pilot study \\
\hline
\end{tabular}

Participants

\author{
Republic of Korea \\ 25 participants, 13 RTT, 12 control
}

Participants were recruited from people receiving inpatient management service in a rehabilitation hospital. Date of recruitment not reported

Inclusion criteria: the first stroke had occurred 6 months to five years before the study, a walking speed of $50.7 \mathrm{~m} / \mathrm{s}$, which indicates unsafe community ambulation, no auditory or visual deficits, no orthopaedic or cardiovascular conditions that may interfere with the study, no cognitive impairment (> 25 in Mini-Mental State Examination)

Exclusion criteria: none stated

Mean age: RTT 59.38 years (SD 8.46), control 56.92 years (SD 7.79)

$48 \%$ male

Stroke details: $60 \%$ ischaemic, $44 \%$ right hemiparesis

Timing post stroke: RTT 28.08 months (SD 12.59), control 28.67 months (SD 17.96)

Pre-intervention functional ability level: Walking Aids: no aid $(n=7)$, ankle foot orthosis $(n=0)$, cane ( $n$ $=13)$, quadruped cane $(n=4)$, ankle foot orthosis + quadruped cane $(n=1)$

Interventions

RTT intervention: participants from the experimental group underwent 1-hour sessions of community-based ambulation training in addition to functional training. The community-based ambulation training programme consisted of 4-phase walking training performed in various community situations, which were differently applied according to a weekly schedule. The difficulty level of the walking training was increased every week, with different environmental demands in each session. During the 4week training period, walking training was conducted at various locations (e.g.in the foyer of a hospital, a pavement, stairs, a ramp, a car park, a pedestrian crossing, and a shopping centre), with progressive changes in the environmental demands. These sessions were conducted $3 \times$ per week for a 4-week period $=12$ hours 
Park 2011 (Continued)

Comparison group: functional training based on the Bobath concept daily for an hour, according to the routine schedule of the rehabilitation unit. The functional training consisted of standing up from a sitting position, therapist-guided movement of the trunk and lower limb to simulate normal walking pattern, forward and backward stepping of affected and unaffected lower limb, and stair climbing

Outcomes Outcomes were recorded at baseline and 4 weeks (post treatment)

Lower limb functional outcome measures: 10 Metre Walk Speed, 6 Minute Walk Test, community walk test, walking ability questionnaire

Balance/sit-to-stand outcome measures: Activities-Specific Balance Confidence Scale

\begin{tabular}{|c|c|c|}
\hline Notes & \multicolumn{2}{|c|}{ No significant differences at baseline } \\
\hline \multicolumn{3}{|l|}{ Risk of bias } \\
\hline Bias & Authors' judgement & Support for judgement \\
\hline $\begin{array}{l}\text { Random sequence genera- } \\
\text { tion (selection bias) }\end{array}$ & Unclear risk & $\begin{array}{l}\text { The participants were randomly allocated to the experimental group or con- } \\
\text { trol group. Each participant was given an envelope containing } 2 \text { cards and was } \\
\text { instructed to blindly draw } 1 \text { card on each occasion }\end{array}$ \\
\hline $\begin{array}{l}\text { Allocation concealment } \\
\text { (selection bias) }\end{array}$ & High risk & Extent to which cards were drawn 'blindly' unclear \\
\hline $\begin{array}{l}\text { Blinding of outcome as- } \\
\text { sessment (detection bias) } \\
\text { All outcomes }\end{array}$ & Low risk & $\begin{array}{l}\text { The person undertaking the assessment and data analysis was unaware of the } \\
\text { group of each participant }\end{array}$ \\
\hline $\begin{array}{l}\text { Incomplete outcome data } \\
\text { (attrition bias) } \\
\text { All outcomes }\end{array}$ & Unclear risk & $\begin{array}{l}1 \text { withdrawal in each group } \\
\text { Number of participants included in outcome analysis not given }\end{array}$ \\
\hline $\begin{array}{l}\text { Selective reporting (re- } \\
\text { porting bias) }\end{array}$ & Unclear risk & No study protocol \\
\hline
\end{tabular}

Peurala 2009

\begin{tabular}{ll}
\hline Methods & RCT \\
\hline Participants & Finland
\end{tabular}

Finland

56 participants: 22 gait trainer group (not included in this review), 21 WALK group, 13 control group

Participants were recruited from inpatients in an acute care hospital between June 2003 and December 2004 and between January 2005 and February 2007

Inclusion criteria: (first supratentorial stroke or no significant disturbance from an earlier stroke (Modified Ranking Scale 0-2); Functional Ambulatory Category (FAC) 0-3; voluntary movement in the leg of the affected side; Barthel Index (BI) 25 to 75 points; age 18 to 85 years; no unstable cardiovascular disease; body mass index (BMI) <32; no severe malposition of joints; and no severe cognitive or communicative disorders

Exclusion criteria: none reported

Mean age (excluding dropouts): RTT 65.3 years (SD 9.9), control 69.5 years (SD 11.0)

$53 \%$ male 
Peurala 2009 (Continued)

Stroke details: ischaemic stroke 26 participants, haemorrhagic stroke 8 participants; left hemiparesis 20 participants, right hemiparesis 14 participants

Timing post stroke (excluding dropouts): RTT 7.8 days (SD 3.0), control 9.5 days (SD 1.9)

Pre-intervention functional activity level: participants in Functional Ambulation Category 0 (not able to walk or needed two assistants to help) RTT 15/21, control 9/13

\begin{abstract}
Interventions
RTT intervention (WALK group): participants practiced walking over ground with 1 or 2 physiotherapists, using their individual walking aids. Training was progressed by increasing the speed and decreasing the amount of manual guidance and reliance on walking aids

Each participant spent a maximum of 1 hour a day to obtain 20 minutes actual walking time. Each participant also received additional gait-oriented physiotherapy for 55 minutes a day

Comparison group: participants were transferred to a health centre after the first set of measurements and visited the hospital on testing days. While in the health centre, the participants normally had 1 or 2 physiotherapy sessions daily, but not at the same intensity as in the WALK group. The content of physiotherapy was determined according to individually set goals
\end{abstract}

Lower limb functional outcome measures: Functional Ambulation Category (primary outcome), $10 \mathrm{Me}-$ tre Walk Test, 6 Minute Walk Test, Modified MAS, RMA Scale and RMI

Notes

Participants were recruited in 2 phases, June 2003 to December 2004 and January 2005 to February 2007. In the first phase, there was not control group. Control group outcome data for the 10 Metre Walk Test and 6 Minute Walk Test not reported. No apparent baseline imbalance

\title{
Risk of bias
}

\begin{tabular}{lll}
\hline Bias & Authors' judgement & Support for judgement \\
\hline $\begin{array}{l}\text { Random sequence genera- } \\
\text { tion (selection bias) }\end{array}$ & Unclear risk & "patients were randomly allocated" \\
\hline $\begin{array}{l}\text { Allocation concealment } \\
\text { (selection bias) }\end{array}$ & Unclear risk & $\begin{array}{l}\text { "envelopes indicating the groups were sealed separately for patients with FAC } \\
\text { [Functional Ambulatory Category] } 0 \text { or } 1 \text { and with FAC } 2 \text { or 3." }\end{array}$ \\
\hline
\end{tabular}

Blinding of outcome as- Unclear risk Participants and outcome assessors do not appear to have been blinded sessment (detection bias) All outcomes

$\begin{array}{ll}\begin{array}{l}\text { Incomplete outcome data } \\ \text { (attrition bias) }\end{array} & \text { Low risk } \\ \text { Proportion of dropouts similar between WALK group (1/21) and control group } \\ (3 / 13)\end{array}$

All outcomes

Selective reporting (re- High risk porting bias)

No study protocol. No data presented for the control group for the 10 Metre Walk Test and the 6 Minute Walk Test at baseline and post intervention

\section{Ross 2009}

\begin{tabular}{ll}
\hline Methods & RCT \\
\hline Participants & Australia \\
& 35 participants, 17 RTT, 18 control
\end{tabular}


Ross 2009 (Continued)

Participants were recruited from a rehabilitation hospital (inpatients and outpatients). Date of recruitment not reported

Inclusion criteria: acquired brain injury within the past five years, over 18 years of age and notable hand impairment (i.e. a score of less than $80 \%$ on the Action Research Arm Test).

Exclusion criteria: co-existing injury or disease affecting hand function; unable to complete six weeks of training (i.e. for geographical, medical or psycho-social reasons). Patients with cognitive or physical problems precluding cooperation with the programme were also excluded.

Mean age: RTT 62.2 years (SD 18.2), control 60.8 years (SD 16.7)

$48.6 \%$ male

Stroke details: $85.7 \%$ ischaemic, $48.72 \%$ right sided hemiplegia

Timing post stroke: RTT median 2.3 months (IQR 0.7 - 4.4), control median 0.7 months (IQR 0.3 - 3.0).

Pre-intervention functional ability level: Scandinavian Stroke Scale: RTT 36.2 (SD 11.7), control 39.8 (SD 8.7)

RTT intervention: all hand training was based on the principles of task-specific motor training and included repetitive practice of tasks which were individualised to the functional goals of each participant. Training was closely supervised on a 1-to-1 basis by 1 of a small number of experienced therapists The amount of actual practice performed in each session was carefully monitored, for this purpose a stopwatch was used to record the time spent performing hand activities. The aim was to achieve at least 45 minutes of repetitious practice in each session. Sessions were 1-hour with a therapist $5 \times$ per week for six weeks $=30$ hours

Comparison group: both groups continued to receive usual arm care which consisted of half an hour of motor training for the shoulder and elbow 5 x per week. A cup or splint was strapped to participants' hands to standardise inadvertent hand training

Usual care for both groups also consisted of strategies such as slings, wheelchair arm troughs and positioning programmes. In addition, participants in the control group had similar hand therapy as participants in the experimental group but for only 10 minutes, $3 \times$ per week

Outcomes Outcomes were recorded at baseline and 6 weeks (post treatment)

Upper limb functional outcome measures: Disability of Shoulder Arm and Hand Assessment, Action Research Arm Test, Summed Manual Muscle Test, Wolf Motor Function Test, long finger flexor extensibility

ADL outcome measures: Canadian Occupational Performance Measure

Notes No significant differences at baseline

\section{Risk of bias}

Bias Authors' judgement Support for judgement

Random sequence genera- Low risk Computer-generated allocation schedule

tion (selection bias)

\begin{tabular}{|c|c|c|}
\hline $\begin{array}{l}\text { Allocation concealment } \\
\text { (selection bias) }\end{array}$ & Low risk & $\begin{array}{l}\text { Concealed opaque consecutively numbered envelopes by a person not other- } \\
\text { wise involved in the study. The allocation schedule and envelopes were kept } \\
\text { off-site }\end{array}$ \\
\hline
\end{tabular}

\begin{tabular}{lll}
\hline $\begin{array}{l}\text { Blinding of outcome as- } \\
\text { sessment (detection bias) }\end{array}$ & Low risk & $\begin{array}{l}\text { Participants were instructed not to discuss their intervention or group alloca- } \\
\text { tion with assessors. The success of blinding was verified by asking assessors }\end{array}$ \\
All outcomes & each time a participant completed the trial whether they had been unblinded.
\end{tabular}


Assessors were then asked for their best guess at which group each participant had been allocated to

\begin{tabular}{l}
\hline Incomplete outcome data Low risk 2 dropouts in the control group unrelated to the intervention \\
(attrition bias) \\
All outcomes
\end{tabular}

Selective reporting (re- Unclear risk $\quad$ No study protocol
porting bias)

Salbach 2004

\begin{tabular}{ll}
\hline Methods & Stratified, multicentre RCT \\
\hline Participants & Canada \\
& 91 participants: 44 mobility group, 47 arm training group \\
& Participants were recruited from 9 hospitals and 2 rehabilitation centres in Montreal or Quebec City be- \\
& tween May 2000 and February 2003 \\
& Inclusion criteria: first or recurrent stroke, under 1 year post stroke at recruitment, able walk 10 metres \\
but with residual walking deficit from most recent stroke, mental competency and ability to compre- & hend instructions, discharged from physical rehabilitation, resident in the community \\
& Exclusion criteria: resident in permanent care facility, co-morbidity precluding participation \\
& Mean age: mobility group 71 years (SD 12), arm training group 73 years (SD 8) \\
& 61.5\% male \\
& Stroke details: first or recurrent stroke, 83\% ischaemic, 56\% right hemiparesis \\
& Timing post stroke: mean 228 days (SD 78) \\
& Pre-intervention functional ability level: 6 Minute Walk Test: mobility group 209 metres (SD 126), arm \\
training group 204 metres (SD 131)
\end{tabular}

Mobility group: 10 walking-related tasks designed to strengthen the lower extremities and enhance walking balance, speed and distance in a progressive manner

Arm training group: functional tasks such as manipulating cards, using a keyboard and writing while seated

Intervention was after discharge from physical rehabilitation

Sessions were 60 minutes, $3 \times$ per week for 6 weeks $=18$ hours

Sessions were delivered individually by a physical or occupational therapist in a hospital outpatient or rehabilitation setting

Comparison group: Salbach 2004a: upper extremity training; Salbach 2004b: lower extremity training

Outcomes Outcomes were recorded at baseline, and at 6 weeks (post treatment)

Limb-specific functional outcome measures: 6 Minute Walk Test, 5 metre walk at comfortable and maximum speed

Balance/sit-to-stand outcome measures: Timed Up and Go Test, Berg Balance Scale, Activities Specific Balance Confidence Scale 
Salbach 2004 (Continued)

ADL outcome measures: Barthel Index

No comparison of groups at baseline

Participants stratified into 3 groups based on comfortable walking speed

$86 \%$ of participants attended 17 or more mobility sessions out of $18,72 \%$ attended 17 or more arm training sessions.

344 people were evaluated for participation but $73 \%$ refused because they could not tolerate the travel required for attendance

\section{Risk of bias}

\begin{tabular}{lll}
\hline Bias & Authors' judgement & Support for judgement \\
\hline $\begin{array}{l}\text { Random sequence genera- } \\
\text { tion (selection bias) }\end{array}$ & Low risk & Computer-generated \\
\hline $\begin{array}{l}\text { Allocation concealment } \\
\text { (selection bias) }\end{array}$ & Unclear risk & $\begin{array}{l}\text { Allocation maintained in sealed, opaque envelopes, prepared prior to recruit- } \\
\text { ment by persons not involved in the study }\end{array}$ \\
\hline $\begin{array}{l}\text { Blinding of outcome as- } \\
\text { sessment (detection bias) } \\
\text { All outcomes }\end{array}$ & High risk & $\begin{array}{l}\text { Assessors were blind to group allocation. Unblinding occurred for } 18 / 42 \text { in the } \\
\text { mobility group and } 16 / 43 \text { of the upper extremity training group, but did not } \\
\text { bias the estimated effect as evaluated by multiple linear regression model }\end{array}$ \\
\hline $\begin{array}{l}\text { Incomplete outcome data } \\
\text { (attrition bias) } \\
\text { All outcomes }\end{array}$ & Low risk & Number of dropouts balanced across groups and reasons provided \\
\hline $\begin{array}{l}\text { Selective reporting (re- } \\
\text { porting bias) }\end{array}$ & Unclear risk & No study protocol \\
\hline
\end{tabular}

Salbach 2004a

\begin{tabular}{ll}
\hline Methods & See Salbach 2004 \\
\hline Participants & \\
\hline Interventions & \\
\hline Outcomes &
\end{tabular}

\section{Risk of bias}

\begin{tabular}{lll}
\hline Bias & Authors' judgement & Support for judgement \\
\hline $\begin{array}{l}\text { Random sequence genera- } \\
\text { tion (selection bias) }\end{array}$ & Low risk & See Salbach 2004 \\
\hline $\begin{array}{l}\text { Allocation concealment } \\
\text { (selection bias) }\end{array}$ & Unclear risk & See Salbach 2004 \\
\hline $\begin{array}{l}\text { Blinding of outcome as- } \\
\text { sessment (detection bias) }\end{array}$ & High risk & See Salbach 2004 \\
\hline
\end{tabular}


Salbach 2004a (Continued)

All outcomes

Incomplete outcome data Low risk $\quad$ See Salbach 2004
(attrition bias)

All outcomes

Selective reporting (re- Unclear risk $\quad$ See Salbach 2004
porting bias)

\section{Salbach 2004b}

Methods See Salbach 2004

\section{Participants}

Interventions

\section{Outcomes}

\section{Notes}

\section{Risk of bias}

\begin{tabular}{lll}
\hline Bias & Authors' judgement & Support for judgement \\
\hline $\begin{array}{l}\text { Random sequence genera- } \\
\text { tion (selection bias) }\end{array}$ & Low risk & See Salbach 2004 \\
\hline $\begin{array}{l}\text { Allocation concealment } \\
\text { (selection bias) }\end{array}$ & Unclear risk & See Salbach 2004 \\
\hline $\begin{array}{l}\text { Blinding of outcome as- } \\
\text { sessment (detection bias) } \\
\text { All outcomes }\end{array}$ & High risk & See Salbach 2004 \\
\hline $\begin{array}{l}\text { Incomplete outcome data } \\
\begin{array}{l}\text { (attrition bias) } \\
\text { All outcomes }\end{array}\end{array}$ & Low risk & See Salbach 2004 \\
\hline $\begin{array}{l}\text { Selective reporting (re- } \\
\text { porting bias) }\end{array}$ & Unclear risk & See Salbach 2004 \\
\hline
\end{tabular}

Song 2015

\begin{tabular}{|c|c|}
\hline Methods & $\mathrm{RCT}$ \\
\hline \multirow[t]{4}{*}{ Participants } & Korea \\
\hline & $\begin{array}{l}20 \text { participants: } 10 \text { RTT, } 10 \text { control (additional individual-based task-oriented circuit training arm not in- } \\
\text { cluded in the review) }\end{array}$ \\
\hline & Inpatient recruitment, date of recruitment not reported \\
\hline & Inclusion criteria: people with hemiplegia who were diagnosed with stroke \\
\hline
\end{tabular}


Song 2015 (Continued)

Exclusion criteria: not reported

Mean age: RTT 62.78 years (SD 9.97), control 59.28 years (SD 5.23)

$\%$ male: not reported

Stroke details: not reported

Time since stroke: RTT 36.67 months (SD 15.12), control 27.66 (SD 19.35)

Pre-intervention functional activity level: 2 Minute Walk Test RTT 76.6 (SD 33.1), control 57.6 (SD 20.5)

Interventions

RTT intervention: task-oriented circuit training. Training tasks were sitting in a chair, walking, walking over obstacles, carrying goods, turning the goods upside down and walking fast in a circle in addition to conventional therapy. Intervention performed for 30 minutes a day, $3 \times$ per week for 4 weeks

Comparison group: conventional therapy for 30 minutes a day, 5 x per week for 4 weeks

Outcomes were recorded at baseline and 4 weeks (post treatment)

Lower limb functional outcome measure: 2 Minute Walk Test

Notes Inadequate specification of inclusion criteria

\section{Risk of bias}

\begin{tabular}{lll}
\hline Bias & Authors' judgement & Support for judgement \\
\hline $\begin{array}{l}\text { Random sequence genera- } \\
\text { tion (selection bias) }\end{array}$ & Unclear risk & "Subjects were randomly allocated" \\
\hline $\begin{array}{l}\text { Allocation concealment } \\
\text { (selection bias) }\end{array}$ & Unclear risk & Method of concealment not reported \\
\hline $\begin{array}{l}\text { Blinding of outcome as- } \\
\text { sessment (detection bias) } \\
\text { All outcomes }\end{array}$ & Unclear risk & No mention of blinding \\
\hline $\begin{array}{l}\text { Incomplete outcome data } \\
\text { (attrition bias) } \\
\text { All outcomes }\end{array}$ & Unclear risk & Number of participants not reported in data tables \\
\hline $\begin{array}{l}\text { Selective reporting (re- } \\
\text { porting bias) }\end{array}$ & Unclear risk & No protocol available \\
\hline
\end{tabular}

Tung 2010

\begin{tabular}{ll}
\hline Methods & Single-blind RCT \\
\hline Participants & Taiwan \\
& 32 participants, 16 RTT, 16 control \\
& Participants were recruited from a rehabilitation medical centre. Date of recruitment not reported \\
& Inclusion criteria: first CVA with unilateral motor deficits, Berg Balance Scale score less than 50, abili- \\
ty to perform the sit-to-stand task independently, stable medical condition to allow participation in as- \\
sessment and intervention, ability to understand instructions and follow commands
\end{tabular}


Tung 2010 (Continued)

Exclusion criteria: any medical condition that would prevent participation in the study, deep sensory deficits or hemi-neglect

Mean age: RTT 51.0 years (SD 12.1), control 52.7 years (SD 14.1)

$62.5 \%$ male

Stroke details: $68.8 \%$ right hemiparesis

Timing post stroke: RTT 26.9 months (SD 16.0), control 12.8 months (SD 12.3)

Pre-intervention functional ability level: static balance weight distribution (\%) affected side: RTT 44.8 (SD 9.7), control 47.5 (SD 8.8)

Interventions

RTT intervention: participants received sit-to-stand training programme for 15 minutes each time in addition to a general physical therapy programme, $3 \times$ per week for 4 weeks $=3$ hours

Comparison group: general physical therapy programme (30 minutes) including balance training, gait training, strengthening exercise for lower extremities, and ADL training

\begin{tabular}{|c|c|c|}
\hline Outcomes & \multirow{2}{*}{\multicolumn{2}{|c|}{$\begin{array}{l}\text { Outcomes were recorded at baseline and } 4 \text { weeks (post treatment) } \\
\text { Balance/sit-to-stand outcome measures: Balance Master System, the limit of stability testing, duration } \\
\text { of sit-to-stand, Berg Balance Scale }\end{array}$}} \\
\hline & & \\
\hline Notes & \multicolumn{2}{|c|}{$\begin{array}{l}\text { There was no significant difference in the baseline data between the experimental and control groups } \\
\text { except the post stroke duration (RTT } 29.9 \text { months (SD 16), control } 12.8 \text { months (SD 12.3)) }\end{array}$} \\
\hline \multicolumn{3}{|l|}{ Risk of bias } \\
\hline Bias & Authors' judgement & Support for judgement \\
\hline $\begin{array}{l}\text { Random sequence genera- } \\
\text { tion (selection bias) }\end{array}$ & Unclear risk & Block randomisation used but not clear how the sequence was generated \\
\hline $\begin{array}{l}\text { Allocation concealment } \\
\text { (selection bias) }\end{array}$ & Unclear risk & Not clear if sealed envelopes were sequentially numbered \\
\hline $\begin{array}{l}\text { Blinding of outcome as- } \\
\text { sessment (detection bias) } \\
\text { All outcomes }\end{array}$ & Low risk & $\begin{array}{l}\text { All participants were evaluated by another physical therapist who was blind to } \\
\text { the assignment }\end{array}$ \\
\hline $\begin{array}{l}\text { Incomplete outcome data } \\
\text { (attrition bias) } \\
\text { All outcomes }\end{array}$ & Unclear risk & $\begin{array}{l}\text { No details provided on the number of participants included in outcome analy- } \\
\text { sis }\end{array}$ \\
\hline $\begin{array}{l}\text { Selective reporting (re- } \\
\text { porting bias) }\end{array}$ & Unclear risk & No study protocol \\
\hline
\end{tabular}

Turton 1990

\begin{tabular}{ll}
\hline Methods & Single-centre, quasi-randomised trial \\
\hline Participants & UK \\
& 22 participants: 12 RTT, 10 control \\
& Participants were recruited from stroke patients discharged from inpatient care at one hospital be- \\
tween 1986 and 1987
\end{tabular}


Turton 1990 (Continued)

Inclusion criteria: some impairment of function of the affected upper limb (i.e. less than $95 \%$ performance on a peg transfer task), able to understand instructions, lives within 25 miles of hospital

Exclusion criteria: none stated

Age: RTT 59 years (SD 11.97), control 58 years (SD 6.86)

$55 \%$ male

Stroke details: unclear whether first or recurrent stroke, $56 \%$ right hemiparesis

Time since stroke: RTT 24 weeks (SD 25.8), control 16 weeks (SD 6.1)

Pre-intervention disability level: $12.5 / 20$ on Southern MAS

Interventions

RTT intervention: usual outpatient care plus home-based exercise programme for the upper limb, based on motor relearning principles. Exercises included movement and task-related reach, grasp and grip

Participants were visited by an occupational therapist at home, and given exercises and repetitions

Participants were visited every 2 to 4 weeks for review

Carers were involved if able and willing

Participants were assigned 2 to 3 practice sessions per day (approximately 1 hour in total), 7 days per week for 8 to 11 weeks $=63$ hours approximately

Sessions were self-managed by the participant and their carer at home, with 2 to 3 home visits by an occupational therapist for programme review

Comparison group: usual outpatient care (some had therapy, but others did not)

$\begin{array}{ll}\text { Outcomes } & \text { Outcomes were recorded at baseline and at } 8 \text { to } 11 \text { weeks (post treatment) } \\ & \text { Upper limb functional outcome measures: sitting part of the upper limb activity assessment - Southern } \\ & \text { Motor Group Assessment, } 10 \text { Hole Peg Test }\end{array}$

\section{Risk of bias}

\section{Bias Authors' judgement Support for judgement}

\begin{tabular}{lll}
\hline Random sequence genera- & High risk & Assigned to home-therapy group or a control group in alternate runs of 5 \\
tion (selection bias)
\end{tabular}
tion (selection bias)

\begin{tabular}{lll}
\hline $\begin{array}{l}\text { Allocation concealment } \\
\text { (selection bias) }\end{array}$ & High risk & As above \\
\hline $\begin{array}{l}\text { Blinding of outcome as- } \\
\text { sessment (detection bias) } \\
\text { All outcomes }\end{array}$ & High risk & Outcome assessor not blinded to treatment group \\
\hline
\end{tabular}

Incomplete outcome data Low risk No loss to follow-up at end of treatment phase
(attrition bias)


Turton 1990 (Continued)

All outcomes

Selective reporting (re-

Unclear risk

No study protocol

porting bias)

van de Port 2012

\begin{tabular}{ll}
\hline Methods & Multicentre RCT \\
\hline Participants & Netherlands \\
& 250 participants: 126 RTT, 124 control \\
& Participants were recruited from 9 rehabilitation centres between June 2008 and December 2010 \\
Inclusion criteria: eligible people had to have had a verified stroke according to the WHO definition, be \\
able to walk a minimum of 10 metres without physical assistance (Functional Ambulation Categories $\geq$ \\
3), be discharged home from a rehabilitation centre, need to continue physiotherapy during outpatient \\
care to improve walking competency or physical condition, or both and be able to give informed con- \\
sent and be motivated to participate in a 12 week intensive programme of physiotherapy
\end{tabular}

Exclusion criteria: cognitive deficits as evaluated by the Mini Mental State Examination ( $<24$ points), were unable to communicate ( $<4$ points on the Utrechts Communicatie Onderzoek, UCO) or lived more than $30 \mathrm{~km}$ from the rehabilitation centre

Mean age: RTT 56 years (SD 10), control 58 years (SD 10)

$64.8 \%$ male

Stroke details: $81.2 \%(n=103)$ ischaemic, $47.2 \%(n=118)$ right hemisphere

Time since stroke: RTT 91 days (SD 42), control 103 days (SD 51)

Pre-intervention functional ability level: Six Minute Walk Test: RTT 339 metres (SD 120), control 306 metres (SD 135)

Interventions

RTT intervention: the training included 8 different workstations, intended to improve meaningful tasks relating to walking competency such as balance control, stair walking, turning, transfers and speed walking. At each workstation, participants worked together in pairs, while 1 participant performed the task for 3 minutes, the other observed their performance. Each participant's performance (such as counts) was recorded in a training log, which was used as a feedback and motivational tool during the next sessions. Motivational music was played in the background during the entire training session. The total FIT-Stroke programme included four stages: warming up (5 minutes), circuit training (60 minutes), evaluation and a short break (10 minutes), and group game (15 minutes). Sessions lasted 90 minutes, twice per week for 12 weeks $=36$ hours

Comparison group: same duration of usual outpatient physiotherapy, mainly one-to-one treatments tailored to the patient with a physiotherapist who had not been on the circuit training course at one of the participating rehabilitation centres

Sessions designed to improve control of standing balance, physical condition, and walking competency were provided according to Dutch physiotherapy guidelines

Outcomes

Outcomes were recorded at baseline, 12 weeks (post treatment), and 24 weeks after completion of training. Lower limb functional outcome measures: Six Minute Walk Test, functional ambulation, modified stairs test, comfortable walk test, RMI, Stroke Impact Scale 3.0 mobility domain

Balance/sit-to-stand outcome measures: Timed Up and Go Test, Timed balance test

Impairment outcome measures: Motricity Index 
van de Port 2012 (Continued)

ADL outcome measures: Nottingham Extended ADL

QoL/health status outcome measures: Stroke Impact Scale (other domains), Hospital Anxiety and Depression Scale

Notes

Significant baseline differences in favour of the circuit training group for a few secondary outcomes, all analyses were adjusted for these covariates at baseline. 29 falls were reported in the circuit training group and 26 in the usual physiotherapy group $(P=0.93) .2$ serious adverse events were reported in the circuit training group: 1 participant fell and consulted a GP and 1 experienced arrhythmias during 1 session

\section{Risk of bias}

\begin{tabular}{lll}
\hline Bias & Authors' judgement & Support for judgement \\
\hline $\begin{array}{l}\text { Random sequence genera- } \\
\text { tion (selection bias) }\end{array}$ & Low risk & Online minimisation procedure \\
\hline $\begin{array}{l}\text { Allocation concealment } \\
\text { (selection bias) }\end{array}$ & Unclear risk & Method of concealment not described \\
\hline $\begin{array}{l}\text { Blinding of outcome as- } \\
\text { sessment (detection bias) } \\
\text { All outcomes }\end{array}$ & Low risk & $\begin{array}{l}\text { Trained research assistants who were blinded to treatment allocation, mea- } \\
\text { sured all outcomes }\end{array}$ \\
\hline $\begin{array}{l}\text { Incomplete outcome data } \\
\text { (attrition bias) } \\
\text { All outcomes }\end{array}$ & Low risk & $\begin{array}{l}\text { Reasons for withdrawals provided. An intention-to-treat analysis was used } \\
\text { with the last observation carried forward for the missing data }\end{array}$ \\
\hline $\begin{array}{l}\text { Selective reporting (re- } \\
\text { porting bias) }\end{array}$ & High risk & EuroQoL not reported \\
\hline
\end{tabular}

Van Vliet 2005

Methods Single-centre RCT

Participants

UK

120 participants: 60 RTT, 60 control

Participants were recruited from admissions to a stroke rehabilitation ward over a period of 21 months. Date of recruitment not reported

Inclusion criteria: diagnosis of stroke, referral to physiotherapy

Exclusion criteria: more than 2 weeks post stroke, unconscious on admission, unable to toilet independently prior to stroke, living more than $25 \mathrm{~km}$ from hospital, unable to tolerate more than 30 minutes of physical tasks required in initial assessment

Mean age: RTT 75 years (SD 9.1), control 73.3 (SD 10.4)

$50 \%$ male

Stroke details: unclear whether first or recurrent stroke included, $51 \%$ right hemiparesis

Time since stroke: within 14 days

Pre-intervention functional ability level: RMA - gross function subscale: RTT median 2 (IQR 1 to 6), control median 1 (IQR 1 to 4$)$ 
Van Vliet 2005 (Continued)

Interventions
RTT intervention: movement science-based therapy based on the principle that skill in performance is a direct function of the amount of practice. Programme involved use of everyday objects for functional training, and practice outside of delivered sessions. Intervention was instead of usual care. Participants received a median 23 minutes treatment by a physiotherapist per week day (IQR 13 to 32 minutes). Median total number of minutes of treatment was 365 (IQR 140 to 1160), equating to approximately 6 hours total training time. Treatment was delivered by physiotherapists, occupational therapists and physiotherapy assistants, in hospital, and as an outpatient after discharge. Treatment was delivered for as long as needed

Comparison group: Bobath-based therapy

Outcomes were recorded at baseline, 4 weeks, 3 months and 6 months
Lower limb functional outcome measures: RMA, MAS, Six Metre Walk Test
Upper limb functional outcome measures: 10 Hole Peg Test
ADL outcome measures: Barthel Index, Extended ADL

Notes

Control group had higher median scores for Rivermead gross function, and leg and trunk subscales, and for supine to side lying, supine to sitting, balanced sitting, and sit-to-stand sections of the MAS; the experimental group had higher median scores for the upper arm section of the MAS. $29 \%$ loss to follow-up at 3 months

\section{Risk of bias}

\begin{tabular}{lll}
\hline Bias & Authors' judgement & Support for judgement \\
\hline $\begin{array}{l}\text { Random sequence genera- } \\
\text { tion (selection bias) }\end{array}$ & Low risk & Computer-generated random sequence provided by an independent person \\
\hline $\begin{array}{l}\text { Allocation concealment } \\
\text { (selection bias) }\end{array}$ & Unclear risk & Allocations were provided in envelopes and opened after initial assessment \\
\hline $\begin{array}{l}\text { Blinding of outcome as- } \\
\text { sessment (detection bias) } \\
\text { All outcomes }\end{array}$ & Low risk & $\begin{array}{l}\text { The assessor was blind to group allocation. To ensure masking, assessments } \\
\text { of inpatients occurred in a room separate from the ward and patients were } \\
\text { brought to the assessor there whenever possible. Patients were asked not to } \\
\text { mention their treatment or therapist to the assessor. For later examination of } \\
\text { the success of masking, the assessor recorded a guess of the patient's group } \\
\text { allocation at each assessment, there was poor agreement }\end{array}$ \\
\hline $\begin{array}{l}\text { Incomplete outcome data } \\
\begin{array}{l}\text { (attrition bias) } \\
\text { All outcomes }\end{array}\end{array}$ & Unclear risk & $\begin{array}{l}\text { Number of dropouts balanced across groups, unclear if reasons provided are } \\
\text { related to the intervention }\end{array}$ \\
\hline $\begin{array}{l}\text { Selective reporting (re- } \\
\text { porting bias) }\end{array}$ & High risk & \begin{tabular}{l} 
Modified Ashworth Scale and Nottingham Sensory Assessment not reported \\
\hline
\end{tabular}
\end{tabular}

Winstein 2004

\begin{tabular}{ll}
\hline Methods & Stratified, single-centre pilot RCT \\
\hline Participants & USA \\
& 43 participants: RTT 22, control 21 \\
& $\begin{array}{l}\text { Participants were recruited from new admissions to a neurorehabilitation services centre. Date of re- } \\
\text { cruitment not reported }\end{array}$ \\
\hline
\end{tabular}


Winstein 2004 (Continued)

Inclusion criteria: aged 29 to 76, first time stroke confirmed by CT or MRI, initially from infarction in the anterior circulation, but widened early in the recruitment phase to include haemorrhagic or pontine stroke, onset of stroke from 2 to 35 days before study entry, FIM score of 40 to 80, widened to include a broader range early in recruitment phase

Exclusion criteria: peripheral nerve or orthopaedic conditions that interfered with arm movements, cardiac disease that limited function, subarachnoid haemorrhage within evidence of infarction, progressive hydrocephalus, previous history of brain injury, severe aphasia, neglect, agitation or depression that could limit participation

Age: RTT<35 years $(n=2), 35$ to 75 years $(n=18)$, control $<35$ years $(n=0), 35$ to 75 years $(n=19),>75$ years $(n=1)$

\section{$52.5 \%$ male}

Stroke details: first stroke, $85 \%$ ischaemic stroke, $62 \%$ right hemiparesis

Time since stroke: RTT 15.5 days (SD 6), control 15.4 days (SD 5.5)

Pre-intervention disability level: $65 \%$ Orpington Score 1.6 to 4.1

Interventions

RTT intervention: usual care plus task-specific functional training based on the principles of motor relearning, focusing on systematic and repetitive practice of tasks. Tasks were randomly ordered, and progressed in difficulty

Sessions were 1 hour per day, 5 days per week, for 4 weeks $=20$ hours additional to usual care

Sessions were delivered by a physical therapist in hospital, and in an outpatient setting when discharged

Comparison group: usual care - delivered primarily by occupational therapists, which could include muscle facilitation exercises emphasising the neurodevelopmental treatment approach, neuromuscular electrical stimulation, stretching exercises, and $\mathrm{ADL}$

Outcomes

Outcomes were recorded at baseline, 4 to 6 weeks (post treatment) and 9 months after stroke

Upper limb functional outcome measures: Functional Test of the Hemiparetic Upper Extremity, Fugl Meyer Assessment

ADL outcome measures: Functional Independence Measure

Notes significant differences reported at baseline
$7 \%$ loss to follow-up at end of treatment phase
Intervention-related reasons for withdrawal: 1 participant in the experimental group lost interest
Compliance reported as near perfect, except for 1 participant in the experimental group who, after dis-
charge, and because of travel distance, completed only 15 of the 20 hours training

\section{Risk of bias}

\begin{tabular}{lll}
\hline Bias & Authors' judgement & Support for judgement \\
\hline $\begin{array}{l}\text { Random sequence genera- } \\
\text { tion (selection bias) }\end{array}$ & Unclear risk & Procedure for generating random numbers not described, except for blocking \\
\hline $\begin{array}{l}\text { Allocation concealment } \\
\text { (selection bias) }\end{array}$ & Unclear risk & $\begin{array}{l}\text { Sealed envelopes delivered by independent person, and opened on enrolment } \\
\text { on next eligible participant }\end{array}$ \\
\hline
\end{tabular}

Blinding of outcome as-

High risk

Outcome assessor not blinded to group allocation

sessment (detection bias)

All outcomes 
Winstein 2004 (Continued)

Incomplete outcome data Low risk Missing data balanced in numbers across groups with similar reasons (attrition bias)

All outcomes

Selective reporting (re- Unclear risk No study protocol

porting bias)

\section{Winstein 2016}

\begin{tabular}{ll}
\hline Methods & RCT \\
\hline Participants & USA
\end{tabular}

Participants

361 participants: 119 structured, task-oriented upper extremity training (Accelerated Skill Acquisition Programme), 120 dose-equivalent occupational therapy (DEUCC), 122 monitoring-only occupational therapy (UCC)

Participants were recruited from 7 sites, predominantly during inpatient rehabilitation, between June 2009 and March 2014

Inclusion criteria: ischaemic or haemorrhagic stroke (subdural and epidural effusions permitted) within the previous 106 days, hemiparesis (weakness) in arm or hand, some active finger extension movement by close of enrolment window, age 21+, able to communicate in English, willing to attend outpatient therapy and all study evaluations

Exclusion criteria:

- Neurologic symptoms or conditions: traumatic or non-vascular brain injury, subarachnoid haemorrhage, AV malformation, acute subdural or epidural haematoma; neurologic condition that may affect motor response (e.g. Parkinson's, ALS, MS); presence of ataxia per NIHSS and evidence of cerebellar or brainstem lesion; absent upper extremity sensation per NIHSS; neglect asymmetry $>3$ per Mesulam Unstructured; a second stroke within the last 72 hours cannot be ruled out before the brief medical exam (BME)

- Physical attributes affecting movement or function: total UE Fugl-Meyer score $<19$ or $>58$, or $=0$ for finger mass extension/grasp release hand score; upper extremity pain that substantially interferes with ADLs; maximum assistance required for mobility

- Passive ROM limitation of the hemiparetic upper extremity that prevents functional use of limb/hand, including any of the following: shoulder: flexion $<90^{\circ}$, abduction $<90^{\circ}$, external rotation $<45^{\circ}$; elbow/forearm: extension $<-20^{\circ}$, supination or pronation $<45^{\circ}$ from neutral; wrist/finger: flexion or extension $<0^{\circ}$, MCP or IP extension $<30^{\circ}$

- Pre-morbid status: head trauma requiring $>48$ hours of hospitalisation within past 12 months; psychiatric illness requiring hospitalisation within past 24 months; arm or hand injury limiting use prior to stroke; amputation of all fingers or thumb of affected hand; pre-morbid motor impairment of the contralateral upper extremity of neurologic origin; Barthel Index $<95$

- Medication, drugs and/or alcohol: active or recent drug treatment for dementia; treated with Botox in affected arm within last 3 months; toxicology screen positive for illegal substances or reported use within the past 3 years; reported alcohol use per CAGE or treatment for withdrawal since index stroke

- Cognition and Participation: enrolment in a conflicting study; expected inability to participate in study due to illness, social, or geographic reasons; unable to follow a 2-step command per NIHSS; 2 on the Mini-Cog with an abnormal Clock Draw Test (CDT) or score = 0; PHQ-9 total score between 10 and 19 without management plan or score > 19; judged medically unstable and/or unable to participate by primary physician or SPI

- Other: received $>6$ hours of outpatient occupational therapy (OT) since stroke (Home Health and OT Evaluation do not count toward 6 hour maximum); clinician's best judgment (multiple factors in combination): the SPI and CSC concur that the PP is NOT a candidate for randomisation; 14-106 days post stroke

Mean age: ASAP 60.9 years (SD 13.7), DEUCC 59.9 years (SD 10.5), UCC 61.1 years (SD 13.1) 
Winstein 2016 (Continued)

\title{
$56.2 \%$ male
}

Stroke details: ischaemic stroke $83.3 \%$, right hemiparesis $46.5 \%$

Time since stroke: total 45.8 days (SD 22.4), ASAP 45.2 days (SD 20.3), DEUCC 45.0 days (SD 22.8), UCC 47.0 days (SD 23.9)

Pre-intervention functional ability level: baseline upper extremity Fugl-Meyer motor score: total 41.6 (SD 9.4), ASAP 41.7 (9.5), DEUCC 41.5 (SD 9.2), UCC 41.6 (SD 9.5)

\begin{abstract}
Interventions
RTT intervention: Accelerated Skill Acquisition Program (ASAP) emphasising purposeful and skilled movement execution, choices of specific tasks to be practiced, collaborative problem solving to identify and address movement needs and encouragement of self-direction in extending practice to community contexts

Sessions were 1 hour, 3 times per week for 10 weeks $=30$ hours

Dose-equivalent usual and customary care group (DEUCC) and monitoring-only usual and customary care (UCC) received outpatient occupational therapy based on usual and customary practice. The DEUCC group received 30 hours of therapy; the UCC group did not have a specified dose
\end{abstract}

\begin{tabular}{ll}
\hline Outcomes & $\begin{array}{l}\text { Outcomes measured at baseline, post intervention (10 weeks) and at } 6 \text { and } 12 \text { months } \\
\text { Upper limb functional outcomes: log-transformed Wolf Motor Function Test (primary outcome); } 12- \\
\text { month change in Wolf Motor Function Test time score; Stroke Impact Scale hand sub-scale score }\end{array}$ \\
\hline Notes & No apparent baseline imbalance
\end{tabular}

\section{Risk of bias}

\begin{tabular}{lll}
\hline Bias & Authors' judgement & Support for judgement \\
\hline $\begin{array}{l}\text { Random sequence genera- } \\
\text { tion (selection bias) }\end{array}$ & Low risk & $\begin{array}{l}\text { A stratified block randomisation scheme within sites balanced assignment by } \\
\text { motor severity and time from stroke onset }\end{array}$ \\
\hline $\begin{array}{l}\text { Allocation concealment } \\
\text { (selection bias) }\end{array}$ & Low risk & $\begin{array}{l}\text { "Once a participant provided informed consent and the baseline assessment } \\
\text { was completed, the study site requested randomization; the data manager } \\
\text { confirmed eligibility and the site team leader was notified of the assignment." }\end{array}$ \\
\hline $\begin{array}{l}\text { Blinding of outcome as- } \\
\text { sessment (detection bias) } \\
\text { All outcomes }\end{array}$ & High risk & $\begin{array}{l}\text { Outcome assessors blinded; not possible to blind participants. Assessor was } \\
\text { unblinded to allocation of } 7 \text { participants }\end{array}$ \\
\hline $\begin{array}{l}\text { Incomplete outcome data } \\
\text { (attrition bias) } \\
\text { All outcomes }\end{array}$ & Low risk & $\begin{array}{l}\text { Data for all participants analysed using intention to treat. Withdrawals: ASAP: } \\
13 / 119, \text { DEUCC 11/120, UCC 22/122 }\end{array}$ \\
\hline $\begin{array}{l}\text { Selective reporting (re- } \\
\text { porting bias) }\end{array}$ & High risk & $\begin{array}{l}\text { Many more outcomes listed in the protocol than reported, e.g. Upper Extremi- } \\
\text { ty Fugl-Meyer }\end{array}$ \\
\hline
\end{tabular}

Yen 2005

\begin{tabular}{ll}
\hline Methods & Single centre RCT \\
\hline Participants & Taiwan \\
& 30 participants: 13 RTT, 17 control
\end{tabular}


Yen 2005 (Continued)

Participants were recruited from a neurology department. Date of recruitment not reported

Inclusion criteria: single stroke resulting in hemiparesis, minimum of 20 degrees of active wrist extension and 10 degrees of active finger extension, aged between 18 to 80 years, no severe aphasia or cognitive impairment

Exclusion criteria: other diseases that would confound the study such as Parkinson's disease, shoulder subluxation, recurrent stroke during the training period

Mean age: RTT 67.85 years (SD 11.2), control 69.53 years (SD 9.23)

$46 \%$ male

Stroke details: first stroke, $60 \%$ right hemiparesis

Time since stroke: RTT 8.4 months (SD 8), control 6.2 months (SD 7.9)

Pre-intervention functional ability level: baseline mean 3.28 seconds per item on the Wolf Motor Function Test

Interventions

RTT intervention: practice of 15 to 20 tasks selected from a battery of 50 tasks, with task shaping (consisting of verbal feedback for small improvements), task selection (based on needs of individual), and performance assistance in the initial stages if unable to perform independently. Intervention was instead of usual care. Sessions were 6 hours per day; it is unclear whether there were 5 or 7 sessions per week. Treatment duration was 2 weeks $=60$ to 84 hours. Sessions were delivered by a physical therapist; it is unclear whether sessions were group based or individual

Comparison group: regular program of physical therapy including gait training, facilitation, balance training, or occupational therapy; it is unclear how much time the control group spent in therapy

Outcomes were recorded at baseline and 2 weeks (post treatment)
Upper limb functional outcome measures: mean time taken to complete individual items on the Wolf
Motor Function Test
Results for items 8 to 15 are only presented for participants able to complete them within 2 minutes

Notes

Exclusion criteria potentially applied during training. No baseline differences reported

\section{Risk of bias}

\begin{tabular}{|c|c|c|}
\hline Bias & Authors' judgement & Support for judgement \\
\hline $\begin{array}{l}\text { Random sequence genera- } \\
\text { tion (selection bias) }\end{array}$ & Unclear risk & Inadequately reported \\
\hline $\begin{array}{l}\text { Allocation concealment } \\
\text { (selection bias) }\end{array}$ & Unclear risk & Not reported \\
\hline $\begin{array}{l}\text { Blinding of outcome as- } \\
\text { sessment (detection bias) } \\
\text { All outcomes }\end{array}$ & Low risk & Assessor blinded \\
\hline $\begin{array}{l}\text { Incomplete outcome data } \\
\text { (attrition bias) } \\
\text { All outcomes }\end{array}$ & Low risk & No loss to follow-up \\
\hline $\begin{array}{l}\text { Selective reporting (re- } \\
\text { porting bias) }\end{array}$ & Unclear risk & No study protocol \\
\hline
\end{tabular}


ADL: activities of daily living

$\mathrm{CT}$ : computed tomography

CVA: cardiovascular accident

IQR: interquartile range

MAS: Motor Assessment Scale

MRI: magnetic resonance imaging

NIHSS: National Institutes of Health Stroke Scale

RCT: randomised controlled trial

RMA: Rivermead Motor Assessment

RMI: Rivermead Mobility Index

RTT: repetitive task training

SD: standard deviation

QoL: quality of life

Characteristics of excluded studies [ordered by study ID]

\begin{tabular}{|c|c|}
\hline Study & Reason for exclusion \\
\hline Allison 2005 & Not repetitive task training \\
\hline Almhdawi 2014 & Compared against another RTT-type intervention \\
\hline Askim 2010 & Alternative mechanism of action \\
\hline Banta 2013 & Alternative mechanism of action \\
\hline Conroy 2011 & Not repetitive task training \\
\hline English 2016 & Alternative mechanism of action \\
\hline Harijan 2013 & Compared against another RTT-type intervention \\
\hline Hillier 2010 & Compared against another RTT-type intervention \\
\hline Hubbard 2015 & Compared against another RTT-type intervention \\
\hline Li 2008 & Alternative mechanism of action \\
\hline Logan 2014 & Not RTT \\
\hline Lord 2008 & Compared against another RTT-type intervention \\
\hline Malagoni 2016 & Compared against another RTT-type intervention \\
\hline McCombe Waller 2014 & Alternative mechanism of action \\
\hline Onigbinde 2009 & Alternative mechanism of action \\
\hline Pang 2013 & Compared against another RTT-type intervention \\
\hline Rao 2013 & Not RTT \\
\hline Saeys 2012 & Alternative mechanism of action \\
\hline Sherrington 2008 & Not specific to stroke patients \\
\hline Shimodozono 2013 & Alternative mechanism of action \\
\hline
\end{tabular}




\begin{tabular}{ll}
\hline Study & Reason for exclusion \\
\hline Tang 2009 & Alternative mechanism of action \\
\hline Taub 2013 & Compared against another RTT-type intervention \\
\hline Verheyden 2009 & Not RTT \\
\hline Vloothuis 2013 & Alternative mechanism of action \\
\hline Wang 2011 & Compared against another RTT-type intervention \\
\hline
\end{tabular}

$\mathrm{RTT}$ : repetitive task training

Characteristics of studies awaiting assessment [ordered by study ID]

\section{Baglary 2013}

\begin{tabular}{ll}
\hline Methods & Pre-test, post test experimental study design \\
\hline Participants & Undergoing hospital rehabilitation \\
\hline Interventions & Backward walking training in gait performance for people with stroke \\
\hline Outcomes & Gait measures \\
\hline Notes & MSc Dissertation not published \\
\hline
\end{tabular}

Bhaskar 2009

\begin{tabular}{ll}
\hline Methods & RCT \\
\hline Participants & Stroke \\
\hline Interventions & Conventional physiotherapy and hand functional activities \\
\hline Outcomes & Hand function \\
\hline
\end{tabular}

Notes

\section{Brkic 2016}

\begin{tabular}{ll}
\hline Methods & RCT \\
\hline Participants & Recruited within 14 days of stroke \\
\hline Interventions & Repetitive functional task practice upper limb \\
\hline Outcomes & Arm function \\
\hline Notes & Trial completed, in follow-up phase \\
\hline
\end{tabular}


ChiCTR-ICR-15005992

\begin{tabular}{ll}
\hline Methods & RCT \\
\hline Participants & Acute ischaemic stroke \\
\hline Interventions & Early and intensive rehabilitation \\
\hline Outcomes & Motor function
\end{tabular}

\section{Notes}

\section{Eng 2009}

\begin{tabular}{ll}
\hline Methods & RCT \\
\hline Participants & Undergoing hospital rehabilitation \\
\hline Interventions & Leg exercise programme \\
\hline Outcomes & Gait speed, balance, physical activity \\
\hline Notes & Trial completed, publication under review \\
\hline
\end{tabular}

Ferrari 2015

\begin{tabular}{ll}
\hline Methods & RCT \\
\hline Participants & People with post stroke Pusher Syndrome \\
\hline Interventions & Specific rehabilitation treatment \\
\hline Outcomes & Sitting and standing balance
\end{tabular}

Notes

Gandhi 2015

\begin{tabular}{ll} 
Methods & RCT \\
\hline Participants & Within 7 days of admission (<1- month post stroke) \\
\hline Interventions & Repetition of task-specific activities (ATTEND Trial) \\
\hline Outcomes & Patient-centred goals, quality of life \\
\hline
\end{tabular}

\section{Notes}


Indurkar 2013

\begin{tabular}{ll}
\hline Methods & RCT \\
\hline Participants & Within 1 year of a first or recurrent stroke and with residual walking deficit \\
\hline Interventions & Task-orientated intervention comprising of 5 tasks \\
\hline Outcomes & Balance, speed and distance \\
\hline Notes & \\
\hline
\end{tabular}

Knox 2014

\begin{tabular}{ll}
\hline Methods & Not known \\
\hline Participants & People with stroke discharged from hospital \\
\hline Interventions & Outpatient-based, task-orientated training programme \\
\hline Outcomes & Not known \\
\hline
\end{tabular}

Notes

Kumar 2012

\begin{tabular}{ll}
\hline Methods & RCT \\
\hline Participants & Stroke patients with paresis of hand \\
\hline Interventions & Task-orientated training \\
\hline Outcomes & Hand function \\
\hline Notes & \\
\hline
\end{tabular}

\section{NCT02429180}

\begin{tabular}{ll}
\hline Methods & RCT \\
\hline Participants & At least 1 month post discharge from hospital \\
\hline Interventions & Excercise-based functional training programme \\
\hline Outcomes & Mobility, balance, ability to perform 5 functional tasks, physical activity \\
\hline Notes & Trial estimated completion date October 2016 \\
\hline
\end{tabular}


Pandian 2014

\begin{tabular}{ll}
\hline Methods & RCT \\
\hline Participants & People with stroke: early supported discharge \\
\hline Interventions & Family-led caregiver-delivered, home-based stroke rehabilitation (ATTEND Trial) \\
\hline Outcomes & Quality of life, anxiety and depression, health costs \\
\hline Notes & \\
\hline
\end{tabular}

Xu 2012

\begin{tabular}{ll}
\hline Methods & RCT \\
\hline Participants & Stroke \\
\hline Interventions & Walking training \\
\hline Outcomes & Lower limb function, activities of daily living \\
\hline Notes & \\
\hline
\end{tabular}

Zhu 2013

\begin{tabular}{ll}
\hline Methods & RCT \\
\hline Participants & People with stroke with upper limb dysfunction \\
\hline Interventions & Rehabilitation training for optimising motor skills \\
\hline Outcomes & Hand function \\
\hline Notes & \\
\hline
\end{tabular}

$\mathrm{RCT}$ : randomised controlled trial

Characteristics of ongoing studies [ordered by study ID]

Bosomworth 2013

\begin{tabular}{ll}
\hline Trial name or title & Robot Assisted Training for the Upper Limb after Stroke (RATULS) \\
\hline Methods & 3-arm multicentre RCT \\
\hline Participants & $\begin{array}{l}1 \text { week to } 5 \text { years post stroke } \\
\text { (Stratified: } 0 \text { to } 3 \text { months; }>3 \text { to } 12 \text { months; > } 12 \text { months to } 5 \text { years) }\end{array}$ \\
\hline Interventions & Enhanced upper limb therapy programme \\
\hline Outcomes & Upper limb function, upper limb impairment, ADL, quality of life, adverse events \\
\hline
\end{tabular}


Bosomworth 2013 (Continued)

\begin{tabular}{ll} 
Starting date & Main Trial 2015 \\
\hline Contact information & helen.rodgers@ncl.ac.uk \\
\hline Notes & Pilot trial 2014 \\
\hline
\end{tabular}

CTRI/2015/06/005877

\begin{tabular}{ll} 
Trial name or title & $\begin{array}{l}\text { Short-term effect of circuit class training for improvement of upper limit in stroke patients: a } \\
\text { randomised clinical trial }\end{array}$ \\
\hline Methods & RCT \\
\hline Participants & Single episode supratentorial stroke \\
\hline Interventions & Task-orientated circuit class training \\
\hline Outcomes & Motor function \\
\hline Starting date & 2014 \\
\hline Contact information & abraham.joshua@manipal.edu \\
\hline
\end{tabular}

Notes

Hariohm 2013

\begin{tabular}{ll} 
Trial name or title & $\begin{array}{l}\text { RCT protocol on efficacy of deep knee flexion exercises on improving activities involving deep knee } \\
\text { flexion and quality of life in persons with stroke }\end{array}$ \\
\hline Methods & Pragmatic RCT \\
\hline Participants & Chronic stroke, community dwelling \\
\hline Interventions & Task specific deep knee flexion activity-training \\
\hline Outcomes & $\begin{array}{l}\text { Deep knee flexion activity goal attainment, quality of life (social participation domain), lower limb } \\
\text { muscle strength, fear of fall, functional ambulation status }\end{array}$ \\
\hline Starting date & 2013 \\
\hline Contact information & Hariohm@hotmail.com \\
\hline Notes & Recruitment target 40 - ongoing
\end{tabular}

\section{Korner-Bitensky 2013}

$\begin{array}{ll}\text { Trial name or title } & \begin{array}{l}\text { Randomised pilot trial of usual care versus LIFE (lifestyle intervention using functional exercise to } \\ \text { reduce falls) in those with mild stroke }\end{array}\end{array}$


Korner-Bitensky 2013 (Continued)

\begin{tabular}{ll} 
Methods & 3-group parallel RCT \\
\hline Participants & Individuals aged $>70$ years with a first mild stroke \\
\hline Interventions & Lifestyle intervention using functional exercise \\
\hline Outcomes & Rate of falls (self-reported), static and dynamic balance \\
\hline Starting date & 2013 \\
\hline Contact information & lindy.clemson@sydney.edu.au \\
\hline Notes & Pilot data being prepared for publication \\
\hline
\end{tabular}

Kumaran 2010

\begin{tabular}{ll}
\hline Trial name or title & RCT to study the effects of a task and context-based exercise program in stroke patients \\
\hline Methods & RCT \\
\hline Participants & $>3$ months post stroke \\
\hline Interventions & Task and context-based exercise program using motor relearning approach \\
\hline Outcomes & $\begin{array}{l}\text { Stroke Impact Scale, Motricity Index Score, gait velocity, Berg Balance Scale, walking distance, Par- } \\
\text { ticipation and Autonomy Questionnaire, Falls Efficacy Scale }\end{array}$ \\
\hline Starting date & 2011 \\
\hline Contact information & senthil.kumaran@manipal.edu \\
\hline Notes & Trial due to complete 2015 \\
\hline
\end{tabular}

\section{NCT02235974}

\begin{tabular}{ll}
\hline Trial name or title & Critical Periods After Stroke Study (CPASS) \\
\hline Methods & 4-arm RCT (Phase 2) \\
\hline Participants & People with stroke within 28 days of admission \\
\hline Interventions & Upper limb motor training (intensive therapy: acute, sub-acute, chronic phase) \\
\hline Outcomes & Upper extremity motor improvement \\
\hline Starting date & 2014 \\
\hline Contact information & Margot.Giannetti@medstar.net \\
\hline Notes & Trial estimated completion date August 2018 \\
\hline
\end{tabular}


NCT02765152

\begin{tabular}{ll}
\hline Trial name or title & $\begin{array}{l}\text { Effects of training rhythmic and discrete aiming movements on arm control and functionality after } \\
\text { stroke }\end{array}$ \\
\hline Methods & 3-arm RCT \\
\hline Participants & Stroke experienced more than 6 months on enrolment \\
\hline Interventions & Discrete and rhythmic aiming movements (repeated) \\
\hline Outcomes & Motor activity, arm function \\
\hline Starting date & May 2016 \\
\hline Contact information & sandra.alouche@unicid.edu.br \\
\hline Notes & Not yet recruiting \\
\hline
\end{tabular}

\begin{tabular}{ll}
\hline Schultz 2012 & Use of repetitive facilitative exercise program in established stroke \\
\hline Methods & RCT \\
\hline Participants & $>6$ months post stroke \\
\hline Interventions & Repetitive facilitative exercise therapy \\
\hline Outcomes & Fugl-Meyer Arm Score, Motor Activity Log, Grasp strength, hand dexterity, patient satisfaction \\
\hline Starting date & 2012 \\
\hline Contact information & schultz.billie@mayo.edu \\
\hline Notes & Trial due to complete 2014 \\
\hline
\end{tabular}

\section{Stuart 2009}

\begin{tabular}{ll}
\hline Trial name or title & Adaptive Physical Activity for chronic stroke (APA-Stroke) \\
\hline Methods & RCT \\
\hline Participants & $>6$ months post stroke \\
\hline Interventions & Progressive exercise program \\
\hline Outcomes & Walking speed, ambulatory activity, balance \\
\hline Starting date & 2009 \\
\hline Contact information & stuart@umbc.edu \\
\hline
\end{tabular}


Stuart 2009 (Continued)
Notes
Trial due to complete 2014

Tanne 2008

\begin{tabular}{ll}
\hline Trial name or title & Virtual reality training program for ambulatory patients with chronic gait deficits after stroke \\
\hline Methods & Pilot RCT \\
\hline Participants & Ambulatory patients following stroke (3 to 72 months post stroke) \\
\hline Interventions & Virtual reality system \\
\hline Outcomes & Ambulation, gait, functional reach \\
\hline Starting date & 2008 \\
\hline Contact information & David.Tanne@sheba.health.gov.il \\
\hline
\end{tabular}

Notes

Turton 2011

\begin{tabular}{ll}
\hline Trial name or title & Home-based reach-to-grasp training for people after stroke: study protocol for a feasibility RCT \\
\hline Methods & Randomised controlled feasibility trial \\
\hline Participants & $<12$ months post stroke \\
\hline Interventions & Task-specific reach-to-grasp training \\
\hline Outcomes & $\begin{array}{l}\text { Arm function, arm movement in } 28 \text { everyday tasks, Stroke Impact Scale, Health and Social Ques- } \\
\text { tionnaire, caregiver burden }\end{array}$ \\
\hline Starting date & 2011 \\
\hline Contact information & ailie.turton@uwe.ac.uk \\
\hline Notes & Trial completed, in follow-up phase \\
\hline
\end{tabular}

ADL: activities of daily living

$\mathrm{RCT}$ : randomised controlled trial

\section{DATA AND ANALYSES}


Comparison 1. Upper limb function: post treatment

\begin{tabular}{lllll}
\hline $\begin{array}{l}\text { Outcome or subgroup } \\
\text { title }\end{array}$ & No. of studies & $\begin{array}{l}\text { No. of partici- } \\
\text { pants }\end{array}$ & Statistical method & Effect size \\
\hline 1 Arm function & 11 & 749 & Std. Mean Difference (IV, Random, 95\% Cl) & $0.25[0.01,0.49]$ \\
\hline 2 Hand function & 8 & 619 & Std. Mean Difference (IV, Random, 95\% Cl) & $0.25[0.00,0.51]$ \\
\hline 3 Sitting balance/reach & 6 & 222 & Std. Mean Difference (IV, Fixed, 95\% Cl) & $0.28[0.01,0.55]$ \\
\hline
\end{tabular}

Analysis 1.1. Comparison 1 Upper limb function: post treatment, Outcome 1 Arm function.

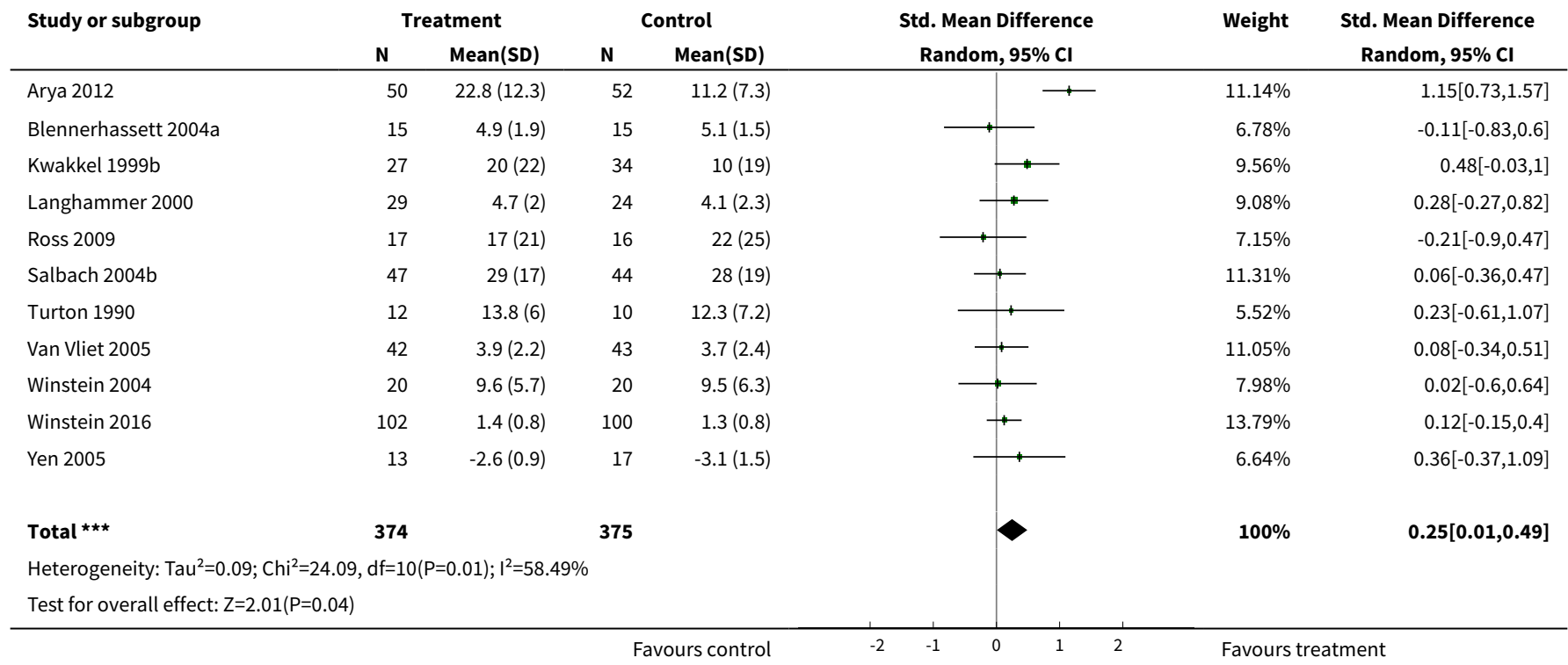

Analysis 1.2. Comparison 1 Upper limb function: post treatment, Outcome 2 Hand function.

\begin{tabular}{|c|c|c|c|c|c|c|c|}
\hline \multirow{3}{*}{$\begin{array}{l}\text { Study or subgroup } \\
\text { Arya } 2012\end{array}$} & \multicolumn{2}{|c|}{ Treatment } & \multicolumn{2}{|c|}{ Control } & \multirow{2}{*}{$\begin{array}{c}\text { Std. Mean Difference } \\
\text { Random, } 95 \% \mathrm{Cl}\end{array}$} & \multirow[t]{2}{*}{ Weight } & \multirow{2}{*}{$\begin{array}{c}\text { Std. Mean Difference } \\
\text { Random, } 95 \% \mathrm{Cl}\end{array}$} \\
\hline & $\mathbf{N}$ & Mean(SD) & $\mathbf{N}$ & Mean(SD) & & & \\
\hline & 50 & $9.6(6.9)$ & 52 & $4.1(4)$ & 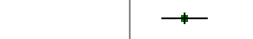 & $15.17 \%$ & $0.97[0.56,1.38]$ \\
\hline Langhammer 2000 & 29 & $4.6(1.9)$ & 24 & $3.9(2.3)$ & + & $11.67 \%$ & $0.33[-0.21,0.87]$ \\
\hline Ross 2009 & 16 & $2.1(1.5)$ & 16 & $2.3(1.5)$ & - & $8.75 \%$ & $-0.13[-0.82,0.56]$ \\
\hline Salbach 2004b & 47 & $-9(3)$ & 44 & $-10(4)$ & 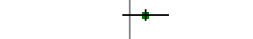 & $15.11 \%$ & $0.28[-0.13,0.7]$ \\
\hline Turton 1990 & 12 & $-43.5(20.8)$ & 10 & $-41.1(20.1)$ & - & $6.71 \%$ & $-0.11[-0.95,0.73]$ \\
\hline Van Vliet 2005 & 42 & $4.3(2.4)$ & 43 & $4.1(2.6)$ & 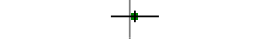 & $14.76 \%$ & $0.09[-0.33,0.52]$ \\
\hline Winstein 2016 & 104 & $70.3(26.4)$ & 100 & $65.3(24.9)$ & "- & $19.43 \%$ & $0.2[-0.08,0.47]$ \\
\hline 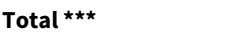 & 315 & & 304 & & $>$ & $100 \%$ & $0.25[0,0.51]$ \\
\hline \multicolumn{8}{|c|}{ Heterogeneity: $\mathrm{Tau}^{2}=0.07 ; \mathrm{Chi}^{2}=15.17, \mathrm{df}=7(\mathrm{P}=0.03) ; \mathrm{I}^{2}=53.84 \%$} \\
\hline \multicolumn{3}{|c|}{ Test for overall effect: $Z=1.96(P=0.05)$} & & & & & \\
\hline
\end{tabular}




\section{Analysis 1.3. Comparison 1 Upper limb function: post treatment, Outcome 3 Sitting balance/reach.}

\begin{tabular}{|c|c|c|c|c|c|c|c|}
\hline \multirow[t]{2}{*}{ Study or subgroup } & \multicolumn{2}{|c|}{ Treatment } & \multicolumn{2}{|c|}{ Control } & \multirow{2}{*}{$\begin{array}{c}\text { Std. Mean Difference } \\
\text { Fixed, } 95 \% \mathrm{Cl}\end{array}$} & \multirow[t]{2}{*}{ Weight } & \multirow{2}{*}{$\begin{array}{c}\text { Std. Mean Difference } \\
\text { Fixed, } 95 \% \mathrm{Cl}\end{array}$} \\
\hline & $\mathbf{N}$ & $\operatorname{Mean}(\mathrm{SD})$ & $\mathbf{N}$ & $\operatorname{Mean}(\mathrm{SD})$ & & & \\
\hline de Sèze 2001 & 10 & $3.3(0.8)$ & 10 & $3(0.8)$ & $+*$ & $9.24 \%$ & $0.36[-0.53,1.24]$ \\
\hline Dean 1997 & 10 & $12(1)$ & 9 & $10.8(0.9)$ & $\longrightarrow$ & $7.2 \%$ & $1.24[0.23,2.24]$ \\
\hline Dean 2007 & 6 & $1.3(0.1)$ & 6 & $1.1(0.1)$ & 工 & $3.84 \%$ & $1.59[0.22,2.96]$ \\
\hline Howe 2005 & 15 & $-1.9(0.8)$ & 18 & $-2.1(0.7)$ & 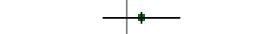 & $15.28 \%$ & $0.26[-0.43,0.95]$ \\
\hline Langhammer 2000 & 29 & $5.4(0.9)$ & 24 & $5(1.5)$ & 廿- & $24.41 \%$ & $0.33[-0.22,0.87]$ \\
\hline 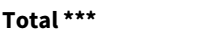 & 112 & & 110 & & 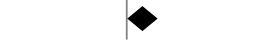 & $100 \%$ & $0.28[0.01,0.55]$ \\
\hline \multicolumn{8}{|c|}{ Heterogeneity: $\mathrm{Tau}^{2}=0 ; \mathrm{Chi}^{2}=9.54, \mathrm{df}=5(\mathrm{P}=0.09) ; \mathrm{I}^{2}=47.57 \%$} \\
\hline \multicolumn{3}{|c|}{ Test for overall effect: $Z=2.03(P=0.04)$} & & & & & \\
\hline
\end{tabular}

Comparison 2. Upper limb function: follow-up

\begin{tabular}{lllll}
\hline Outcome or subgroup title & No. of studies & $\begin{array}{l}\text { No. of partici- } \\
\text { pants }\end{array}$ & Statistical method & Effect size \\
\hline 1 All outcomes & 9 & & Std. Mean Difference (IV, Fixed, 95\% CI) & Subtotals only \\
\hline $\begin{array}{l}1.1 \text { Under } 6 \text { months post } \\
\text { treatment }\end{array}$ & 3 & 153 & Std. Mean Difference (IV, Fixed, 95\% Cl) & $0.92[0.58,1.26]$ \\
\hline $\begin{array}{l}1.26 \text { to } 12 \text { months post } \\
\text { treatment }\end{array}$ & 6 & 412 & Std. Mean Difference (IV, Fixed, 95\% Cl) & $0.10[-0.09,0.30]$ \\
\hline
\end{tabular}

Analysis 2.1. Comparison 2 Upper limb function: follow-up, Outcome 1 All outcomes.

\begin{tabular}{|c|c|c|c|c|c|c|c|}
\hline \multirow[t]{2}{*}{ Study or subgroup } & \multicolumn{2}{|c|}{ Treatment } & \multicolumn{2}{|c|}{ Control } & \multirow{2}{*}{$\begin{array}{c}\text { Std. Mean Difference } \\
\text { Fixed, } 95 \% \mathrm{Cl}\end{array}$} & \multirow[t]{2}{*}{ Weight } & \multirow{2}{*}{$\begin{array}{c}\text { Std. Mean Difference } \\
\text { Fixed, } 95 \% \mathrm{Cl}\end{array}$} \\
\hline & $\mathbf{N}$ & Mean(SD) & $\mathbf{N}$ & $\operatorname{Mean}(S D)$ & & & \\
\hline \multicolumn{8}{|c|}{ 2.1.1 Under 6 months post treatment } \\
\hline Arya 2012 & 50 & $25.5(12.1)$ & 52 & $13.5(8.2)$ & & $63.88 \%$ & $1.16[0.74,1.58]$ \\
\hline de Sèze 2001 & 10 & $3.6(0.5)$ & 10 & $3.4(0.6)$ & ++ & $14.45 \%$ & $0.35[-0.54,1.23]$ \\
\hline Howe 2005 & 15 & $2.5(1.3)$ & 16 & $1.9(0.5)$ & " & $21.67 \%$ & $0.6[-0.12,1.32]$ \\
\hline Subtotal $* * \star$ & 75 & & 78 & & & $100 \%$ & $0.92[0.58,1.26]$ \\
\hline \multicolumn{8}{|c|}{ Heterogeneity: $\mathrm{Tau}^{2}=0 ; \mathrm{Chi}^{2}=3.61, \mathrm{df}=2(\mathrm{P}=0.16) ; \mathrm{I}^{2}=44.54 \%$} \\
\hline \multicolumn{8}{|c|}{ Test for overall effect: $Z=5.37(P<0.0001)$} \\
\hline \multicolumn{8}{|c|}{ 2.1.2 6 to 12 months post treatment } \\
\hline Blennerhassett 2004a & 10 & $-23.6(12.2)$ & 11 & $-31(33.2)$ & & $5.1 \%$ & $0.28[-0.58,1.14]$ \\
\hline Dean 2007 & 5 & $1.3(0.1)$ & 4 & $1.1(0.1)$ & & $1.11 \%$ & $2.11[0.26,3.96]$ \\
\hline Langhammer 2000 & 27 & $3.9(2.5)$ & 27 & $3.5(2.8)$ & + & $13.27 \%$ & $0.15[-0.39,0.68]$ \\
\hline Van Vliet 2005 & 42 & $3.5(2.4)$ & 45 & $3.8(2.4)$ & $\rightarrow$ & $21.37 \%$ & $-0.13[-0.55,0.29]$ \\
\hline Winstein 2004 & 17 & $9.7(5.8)$ & 16 & $11(6.2)$ & $\longrightarrow$ & $8.08 \%$ & $-0.21[-0.9,0.47]$ \\
\hline Winstein 2016 & 104 & $1.4(1.1)$ & 104 & $1.2(1.1)$ & + & $51.07 \%$ & $0.18[-0.09,0.45]$ \\
\hline
\end{tabular}




\begin{tabular}{|c|c|c|c|c|c|c|}
\hline \multirow[t]{2}{*}{ Study or subgroup } & \multicolumn{2}{|c|}{ Treatment } & Control & \multirow{2}{*}{$\begin{array}{c}\text { Std. Mean Difference } \\
\text { Fixed, } 95 \% \mathrm{Cl}\end{array}$} & \multirow[t]{2}{*}{ Weight } & \multirow{2}{*}{$\begin{array}{c}\text { Std. Mean Difference } \\
\text { Fixed, } 95 \% \mathrm{Cl}\end{array}$} \\
\hline & $\mathbf{N}$ & Mean(SD) & Mean(SD) & & & \\
\hline Subtotal $* \star \star$ & 205 & & 207 & $\gamma$ & $100 \%$ & $0.1[-0.09,0.3]$ \\
\hline \multicolumn{7}{|c|}{ Heterogeneity: $\mathrm{Tau}^{2}=0 ; \mathrm{Chi}^{2}=7.06, \mathrm{df}=5(\mathrm{P}=0.22) ; \mathrm{I}^{2}=29.16 \%$} \\
\hline \multicolumn{3}{|c|}{ Test for overall effect: $Z=1.05(P=0.29)$} & & & & \\
\hline
\end{tabular}

\section{Comparison 3. Upper limb function: subgroup analyses}

\begin{tabular}{|c|c|c|c|c|}
\hline $\begin{array}{l}\text { Outcome or subgroup } \\
\text { title }\end{array}$ & No. of studies & $\begin{array}{l}\text { No. of partici- } \\
\text { pants }\end{array}$ & Statistical method & Effect size \\
\hline $\begin{array}{l}1 \text { Dosage of task prac- } \\
\text { tice }\end{array}$ & 15 & 833 & Std. Mean Difference (IV, Random, 95\% CI) & $0.33[0.11,0.56]$ \\
\hline 1.10 to 20 hours & 9 & 383 & Std. Mean Difference (IV, Random, 95\% CI) & $0.23[0.00,0.46]$ \\
\hline 1.2 More than 20 hours & 6 & 450 & Std. Mean Difference (IV, Random, 95\% CI) & $0.38[-0.03,0.80]$ \\
\hline 2 Time since stroke & 15 & 833 & Std. Mean Difference (IV, Random, 95\% CI) & $0.33[0.11,0.56]$ \\
\hline 2.10 to 15 days & 4 & 239 & Std. Mean Difference (IV, Random, 95\% CI) & $0.21[-0.04,0.47]$ \\
\hline 2.216 days to 6 months & 7 & 421 & Std. Mean Difference (IV, Random, 95\% CI) & $0.48[0.06,0.91]$ \\
\hline 2.3 More than 6 months & 4 & 173 & Std. Mean Difference (IV, Random, 95\% CI) & $0.24[-0.23,0.72]$ \\
\hline 3 Type of intervention & 15 & 833 & Std. Mean Difference (IV, Random, 95\% CI) & $0.33[0.11,0.56]$ \\
\hline 3.1 Whole therapy & 3 & 240 & Std. Mean Difference (IV, Random, 95\% CI) & $0.51[-0.18,1.20]$ \\
\hline 3.2 Mixed training & 8 & 509 & Std. Mean Difference (IV, Random, 95\% CI) & $0.14[-0.03,0.32]$ \\
\hline 3.3 Single task training & 4 & 84 & Std. Mean Difference (IV, Random, 95\% CI) & $0.71[0.11,1.30]$ \\
\hline
\end{tabular}

Analysis 3.1. Comparison 3 Upper limb function: subgroup analyses, Outcome 1 Dosage of task practice.

\begin{tabular}{|c|c|c|c|c|c|c|c|}
\hline \multirow{3}{*}{$\begin{array}{l}\text { Study or subgroup } \\
3.1 .10 \text { to } 20 \text { hours }\end{array}$} & \multicolumn{2}{|c|}{ Treatment } & \multicolumn{2}{|c|}{ Control } & \multirow{2}{*}{$\begin{array}{c}\text { Std. Mean Difference } \\
\text { Random, } 95 \% \mathrm{Cl}\end{array}$} & \multirow[t]{2}{*}{ Weight } & \multirow{2}{*}{$\begin{array}{c}\text { Std. Mean Difference } \\
\text { Random, } 95 \% \mathrm{Cl}\end{array}$} \\
\hline & $\mathbf{N}$ & $\operatorname{Mean}(S D)$ & $\mathbf{N}$ & $\operatorname{Mean}(S D)$ & & & \\
\hline & & & & & & & \\
\hline Blennerhassett 2004a & 15 & $4.5(2.5)$ & 15 & $4.1(2.7)$ & $\longleftarrow$ & $5.69 \%$ & $0.15[-0.57,0.87]$ \\
\hline de Sèze 2001 & 10 & $3.3(0.8)$ & 10 & $3(0.8)$ & 1 & $4.34 \%$ & $0.36[-0.53,1.24]$ \\
\hline Dean 1997 & 10 & $12(1)$ & 9 & $10.8(0.9)$ & 1 & $3.63 \%$ & $1.24[0.23,2.24]$ \\
\hline Dean 2007 & 6 & $1.3(0.1)$ & 6 & $1.1(0.1)$ & 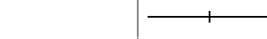 & $2.2 \%$ & $1.59[0.22,2.96]$ \\
\hline Howe 2005 & 15 & $-1.9(0.8)$ & 18 & $-2.1(0.7)$ & $\longrightarrow$ & $5.97 \%$ & $0.26[-0.43,0.95]$ \\
\hline Langhammer 2000 & 29 & $4.7(2)$ & 24 & $4.1(2.3)$ & + & $7.62 \%$ & $0.28[-0.27,0.82]$ \\
\hline Salbach 2004b & 47 & $29(17)$ & 44 & $28(19)$ & $\rightarrow$ & $9.47 \%$ & $0.06[-0.36,0.47]$ \\
\hline Van Vliet 2005 & 42 & $3.9(2.2)$ & 43 & $3.7(2.4)$ & 7 & $9.26 \%$ & $0.08[-0.34,0.51]$ \\
\hline Winstein 2004 & 20 & $9.6(5.7)$ & 20 & $9.5(6.3)$ & $\longrightarrow$ & $6.7 \%$ & $0.02[-0.6,0.64]$ \\
\hline 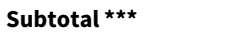 & 194 & & 189 & & $\boldsymbol{\gamma}$ & $54.88 \%$ & $0.23[0,0.46]$ \\
\hline
\end{tabular}




\begin{tabular}{|c|c|c|c|c|c|c|c|}
\hline \multirow[t]{2}{*}{ Study or subgroup } & \multicolumn{2}{|c|}{ Treatment } & \multicolumn{2}{|c|}{ Control } & \multirow{2}{*}{$\begin{array}{c}\text { Std. Mean Difference } \\
\text { Random, } 95 \% \mathrm{Cl}\end{array}$} & \multirow[t]{2}{*}{ Weight } & \multirow{2}{*}{$\begin{array}{c}\text { Std. Mean Difference } \\
\text { Random, } 95 \% \mathrm{Cl}\end{array}$} \\
\hline & $\mathbf{N}$ & Mean(SD) & $\mathbf{N}$ & Mean(SD) & & & \\
\hline \multicolumn{8}{|c|}{ Heterogeneity: $\operatorname{Tau}^{2}=0.02 ; \mathrm{Chi}^{2}=9.4, \mathrm{df}=8(\mathrm{P}=0.31) ; \mathrm{I}^{2}=14.85 \%$} \\
\hline \multicolumn{8}{|c|}{ Test for overall effect: $Z=2(P=0.05)$} \\
\hline \multicolumn{8}{|c|}{ 3.1.2 More than 20 hours } \\
\hline Kwakkel 1999b & 27 & $20(22)$ & 34 & $10(19)$ & 世 & $8.02 \%$ & $0.48[-0.03,1]$ \\
\hline Ross 2009 & 17 & $17(21)$ & 16 & $22(25)$ & $\longrightarrow$ & $6 \%$ & $-0.21[-0.9,0.47]$ \\
\hline Turton 1990 & 12 & $13.8(6)$ & 10 & $12.3(7.2)$ & $\longrightarrow$ & $4.64 \%$ & $0.23[-0.61,1.07]$ \\
\hline Winstein 2016 & 102 & $1.4(0.8)$ & 100 & $1.3(0.8)$ & + & $11.54 \%$ & $0.12[-0.15,0.4]$ \\
\hline Yen 2005 & 13 & $-2.6(0.9)$ & 17 & $-3.1(1.5)$ & 1 & $5.58 \%$ & $0.36[-0.37,1.09]$ \\
\hline Subtotal ${ }^{\star \star \star}$ & 221 & & 229 & & & $45.12 \%$ & $0.38[-0.03,0.8]$ \\
\hline \multicolumn{8}{|c|}{ Heterogeneity: $\mathrm{Tau}^{2}=0.19 ; \mathrm{Chi}^{2}=19.4, \mathrm{df}=5(\mathrm{P}=0) ; \mathrm{I}^{2}=74.23 \%$} \\
\hline \multicolumn{8}{|c|}{ Test for overall effect: $\mathrm{Z}=1.8(\mathrm{P}=0.07)$} \\
\hline Total *** & 415 & & 418 & & $\diamond$ & $100 \%$ & $0.33[0.11,0.56]$ \\
\hline \multicolumn{8}{|c|}{ Heterogeneity: $\mathrm{Tau}^{2}=0.09 ; \mathrm{Chi}^{2}=30.14, \mathrm{df}=14(\mathrm{P}=0.01) ; \mathrm{I}^{2}=53.55 \%$} \\
\hline \multicolumn{8}{|c|}{ Test for overall effect: $Z=2.94(P=0)$} \\
\hline \multicolumn{8}{|c|}{ Test for subgroup differences: $\mathrm{Chi}^{2}=0.39, \mathrm{df}=1(\mathrm{P}=0.53), \mathrm{I}^{2}=0 \%$} \\
\hline & & & & ours control -5 & -2.5 & 5 Favourst & ment \\
\hline
\end{tabular}

Analysis 3.2. Comparison 3 Upper limb function: subgroup analyses, Outcome 2 Time since stroke.

\begin{tabular}{|c|c|c|c|c|c|c|c|}
\hline \multirow{3}{*}{$\begin{array}{l}\text { Study or subgroup } \\
\text { 3.2.1 } 0 \text { to } 15 \text { days }\end{array}$} & \multicolumn{2}{|c|}{ Treatment } & \multicolumn{2}{|c|}{ Control } & \multirow{2}{*}{$\begin{array}{c}\text { Std. Mean Difference } \\
\text { Random, } 95 \% \mathrm{Cl}\end{array}$} & \multirow[t]{2}{*}{ Weight } & \multirow{2}{*}{$\begin{array}{c}\text { Std. Mean Difference } \\
\text { Random, } 95 \% \mathrm{Cl}\end{array}$} \\
\hline & \multirow[t]{2}{*}{$\mathbf{N}$} & \multirow[t]{2}{*}{ Mean(SD) } & \multirow[t]{2}{*}{$\mathbf{N}$} & \multirow[t]{2}{*}{ Mean(SD) } & & & \\
\hline & & & & & & & \\
\hline Kwakkel 1999b & 27 & $20(22)$ & 34 & $10(19)$ & $\rightarrow$ & $8.02 \%$ & $0.48[-0.03,1]$ \\
\hline Langhammer 2000 & 29 & $4.7(2)$ & 24 & $4.1(2.3)$ & 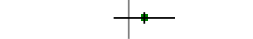 & $7.62 \%$ & $0.28[-0.27,0.82]$ \\
\hline Van Vliet 2005 & 42 & $3.9(2.2)$ & 43 & $3.7(2.4)$ & 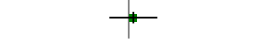 & $9.26 \%$ & $0.08[-0.34,0.51]$ \\
\hline Winstein 2004 & 20 & $9.6(5.7)$ & 20 & $9.5(6.3)$ & 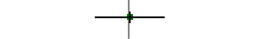 & $6.7 \%$ & $0.02[-0.6,0.64]$ \\
\hline Subtotal $\star \star \star$ & 118 & & 121 & & & $31.6 \%$ & $0.21[-0.04,0.47]$ \\
\hline \multicolumn{8}{|c|}{ Heterogeneity: $\mathrm{Tau}^{2}=0 ; \mathrm{Chi}^{2}=1.87, \mathrm{df}=3(\mathrm{P}=0.6) ; \mathrm{I}^{2}=0 \%$} \\
\hline \multicolumn{8}{|c|}{ Test for overall effect: $Z=1.64(P=0.1)$} \\
\hline \multicolumn{8}{|c|}{ 3.2.2 16 days to 6 months } \\
\hline Arya 2012 & 50 & $22.8(12.3)$ & 52 & $11.2(7.3)$ & $\rightarrow$ & $9.34 \%$ & $1.15[0.73,1.57]$ \\
\hline Blennerhassett 2004a & 15 & $4.5(2.5)$ & 15 & $4.1(2.7)$ & t & $5.69 \%$ & $0.15[-0.57,0.87]$ \\
\hline Dean 2007 & 6 & $1.3(0.1)$ & 6 & $1.1(0.1)$ & & $2.2 \%$ & $1.59[0.22,2.96]$ \\
\hline Howe 2005 & 15 & $-1.9(0.8)$ & 18 & $-2.1(0.7)$ & 4 & $5.97 \%$ & $0.26[-0.43,0.95]$ \\
\hline Turton 1990 & 12 & $13.8(6)$ & 10 & $12.3(7.2)$ & $\longleftarrow$ & $4.64 \%$ & $0.23[-0.61,1.07]$ \\
\hline Winstein 2016 & 102 & $1.4(0.8)$ & 100 & $1.3(0.8)$ & - & $11.54 \%$ & $0.12[-0.15,0.4]$ \\
\hline Subtotal $* \star \star$ & 210 & & 211 & & & $43.72 \%$ & $0.48[0.06,0.91]$ \\
\hline \multicolumn{8}{|c|}{ Heterogeneity: $\mathrm{Tau}^{2}=0.2 ; \mathrm{Chi}^{2}=19.81, \mathrm{df}=6(\mathrm{P}=0) ; \mathrm{I}^{2}=69.71 \%$} \\
\hline \multicolumn{8}{|c|}{ Test for overall effect: $\mathrm{Z}=2.22(\mathrm{P}=0.03)$} \\
\hline \multicolumn{8}{|c|}{ 3.2.3 More than 6 months } \\
\hline Dean 1997 & 10 & $12(1)$ & 9 & $10.8(0.9)$ & - & $3.63 \%$ & $1.24[0.23,2.24]$ \\
\hline Ross 2009 & 17 & $17(21)$ & 16 & $22(25)$ & $\longrightarrow$ & $6 \%$ & $-0.21[-0.9,0.47]$ \\
\hline Salbach 2004b & 47 & $29(17)$ & 44 & $28(19)$ & $\rightarrow$ & $9.47 \%$ & $0.06[-0.36,0.47]$ \\
\hline
\end{tabular}




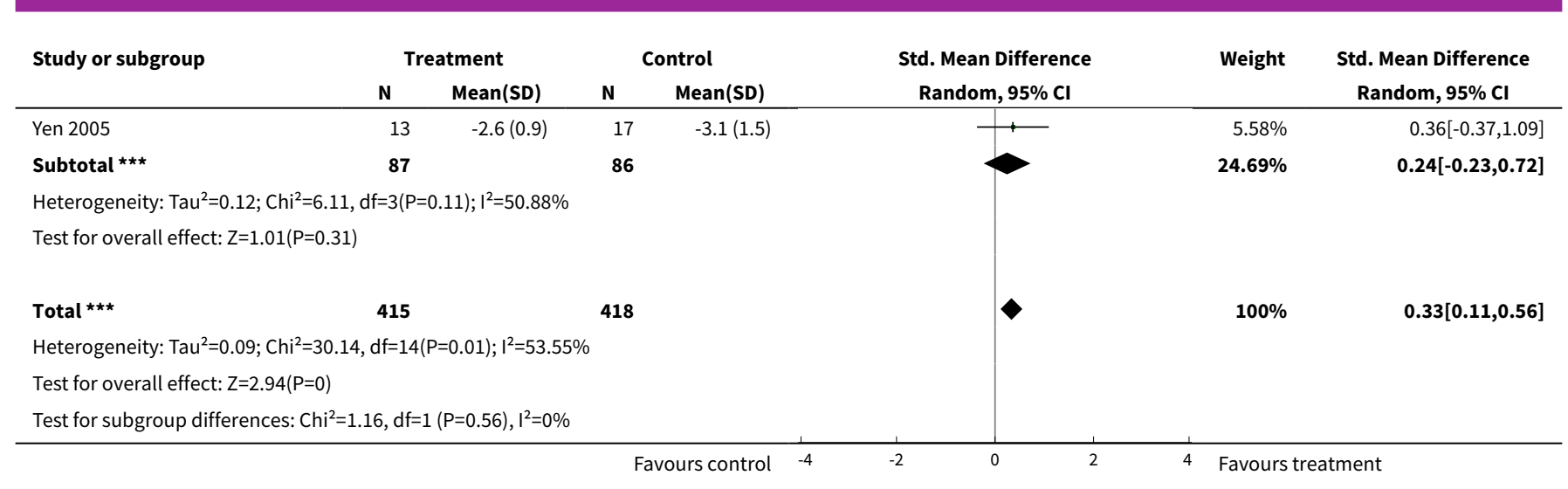

Analysis 3.3. Comparison 3 Upper limb function: subgroup analyses, Outcome 3 Type of intervention.

\begin{tabular}{|c|c|c|c|c|c|c|c|}
\hline \multirow{3}{*}{$\begin{array}{l}\text { Study or subgroup } \\
\text { 3.3.1 Whole therapy }\end{array}$} & \multicolumn{2}{|c|}{ Treatment } & \multicolumn{2}{|c|}{ Control } & \multirow{2}{*}{$\begin{array}{c}\text { Std. Mean Difference } \\
\text { Random, } 95 \% \mathrm{Cl}\end{array}$} & \multirow[t]{2}{*}{ Weight } & \multirow{2}{*}{$\begin{array}{l}\text { Std. Mean Difference } \\
\text { Random, } 95 \% \mathrm{Cl}\end{array}$} \\
\hline & \multirow[t]{2}{*}{$\mathbf{N}$} & \multirow[t]{2}{*}{$\operatorname{Mean}(S D)$} & \multirow[t]{2}{*}{$\mathbf{N}$} & \multirow[t]{2}{*}{$\operatorname{Mean}(S D)$} & & & \\
\hline & & & & & & & \\
\hline Arya 2012 & 50 & $22.8(12.3)$ & 52 & $11.2(7.3)$ & $\rightarrow$ & $9.34 \%$ & $1.15[0.73,1.57]$ \\
\hline Langhammer 2000 & 29 & $4.7(2)$ & 24 & $4.1(2.3)$ & 7 & $7.62 \%$ & $0.28[-0.27,0.82]$ \\
\hline Van Vliet 2005 & 42 & $3.9(2.2)$ & 43 & $3.7(2.4)$ & & $9.26 \%$ & $0.08[-0.34,0.51]$ \\
\hline Subtotal $* \star \star$ & 121 & & 119 & & & $26.22 \%$ & $0.51[-0.18,1.2]$ \\
\hline \multicolumn{8}{|c|}{ Heterogeneity: $\mathrm{Tau}^{2}=0.31 ; \mathrm{Chi}^{2}=13.46, \mathrm{df}=2(\mathrm{P}=0) ; \mathrm{I}^{2}=85.15 \%$} \\
\hline \multicolumn{8}{|c|}{ Test for overall effect: $Z=1.45(P=0.15)$} \\
\hline \multicolumn{8}{|l|}{ 3.3.2 Mixed training } \\
\hline Blennerhassett 2004a & 15 & $4.5(2.5)$ & 15 & $4.1(2.7)$ & & $5.69 \%$ & $0.15[-0.57,0.87]$ \\
\hline Kwakkel 1999b & 27 & $20(22)$ & 34 & $10(19)$ & $\rightarrow$ & $8.02 \%$ & $0.48[-0.03,1]$ \\
\hline Ross 2009 & 17 & $17(21)$ & 16 & $22(25)$ & $\rightarrow$ & $6 \%$ & $-0.21[-0.9,0.47]$ \\
\hline Salbach 2004b & 47 & $29(17)$ & 44 & $28(19)$ & & $9.47 \%$ & $0.06[-0.36,0.47]$ \\
\hline Turton 1990 & 12 & $13.8(6)$ & 10 & $12.3(7.2)$ & 1 & $4.64 \%$ & $0.23[-0.61,1.07]$ \\
\hline Winstein 2004 & 20 & $9.6(5.7)$ & 20 & $9.5(6.3)$ & 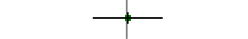 & $6.7 \%$ & $0.02[-0.6,0.64]$ \\
\hline Winstein 2016 & 102 & $1.4(0.8)$ & 100 & $1.3(0.8)$ & 4 & $11.54 \%$ & $0.12[-0.15,0.4]$ \\
\hline Yen 2005 & 13 & $-2.6(0.9)$ & 17 & $-3.1(1.5)$ & + & $5.58 \%$ & $0.36[-0.37,1.09]$ \\
\hline 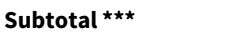 & 253 & & 256 & & $\checkmark$ & $57.65 \%$ & $0.14[-0.03,0.32]$ \\
\hline \multicolumn{8}{|c|}{ Heterogeneity: $\operatorname{Tau}^{2}=0 ; \mathrm{Chi}^{2}=3.48, \mathrm{df}=7(\mathrm{P}=0.84) ;\left.\right|^{2}=0 \%$} \\
\hline \multicolumn{8}{|c|}{ Test for overall effect: $Z=1.6(P=0.11)$} \\
\hline \multicolumn{8}{|c|}{ 3.3.3 Single task training } \\
\hline de Sèze 2001 & 10 & $3.3(0.8)$ & 10 & $3(0.8)$ & $\ldots$ & $4.34 \%$ & $0.36[-0.53,1.24]$ \\
\hline Dean 1997 & 10 & $12(1)$ & 9 & $10.8(0.9)$ & 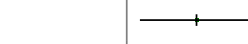 & $3.63 \%$ & $1.24[0.23,2.24]$ \\
\hline Dean 2007 & 6 & $1.3(0.1)$ & 6 & $1.1(0.1)$ & & $2.2 \%$ & $1.59[0.22,2.96]$ \\
\hline Howe 2005 & 15 & $-1.9(0.8)$ & 18 & $-2.1(0.7)$ & 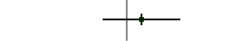 & $5.97 \%$ & $0.26[-0.43,0.95]$ \\
\hline Subtotal ${ }^{\star \star \star}$ & 41 & & 43 & & & $16.13 \%$ & $0.71[0.11,1.3]$ \\
\hline \multicolumn{8}{|c|}{ Heterogeneity: $\mathrm{Tau}^{2}=0.13 ; \mathrm{Chi}^{2}=4.75, \mathrm{df}=3(\mathrm{P}=0.19) ; \mathrm{I}^{2}=36.87 \%$} \\
\hline \multicolumn{8}{|c|}{ Test for overall effect: $Z=2.34(P=0.02)$} \\
\hline Total $* \star \star$ & 415 & & 418 & & 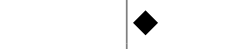 & $100 \%$ & $0.33[0.11,0.56]$ \\
\hline \multicolumn{8}{|c|}{ Heterogeneity: $\operatorname{Tau}^{2}=0.09 ; \mathrm{Chi}^{2}=30.14, \mathrm{df}=14(\mathrm{P}=0.01) ; \mathrm{I}^{2}=53.55 \%$} \\
\hline \multicolumn{8}{|c|}{ Test for overall effect: $Z=2.94(P=0)$} \\
\hline Test for subgroup diffe & $1, \mathrm{df}=$ & $P=0.13), I^{2}=50$ & & & & & \\
\hline
\end{tabular}


Comparison 4. Lower limb function: post treatment

\begin{tabular}{|c|c|c|c|c|}
\hline Outcome or subgroup title & No. of studies & $\begin{array}{l}\text { No. of partici- } \\
\text { pants }\end{array}$ & Statistical method & Effect size \\
\hline $\begin{array}{l}1 \text { Walking distance: change } \\
\text { from baseline }\end{array}$ & 9 & 610 & Mean Difference (IV, Random, 95\% CI) & $\begin{array}{l}34.80[18.19 \\
51.41]\end{array}$ \\
\hline 2 Walking speed & 12 & 685 & $\begin{array}{l}\text { Std. Mean Difference (IV, Random, } \\
95 \% \mathrm{Cl})\end{array}$ & $0.39[-0.02,0.79]$ \\
\hline 3 Functional ambulation & 8 & 525 & $\begin{array}{l}\text { Std. Mean Difference (IV, Random, } \\
95 \% \mathrm{CI})\end{array}$ & $0.35[0.04,0.66]$ \\
\hline $\begin{array}{l}4 \text { Sit-to-stand: post treat- } \\
\text { ment/change from baseline }\end{array}$ & 7 & 346 & Std. Mean Difference (Fixed, 95\% Cl) & $0.35[0.13,0.56]$ \\
\hline $\begin{array}{l}5 \text { Lower limb functional mea- } \\
\text { sures }\end{array}$ & 5 & 419 & $\begin{array}{l}\text { Std. Mean Difference (IV, Fixed, 95\% } \\
\mathrm{CI} \text { ) }\end{array}$ & $0.29[0.10,0.48]$ \\
\hline 6 Standing balance/reach & 9 & 504 & $\begin{array}{l}\text { Std. Mean Difference (IV, Fixed, 95\% } \\
\mathrm{Cl} \text { ) }\end{array}$ & $0.24[0.07,0.42]$ \\
\hline
\end{tabular}

Analysis 4.1. Comparison 4 Lower limb function: post treatment, Outcome 1 Walking distance: change from baseline.

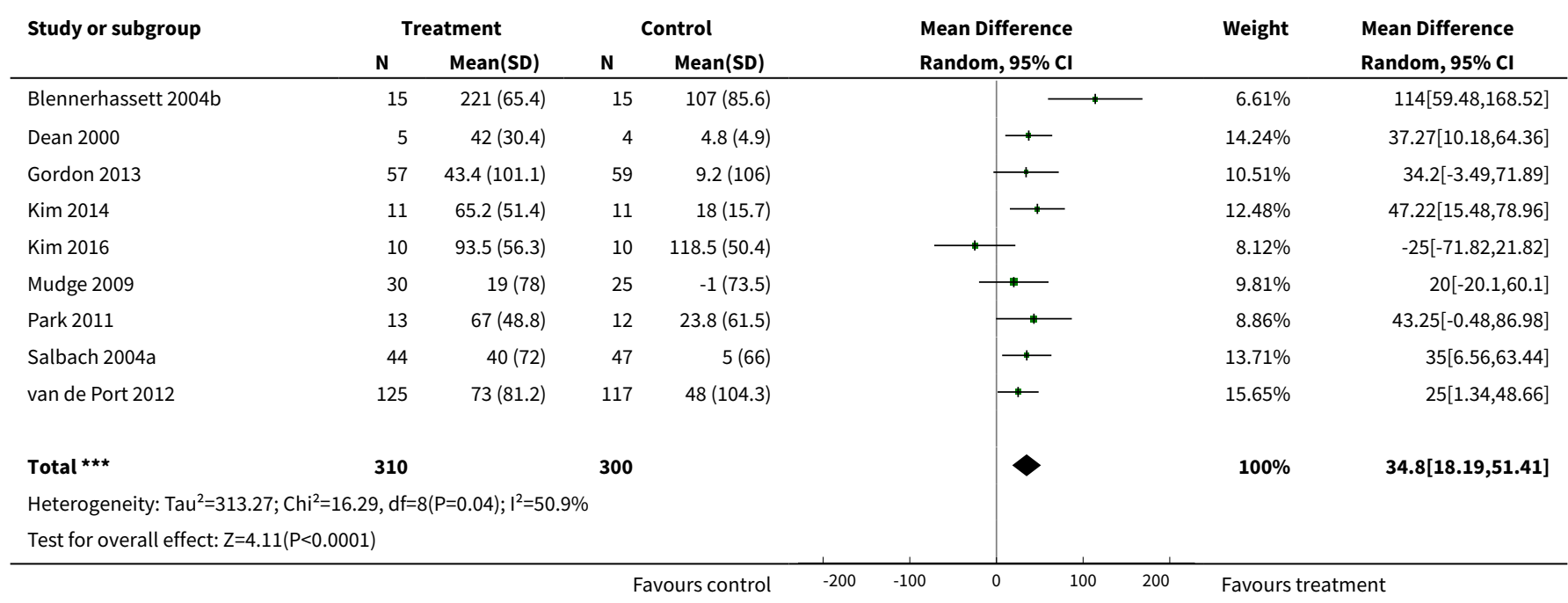

Analysis 4.2. Comparison 4 Lower limb function: post treatment, Outcome 2 Walking speed.

\begin{tabular}{|c|c|c|c|c|c|c|c|c|}
\hline \multirow[t]{2}{*}{ Study or subgroup } & \multicolumn{2}{|c|}{ Treatment } & \multicolumn{2}{|c|}{ Control } & \multirow{2}{*}{\multicolumn{2}{|c|}{$\begin{array}{c}\text { Std. Mean Difference } \\
\text { Random, } 95 \% \mathrm{Cl}\end{array}$}} & \multirow[t]{2}{*}{ Weight } & \multirow{2}{*}{$\begin{array}{c}\text { Std. Mean Difference } \\
\text { Random, } 95 \% \mathrm{Cl}\end{array}$} \\
\hline & $\mathbf{N}$ & Mean(SD) & $\mathbf{N}$ & Mean(SD) & & & & \\
\hline Dean 1997 & 10 & $0.4(0.2)$ & 8 & $0.6(0.3)$ & $\rightarrow$ & & $7.19 \%$ & $-0.81[-1.79,0.17]$ \\
\hline
\end{tabular}




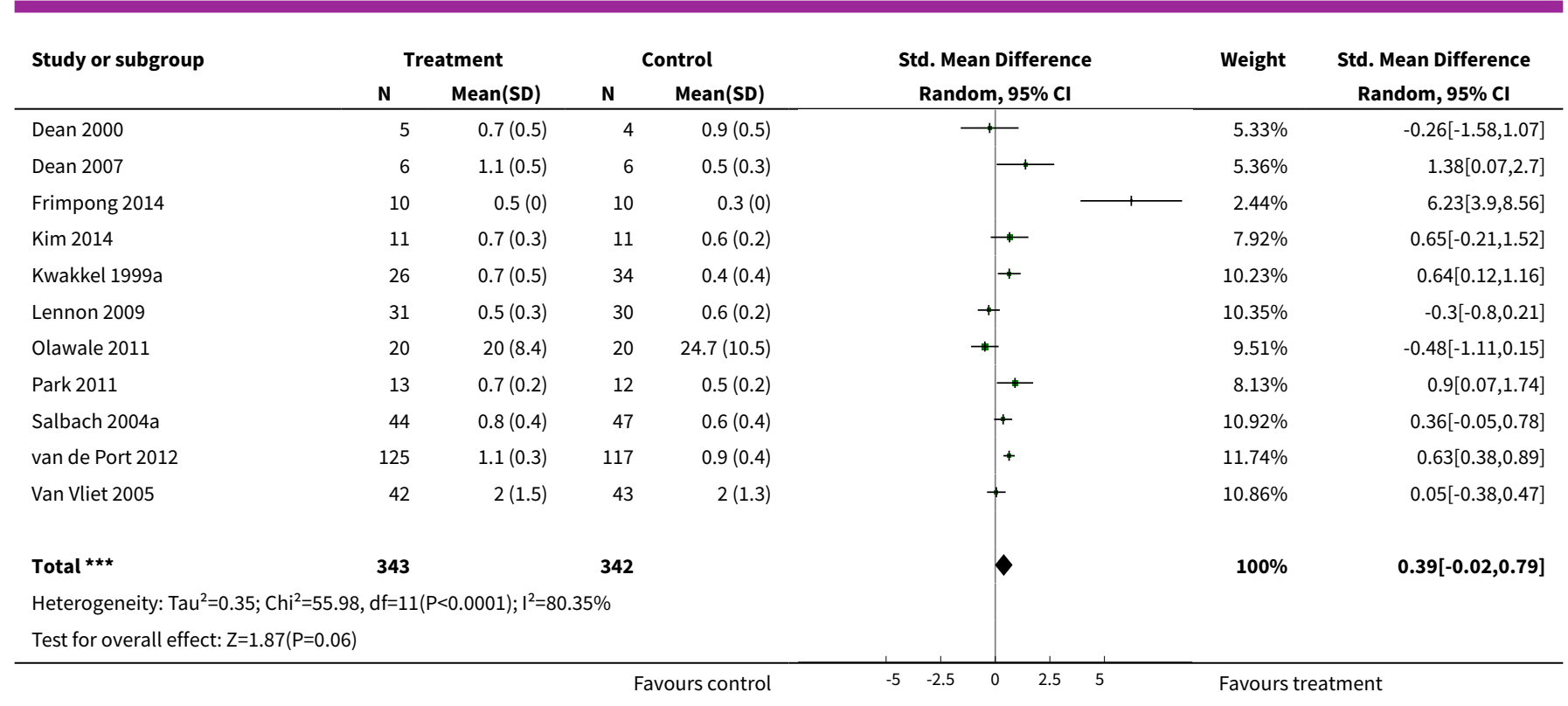

\section{Analysis 4.3. Comparison 4 Lower limb function: post treatment, Outcome 3 Functional ambulation.}

\begin{tabular}{|c|c|c|c|c|c|c|c|}
\hline \multirow[t]{2}{*}{ Study or subgroup } & \multicolumn{2}{|c|}{ Treatment } & \multicolumn{2}{|c|}{ Control } & \multirow{2}{*}{$\begin{array}{c}\text { Std. Mean Difference } \\
\text { Random, } 95 \% \mathrm{Cl}\end{array}$} & \multirow[t]{2}{*}{ Weight } & \multirow{2}{*}{$\begin{array}{c}\text { Std. Mean Difference } \\
\text { Random, } 95 \% \mathrm{Cl}\end{array}$} \\
\hline & $\mathbf{N}$ & Mean(SD) & $\mathbf{N}$ & $\operatorname{Mean}(S D)$ & & & \\
\hline de Sèze 2001 & 10 & $2.6(1.4)$ & 10 & $1.6(1.5)$ & $\longrightarrow$ & $8.07 \%$ & $0.66[-0.25,1.57]$ \\
\hline Frimpong 2014 & 10 & $4.6(0.5)$ & 10 & $3.4(0.5)$ & & $5.44 \%$ & $2.3[1.12,3.48]$ \\
\hline Kwakkel 1999a & 25 & $4(1)$ & 34 & $3(2)$ & $\longrightarrow$ & $14.72 \%$ & $0.6[0.07,1.12]$ \\
\hline Langhammer 2000 & 29 & $4(1.6)$ & 24 & $3.8(2)$ & 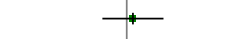 & $14.41 \%$ & $0.11[-0.43,0.65]$ \\
\hline McClellan 2004 & 12 & $4.3(1.2)$ & 9 & $4.7(1)$ & $\longrightarrow$ & $8.49 \%$ & $-0.34[-1.21,0.53]$ \\
\hline van de Port 2012 & 125 & $87.3(12.4)$ & 117 & $83.7(13.3)$ & *- & $21.87 \%$ & $0.28[0.02,0.53]$ \\
\hline Van Vliet 2005 & 42 & $3.7(1.6)$ & 43 & $3.4(1.9)$ & + & $17.28 \%$ & $0.17[-0.25,0.6]$ \\
\hline Total $* \star \star$ & 266 & & 259 & & & $100 \%$ & $0.35[0.04,0.66]$ \\
\hline \multicolumn{8}{|c|}{ Heterogeneity: $\mathrm{Tau}^{2}=0.1 ; \mathrm{Chi}^{2}=15.96, \mathrm{df}=7(\mathrm{P}=0.03) ; \mathrm{I}^{2}=56.15 \%$} \\
\hline \multicolumn{3}{|c|}{ Test for overall effect: $Z=2.22(P=0.03)$} & & & & & \\
\hline
\end{tabular}

\section{Analysis 4.4. Comparison 4 Lower limb function: post treatment, Outcome 4 Sit-to-stand: post treatment/change from baseline.}

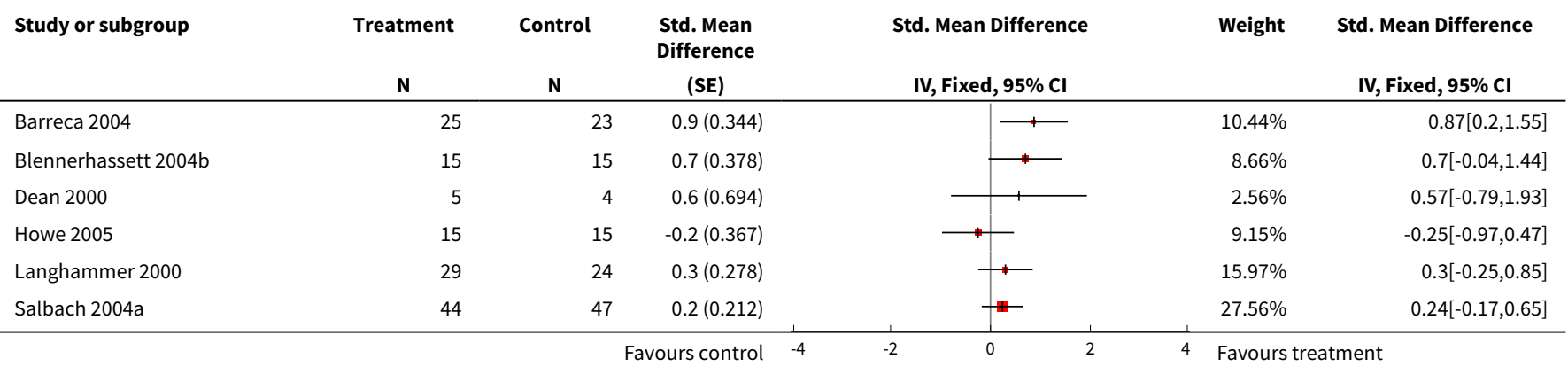




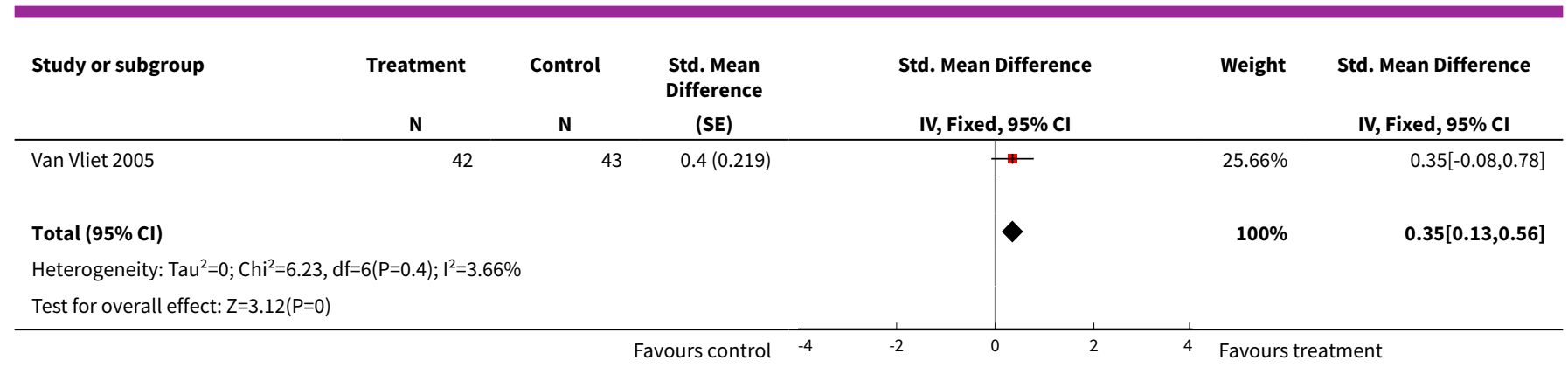

\section{Analysis 4.5. Comparison 4 Lower limb function: post treatment, Outcome 5 Lower limb functional measures.}

\begin{tabular}{|c|c|c|c|c|c|c|c|}
\hline \multirow{3}{*}{$\begin{array}{l}\text { Study or subgroup } \\
\text { Blennerhassett 2004b }\end{array}$} & \multicolumn{2}{|c|}{ Treatment } & \multicolumn{2}{|c|}{ Control } & \multirow{2}{*}{$\begin{array}{c}\text { Std. Mean Difference } \\
\text { Fixed, } 95 \% \mathrm{Cl}\end{array}$} & \multirow[t]{2}{*}{ Weight } & \multirow{2}{*}{$\begin{array}{c}\text { Std. Mean Difference } \\
\text { Fixed, } 95 \% \mathrm{Cl}\end{array}$} \\
\hline & $\mathbf{N}$ & $\operatorname{Mean}(S D)$ & $\mathbf{N}$ & Mean(SD) & & & \\
\hline & 15 & $11.1(5)$ & 15 & $8.5(4.6)$ & \# & $7.01 \%$ & $0.53[-0.2,1.26]$ \\
\hline Dean 2000 & 5 & $9.8(4)$ & 4 & $5.8(4.3)$ & \begin{tabular}{l|l} 
& 1
\end{tabular} & $1.86 \%$ & $0.86[-0.56,2.28]$ \\
\hline Langhammer 2000 & 29 & $41(18)$ & 24 & $39(21)$ & $\longrightarrow$ & $12.74 \%$ & $0.1[-0.44,0.64]$ \\
\hline van de Port 2012 & 125 & $76.4(19.2)$ & 117 & $69.2(21.2)$ & + & $57.78 \%$ & $0.36[0.1,0.61]$ \\
\hline Van Vliet 2005 & 42 & $5.6(4)$ & 43 & $5.2(4.3)$ & 7 & $20.62 \%$ & $0.09[-0.34,0.52]$ \\
\hline Total ${ }^{\star \star \star}$ & 216 & & 203 & & $\diamond$ & $100 \%$ & $0.29[0.1,0.48]$ \\
\hline \multicolumn{8}{|c|}{ Heterogeneity: $\mathrm{Tau}^{2}=0 ; \mathrm{Chi}^{2}=2.6, \mathrm{df}=4(\mathrm{P}=0.63) ; \mathrm{I}^{2}=0 \%$} \\
\hline \multicolumn{8}{|c|}{ Test for overall effect: $Z=2.94(P=0)$} \\
\hline
\end{tabular}

Analysis 4.6. Comparison 4 Lower limb function: post treatment, Outcome 6 Standing balance/reach.

\begin{tabular}{|c|c|c|c|c|c|c|c|}
\hline \multirow[t]{2}{*}{ Study or subgroup } & \multicolumn{2}{|c|}{ Treatment } & \multicolumn{2}{|c|}{ Control } & \multirow{2}{*}{$\begin{array}{c}\text { Std. Mean Difference } \\
\text { Fixed, } 95 \% \mathrm{Cl} \\
\end{array}$} & \multirow[t]{2}{*}{ Weight } & \multirow{2}{*}{$\begin{array}{c}\text { Std. Mean Difference } \\
\text { Fixed, } 95 \% \mathrm{Cl}\end{array}$} \\
\hline & $\mathbf{N}$ & Mean(SD) & $\mathbf{N}$ & $\operatorname{Mean}(S D)$ & & & \\
\hline de Sèze 2001 & 10 & $2.4(1.6)$ & 10 & $2(0.8)$ & \begin{tabular}{l|l}
1 \\
\end{tabular} & $3.99 \%$ & $0.3[-0.58,1.19]$ \\
\hline Holmgren 2010 & 14 & $45.2(9)$ & 19 & $45.5(7.7)$ & 1 & $6.52 \%$ & $-0.04[-0.73,0.66]$ \\
\hline Kim 2012 & 10 & $50.1(4.1)$ & 10 & $44.6(10.2)$ & $\longrightarrow$ & $3.77 \%$ & $0.68[-0.23,1.59]$ \\
\hline Kim 2016 & 10 & $46.7(9.4)$ & 10 & $49.8(4.6)$ & \begin{tabular}{l|l}
+ &
\end{tabular} & $3.94 \%$ & $-0.4[-1.29,0.49]$ \\
\hline McClellan 2004 & 12 & $21.9(9.4)$ & 9 & $17.8(7.4)$ & 1 & $4.03 \%$ & $0.46[-0.42,1.33]$ \\
\hline Salbach 2004a & 44 & $44(11)$ & 47 & $41(13)$ & 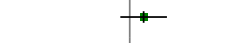 & $18.23 \%$ & $0.25[-0.17,0.66]$ \\
\hline Tung 2010 & 16 & $48.3(4.6)$ & 16 & $49.4(4.4)$ & 1 & $6.42 \%$ & $-0.24[-0.93,0.46]$ \\
\hline van de Port 2012 & 125 & $4.1(1)$ & 117 & $3.7(1.1)$ & \# & $48.28 \%$ & $0.31[0.05,0.56]$ \\
\hline Total $\star \star \star ~$ & 254 & & 250 & & 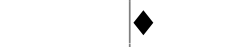 & $100 \%$ & $0.24[0.07,0.42]$ \\
\hline \multicolumn{8}{|c|}{ Heterogeneity: $\mathrm{Tau}^{2}=0 ; \mathrm{Chi}^{2}=6.39, \mathrm{df}=8(\mathrm{P}=0.6) ; \mathrm{I}^{2}=0 \%$} \\
\hline
\end{tabular}


Comparison 5. Lower limb function: follow-up

\begin{tabular}{lllll}
\hline Outcome or subgroup title & No. of studies & $\begin{array}{l}\text { No. of partici- } \\
\text { pants }\end{array}$ & Statistical method & Effect size \\
\hline 1 All outcomes & 12 & & Std. Mean Difference (IV, Fixed, 95\% CI) & Subtotals only \\
\hline $\begin{array}{l}1.1 \text { Under } 6 \text { months post } \\
\text { treatment }\end{array}$ & 8 & 471 & Std. Mean Difference (IV, Fixed, 95\% Cl) & $0.34[0.16,0.52]$ \\
\hline $\begin{array}{l}1.26 \text { to } 12 \text { months post } \\
\text { treatment }\end{array}$ & 6 & 268 & Std. Mean Difference (IV, Fixed, 95\% Cl) & $0.06[-0.18,0.31]$ \\
\hline
\end{tabular}

Analysis 5.1. Comparison 5 Lower limb function: follow-up, Outcome 1 All outcomes.

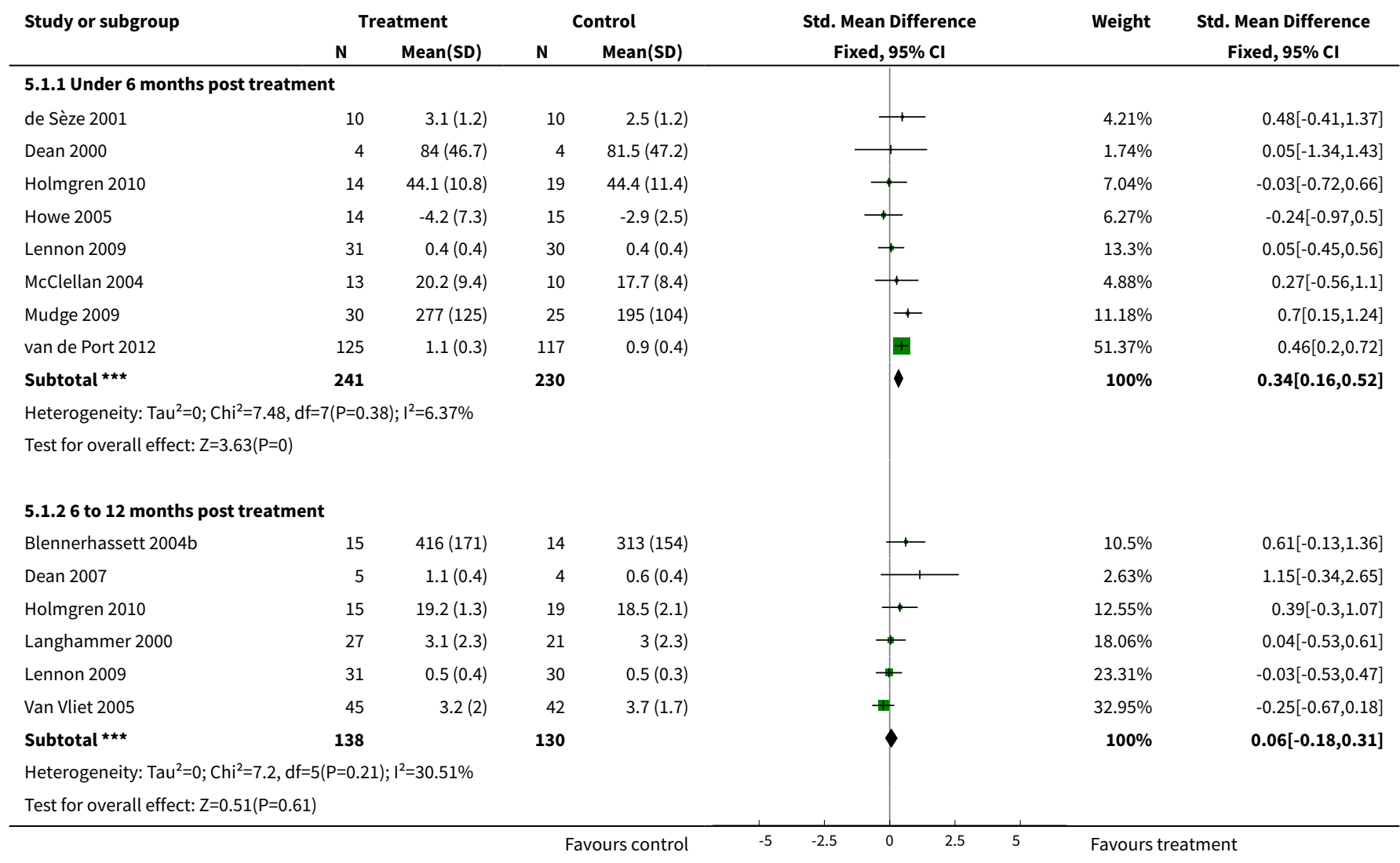

\section{Comparison 6. Lower limb function: subgroup analyses}

\begin{tabular}{lllll}
\hline $\begin{array}{l}\text { Outcome or subgroup } \\
\text { title }\end{array}$ & No. of studies & $\begin{array}{l}\text { No. of partici- } \\
\text { pants }\end{array}$ & Statistical method & Effect size \\
\hline $\begin{array}{l}1 \text { Dosage of task prac- } \\
\text { tice }\end{array}$ & 24 & 1144 & Std. Mean Difference (IV, Random, 95\% Cl) & $0.32[0.12,0.53]$ \\
\hline 1.10 to 20 hours & 16 & 583 & Std. Mean Difference (IV, Random, 95\% Cl) & $0.39[0.07,0.71]$ \\
\hline
\end{tabular}




\begin{tabular}{|c|c|c|c|c|}
\hline $\begin{array}{l}\text { Outcome or subgroup } \\
\text { title }\end{array}$ & No. of studies & $\begin{array}{l}\text { No. of partici- } \\
\text { pants }\end{array}$ & Statistical method & Effect size \\
\hline 1.2 More than 20 hours & 8 & 561 & Std. Mean Difference (IV, Random, 95\% CI) & $0.33[0.16,0.50]$ \\
\hline 2 Time since stroke & 24 & 1144 & Std. Mean Difference (IV, Random, 95\% CI) & $0.32[0.12,0.53]$ \\
\hline 2.10 to 15 days & 5 & 288 & Std. Mean Difference (IV, Random, 95\% CI) & $0.16[-0.15,0.46]$ \\
\hline 2.216 days to 6 months & 9 & 428 & Std. Mean Difference (IV, Random, 95\% CI) & $0.52[-0.03,1.07]$ \\
\hline 2.3 More than 6 months & 10 & 428 & Std. Mean Difference (IV, Random, 95\% CI) & $0.41[0.21,0.60]$ \\
\hline 3 Type of intervention & 24 & 1144 & Std. Mean Difference (IV, Random, 95\% CI) & $0.32[0.12,0.53]$ \\
\hline 3.1 Whole therapy & 2 & 138 & Std. Mean Difference (IV, Random, 95\% CI) & $0.10[-0.24,0.43]$ \\
\hline 3.2 Mixed training & 17 & 894 & Std. Mean Difference (IV, Random, 95\% CI) & $0.42[0.17,0.67]$ \\
\hline 3.3 Single task training & 5 & 112 & Std. Mean Difference (IV, Random, 95\% CI) & $0.07[-0.42,0.55]$ \\
\hline
\end{tabular}

Analysis 6.1. Comparison 6 Lower limb function: subgroup analyses, Outcome 1 Dosage of task practice.

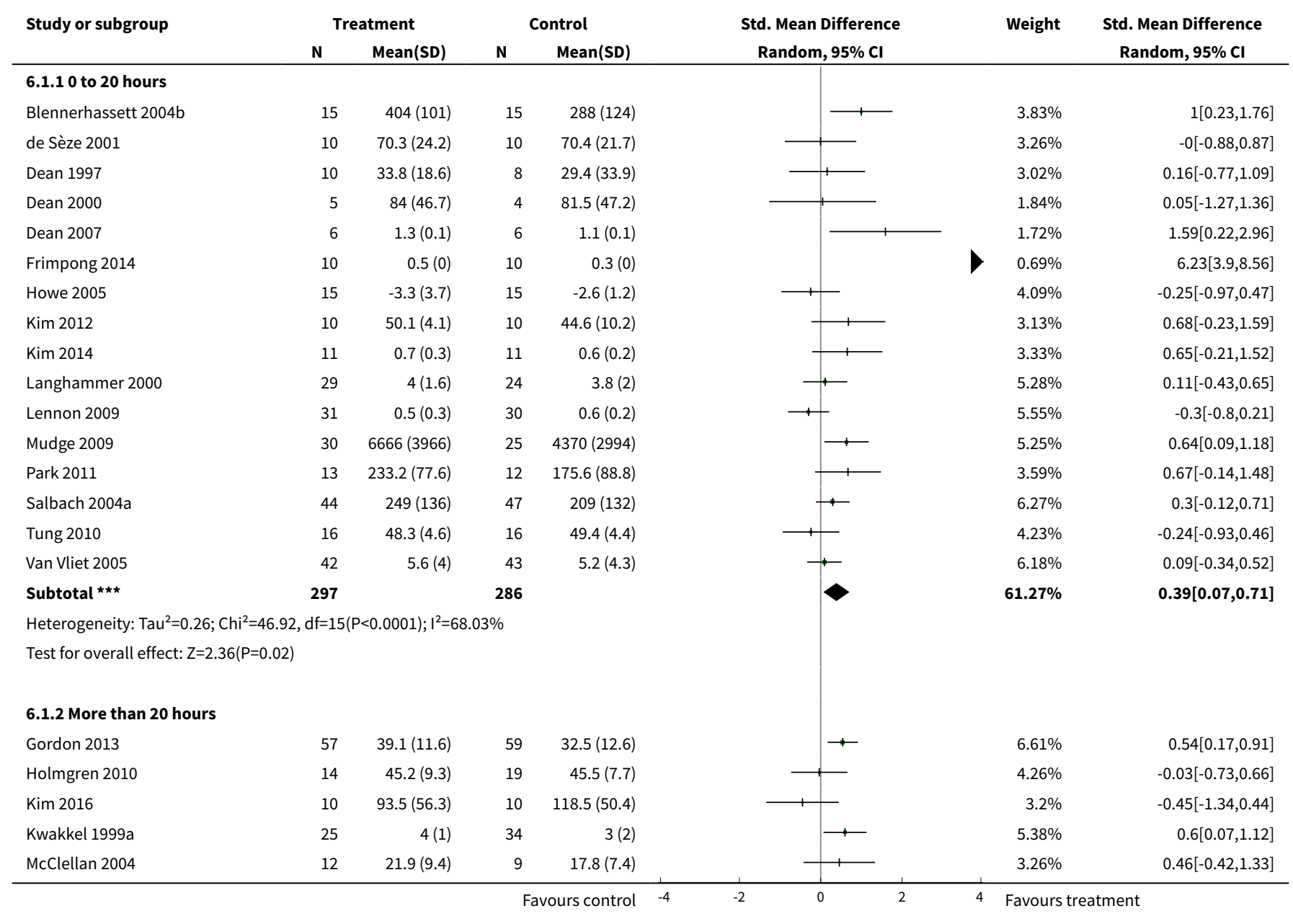




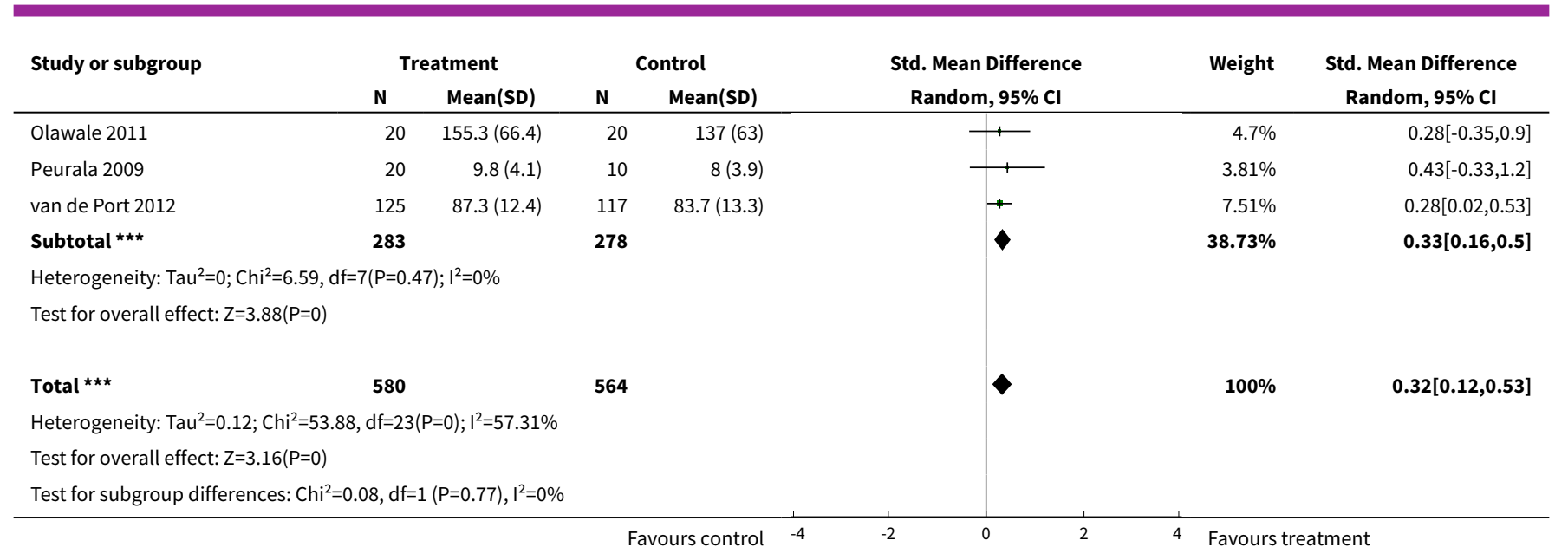

Analysis 6.2. Comparison 6 Lower limb function: subgroup analyses, Outcome 2 Time since stroke.

\begin{tabular}{|c|c|c|c|c|c|c|c|}
\hline \multirow[t]{2}{*}{ Study or subgroup } & \multicolumn{2}{|c|}{ Treatment } & \multicolumn{2}{|c|}{ Control } & \multirow{2}{*}{$\begin{array}{c}\text { Std. Mean Difference } \\
\text { Random, } 95 \% \mathrm{Cl}\end{array}$} & \multirow[t]{2}{*}{ Weight } & \multirow{2}{*}{$\begin{array}{c}\text { Std. Mean Difference } \\
\text { Random, } 95 \% \mathrm{Cl}\end{array}$} \\
\hline & $\mathbf{N}$ & Mean(SD) & $\mathbf{N}$ & Mean(SD) & & & \\
\hline \multicolumn{8}{|l|}{ 6.2.1 0 to 15 days } \\
\hline Kwakkel 1999a & 25 & $4(1)$ & 34 & $3(2)$ & $\longrightarrow$ & $5.38 \%$ & $0.6[0.07,1.12]$ \\
\hline Langhammer 2000 & 29 & $4(1.6)$ & 24 & $3.8(2)$ & 1 & $5.28 \%$ & $0.11[-0.43,0.65]$ \\
\hline Lennon 2009 & 31 & $0.5(0.3)$ & 30 & $0.6(0.2)$ & $\longrightarrow$ & $5.55 \%$ & $-0.3[-0.8,0.21]$ \\
\hline Peurala 2009 & 20 & $9.8(4.1)$ & 10 & $8(3.9)$ & & $3.81 \%$ & $0.43[-0.33,1.2]$ \\
\hline Van Vliet 2005 & 42 & $5.6(4)$ & 43 & $5.2(4.3)$ & . & $6.18 \%$ & $0.09[-0.34,0.52]$ \\
\hline Subtotal $* \star \star$ & 147 & & 141 & & & $26.19 \%$ & $0.16[-0.15,0.46]$ \\
\hline \multicolumn{8}{|c|}{ Heterogeneity: $\mathrm{Tau}^{2}=0.04 ; \mathrm{Chi}^{2}=6.38, \mathrm{df}=4(\mathrm{P}=0.17) ; \mathrm{I}^{2}=37.26 \%$} \\
\hline \multicolumn{8}{|c|}{ Test for overall effect: $Z=1.01(P=0.31)$} \\
\hline \multicolumn{8}{|c|}{ 6.2.2 16 days to 6 months } \\
\hline Blennerhassett 2004b & 15 & $404(101)$ & 15 & $288(124)$ & + & $3.83 \%$ & $1[0.23,1.76]$ \\
\hline de Sèze 2001 & 10 & $70.3(24.2)$ & 10 & $70.4(21.7)$ & & $3.26 \%$ & $-0[-0.88,0.87]$ \\
\hline Dean 2007 & 6 & $1.3(0.1)$ & 6 & $1.1(0.1)$ & & $1.72 \%$ & $1.59[0.22,2.96]$ \\
\hline Frimpong 2014 & 10 & $0.5(0)$ & 10 & $0.3(0)$ & & $0.69 \%$ & $6.23[3.9,8.56]$ \\
\hline Holmgren 2010 & 14 & $45.2(9.3)$ & 19 & $45.5(7.7)$ & $\bar{v}$ & $4.26 \%$ & $-0.03[-0.73,0.66]$ \\
\hline Howe 2005 & 15 & $-3.3(3.7)$ & 15 & $-2.6(1.2)$ & & $4.09 \%$ & $-0.25[-0.97,0.47]$ \\
\hline Kim 2016 & 10 & $93.5(56.3)$ & 10 & $118.5(50.4)$ & - & $3.2 \%$ & $-0.45[-1.34,0.44]$ \\
\hline McClellan 2004 & 12 & $21.9(9.4)$ & 9 & $17.8(7.4)$ & 1 & $3.26 \%$ & $0.46[-0.42,1.33]$ \\
\hline van de Port 2012 & 125 & $87.3(12.4)$ & 117 & $83.7(13.3)$ & + & $7.51 \%$ & $0.28[0.02,0.53]$ \\
\hline 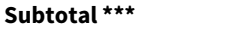 & 217 & & 211 & & & $31.83 \%$ & $0.52[-0.03,1.07]$ \\
\hline \multicolumn{8}{|c|}{ Heterogeneity: Tau $^{2}=0.49 ; \mathrm{Chi}^{2}=38.02, \mathrm{df}=8(\mathrm{P}<0.0001) ; \mathrm{I}^{2}=78.96 \%$} \\
\hline \multicolumn{8}{|c|}{ Test for overall effect: $Z=1.84(P=0.07)$} \\
\hline \multicolumn{8}{|c|}{ 6.2.3 More than 6 months } \\
\hline Dean 1997 & 10 & $33.8(18.6)$ & 8 & $29.4(33.9)$ & & $3.02 \%$ & $0.16[-0.77,1.09]$ \\
\hline Dean 2000 & 5 & $84(46.7)$ & 4 & $81.5(47.2)$ & & $1.84 \%$ & $0.05[-1.27,1.36]$ \\
\hline Gordon 2013 & 57 & $39.1(11.6)$ & 59 & $32.5(12.6)$ & $\rightarrow$ & $6.61 \%$ & $0.54[0.17,0.91]$ \\
\hline Kim 2012 & 10 & $50.1(4.1)$ & 10 & $44.6(10.2)$ & - & $3.13 \%$ & $0.68[-0.23,1.59]$ \\
\hline Kim 2014 & 11 & $0.7(0.3)$ & 11 & $0.6(0.2)$ & & $3.33 \%$ & $0.65[-0.21,1.52]$ \\
\hline Mudge 2009 & 30 & 6666 (3966) & 25 & 4370 (2994) & $\longrightarrow$ & $5.25 \%$ & $0.64[0.09,1.18]$ \\
\hline Olawale 2011 & 20 & $155.3(66.4)$ & 20 & $137(63)$ & + & $4.7 \%$ & $0.28[-0.35,0.9]$ \\
\hline
\end{tabular}




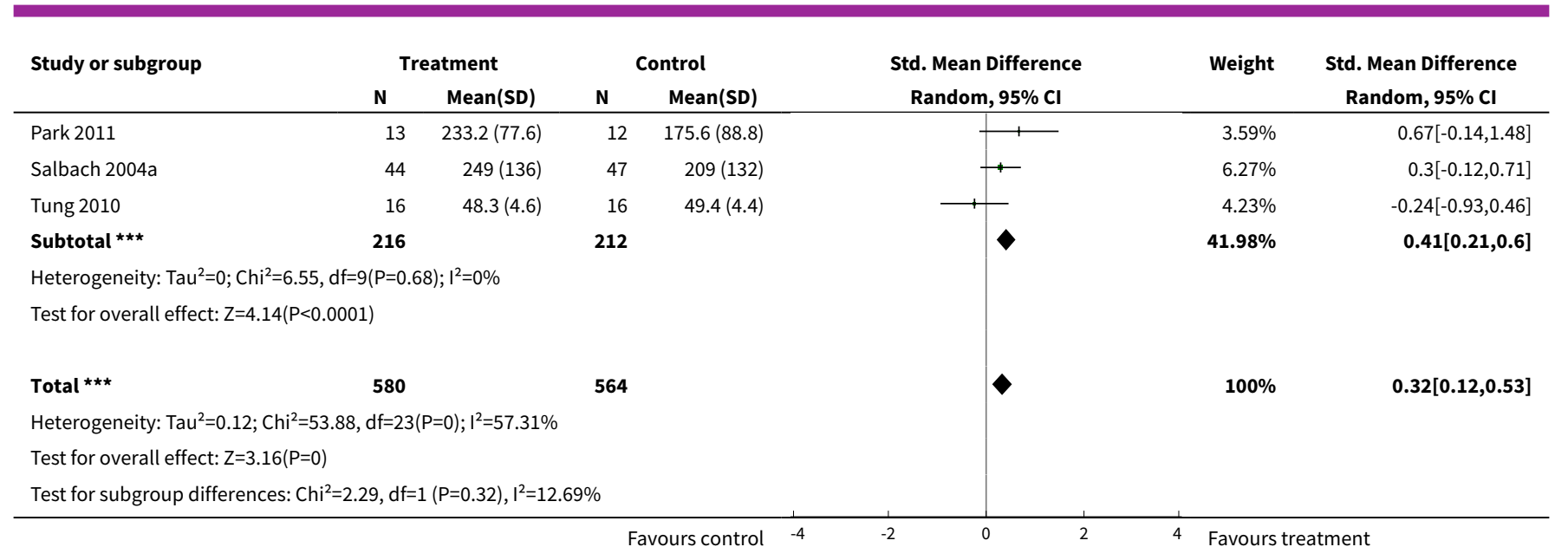

Analysis 6.3. Comparison 6 Lower limb function: subgroup analyses, Outcome 3 Type of intervention.

\begin{tabular}{|c|c|c|c|c|c|c|c|}
\hline \multirow[t]{2}{*}{ Study or subgroup } & \multicolumn{2}{|c|}{ Treatment } & \multicolumn{2}{|c|}{ Control } & \multirow{2}{*}{$\begin{array}{c}\text { Std. Mean Difference } \\
\text { Random, } 95 \% \mathrm{Cl}\end{array}$} & \multirow[t]{2}{*}{ Weight } & \multirow{2}{*}{$\begin{array}{l}\text { Std. Mean Difference } \\
\text { Random, } 95 \% \mathrm{Cl}\end{array}$} \\
\hline & $\mathbf{N}$ & Mean(SD) & $\mathbf{N}$ & Mean(SD) & & & \\
\hline \multicolumn{8}{|l|}{ 6.3.1 Whole therapy } \\
\hline Langhammer 2000 & 29 & $4(1.6)$ & 24 & $3.8(2)$ & + & $5.28 \%$ & $0.11[-0.43,0.65]$ \\
\hline Van Vliet 2005 & 42 & $5.6(4)$ & 43 & $5.2(4.3)$ & + & $6.18 \%$ & $0.09[-0.34,0.52]$ \\
\hline Subtotal $* \star \star$ & 71 & & 67 & & 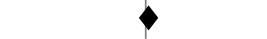 & $11.46 \%$ & $0.1[-0.24,0.43]$ \\
\hline \multicolumn{8}{|c|}{ Heterogeneity: $\operatorname{Tau}^{2}=0 ; \mathrm{Chi}^{2}=0, \mathrm{df}=1(\mathrm{P}=0.96) ; \mathrm{I}^{2}=0 \%$} \\
\hline \multicolumn{8}{|c|}{ Test for overall effect: $Z=0.57(P=0.57)$} \\
\hline \multicolumn{8}{|l|}{ 6.3.2 Mixed training } \\
\hline Blennerhassett 2004b & 15 & $404(101)$ & 15 & $288(124)$ & 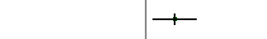 & $3.83 \%$ & $1[0.23,1.76]$ \\
\hline Dean 2000 & 5 & $84(46.7)$ & 4 & $81.5(47.2)$ & 1 & $1.84 \%$ & $0.05[-1.27,1.36]$ \\
\hline Frimpong 2014 & 10 & $0.5(0)$ & 10 & $0.3(0)$ & & $0.69 \%$ & $6.23[3.9,8.56]$ \\
\hline Gordon 2013 & 57 & $39.1(11.6)$ & 59 & $32.5(12.6)$ & + & $6.61 \%$ & $0.54[0.17,0.91]$ \\
\hline Holmgren 2010 & 14 & $45.2(9.3)$ & 19 & $45.5(7.7)$ & + & $4.26 \%$ & $-0.03[-0.73,0.66]$ \\
\hline Kim 2012 & 10 & $50.1(4.1)$ & 10 & $44.6(10.2)$ & 1 & $3.13 \%$ & $0.68[-0.23,1.59]$ \\
\hline Kim 2014 & 11 & $0.7(0.3)$ & 11 & $0.6(0.2)$ & 1 & $3.33 \%$ & $0.65[-0.21,1.52]$ \\
\hline Kim 2016 & 10 & $93.5(56.3)$ & 10 & $118.5(50.4)$ & 1 & $3.2 \%$ & $-0.45[-1.34,0.44]$ \\
\hline Kwakkel 1999a & 25 & $4(1)$ & 34 & $3(2)$ & + & $5.38 \%$ & $0.6[0.07,1.12]$ \\
\hline Lennon 2009 & 31 & $0.5(0.3)$ & 30 & $0.6(0.2)$ & + & $5.55 \%$ & $-0.3[-0.8,0.21]$ \\
\hline McClellan 2004 & 12 & $21.9(9.4)$ & 9 & $17.8(7.4)$ & 1 & $3.26 \%$ & $0.46[-0.42,1.33]$ \\
\hline Mudge 2009 & 30 & 6666 (3966) & 25 & 4370 (2994) & + & $5.25 \%$ & $0.64[0.09,1.18]$ \\
\hline Olawale 2011 & 20 & $155.3(66.4)$ & 20 & $137(63)$ & + & $4.7 \%$ & $0.28[-0.35,0.9]$ \\
\hline Park 2011 & 13 & $233.2(77.6)$ & 12 & $175.6(88.8)$ & 1 & $3.59 \%$ & $0.67[-0.14,1.48]$ \\
\hline Peurala 2009 & 20 & $9.8(4.1)$ & 10 & $8(3.9)$ & 1 & $3.81 \%$ & $0.43[-0.33,1.2]$ \\
\hline Salbach 2004a & 44 & $249(136)$ & 47 & $209(132)$ & + & $6.27 \%$ & $0.3[-0.12,0.71]$ \\
\hline van de Port 2012 & 125 & $87.3(12.4)$ & 117 & $83.7(13.3)$ & + & $7.51 \%$ & $0.28[0.02,0.53]$ \\
\hline Subtotal *** & 452 & & 442 & & $\downarrow$ & $72.21 \%$ & $0.42[0.17,0.67]$ \\
\hline \multicolumn{8}{|c|}{ Heterogeneity: $\mathrm{Tau}^{2}=0.15 ; \mathrm{Chi}^{2}=43.11, \mathrm{df}=16(\mathrm{P}=0) ; \mathrm{I}^{2}=62.88 \%$} \\
\hline \multicolumn{8}{|c|}{ Test for overall effect: $Z=3.33(P=0)$} \\
\hline \multicolumn{8}{|c|}{ 6.3.3 Single task training } \\
\hline de Sèze 2001 & 10 & $70.3(24.2)$ & 10 & $70.4(21.7)$ & 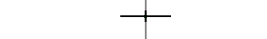 & $3.26 \%$ & $-0[-0.88,0.87]$ \\
\hline Dean 1997 & 10 & $33.8(18.6)$ & 8 & $29.4(33.9)$ & 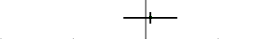 & $3.02 \%$ & $0.16[-0.77,1.09]$ \\
\hline
\end{tabular}




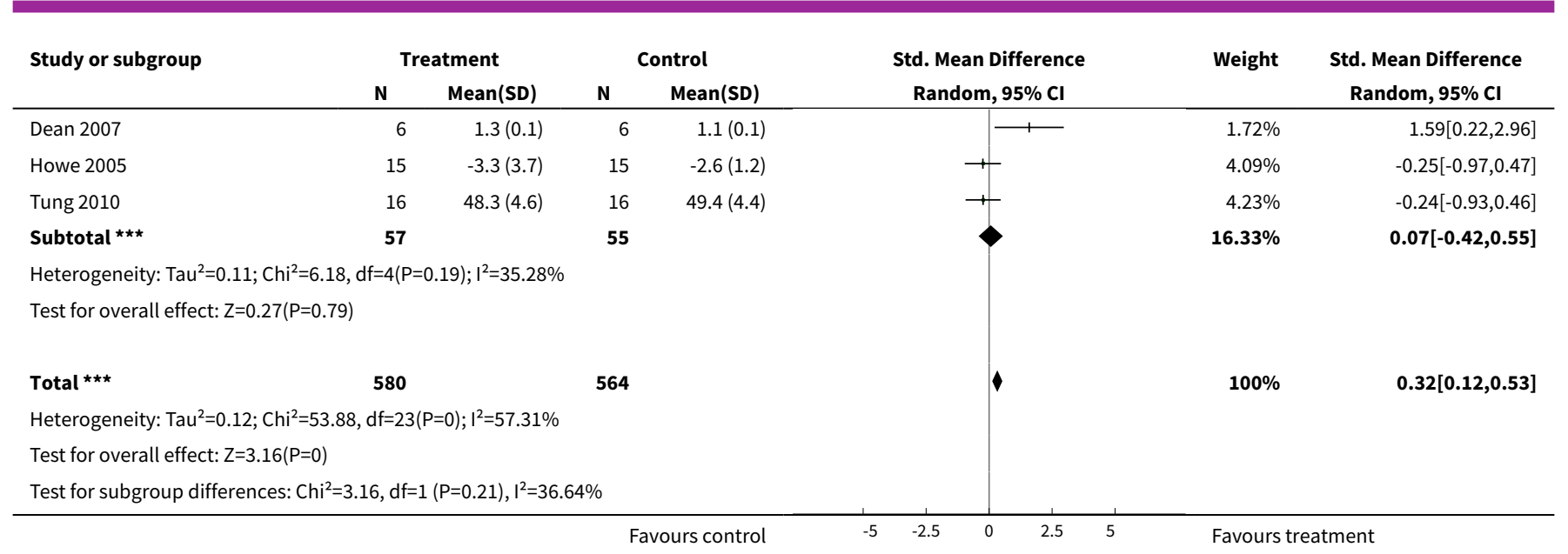

\section{Comparison 7. Secondary outcomes}

\begin{tabular}{llllll}
\hline Outcome or subgroup title & No. of studies & $\begin{array}{l}\text { No. of partici- } \\
\text { pants }\end{array}$ & Statistical method & Effect size \\
\hline $\begin{array}{l}1 \text { Activities of daily living func- } \\
\text { tion }\end{array}$ & 9 & 527 & $\begin{array}{l}\text { Std. Mean Difference (IV, Fixed, 95\% } \\
\text { CI) }\end{array}$ & 0.28 [0.10, 0.45] \\
\hline 2 Global motor function scales & 5 & 222 & $\begin{array}{l}\text { Std. Mean Difference (IV, Fixed, 95\% } \\
\text { CI) }\end{array}$ & $0.38[0.11,0.65]$ \\
\hline 3 Quality of life/health status & 4 & 264 & $\begin{array}{l}\text { Std. Mean Difference (IV, Fixed, 95\% } \\
\text { CI) }\end{array}$ & $0.28[0.04,0.53]$ \\
\hline
\end{tabular}

\section{Analysis 7.1. Comparison 7 Secondary outcomes, Outcome 1 Activities of daily living function.}

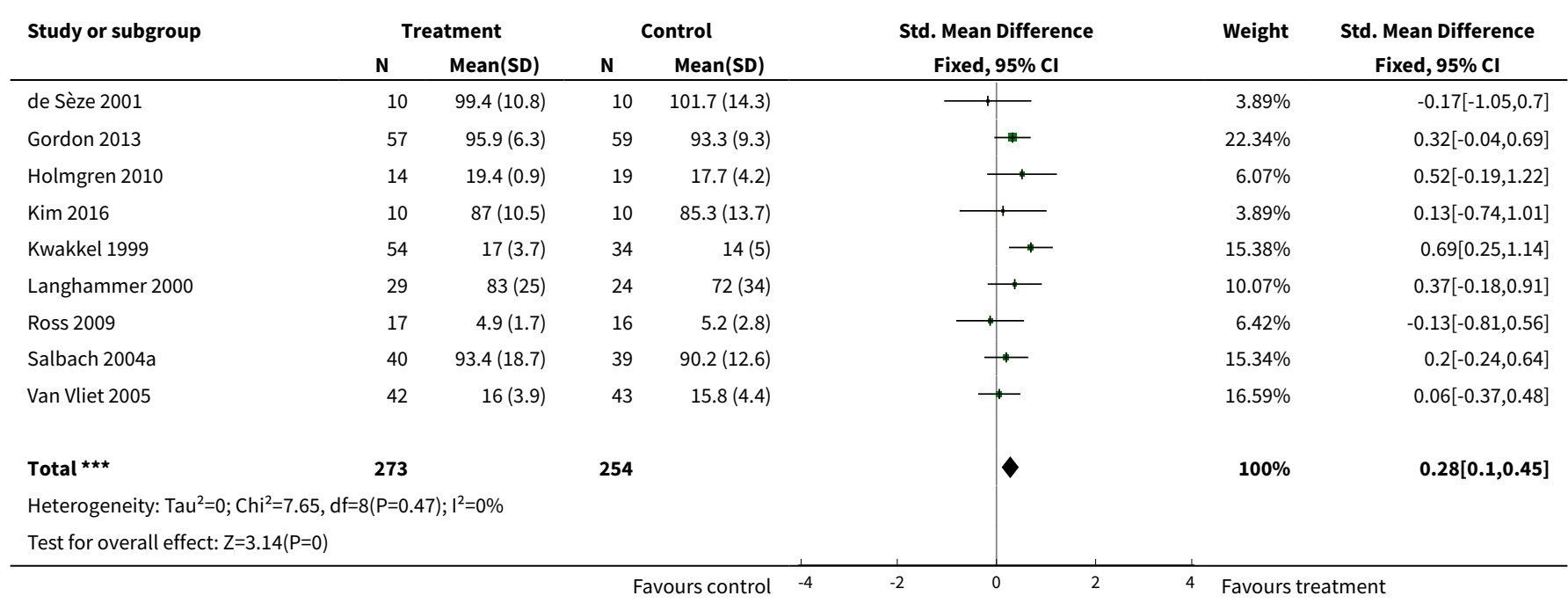


Analysis 7.2. Comparison 7 Secondary outcomes, Outcome 2 Global motor function scales.

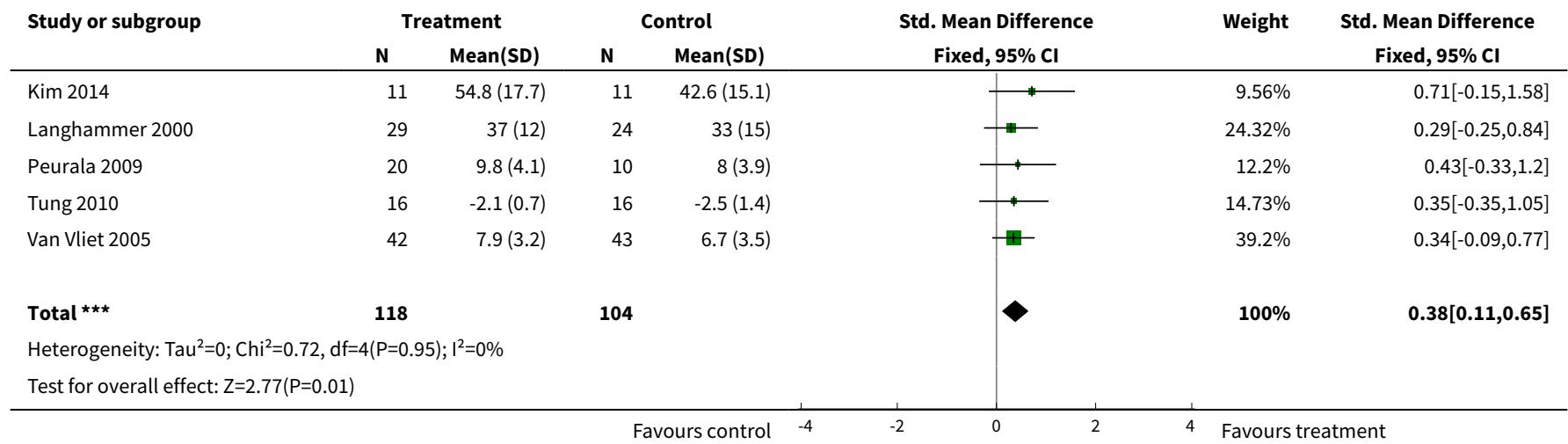

Analysis 7.3. Comparison 7 Secondary outcomes, Outcome 3 Quality of life/health status.

\begin{tabular}{|c|c|c|c|c|c|c|c|}
\hline \multirow[t]{2}{*}{ Study or subgroup } & \multicolumn{2}{|c|}{ Treatment } & \multicolumn{2}{|c|}{ Control } & \multirow{2}{*}{$\begin{array}{c}\text { Std. Mean Difference } \\
\text { Fixed, } 95 \% \mathrm{Cl}\end{array}$} & \multirow[t]{2}{*}{ Weight } & \multirow{2}{*}{$\begin{array}{c}\text { Std. Mean Difference } \\
\text { Fixed, } 95 \% \mathrm{Cl}\end{array}$} \\
\hline & $\mathbf{N}$ & Mean(SD) & $\mathbf{N}$ & Mean(SD) & & & \\
\hline Barreca 2004 & 21 & $-17.8(5)$ & 19 & $-17.2(4.3)$ & $\because$ & $15.4 \%$ & $-0.12[-0.75,0.5]$ \\
\hline Gordon 2013 & 57 & $39.1(11.6)$ & 59 & $32.5(12.6)$ & \# & $43.23 \%$ & $0.54[0.17,0.91]$ \\
\hline Kwakkel 1999 & 29 & $-9.8(8.1)$ & 26 & $-11.6(7.9)$ & + & $21.08 \%$ & $0.22[-0.31,0.75]$ \\
\hline Langhammer 2000 & 29 & $-22(18)$ & 24 & $-24(21)$ & 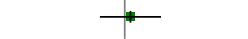 & $20.29 \%$ & $0.1[-0.44,0.64]$ \\
\hline \multicolumn{8}{|c|}{ Heterogeneity: $\mathrm{Tau}^{2}=0 ; \mathrm{Chi}^{2}=4, \mathrm{df}=3(\mathrm{P}=0.26) ; \mathrm{I}^{2}=24.95 \%$} \\
\hline \multicolumn{8}{|c|}{ Test for overall effect: $\mathrm{Z}=2.27(\mathrm{P}=0.02)$} \\
\hline
\end{tabular}




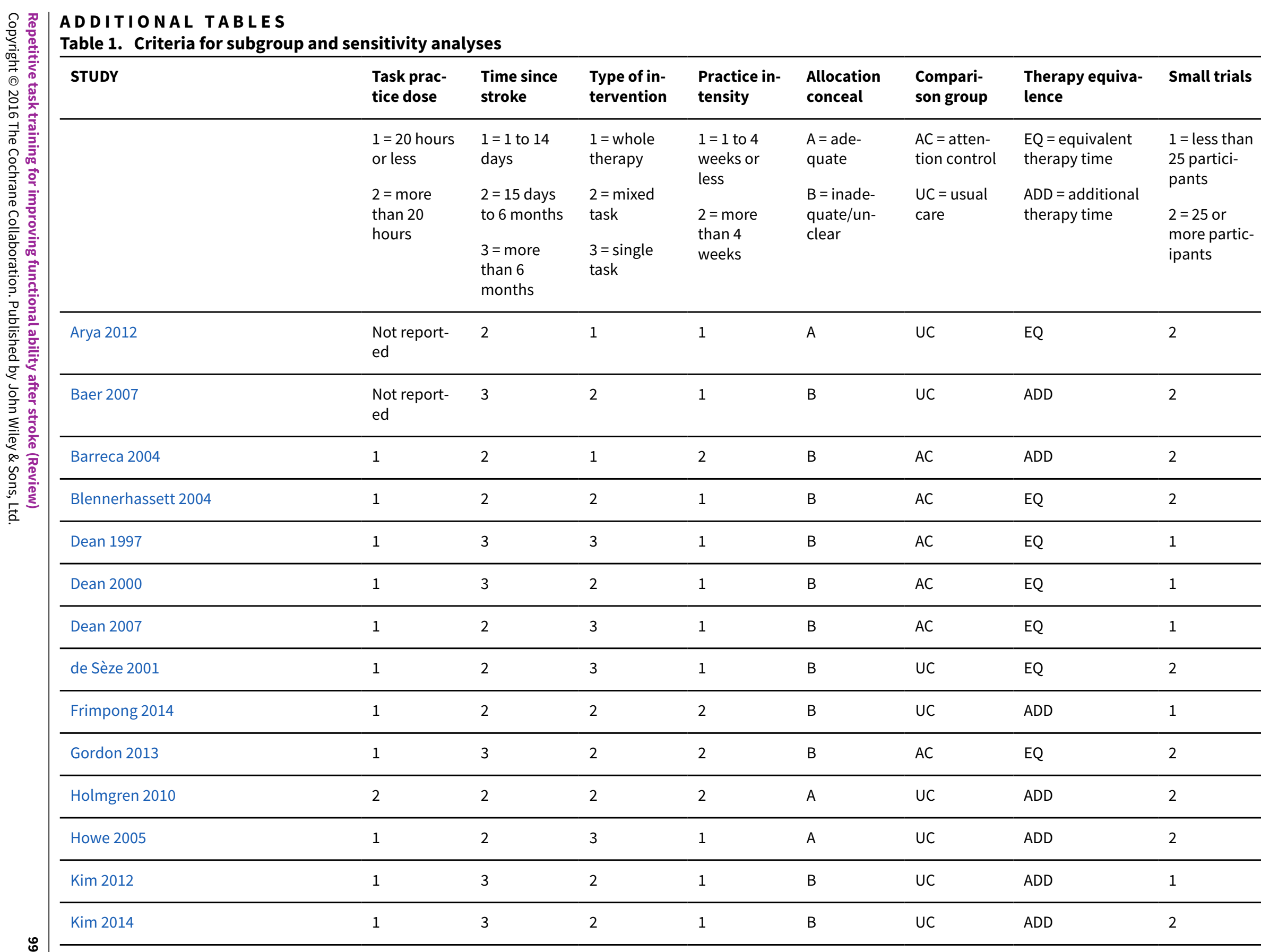




\begin{tabular}{|c|c|c|c|c|c|c|c|c|}
\hline Kim 2016 & 2 & 2 & 2 & 1 & B & UC & $A D D$ & 1 \\
\hline Kwakkel 1999 & 2 & 1 & 2 & 2 & B & $A C$ & $\mathrm{EQ}$ & 2 \\
\hline Langhammer 2000 & 1 & 1 & 1 & 1 & B & UC & $\mathrm{EQ}$ & 2 \\
\hline Lennon 2009 & 1 & 1 & 2 & 1 & B & UC & $\mathrm{EQ}$ & 2 \\
\hline McClellan 2004 & 2 & 3 & 2 & 2 & B & $A C$ & EQ & 2 \\
\hline Mudge 2009 & 1 & 3 & 2 & 1 & B & $A C$ & EQ & 2 \\
\hline Olawale 2011 & 2 & 3 & 2 & 2 & B & UC & $\mathrm{EQ}$ & 2 \\
\hline Park 2011 & 1 & 3 & 2 & 1 & B & UC & ADD & 2 \\
\hline Peurala 2009 & 2 & 1 & 2 & 1 & B & UC & $A D D$ & 2 \\
\hline Ross 2009 & 2 & 3 & 2 & 2 & $A$ & UC & $A D D$ & 2 \\
\hline Salbach 2004 & 1 & 3 & 2 & 2 & B & $A C$ & $\mathrm{EQ}$ & 2 \\
\hline Song 2015 & 1 & 3 & 2 & 1 & $B$ & UC & ADD & 1 \\
\hline Tung 2010 & 1 & 3 & 1 & 1 & B & UC & ADD & 2 \\
\hline Turton 1990 & 2 & 2 & 2 & 2 & $B$ & UC & $A D D$ & 1 \\
\hline van de Port 2012 & 2 & 2 & 2 & 2 & B & UC & $A D D$ & 2 \\
\hline Van Vliet 2005 & 1 & 1 & 1 & 1 & $B$ & UC & $\mathrm{EQ}$ & 2 \\
\hline Winstein 2004 & 1 & 1 & 2 & 1 & B & UC & $A D D$ & 2 \\
\hline Winstein 2016 & 2 & 2 & 2 & 2 & A & UC & $\mathrm{EQ}$ & 2 \\
\hline Yen 2005 & 2 & 3 & 2 & 1 & $B$ & UC & $E Q$ & 2 \\
\hline
\end{tabular}




\begin{tabular}{|c|c|c|c|c|c|c|c|c|}
\hline Author and year & $\begin{array}{l}\text { Global } \\
\text { function }\end{array}$ & Lower limb function & $\begin{array}{l}\text { Balance/sit-to- } \\
\text { stand }\end{array}$ & $\begin{array}{l}\text { Upper limb } \\
\text { function }\end{array}$ & $\begin{array}{l}\text { Hand func- } \\
\text { tion }\end{array}$ & $\begin{array}{l}\text { ADL func- } \\
\text { tion }\end{array}$ & $\begin{array}{l}\text { QOL, health } \\
\text { status }\end{array}$ & $\begin{array}{l}\text { Adverse } \\
\text { events }\end{array}$ \\
\hline Arya 2012 & & & & $\begin{array}{l}\text { Action Re- } \\
\text { search Arm } \\
\text { Test - gross } \\
\text { arm move- } \\
\text { ment }\end{array}$ & & & & \\
\hline Barreca 2004 & & & $\begin{array}{l}\text { Number of partici- } \\
\text { pants able to stand }\end{array}$ & & & & $\begin{array}{l}\text { Dartmouth } \\
\text { COOP }\end{array}$ & Falls \\
\hline $\begin{array}{l}\text { Blennerhassett } \\
\text { 2004; Blenner- } \\
\text { hassett 2004a; } \\
\text { Blennerhassett } \\
\text { 2004b }\end{array}$ & & 6 Minute Walk Test; Step Test & Timed Up \& Go Test & $\begin{array}{l}\text { Motor Assess- } \\
\text { ment Scale - } \\
\text { arm }\end{array}$ & $\begin{array}{l}\text { Motor As- } \\
\text { sessment } \\
\text { Scale - hand }\end{array}$ & & & \\
\hline Dean 1997 & & 10 Metre Walk Speed & Reaching distance & & & & & \\
\hline Dean 2000 & & 6 Minute Walk Test; & Timed Up \& Go Test & & & & & \\
\hline & & 10 Metre Walk Speed; & & & & & & \\
\hline & & Step Test & & & & & & \\
\hline Dean 2007 & & 10 Metre Walk Test & Reaching distance & & & & & \\
\hline de Sèze 2001 & & $\begin{array}{l}\text { Functional Ambulation Classi- } \\
\text { fication }\end{array}$ & $\begin{array}{l}\text { Sitting and Standing } \\
\text { Equilibrium Index }\end{array}$ & & & $\begin{array}{l}\text { Function- } \\
\text { al Indepen- } \\
\text { dence Mea- } \\
\text { sure }\end{array}$ & & \\
\hline Frimpong 2014 & & 10 Metre Walk Test & & & & & & \\
\hline & & $\begin{array}{l}\text { Functional Ambulatory Cate- } \\
\text { gory }\end{array}$ & & & & & & \\
\hline Gordon 2013 & & 6 Minute Walk Test & & & & $\begin{array}{l}\text { Barthel In- } \\
\text { dex }\end{array}$ & $\begin{array}{l}\text { SF-36 phys- } \\
\text { ical health } \\
\text { component }\end{array}$ & \\
\hline Holmgren 2010 & & & Berg Balance Scale & & & $\begin{array}{l}\text { Barthel In- } \\
\text { dex }\end{array}$ & & \\
\hline
\end{tabular}




\begin{tabular}{|c|c|c|c|c|c|c|c|}
\hline \multicolumn{3}{|l|}{ Howe 2005} & \multicolumn{5}{|l|}{$\begin{array}{l}\text { Lateral reach - time, } \\
\text { sit-to-stand - time }\end{array}$} \\
\hline Kim 2012 & & 10 Metre Walk Speed & $\begin{array}{l}\text { Berg Balance Scale; } \\
\text { Timed Up \& Go Test }\end{array}$ & & & & \\
\hline Kim 2014 & $\begin{array}{l}\text { Stroke Im- } \\
\text { pact Scale } \\
\text { - social par- } \\
\text { ticipation } \\
\text { subscale }\end{array}$ & $\begin{array}{l}10 \text { Metre Walk Test } \\
6 \text { Minute Walk Test }\end{array}$ & & & & & \\
\hline Kim 2016 & & 6 Minute Walk Test & Berg Balance Scale & & & $\begin{array}{l}\text { Korean ver- } \\
\text { sion of Mod- } \\
\text { ified Barthel } \\
\text { Index }\end{array}$ & \\
\hline $\begin{array}{l}\text { Kwakkel 1999; } \\
\text { Kwakkel 1999a; } \\
\text { Kwakkel 1999b }\end{array}$ & & $\begin{array}{l}\text { Functional Ambulation Classi- } \\
\text { fication; } \\
\text { Walking speed }\end{array}$ & & $\begin{array}{l}\text { Action Re- } \\
\text { search Arm } \\
\text { Test }\end{array}$ & & $\begin{array}{l}\text { Barthel In- } \\
\text { dex }\end{array}$ & $\begin{array}{l}\text { Nottingham } \\
\text { Health Pro- } \\
\text { file }\end{array}$ \\
\hline $\begin{array}{l}\text { Langhammer } \\
2000\end{array}$ & $\begin{array}{l}\text { Motor As- } \\
\text { sessment } \\
\text { Scale }\end{array}$ & $\begin{array}{l}\text { Motor Assessment Scale - } \\
\text { walking; } \\
\text { Sødring Motor Evaluation } \\
\text { Scale - trunk, balance and } \\
\text { gait }\end{array}$ & $\begin{array}{l}\text { Motor Assessment } \\
\text { Scale - balanced sit- } \\
\text { ting, Motor Assess- } \\
\text { ment Scale - sit-to- } \\
\text { stand }\end{array}$ & $\begin{array}{l}\text { Motor Assess- } \\
\text { ment Scale - } \\
\text { arm }\end{array}$ & $\begin{array}{l}\text { Motor As- } \\
\text { sessment } \\
\text { Scale - hand }\end{array}$ & $\begin{array}{l}\text { Barthel In- } \\
\text { dex }\end{array}$ & $\begin{array}{l}\text { Nottingham } \\
\text { Health Pro- } \\
\text { file }\end{array}$ \\
\hline Lennon 2009 & & 5 Metre Walk Speed & & & & & \\
\hline McClellan 2004 & & $\begin{array}{l}\text { Motor Assessment Scale - } \\
\text { walking }\end{array}$ & $\begin{array}{l}\text { Functional Reach } \\
\text { Test }\end{array}$ & & & & \\
\hline Mudge 2009 & & 6 Minute Walk Test & & & & & \\
\hline Olawale 2011 & & 10 Metre Walk Speed & & & & & \\
\hline Park 2011 & & $\begin{array}{l}10 \text { Metre Walk Speed; } \\
6 \text { Minute Walk Test; } \\
\text { Walking ability questionnaire }\end{array}$ & $\begin{array}{l}\text { Activities-Specific } \\
\text { Balance Confidence } \\
\text { Scale }\end{array}$ & & & & \\
\hline
\end{tabular}




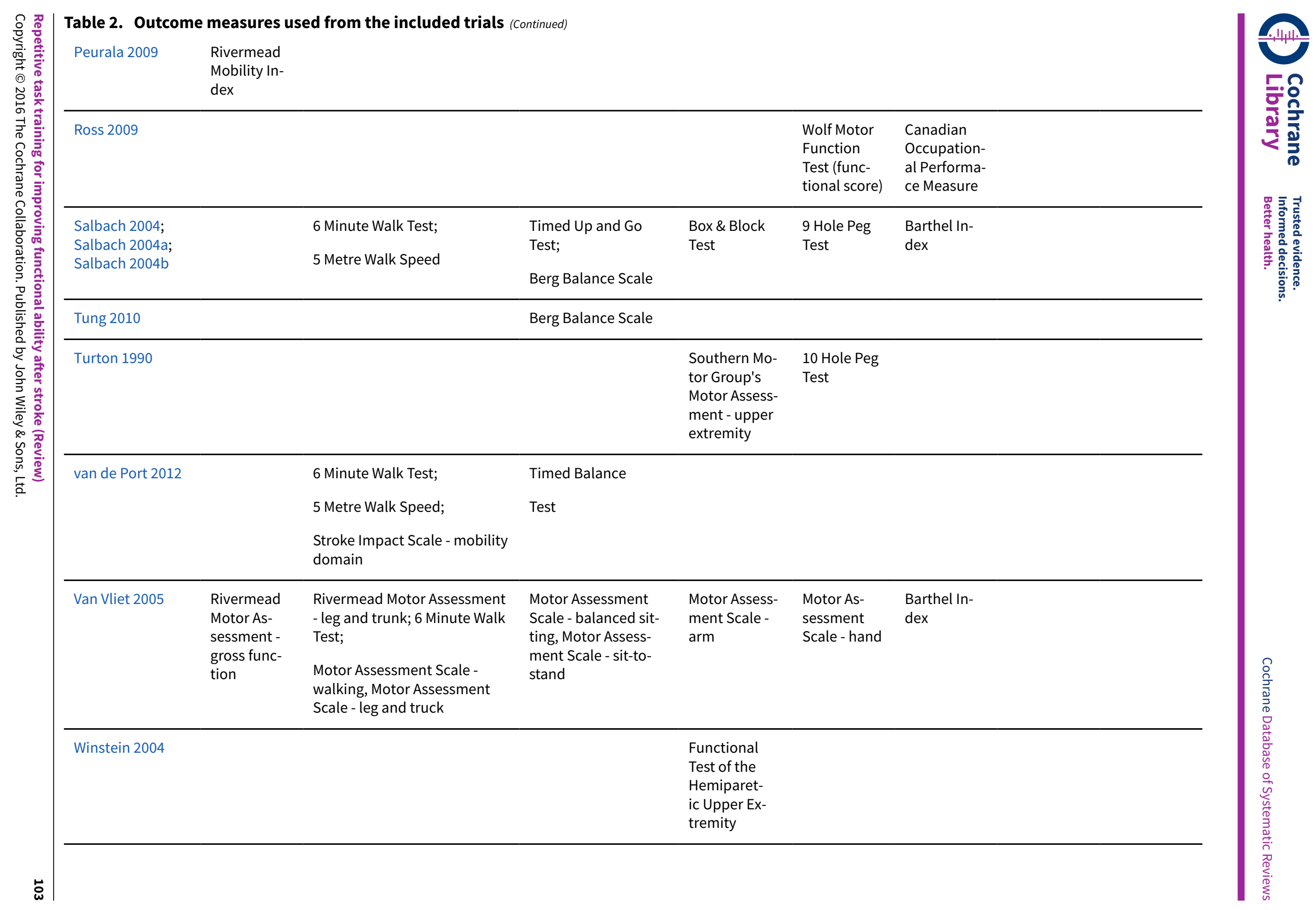




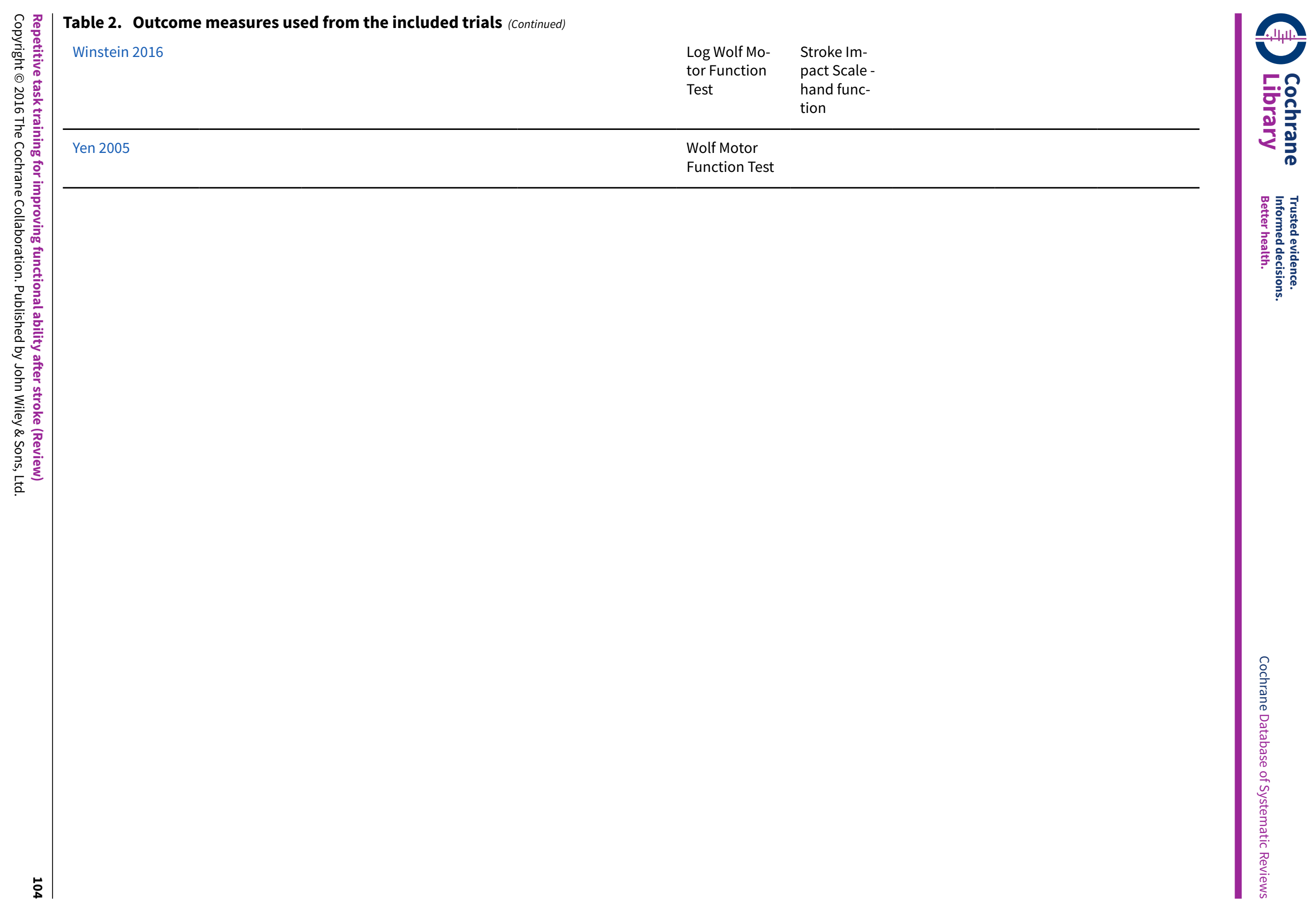




\section{A P PEN DICES}

\section{Appendix 1. Cochrane Central Register of Controlled Trials (CENTRAL) search strategy}

\#1 MeSH descriptor: [Cerebrovascular Disorders] explode all trees

\#2 MeSH descriptor: [Basal Ganglia Cerebrovascular Disease] explode all trees

\#3 MeSH descriptor: [Brain Ischemia] explode all trees

\#4 MeSH descriptor: [Carotid Artery Diseases] explode all trees

\#5 MeSH descriptor: [Intracranial Arterial Diseases] explode all trees

\#6 MeSH descriptor: [Intracranial Arteriovenous Malformations] explode all trees

\#7 MeSH descriptor: [Intracranial Embolism and Thrombosis] explode all trees

\#8 MeSH descriptor: [Intracranial Hemorrhages] explode all trees

\#9 MeSH descriptor: [Stroke] this term only

\#10 MeSH descriptor: [Brain Infarction] explode all trees

\#11 (stroke\$ or cva or poststroke or post-stroke or cerebrovasc\$ or cerebral vascular):ti,ab,kw (Word variations have been searched)

\#12 (cerebral or cerebellar or brain\$ or vertebrobasilar):ti,ab,kw (Word variations have been searched)

\#13 (infarct\$ or isch?emi\$ or thrombo\$ or emboli\$ or apoplexy):ti,ab,kw (Word variations have been searched)

\#14 MeSH descriptor: [Hemiplegia] explode all trees

\#15 MeSH descriptor: [Paresis] explode all trees

\#16 (hempar\$ or hemipleg\$ or paresis or paretic or brain injur\$):ti,ab,kw (Word variations have been searched)

\#17 MeSH descriptor: [Gait Disorders, Neurologic] explode all trees

$\# 18 \# 1$ or \#2 or \#3 or \#4 or \#5 or \#6 or \#7 or \#8 or \#9 or \#10 or \#11 or \#14 or \#15 or \#16 or \#17 or (\#12 and \#13)

\#19 MeSH descriptor: [Rehabilitation] explode all trees

\#20 MeSH descriptor: [Activities of Daily Living] explode all trees

\#21 MeSH descriptor: [Exercise Therapy] explode all trees

\#22 MeSH descriptor: [Occupational Therapy] 2 tree(s) exploded

\#23 MeSH descriptor: [Physical Therapy Modalities] explode all trees

\#24 MeSH descriptor: [Exercise Movement Techniques] this term only

\#25 MeSH descriptor: [Psychomotor Performance] explode all trees

\#26 MeSH descriptor: [Movement] this term only

\#27 MeSH descriptor: [Gait] explode all trees

\#28 MeSH descriptor: [Range of Motion, Articular] this term only

\#29 MeSH descriptor: [Task Performance and Analysis] 3 tree(s) exploded

\#30 MeSH descriptor: [Recovery of Function] this term only

\#31 functional:ti,ab,kw (Word variations have been searched)

\#32 (task\$ or movement):ti,ab,kw (Word variations have been searched) 
\#33 (motor or movement\$ or task\$ or skill\$ or performance):ti,ab,kw (Word variations have been searched)

\#34 (repetit\$ or repeat\$ or train $\$$ or re?train\$ or learn\$ or re?learn\$ or practice $\$$ or practis\$ or rehears\$ or rehers\$):ti,ab, $\mathrm{kw}$ (Word variations have been searched)

\#35 (motor or movement\$ or task\$ or skill\$ or performance):ti,ab,kw (Word variations have been searched)

\#36 (schedule\$ or intervention or therap\$ or program\$ or regim\$ or protocol\$):ti,ab,kw (Word variations have been searched)

$\# 37 \# 19$ or \#20 or \#21 or \#22 or \#23 or \#24 or \#25 or \#26 or \#27 or \#28 or \#29 or \#32 or (\#30 and \#31) or (\#33 and \#34) or (\#35 and \#36) \#38 \#18 and \#37

\section{Appendix 2. MEDLINE (Ovid) search strategy}

1. cerebrovascular disorders/ or exp basal ganglia cerebrovascular disease/ or exp brain ischemia/ or exp carotid artery diseases/ or exp intracranial arterial diseases/ or exp intracranial arteriovenous malformations/ or exp "intracranial embolism and thrombosis"/ or exp intracranial hemorrhages/ or stroke/ or exp brain infarction/

2. brain injuries/ or brain injury, chronic/

3. (stroke\$ or cva or poststroke or post-stroke or cerebrovasc\$ or cerebral vascular).tw.

4. ((cerebral or cerebellar or brain $\$$ or vertebrobasilar) adj5 (infarct\$ or isch?emi\$ or thrombo\$ or emboli\$ or apoplexy)).tw.

5. ((cerebral or brain or subarachnoid) adj5 (haemorrhage or hemorrhage or haematoma or hematoma or bleed\$)).tw.

6. exp hemiplegia/ or exp paresis/

7. (hempar\$ or hemipleg\$ or paresis or paretic or brain injur\$).tw.

8. Gait Disorders, Neurologic/

9. 1 or 2 or 3 or 4 or 5 or 6 or 7 or 8

10. rehabilitation/ or "activities of daily living"/ or exercise therapy/ or occupational therapy/

11. Physical Therapy Modalities/

12. Exercise Movement Techniques/

13. exp Psychomotor Performance/

14. movement/ or gait/ or exp locomotion/ or exp motor activity/

15. "Range of Motion, Articular"/ or "Task Performance and Analysis"/ or "Practice (Psychology)"/

16. "Recovery of Function"/

17. ((motor or movement $\$$ or task\$ or skill\$ or performance) adj5 (repetit $\$$ or repeat $\$$ or train $\$$ or re?train $\$$ or learn\$ or re?learn\$ or practice $\$$ or practis $\$$ or rehears\$ or rehers\$)).tw.

18. ((motor or movement\$ or task\$ or skill\$ or performance) adj5 (schedule\$ or intervention or therap\$ or program\$ or regim\$ or protocol \$).tw.

19. (functional adj5 (task\$ or movement)).tw.

20. or $/ 10-19$

21. Randomized Controlled Trials as Topic/

22. random allocation/

23. Controlled Clinical Trials as Topic/

24. control groups/ 
25. clinical trials as topic/

26. double-blind method/

27. single-blind method/

28. Placebos/

29. placebo effect/

30. cross-over studies/

31. Research Design/

32. randomized controlled trial.pt.

33. controlled clinical trial.pt.

34. clinical trial.pt.

35. (random\$ or RCT or RCTs).tw.

36. (controlled adj5 (trial\$ or stud\$)).tw.

37. (clinical\$ adj5 trial\$).tw.

38. ((control or treatment or experiment\$ or intervention) adj5 (group\$ or subject\$ or patient\$)).tw.

39. (quasi-random\$ or quasi random\$ or pseudo-random\$ or pseudo random\$).tw.

40. ((control or experiment\$ or conservative) adj5 (treatment or therapy or procedure or manage\$)).tw.

41. ((singl\$ or doubl\$ or tripl\$ or trebl\$) adj5 (blind\$ or mask\$)).tw.

42. (cross-over or cross over or crossover).tw.

43. (placebo\$ or sham).tw.

44. trial.ti.

45. (assign\$ or allocat\$).tw.

46. $\mathrm{or} / 21-45$

47.9 and 20 and 46

\section{Appendix 3. Embase (Ovid) search strategy}

1. cerebrovascular disease/ or brain disease/ or exp basal ganglion hemorrhage/ or exp brain hemangioma/ or exp brain hematoma/ or exp brain hemorrhage/ or exp brain infarction/ or exp brain ischemia/ or exp carotid artery disease/ or exp cerebral artery disease/ or exp cerebrovascular accident/ or exp cerebrovascular malformation/ or exp intracranial aneurysm/ or exp occlusive cerebrovascular disease/ or exp vertebrobasilar insufficiency/

2. stroke patient/ or stroke unit/

3. (stroke\$ or poststroke or post-stroke or apoplex\$ or cerebral vasc\$ or cerebrovasc\$ or cva or SAH).tw.

4. ((brain or cerebell\$ or cerebr $\$$ or hemisphere $\$$ or intracran $\$$ or intracerebral) adj5 (isch?emi\$ or infarct\$ or thrombo $\$$ or emboli\$ or occlus \$ or hypoxi\$)).tw.

5. ((brain $\$$ or cerebr\$ or cerebell\$ or intracerebral or intracran\$ or basal gangli\$ or hemisphere $\$$ or subarachnoid) adj5 (h?emorrhag\$ or h\$ematoma\$ or bleed\$)).tw.

6. exp hemiplegia/ or exp paresis/

7. (hempar\$ or hemipleg\$ or paresis or paretic).tw.

8. or/1-7 
9. physiotherapy/ or occupational therapy/or rehabilitation/ or exp kinesiotherapy/

10. exercise/ or functional training/

11. grip strength/ or hand strength/

12. task performance/ or psychomotor performance/

13. "physical activity, capacity and performance"/ or exp motor activity/ or motor performance/ or exp physical performance/

14. ( (motor or movement $\$$ or task\$ or skill\$ or performance) adj5 (repetit $\$$ or repeat $\$$ or train $\$$ or re?train $\$$ or learn $\$$ or re? learn $\$$ or practice \$ or practis\$ or rehears\$ or rehers\$)).tw.

15. ((motor or movement $\$$ or task\$ or skill\$ or performance) adj5 (schedule $\$$ or intervention or therap\$ or program $\$$ or regim $\$$ or protocol \$)).tw.

16. (functional adj5 (task\$ or movement)).tw.

17. or/9-16

18. Randomized Controlled Trial/ or "randomized controlled trial (topic)"/

19. Randomization/

20. Controlled clinical trial/ or "controlled clinical trial (topic)"/

21. control group/ or controlled study/

22. clinical trial/ or "clinical trial (topic)"/ or phase 1 clinical trial/ or phase 2 clinical trial/ or phase 3 clinical trial/ or phase 4 clinical trial/

23. Crossover Procedure/

24. Double Blind Procedure/

25. Single Blind Procedure/ or triple blind procedure/

26. placebo/ or placebo effect/

27. (random\$ or RCT or RCTs).tw.

28. (controlled adj5 (trial\$ or stud\$)).tw.

29. (clinical\$ adj5 trial\$).tw.

30. ((control or treatment or experiment\$ or intervention) adj5 (group\$ or subject\$ or patient\$)).tw.

31. (quasi-random\$ or quasi random\$ or pseudo-random\$ or pseudo random\$).tw.

32. ((control or experiment\$ or conservative) adj5 (treatment or therapy or procedure or manage\$)).tw.

33. ((singl\$ or doubl\$ or tripl\$ or trebl\$) adj5 (blind\$ or mask\$)).tw.

34. (cross-over or cross over or crossover).tw.

35. (placebo $\$$ or sham).tw.

36. trial.ti.

37. (assign\$ or allocat\$).tw.

38. controls.tw.

39. or $/ 18-38$

\section{Appendix 4. CINAHL (EBSCO) search strategy}

S39 S15 AND S29 AND S38

S38 S30 OR S31 OR S32 OR S33 OR S34 OR S35 OR S36 OR S37

S37 (MH "Quantitative Studies")

Repetitive task training for improving functional ability after stroke (Review) 
S36 (MH "Placebos")

S35 (MH "Random Assignment")

S34 TX randomi* control ${ }^{\star}$ trial ${ }^{\star}$ OR TX random* allocat* OR TX placebo* OR TX allocat* ${ }^{\star}$ random ${ }^{\star}$

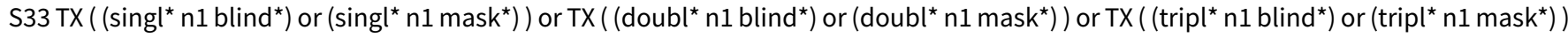

or TX ( (trebl* $n 1$ blind $\left.{ }^{\star}\right)$ or (trebl* $n 1$ mask $\left.^{\star}\right)$ )

S32 TX clinic* n1 trial*

S31 PT Clinical trial

S30 (MH "Clinical Trials+")

S29 S16 OR S17 OR S18 OR S19 OR S20 OR S21 OR S22 OR S23 OR S24 OR S25 OR S26 OR S27 OR S28 123,562

S28 (MH "Gait Disorders, Neurologic+")

S27 (MH "Hemiplegia")

S26 hempar* or hemipleg* or paresis or paretic or brain injur ${ }^{\star}$

S25 ((cerebral or cerebellar or brain* or vertebrobasilar) n2 (infarct* or isch?emi* or thrombo* or emboli* or apoplexy))

S24 stroke* or cva or poststroke or post-stroke or cerebrovasc* or cerebral vascular

S23 ((cerebral or brain or subarachnoid) n2 (haemorrhage or hemorrhage or haematoma or hematoma or bleed*)).

S22 (MH "Brain Injuries+")

S21 (MH "Cerebrovascular Circulation") OR (MH "Basal Ganglia Cerebrovascular Disease+")

S20 (MH "Hypoxia-Ischemia, Brain+") OR (MH "Cerebral Ischemia+")

S19 (MH "Intracranial Hemorrhage+")

S18 (MH "Basal Ganglia Hemorrhage")

S17 (MH "Stroke+") OR (MH "Stroke Units") OR (MH "Stroke Patients")

S16 (MH "Cerebrovascular Disorders+")

S15 S1 OR S2 OR S3 OR S4 OR S5 OR S6 OR S7 OR S8 OR S9 OR S10 OR S11 OR S12 OR S13 OR S14 263,000

S14 (MH "Range of Motion")

S13 (MH "Grip Strength")

S12 (MH "Muscle Contraction+")

S11 (MH "Locomotion+") OR (MH "Movement+") OR (MH "Gait Disorders, Neurologic+")

S10 (MH "Movement+")

S9 (MH "Movement+") OR (MH "Body Positions+")

S8 (MH "Psychomotor Performance+")

S7 (MH "Physical Activity")

S6 (MH "Physical Performance")

S5 (MH "Motor Activity+")

S4 (MH "Task Performance and Analysis+") OR (MH "Psychomotor Performance+")

S3 (MH "Exercise+") OR (MH "Resistance Training") OR (MH "Therapeutic Exercise+") OR (MH "Warm-Up Exercise") OR (MH "Recovery, Exercise") OR (MH "Upper Extremity Exercises+") OR (MH "Aerobic Exercises+")

S2 (MH "Occupational Therapy+")

S1 (MH "Physical Therapy+")

\section{Appendix 5. AMED search strategy}

1. cerebrovascular disorders/or cerebral hemorrhage/ or cerebral infarction/or cerebral ischemia/ or cerebrovascular accident/ or stroke/

2. (stroke or poststroke or post-stroke or cerebrovasc\$ or brain vasc\$ or cerebral vasc\$ or cva\$ or apoplex\$ or SAH).tw.

3. ((brain\$ or cerebr\$ or cerebell\$ or intracran\$ or intracerebral) adj5 (isch?emi\$ or infarct\$ or thrombo $\$$ or emboli\$ or occlus\$)).tw.

4. ((brain\$ or cerebr\$ or cerebell\$ or intracerebral or intracranial or subarachnoid) adj5 (haemorrhage\$ or hemorrhage\$ or haematoma\$ or hematoma or bleed\$)).tw.

5. hemiplegia/

6. (hemipleg\$ or hemipar\$ or paresis or paretic).tw.

7. 1 or 2 or 3 or 4 or 5 or 6

8. Rehabilitation/ or rehabilitation techniques/ or exp rehabilitation modalities/ or exp physical therapy modalities/

9. occupational therapy modalities/ or occupational therapy techniques/ or "Activities of daily living"/

10. exercise/ or exp Exercise movement techniques/

11. exp Psychomotor Performance/

12. "Range of motion"/ 
13. ((motor or movement $\$$ or task\$ or skill\$ or performance) adj5 (repetit $\$$ or repeat $\$$ or train $\$$ or re?train $\$$ or learn $\$$ or re?learn $\$$ or practice \$ or practis\$ or rehears\$ or rehers\$)).tw.

14. ((motor or movement\$ or task\$ or skill\$ or performance) adj5 (schedule\$ or intervention or therap\$ or program\$ or regim\$ or protocol \$)).tw.

15. (functional adj5 (task\$ or movement)).tw.

16. 8 or 9 or 10 or 11 or 12 or 13 or 14 or 15

17. clinical trials/ or randomized controlled trials/ or random allocation/

18. double blind method/ or single blind method/

19. placebos/

20. (random\$ or RCT or RCTs).tw.

21. (controlled adj5 (trial\$ or stud\$)).tw.

22. (clinical\$ adj5 trial\$).tw.

23. ((control or treatment or experiment\$ or intervention) adj5 (group\$ or subject\$ or patient\$)).tw.

24. (quasi-random\$ or quasi random\$ or pseudo-random\$ or pseudo random\$).tw.

25. ((control or experiment\$ or conservative) adj5 (treatment or therapy or procedure or manage\$)).tw.

26. ((singl\$ or doubl\$ or tripl\$ or trebl\$) adj5 (blind\$ or mask\$)).tw.

27. (cross-over or cross over or crossover).tw.

28. (placebo\$ or sham).tw.

29. trial.ti.

30. (assign\$ or allocat\$).tw.

31. controls.tw.

32. 17 or 18 or 19 or 20 or 21 or 22 or 23 or 24 or 25 or 26 or 27 or 28 or 29 or 30 or 31

33. 7 and 16 and 32

\section{Appendix 6. SPORTSDiscus search strategy}

S19S7 AND S11 AND S18

S18S12 OR S13 OR S14 OR S15 OR S16 OR S17

S17SU ( random* or trial or crossover or cross-over or placebo* or control ${ }^{\star}$ or factorial or sham or counterbalance* or multiple baseline* or $A B A B$ design) or KW ( random* or trial or crossover or cross-over or placebo* or control* or factorial or sham or counterbalance* or multiple baseline* or ABAB design )

S16TI ( assign ${ }^{\star}$ or allocate* or counterbalance* or multiple baseline ${ }^{\star}$ or ABAB design ) or AB ( assign $^{\star}$ or allocate* or counterbalance* or multiple baseline* or ABAB design

S15 ( TI ( clin* or intervention* or compar ${ }^{\star}$ or experiment ${ }^{\star}$ or preventive or therapeutic ) or AB ( clin* or intervention* or compar ${ }^{\star}$ or experiment ${ }^{\star}$ or preventive or therapeutic ) ) and ( TI trial $^{\star}$ or AB trial $\left.{ }^{\star}\right)$

S14TI ( crossover or cross-over or placebo* or control* or factorial or sham ) or AB ( crossover or cross-over or placebo* or control* or factorial or sham )

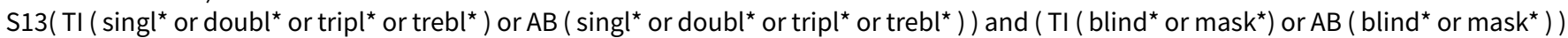
S12TI (random* or RCT or RCTs) or AB (random* or RCT or RCTs)

S11S8 OR S9 OR S10

$\mathrm{S} 10$ (TI (exercise or rehab* or physical therap or physio* or occupation* or motor or psychomotor) or AB (exercise or rehab* or physical therap or physio* or occupation* or motor or psychomotor))

S9DE "OCCUPATIONAL therapy" OR DE "PHYSICAL therapy" OR DE "ACTIVITIES of daily living training" OR DE "OCCUPATIONAL therapists" S8(DE "EXERCISE therapy" OR DE "EXERCISE" OR DE "THERAPEUTICS" OR DE "OCCUPATIONAL therapy" OR DE "PHYSICAL therapy" OR DE "REHABILITATION")

S7S1 OR S2 OR S3 OR S4 OR S5 OR S6

S6TI ( hemipleg* or hemipar $^{\star}$ or paresis or paretic) or AB ( hemipleg* or hemipar* or paresis or paretic) 
S5DE "HEMIPLEGIA" OR DE "HEMIPLEGICS" OR DE "GAIT disorders"

S4 ( TI ( brain* or cerebr* or cerebell* or intracerebral or intracranial or subarachnoid ) or AB ( brain* or cerebr* or cerebell* or intracerebral or intracranial or subarachnoid) ) and ( $\mathrm{TI}$ ( haemorrhage* or hemorrhage* or haematoma* or hematoma* or bleed ${ }^{\star}$ ) or AB ( haemorrhage* or hemorrhage* or haematoma* or hematoma* or bleed*))

S3 ( TI ( brain* or cerebr ${ }^{\star}$ or cerebell* or intracran* or intracerebral ) or AB ( brain* or cerebr ${ }^{\star}$ or cerebell* or intracran* or intracerebral ) ) and ( TI ( ischemi ${ }^{\star}$ or ischaemi ${ }^{\star}$ or infarct ${ }^{\star}$ or thrombo* or emboli* or occlus ${ }^{\star}$ ) or AB (ischemi ${ }^{\star}$ or ischaemi ${ }^{\star}$ or infarct ${ }^{\star}$ or thrombo $^{\star}$ or emboli* or occlus* $)$ )

S2TI ( stroke or poststroke or post-stroke or cerebrovasc* or brain vasc* or cerebral vasc or cva or apoplex or SAH ) or AB ( $\mathrm{stroke}$ or poststroke or post-stroke or cerebrovasc* or brain vasc* or cerebral vasc or cva or apoplex or SAH )

S1DE "CEREBROVASCULAR disease" OR DE "BRAIN -- Hemorrhage" OR DE "CEREBRAL embolism \& thrombosis" OR DE "STROKE" OR DE "BRAIN -- Wounds \& injuries" OR DE "BRAIN damage" OR DE "CEREBROVASCULAR disease -- Patients"

S20S7 AND S11 AND S18

S19S7 AND S11 AND S18

S18S12 OR S13 OR S14 OR S15 OR S16 OR S17

S17SU ( random ${ }^{\star}$ or trial or crossover or cross-over or placebo* or control* or factorial or sham or counterbalance* or multiple baseline* or $A B A B$ design) or KW ( random* or trial or crossover or cross-over or placebo* or control* or factorial or sham or counterbalance* or multiple baseline ${ }^{\star}$ or $A B A B$ design )

S16TI ( assign $^{\star}$ or allocate ${ }^{\star}$ or counterbalance* or multiple baseline $e^{\star}$ or ABAB design ) or AB ( assign $^{\star}$ or allocate $^{\star}$ or counterbalance or $^{*}$ multiple baseline* or ABAB design

S15 ( TI ( clin* or intervention* or compar* or experiment* or preventive or therapeutic) or AB ( clin* or intervention* or compar* or experiment ${ }^{\star}$ or preventive or therapeutic $)$ ) and ( TI trial $^{\star}$ or AB trial ${ }^{\star}$ )

S14TI ( crossover or cross-over or placebo* or control* or factorial or sham ) or AB ( crossover or cross-over or placebo* or control* or factorial or sham )

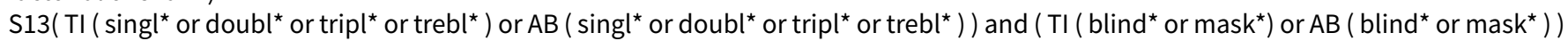
S12TI (random* or RCT or RCTs) or AB (random* or RCT or RCTs)

S11S8 OR S9 OR S10

S10 (TI (exercise or rehab* or physical therap or physio* or occupation* or motor or psychomotor) or AB (exercise or rehab* or physical therap or physio* or occupation* or motor or psychomotor))

S9DE "OCCUPATIONAL therapy" OR DE "PHYSICAL therapy" OR DE "ACTIVITIES of daily living training" OR DE "OCCUPATIONAL therapists" S8(DE "EXERCISE therapy" OR DE "EXERCISE" OR DE "THERAPEUTICS" OR DE "OCCUPATIONAL therapy" OR DE "PHYSICAL therapy" OR DE "REHABILITATION")

S7S1 OR S2 OR S3 OR S4 OR S5 OR S6

S6TI ( hemipleg* or hemipar* or paresis or paretic) or AB ( hemipleg* or hemipar ${ }^{\star}$ or paresis or paretic)

S5DE "HEMIPLEGIA" OR DE "HEMIPLEGICS" OR DE "GAIT disorders"

S4 ( TI ( brain* or cerebr ${ }^{\star}$ or cerebell* or intracerebral or intracranial or subarachnoid ) or AB ( brain ${ }^{\star}$ or cerebr ${ }^{*}$ or cerebell ${ }^{*}$ or intracerebral or intracranial or subarachnoid ) ) and ( $\mathrm{TI}$ ( haemorrhage* or hemorrhage* or haematoma* or hematoma* or bleed ${ }^{\star}$ ) or $\mathrm{AB}$ ( haemorrhage* or hemorrhage* or haematoma* or hematoma* or bleed*))

S3 ( TI ( brain* or cerebr ${ }^{\star}$ or cerebell* or intracran* or intracerebral ) or AB ( brain* or cerebr ${ }^{\star}$ or cerebell* or intracran* or intracerebral ) ) and ( $\mathrm{TI}$ ( ischemi ${ }^{\star}$ or ischaemi ${ }^{\star}$ or infarct ${ }^{\star}$ or thrombo* or emboli* or occlus ${ }^{\star}$ ) or AB (ischemi ${ }^{\star}$ or ischaemi ${ }^{\star}$ or infarct $^{\star}$ or thrombo $^{\star}$ or emboli* or occlus* $)$ )

\section{Appendix 7. ClinicalTrials.gov search strategy}

stroke rehabilitation

stroke

rehabilitation therapy

adult, Senior

\section{Appendix 8. World Health Organization (WHO) International Clinical Trials Registry search strategy}

cerebrovascular accident

functional recovery

intervention program

occupational therapy

physiatry

physical therapy 
recovery of function

rehab

WHAT'S NEW

\begin{tabular}{lll}
\hline Date & Event & Description \\
\hline 22 September 2016 & $\begin{array}{l}\text { New citation required and conclusions } \\
\text { have changed }\end{array}$ & $\begin{array}{l}\text { The conclusions of the review have changed since the original re- } \\
\text { view was published in 2007; there is now low-quality evidence } \\
\text { for the effectiveness of repetitive task training on upper limb } \\
\text { function. }\end{array}$ \\
\end{tabular}

22 September $2016 \quad$ New search has been performed

We updated selected searches to March 2016. We have added 19 new studies with 1355 participants, bringing the total number of included studies to 33, involving a total of 2014 participants. We have revised the review throughout and included an assessment of the quality of the evidence (presented in a 'Summary of findings' table).

\section{CONTRIBUTIONS OF AUTHORS}

Beverley French co-ordinated the review process. Beverley French, Lois Thomas, Jacqueline Coupe, Naoimh McMahon, Louise Connell, Michael Leathley, and Joanna Harrison undertook data filtration, extraction, appraisal and analysis. Jacqueline Coupe was responsible for the administration of the review process. Chris Sutton provided statistical expertise. Caroline Watkins undertook critical reading of outputs.

\section{DECLARATIONS OF INTEREST}

Beverley French: none known.

Lois H Thomas: none known.

Jacqueline Coupe: none known.

Naoimh E McMahon: none known.

Louise Connell: none known.

Joanna Harrison: none known.

Christopher J Sutton: none known.

Svetlana Tishkovskaya: none known.

Caroline L Watkins: none known.

\section{SOURCES OF SUPPORT}

\section{Internal sources}

- NIHR Cochrane Review Incentive Scheme 2015, UK.

$£ 5000$

\section{External sources}

- Department of Health Research and Development Health Technology Assessment Programme, UK.

\section{DIFFERENCES BETWEEN PROTOCOL AND REVIEW}

As all the studies in the original review were identified from the Cochrane Stroke Trials Register, we limited searching for this update to the Cochrane Stroke Trials Register and key electronic databases (MEDLINE, Embase, CIHAHL, SPORTSDiscus, AMED, the Cochrane Central Register of Controlled Trials, ClinicalTrials.gov and the World Health Organization International Clinical Trials Registry Platform). 


\section{N D EX TERMS}

\section{Medical Subject Headings (MeSH)}

*Activities of Daily Living; *Physical Therapy Modalities; *Recovery of Function; Extremities; Motor Activity; Randomized Controlled Trials as Topic; Stroke Rehabilitation [ ${ }^{\star}$ methods]; Task Performance and Analysis; Walking

\section{MeSH check words}

Adult; Humans 